Portland State University

PDXScholar

Fall 11-7-2016

\title{
A Measurement System for Science and Engineering Research Center Performance Evaluation
}

Elizabeth Carole Gibson

Portland State University

Follow this and additional works at: https://pdxscholar.library.pdx.edu/open_access_etds

Part of the Organizational Behavior and Theory Commons Let us know how access to this document benefits you.

\section{Recommended Citation}

Gibson, Elizabeth Carole, "A Measurement System for Science and Engineering Research Center Performance Evaluation" (2016). Dissertations and Theses. Paper 3285.

https://doi.org/10.15760/etd.3276

This Dissertation is brought to you for free and open access. It has been accepted for inclusion in Dissertations and Theses by an authorized administrator of PDXScholar. Please contact us if we can make this document more accessible: pdxscholar@pdx.edu. 
A Measurement System for Science and Engineering Research Center Performance

Evaluation

by

Elizabeth Carole Gibson

A dissertation submitted in partial fulfillment of the requirements for the degree of

Doctor of Philosophy

in

Technology Management

Dissertation Committee:

Tugrul U. Daim, Chair

Dundar F. Kocaoglu, Co-Chair

Jun Jiao

Jonathan Fink

Portland State University

2016 
(C) 2016 Elizabeth Carole Gibson 


\begin{abstract}
This research provides performance metrics for cooperative research centers that enhance translational research formed by the partnership of government, industry and academia. Centers are part of complex ecosystems that vary greatly in the type of science conducted, organizational structures and expected outcomes. The ability to realize their objectives depends on transparent measurement systems to assist in decision making in research translation.

A generalizable, hierarchical decision model that uses both quantitative and qualitative metrics is developed based upon program goals. Mission-oriented metrics are used to compare the effectiveness of the cooperative research centers through case studies.

The US National Science Foundation (NSF) industry university cooperative research center (IUCRC) program is the domain of organizational effectiveness because of its longevity, clear organizational structure, repeated use and availability of data. Not unlike a franchise business model, the program has been replicated numerous times gaining recognition as one of the most successful federally funded collaborative research center (CRC) programs. Understanding IUCRCs is important because they are a key US policy lever for enhancing translational research. While the program's model is somewhat unique, the research project begins to close the gap for comparing CRCs by introducing a generalizable model and method into the literature stream.
\end{abstract}


Through a literature review, program objectives, goals, and outputs are linked together to construct a four-level hierarchical decision model (HDM). At level 1, the purpose of the HDM is to determine the degree to which a center meets the mission of the NSF IUCRC program by evaluating a holistic set of metrics. Level 2 specifies three program objectives of industry-relevant research, the promotion of students and knowledge and technology transfer. Six goals populate level 3 and seventeen measurable outputs, characterized by desirability functions, fill level 4. A structured model development process shows how experts validate the content and construct of the model using these linked concepts.

A subjective data collection approach is discussed showing how collection, analysis and quantification of expert pair-wise-comparison data is used to establish weights for each of the decision criteria. Several methods are discussed showing how inconsistency and disagreement are measured and analyzed until acceptable levels are reached.

Through six developed case studies, actual center data are used to illustrate how the model calculates a score and how criterion-related validity is conducted with experts. First, the Wood-Based Composites (WBC) IUCRC uses the validated model construct to illustrate how a performance measurement score is calculated. Results are discussed that show how the WBC could obtain a significant performance increase by re-configuring project teams to include multi-disciplinary researchers and 
encouraging students to select center research projects towards completion of dissertations or theses.

Populating metrics with actual data from five (5) more IUCRCs establishes baseline performance scores for a total of six case examples. These case studies are used to compare results, evaluate the impact of expert disagreement and conduct criterion-related validity. Comparative analysis demonstrates the ability of the model to efficiently ascertain criteria that are relatively more important towards each centers' performance score. Applying this information, specific performance improvement recommendations for each center are presented.

Upon review, experts generally agreed with the results. Criterion-related validity discusses how the performance measurement scoring system can be used for comparative analysis among science and engineering focused research centers. Dendrograms highlight where experts disagree and provide a method for further disagreement analysis. Judgment quantification values for different expert clusters are substituted into the model one-at-a-time (OAT) providing a method to analyze how changes in decisions based on these disagreements impact the results of the model's output.

This research project contributes to the field by introducing a generalizable model and measurement system that compares performance of NSF supported science and engineering focused research centers. Funding these centers is expensive. Understanding where to shift resources can be a powerful decision- 
support tool for center directors. Transparency among experts regarding disagreement within the ecosystem about the decision criteria can help policy makers understand how to clarify objectives and analyze the impact of policy changes. 


\section{DEDICATION}

I would like to dedicate this work to my family:

To Darin, who has supported me financially, emotionally and spiritually through this journey;

To my daughters, who supported me with their kindness, patience and love. 


\section{ACKNOWLEDGMENTS}

First, I would like to acknowledge my committee chair and PhD advisor, Dr. Tugrul U. Daim, for his strategic guidance and keen insight. His support and encouragement helped me to integrate previous coursework, work experience and research interests into a research topic of interest that I could extend beyond this dissertation. His dedication to the field, the department and his students is admirable. I am extremely grateful for his work ethic and responsiveness to my many questions that helped provide clarity during times I felt the most confused.

Dr. Dundar F. Kocaoglu, my co-chair, not only developed and guided the Engineering and Technology Management (ETM) department to become an internationally acclaimed program, he also deeply cares about all his students. For his care and patience I am deeply grateful as well as for the time he took to share his seminal work and knowledge of the methodology with me.

I also want to express my gratitude for the support of my committee members, Dr. Jonathan Fink and Dr. Jun Jiao as well as Dr. Gray for their valuable time and support, encouraging me through the completion of my dissertation. Dr. Gray was instrumental in providing guidance, knowledge and connections. Without the support of the NSF Science of Science Policy program, data collection would have been more difficult. I especially want to thank Maryann Feldman for her patience and input after my dissertation was recommended for funding, crafting an abstract for 
public consumption. This program provided an opportunity for me to obtain quality data resulting in a more comprehensive study.

This research would not have been possible without the time, support and information provided by the many NSF IUCRC experts who provided input and expertise towards this research. I am grateful to the NSF, the past NSF IUCRC program director Alex Schwarzkopf, and other NSF evaluators who supported my research providing valuable feedback and recognizing the promise in this dissertation. I appreciate their time and the knowledge I received through their willingness to transfer. This gift I will take with me beyond the completion of this dissertation.

I would also like to acknowledge Dr. Margaret Everett, the Dean of Graduate Studies, the other faculty members and the office staff in the ETM department. They were always available to answer questions and clarify the process.

I'd like to acknowledge and thank the many other ETM students with whom I had the opportunity to collaborate, learn, vent, and produce. I'd like to express thanks to all members of the Technology Evaluation Research and Applications (TERA) research group with a special note of appreciation for Judith and Noshad. I'd also like to appreciate my dear friend Judi and the members in my Wednesday study group.

Finally, I want to express my gratitude to my family. I will always remember the pride I heard in my last conversation with my father, George, before his death months before I completed this work. I received peace from that gentle last touch and 
his mention of "Dr. Beth." Without their love and support my journey would have been much more difficult. 


\title{
TABLE OF CONTENTS
}

\author{
ABSTRACT i \\ DEDICATION v
}

ACKNOWLEDGMENTSvi

LIST OF TABLES xiv

LIST OF FIGURES xvi

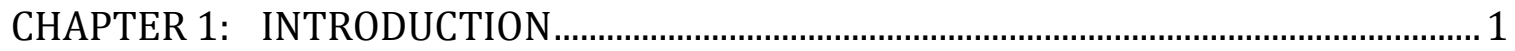

CHAPTER 2: LITERATURE REVIEW .................................................................................. 7

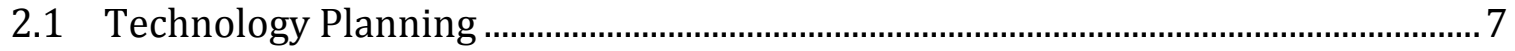

2.2 Cooperative Research Centers.............................................................................. 11

2.3 Program Evaluation Methods................................................................................... 15

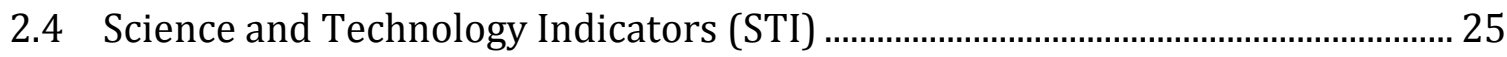

2.5 NSF IUCRC program ........................................................................................... 29

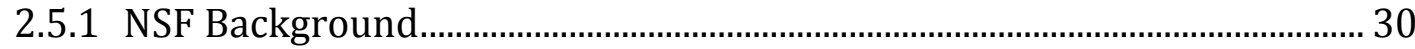

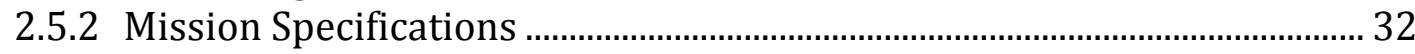

2.5.3 Organizational Mechanisms ........................................................................... 32

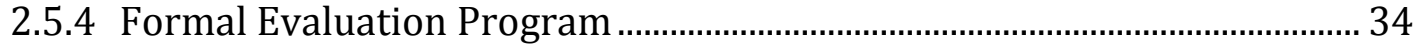

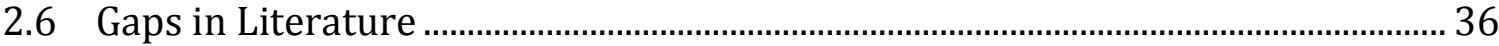

CHAPTER 3: RESEARCH APPROACH ........................................................................... 40

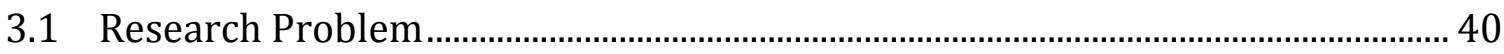

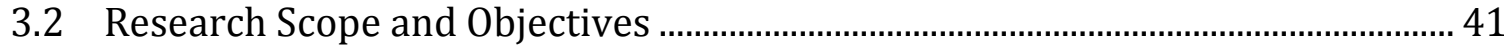

ix 
3.3 Multi Criteria Decision Problem....................................................................................... 43

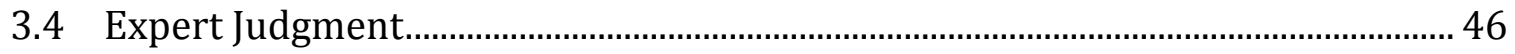

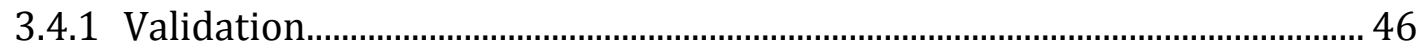

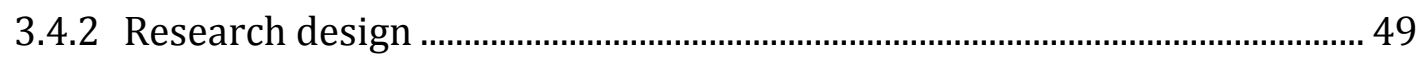

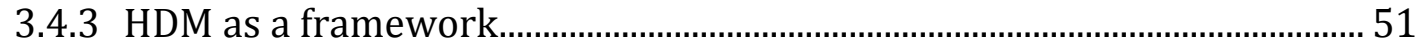

3.4.4 Expert panel configuration ………………………………………………. 53

3.4.5 Data collection approach ………………………………………………..... 59

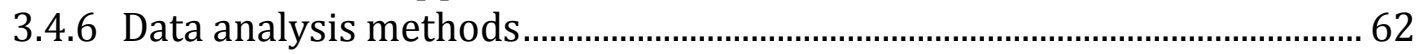

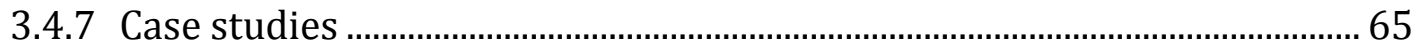

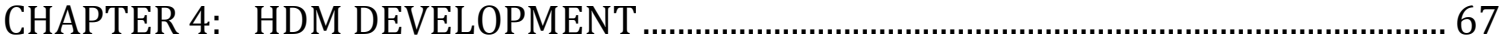

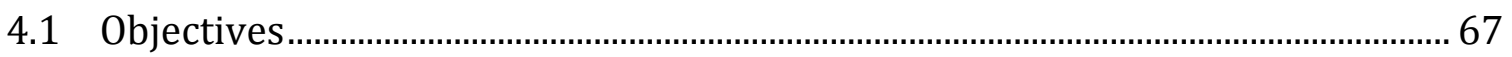

4.1.1 Pursuit of fundamental research .................................................................... 68

4.1.2 Producing graduates …………………………………………………….... 70

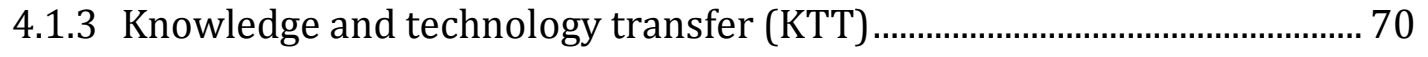

4.2 Goals and Outputs................................................................................................. 70

4.2.1 New knowledge .......................................................................................... 72

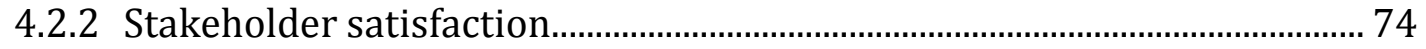

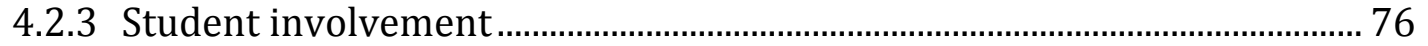

4.2.4 Student development...................................................................................... 76

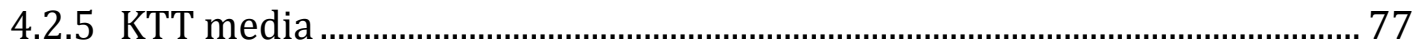

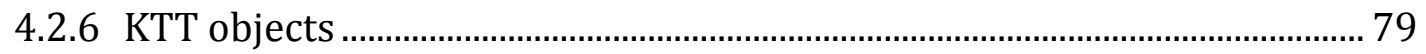

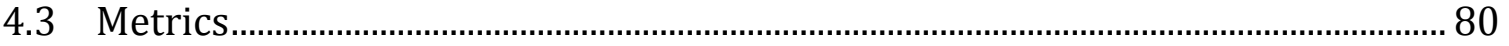

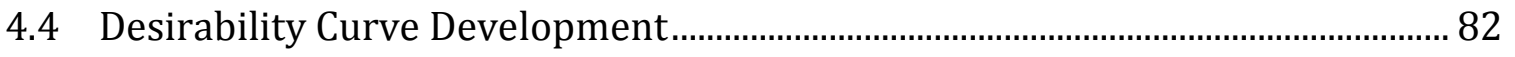

CHAPTER 5: FINALIZING THE MODEL ……………………………................................ 94

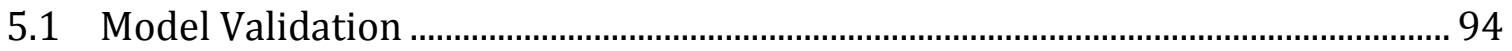

5.2 Data Collection and Quantification ........................................................................ 95

5.3 Inconsistency ...................................................................................................... 96

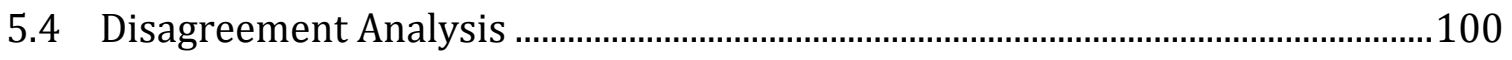

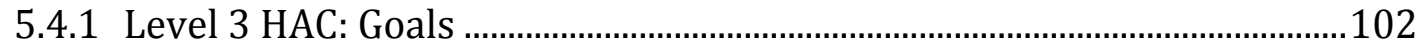

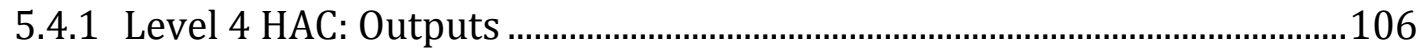

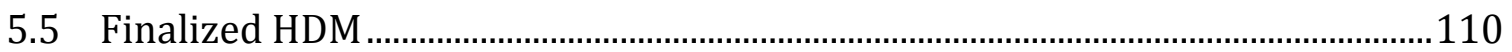

CHAPTER 6: CASE STUDIES ……………………………............................................112 


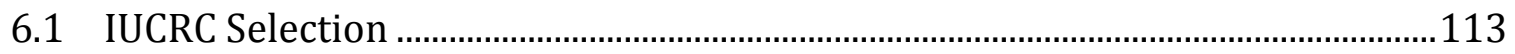

6.1.1 Integrative Joining of Materials for Energy Applications .........................117

6.1.2 Center for Pharmaceutical Development.....................................................118

6.1.3 Security and Software Engineering Research Center.................................119

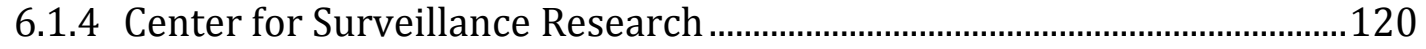

6.1.5 Water Equipment \& Policy Research Center ..............................................121

6.1.6 Wood-Based Composites Center ..................................................................122

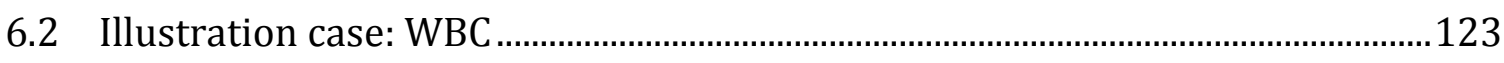

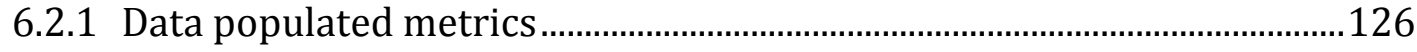

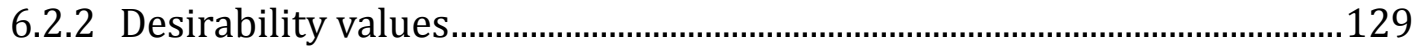

6.2.3 Calculating performance evaluation ............................................................131

6.3 IUCRC Comparative Analysis..................................................................................134

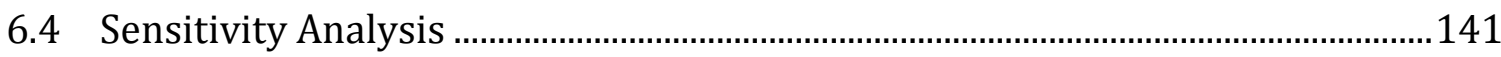

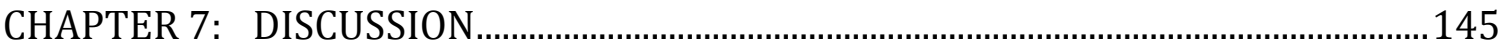

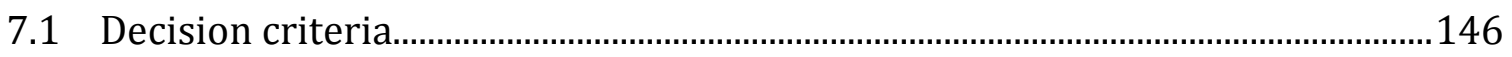

7.2 Balanced set of relative indicators ……………………….....................................148

7.3 Metrics............................................................................................................149

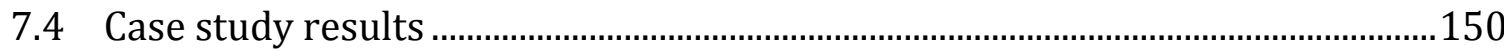

7.5 Disagreement impact........................................................................................... 151

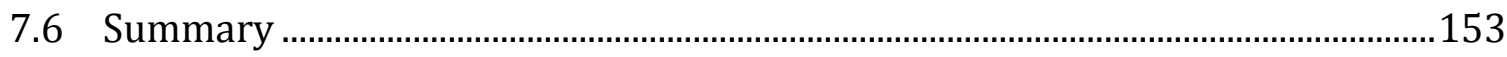

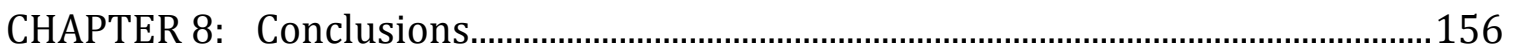

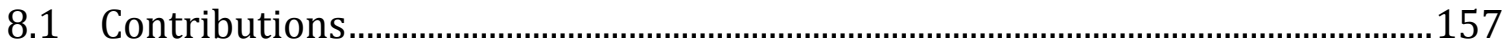

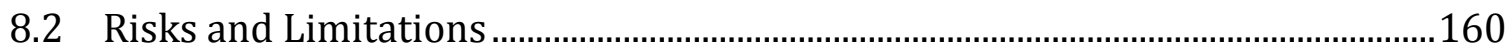

8.3 Future Research....................................................................................................161

REFERENCES 163

APPENDICES 176

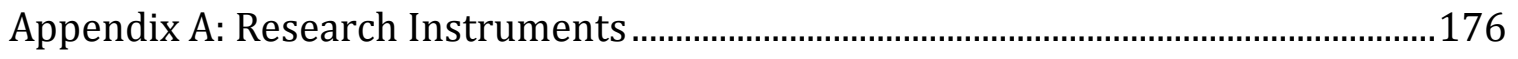

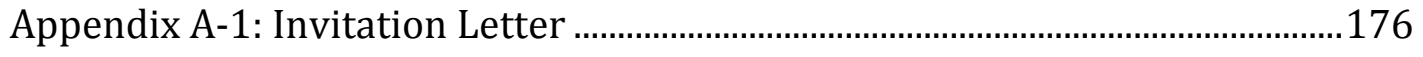




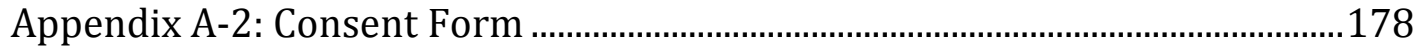

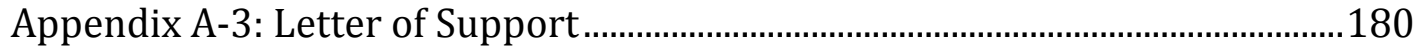

Appendix A-4: Web based validation instrument ...................................................181

Appendix A-5: Web based judgment quantification instrument..........................182

Appendix A-6: Table of research instruments........................................................183

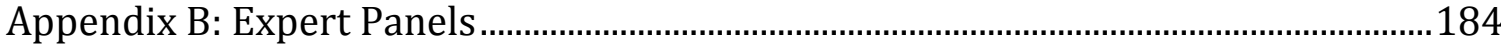

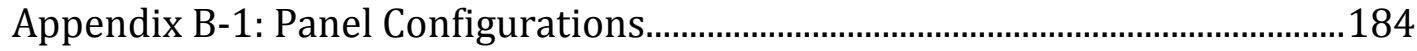

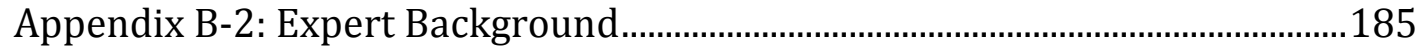

Appendix B-3: Expert Panels 1 and 2 configuration (Phase 1)...........................186

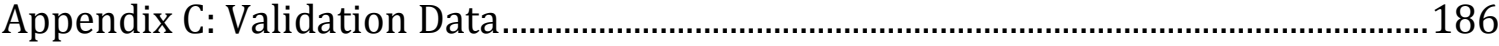

Appendix C-1: Validation Data for Objectives..........................................................186

Appendix C-2: Validation Data for Goals................................................................187

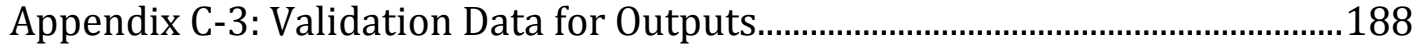

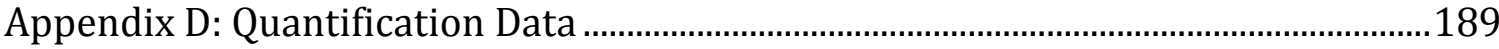

Appendix D-1: Quantification of Goals...............................................................189

Appendix D-2: Quantification of Outputs ..............................................................190

Appendix D-3: Quantification Data Entry and Analysis Tool...............................194

Appendix E: Desirability Curves ......................................................................................195

Appendix E-1: Desirability Curve illustration.........................................................195

Appendix E-2: Desirability Curve Data …………………………………………...196

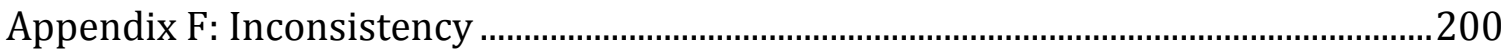

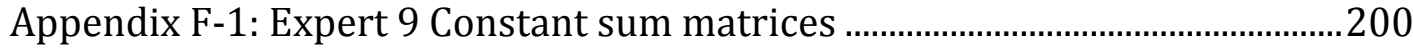

Appendix F-2: Example Orientations .....................................................................201

Appendix F-3: Example Standardized values orientations.....................................201

Appendix G: Disagreement Analysis using R .................................................................202

Appendix G-1: New Knowledge vs. Stakeholder Satisfaction ................................203

Appendix G-2: Student Involvement vs. Student Development...........................205

Appendix G-3: KTT Medium vs. KTT Object ............................................................206

Appendix G-4: New knowledge outputs...................................................................208

Appendix G-5: Stakeholder satisfaction outputs .................................................2210

Appendix G-6: Student involvement outputs.......................................................212

Appendix G-7: Student development outputs..........................................................213

Appendix H: Case Study Data .........................................................................................214

Appendix H-1: IUCRC selection .........................................................................214

Appendix H-2: Center resource data 2016 from partner websites.....................215

Appendix H-3: Secondary Data Sources..................................................................217 
Appendix H-4: Example project scoring sheet (WBC 2014) .................................218

Appendix H-5: WBC Research Project Data ..................................................................222

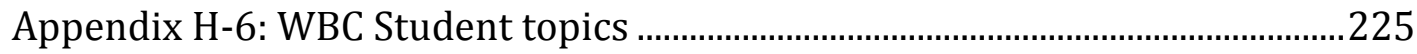

Appendix H-7: WBC IAB attendance data.................................................................22

Appendix H-8: WBC performance evaluation score .............................................226

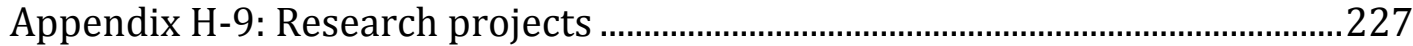

Appendix H-10: New processes and methods data ...............................................229

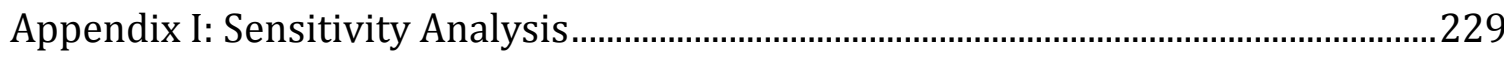

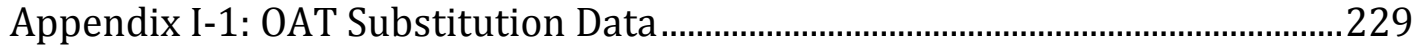

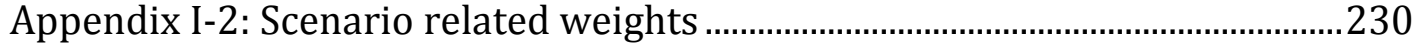

Appendix I-3: IUCRC scores for scenarios D, G, and J...........................................231

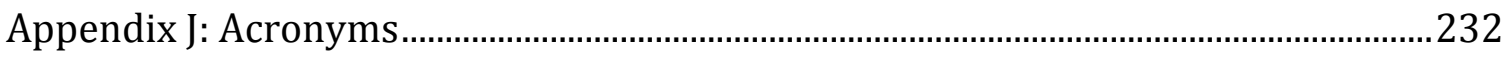




\section{LIST OF TABLES}

Table 1 CRC articles published in leading academic journals..................................... 15

Table 2 Quantitative based research in CRC literature .............................................. 17

Table 3 Case-based research in CRC literature............................................................ 20

Table 4 SNA research in CRC literature ...................................................................... 22

Table 5 Literature researching the "right" metrics...................................................... 28

Table 6 IUCRC characteristics ..................................................................................... 34

Table 7 Performance evaluation gaps in CRC literature ............................................ 37

Table 8 Summary of evaluation tests ....................................................................... 47

Table 9 Selected expert background............................................................................. 56

Table 10 Dimensions of KTT for an IUCRC ………………………………………….... 72

Table 11 Literature identified new knowledge outputs ................................................. 74

Table 12 Literature identified KTT media...................................................................... 78

Table 13 Literature identified KTT objects..................................................................... 79

Table 14 Output decision elements with proposed metrics ........................................ 81

Table 15 New knowledge characterization .................................................................. 83

Table 16 Stakeholder satisfaction characterization ....................................................... 85

Table 17 Student involvement characterization........................................................... 88

Table 18 Student development characterization ……………………………………..... 89

Table 19 KTT media characterization.............................................................................. 91

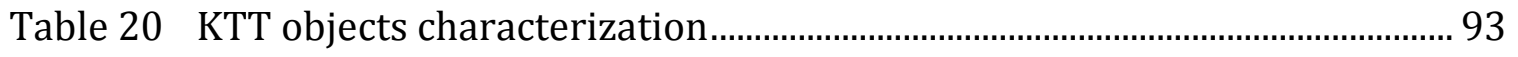

Table 21 Mean, Std Deviation and variance for Expert 9 data ..................................... 98

Table 22 Expert background: student involvement and development......................105

Table 23 Student advisors ..............................................................................................109

Table 24 IUCRC alternatives .........................................................................................115

Table 25 WBC description (wbc.vt.edu) …………….............................................125

Table 26 Metric values for WBC test case …………………………………………128

Table 27 WBC Metrics and desirability values..............................................................131 
Table 28 Calculated Performance Evaluation Score ......................................................132

Table 29 IUCRC performance evaluation scores ............................................................135

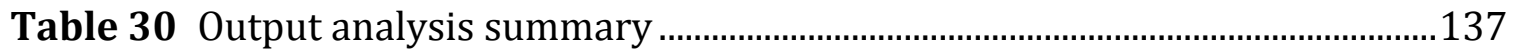

Table 31 Performance improvement recommendations ............................................139

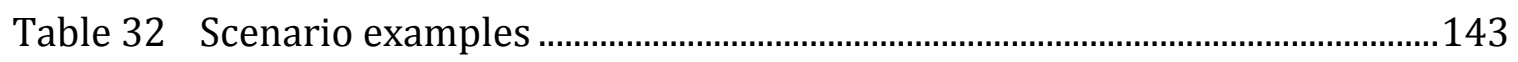

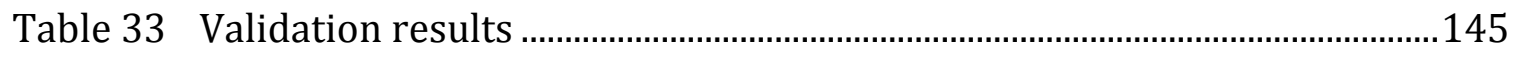

Table 34 Case scenarios tested for sensitivity .............................................................152 


\section{LIST OF FIGURES}

Figure 1 Generic Evaluation Logic Model .......................................................................

Figure 2 CRCs in the middle of performance evaluation problems............................. 14

Figure 3 NSF Programs ............................................................................................ 31

Figure 4 IUCRC organizational structures..................................................................... 33

Figure 5 Research gaps, objectives and questions ......................................................... 43

Figure 6 Comparison of research methods ..................................................................... 44

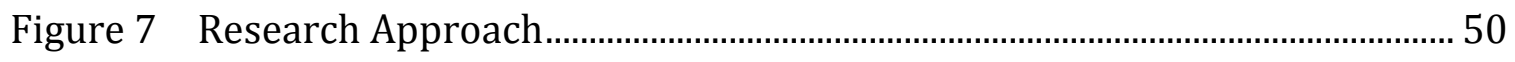

Figure 8 Generalized hierarchical framework …………………………………….... 51

Figure 9 Research Instruments ................................................................................... 55

Figure 10 Expert functions........................................................................................... 57

Figure 11 Panel configurations (Appendix B-1) …………………………………... 58

Figure 12 Expert panel 1 and 2 configurations.............................................................. 59

Figure 13 Disagreement analysis framework................................................................. 64

Figure 14 Desirability curves for new knowledge outputs ............................................. 84

Figure 15 Desirability curves for stakeholder satisfaction outputs................................ 87

Figure 16 Desirability curves for student involvement outputs ..................................... 88

Figure 17 Desirability curves for student development outputs................................... 89

Figure 18 Desirability curves for KTT media................................................................... 92

Figure 19 Desirability curves for KTT object outputs ..................................................... 93

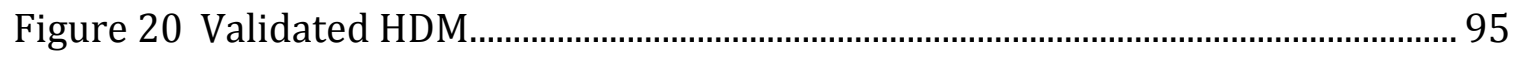

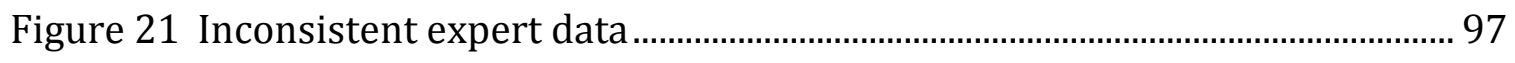

Figure 22 Inconsistency threshold for 5 decision elements ([162] p 99) ................... 99

Figure 23 Disagreement levels among experts...........................................................101

Figure 24 HAC: new knowledge vs. stakeholder satisfaction.......................................102

Figure 25 HAC: student involvement vs. development.................................................104

Figure 26 HAC: KTT media vs. KTT objects ……………………………………….....105

Figure 27 HAC: new knowledge outputs .........................................................................106 
Figure 28 HAC: stakeholder satisfaction outputs.............................................................107

Figure 29 HAC: student involvement outputs .................................................................... 108

Figure 30 HAC: Student development outputs................................................................110

Figure 31 Generalized HDM for IUCRC performance evaluation...................................111

Figure 32 Identification and selection of IUCRC alternatives.......................................114

Figure 33 Manufacturing \& Materials Joining Innovation Center (Ma²JIC) ...............117

Figure 34 Center for Pharmaceutical Development......................................................118

Figure 35 Security and Software Engineering Research Center ...................................119

Figure 36 Center for Surveillance Research.................................................................120

Figure 37 Water Equipment and Policy Research Center..............................................121

Figure 38 Wood-Based Composites Center ........................................................................122

Figure 39 WBC value for \% membership renewal results ...........................................129

Figure 40 Performance evaluation scores .....................................................................144 


\section{CHAPTER 1: INTRODUCTION}

Increasing U.S. public policy support for multi-disciplined research and technology transfer initiatives has resulted in the evolution of many different forms of technology transfer mechanisms [1]. The plethora of literature studying the impact of these policies has led researchers to claim we are in "the era of inter-institutional research collaboration" [[2] p 975]. Thus, it is not surprising that today, universitybased research centers "are prevalent as both policy mechanisms and industry strategies" [[3] p 76].

Cooperative research centers (CRCs) that involve partnership agreements with actors from three different sectors of government, academia and industry are often referred to as a "triple-helix" [4] or a government-university-industry (GUI) [5] type of collaboration. Public policies will most likely continue to support GUI CRCs because industry-university collaborations and multi-disciplinary research are required to solve increasingly complex social problems [6]. While there are many types of technology transfer mechanisms, literature shows that the most sustainable mechanisms require industry-sponsored collaborative research [7].

The National Science Foundation (NSF) is responsible for technology planning and science and engineering based research and education in the United States. Recognizing the value of industry sponsored cooperative research, the NSF launched a program in 1980 to improve the linkage between industry and university for cooperative research [8]; now known as the Industry-University Cooperative Research Center (IUCRC) program. The success of this model led to the development 
of other NSF science and engineering centers. Acting as a type of franchise business model, the program model has been replicated multiple times. Therefore, the social technology clarifies the unit of analysis making it a better candidate for study than other CRCs. Today, with over 66 centers actively being supported by the NSF, literature shows the IUCRC to be one of the more successful CRCs [9].

Supporting such centers is expensive. So, academia, policy makers [10] and CRC managers are all invested in understanding the performance and impact of these centers [11]. Researchers acknowledge that "the growth in private and public investment in university-based technology initiatives has raised important policy questions regarding the impact of such activities" [[12] p 254]. This interest has led to a wealth of literature examining program evaluation through primarily qualitative case-based methods or quantitative methods based on traditional indicators such as patents and publications.

Despite the effort and many excellent studies, researchers are cautioning that traditional measures are "wrong" [14][15] or inadequate [16], placing a call-to-arms for further research. A multi-dimensional-holistic study with a flexible approach that can evaluate both quantitative and qualitative output indicators is needed [17].

This study examines the literature to explore the concerns about current indicators and measurement systems. It adds value by presenting a balanced approach using output indicators by developing a flexible measurement system that incorporates both qualitative and quantitative metrics. A generalizable model is 
developed and validated by experts that produces a score to evaluate and compare the effectiveness in which a center is achieving the NSF IUCRC program's mission. Through a criterion-related validation process, experts agree with the improvement recommendations summarized in the case study results for the centers and generally agree that the model accurately reflects the performance results.

Including this introduction, the paper is organized into 8 chapters. Chapter 2 reviews the academic literature on national planning of technology and cooperative research center program evaluation. The US National Science Foundation (NSF) industry university cooperative research center (IUCRC) program is introduced as the domain of organizational effectiveness for the study. Key organizational mechanisms are described including a formal evaluation program. Research gaps are identified highlighting the need for a holistic performance evaluation model. Validating the importance of this research is the recommendation by the NSF Science of Science and Innovation Policy (SciSIP) program to fund part of this research.

Chapter 3 clarifies the problem and outlines the structured approach that was developed to guide this research project. Several multi-criteria decision making methods are discussed to explain why the HDM is an appropriate framework for this decision problem. Because this method relies on subjective research, the importance of expert judgment is emphasized. Important aspects of working with experts are discussed including: identification and selection methods, panel criteria and formation and research instrument development. A structured approach that 
identifies tools and methods for the collection, quantification and analysis of expert judgment data is outlined.

Chapter 4 describes how the hierarchical decision model (HDM) is first developed through a literature review and then modified through a validation process involving expert panels. The validated four-level model shows how objectives, goals and outputs are linked together. At level 1, the purpose of the HDM is to determine the degree to which a center meets the mission of the NSF IUCRC program by evaluating a holistic set of metrics. Level 2 specifies three program objectives of industry-relevant research, the promotion of students and knowledge and technology transfer. Six goals populate level 3 and seventeen measurable outputs characterized by desirability functions fill level 4 .

Chapter 5 discusses how the generalizable model was finalized. The first section explains how experts quantified the linked decision elements through a series of pairwise comparisons. Upon curing the data, weights are assigned to each decision element. Key in this process is the analysis of the data first for an individual expert inconsistency and then for disagreement among the panel members. Two calculations are used providing a more robust consistency analysis.

Disagreement analysis is conducted using hierarchical agglomerative clustering (HAC) techniques for all data exhibiting a disagreement level greater than a $10 \%$ tolerance level. Dendrograms show how configuring experts into subgroups enables expert disagreement to be analyzed until a satisfactory level of disagreement 
is achieved. Testing the model using a "brute-force" sensitivity analysis ascertains the ordinal impact of the expert disagreement resulting in weighted decision criteria value differences. The finalized generalizable model is presented.

Chapter 6 describes how the model is used to illustrate the method and compare and analyze multiple IUCRCs for organizational performance effectiveness. The results are validated through consultation with experts. Selection criteria identifies six (6) IUCRCs that are profiled in the subsequent sections: Integrative Joining of Materials for Energy Applications (Ma2JIC), Center for Pharmaceutical Development (CPD), Security and Software Engineering Research Center ( $\mathrm{S}^{2} \mathrm{ERC}$ ), Center for Surveillance Research (CSR), Water Equipment Policy (WEP) and WoodBased Composites (WBC) center.

First, the WBC center is used to illustrate how data are collected, metrics are populated and a score is calculated through a step-by-step tutorial using actual center data. The metrics, desirability values and performance evaluation score are used to demonstrate how a center director can use the model as a decision support tool to evaluate the impact of different improvement scenarios.

Then, the model is used to calculate performance evaluation scores for the remaining 5 centers. Scores and metric values are analyzed to provide realistic recommendations for performance improvement. Specific recommendation scenarios show how the scores are used to help identify and then quantify performance impact for each center. 
Chapter 7 analyzes the model development and validation process and the results of the case studies using literature and expert judgment. Expert responses during the model validation process support concerns in literature about some of the traditional metrics. Results of the case studies are summarized. Criterion-related validity refers to the ability of the model to accurately reflect performance of the centers under analysis. The results of the criterion-related validity are summarized showing how the generalizable model is valid and why it has promise for extension to other CRC programs.

Experts who reviewed the results were in general agreement of the accuracy of the model and validity of the method. Further support for this method and research is in the form of funding provided through an NSF Science of Science and Policy program grant for improved data collection and dissemination of the results. A summary of comments offered by the reviewers of the dissertation research grant proposal are shared.

Chapter 8 summarizes and concludes the discussion. Contributions to the field, limitations of the study and areas for future research opportunities are presented. 


\section{CHAPTER 2: LITERATURE REVIEW}

\subsection{Technology Planning}

Technology planning is driven by changes in societal goals over time. For example, US interest in national technology foresight activities increased, during the 1940's and 1950's, as a result of successful cooperative research projects achieved during WWII [18]. Competing for supremacy during the Cold War drove further technology development in both national defense and space exploration programs [19]. In the 80's, global economic competition, especially from Japan, exacerbated by the recession, encouraged commercialization of the defense industry [20]. Large government research organizations began to use a collaborative technology foresight approach to complement their strategic planning processes [21].

Technology foresight is a process that systematically looks into the future to examine areas of research and emerging technologies [22]. Martin originally defined foresight as a systematic process to look into the longer-term future of science and technology for strategic research identification [23]; however, Coates [24] and others [25] expanded the definition to include a shift towards participative approaches to create shared longer-term vision to support short-term, decision-making processes about national initiatives. It has also been defined as a tool in policy and strategic planning [26], [27], for priority setting and decision making [28] and for creation of vision and pursuit of knowledge [29][30] to solve complex socio-technical problems. 
"System changes are labelled 'socio-technical' because they not only entail new technologies, but also changes in markets, user practices, policy and cultural meanings" [[31] p 495]. Major industries such as information and communication technology (ICT) [32], energy [33], food [34], health [35] and transportation [36] are faced with complex socio-technical challenges. Solving environmental problems is a national concern that entails cultural value and belief systems [37] that goes far beyond a technological problem.

This is a large and complex topic. A variety of approaches have been used to cover different aspects of US National Technology as well as CRC evaluation. Therefore, a framework is warranted to organize this chapter. Figure 1 shows how Ruegg and Feller's evaluation logic model [38] was adapted creating a useful framework to organize and drive the literature review. Similar to other research studies [39][40], this framework employs a top-down organizational approach. 


\section{Figure 1 Generic Evaluation Logic Model}

Goal 1: Identify

National technology

planning and

infrastructure

\section{Goal 2:}

Identify CRC

programs

and methods

for their

evaluation

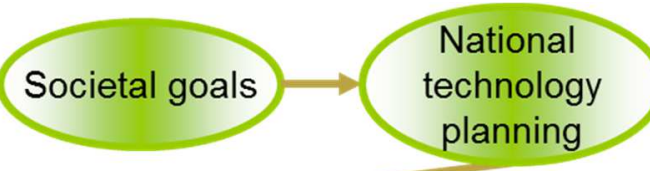

\section{Technology}

transfer

policies

mechanisms

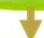

Cooperative science and

engineering research Center (CRC)

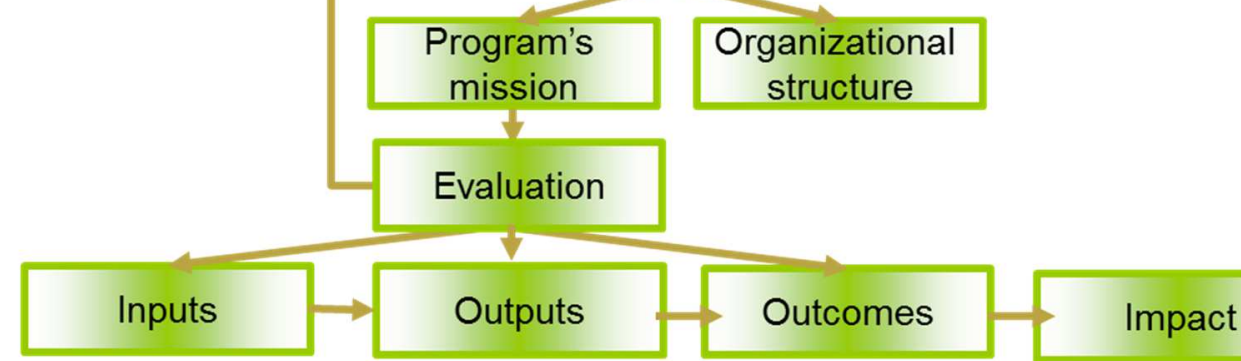

Public policy strategies are often the result of national foresight activities [41].

Grupp and Linstone agree emphasizing the importance of foresight as a national policy tool to "wire-up" national innovation programs [22]. In the US, these policies have traditionally focused on facilitating collaboration among industry and academia [1][42][43][44]. However, there was a shift in the national research agenda to place more focus on technology transfer in the early 1980's. Roessner defines technology transfer as "the movement of know-how, technical knowledge, or technology from one organizational setting to another"[[45] p 31]. Some examples of policies that support technology transfer and program evaluation include: 
- 1980: The Bayh-Dole Act permits universities to obtain title and license to inventions generated with projects funded by the government [46],

- 1984: The Cooperative Research Act supports the engagement of universities and federal laboratories to conduct joint pre-competitive R\&D projects [13].

- 1986: The Federal Technology Transfer Act [40] and the Technical Memorandum from the Office of Technology Assessment improves funding for pubic research decisions through the use of quantitative techniques [47].

- 1993: The Government Performance and Results Act requires codification of the use of quantitative metrics for program evaluation [19].

- 2010: America Competes Act Reauthorization supporting linkages between research investments and economic growth and societal benefits [48]

This rapid increase in U.S. public policy strategy changed the university environment [13] driving more research interest in the literature. One of the first outcomes, attributed to the Bayh-Dole Act in 1980, was the creation of technology transfer offices (TTOs) at many US universities [13]. As a result of this Act, universities were able to retain ownership of inventions developed with government funding and license these technologies. Evidence of this impact was the expansion of many university missions for inclusion of entrepreneurial and commercialization activities [49].

Interested in further supportive policies, government started looking for practical organizational structures [50][51] that encouraged knowledge and 
technology transfer [52] beyond the university sector [53]. Initiatives to facilitate technology transfer have been developed using a variety of different mechanisms that vary in terms of complexity, structure and longevity including: research parks, licensing agreements, R\&D limited partnerships, joint facility use agreements, research institutes, research centers and state-supported science and technology centers. The most sustainable technology transfer mechanisms require industrysponsored collaborative research [7].

\subsection{Cooperative Research Centers}

Today, cooperative research centers (CRCs) are popular public policy mechanisms for technology transfer [9][54] because industry-sponsored collaborative research [7] has been found to be a required business model component for sustainable innovations [33]. Just in the US there are thousands of CRC programs [55]. Studies provide evidence that public funding of research has had significant impact on CRC programs [56]. Bozeman calls one stream of this literature the "cooperative technology policy paradigm" because it "features an active role for government actors and universities in technology development and transfer" [[57] p 632]. CRC evaluation literature, aligned with this stream, requires a multi-levelperspective (MLP) to effectively transition technology to solve these type of "sociotechnical" system problems [37]. 
The largest concentration of university-industry cooperative research articles are published in four (4) journals: Research Policy, Technovation, the Journal of Technology Transfer and Management Science. At the university-based level, Sigel, Link and Feldman are some of the leading authors. A common technology transfer mechanism studied by this group of authors includes the university-based technology transfer office (TTO).

Another group of articles are more focused on the GUI type of CRC where additional organizational formality is introduced because a portion of their funding is from the government. This "triple-helix" type of structure has attracted several leading researchers including: Etzkowitz, Leydesdorff, Carayannis, Porter and Corley. The literature in this group is increasing rapidly [58].

CRCs are "inherently complex and therefore a challenging phenomenon to understand" [[6] p 5]. The wide variety of mission specifications and organizational mechanisms [22] of "more than 27,500 worldwide" [[59]p74] makes the unit of analysis difficult to define. For example, some organizational structures include: innovation centers, engineering research centers (ERCs), university research centers, industry consortia, centers of excellence, proof of concept centers, and of course the NSF IUCRCs.

While there is still some debate about what constitutes a CRC, Boardman and Gray have made recent progress towards definitional consensus. They define a CRC in terms of three characteristics: 
- it has an organizational structure and exhibits "organizational formality",

- $\quad$ engages in research, and

- $\quad$ promotes external, "cross-sector collaboration and transfer" [[6] p 451].

The move from single-actor environments to "ecosystem settings raise a new set of issues for both researchers and managers to consider" [[60] p 330]. Multiple actors in cross-disciplines are involved in examining these issues requiring a systems perspective [61].

Figure 2 shows how three of the NSF sponsored CRC programs are positioned in the middle level of performance evaluation problems: materials science and engineering research centers (MRSECs), engineering research centers (ERCs) and industry/university cooperative research centers (IUCRCs). "Increasingly, firms are bypassing traditional mechanisms (e.g. contracts, gifts) and providing support through I/U linkage mechanisms" [[62] p 5]. GUI CRCs are more formal with organizational structures designed to span the boundaries between stakeholder entities and link them together. 
Figure 2 CRCs in the middle of performance evaluation problems

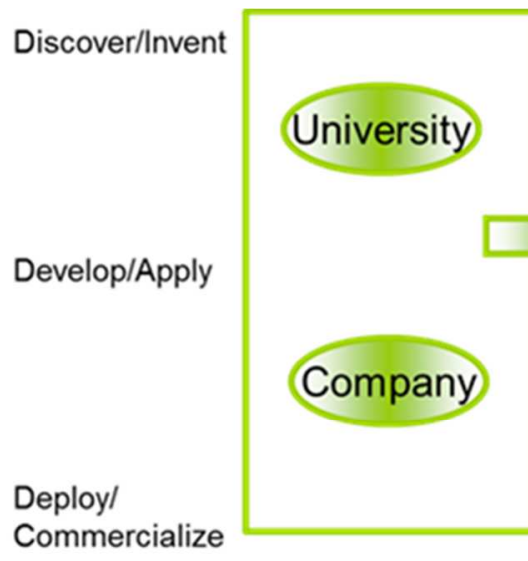

Micro Level:

Research focused on individual actors.

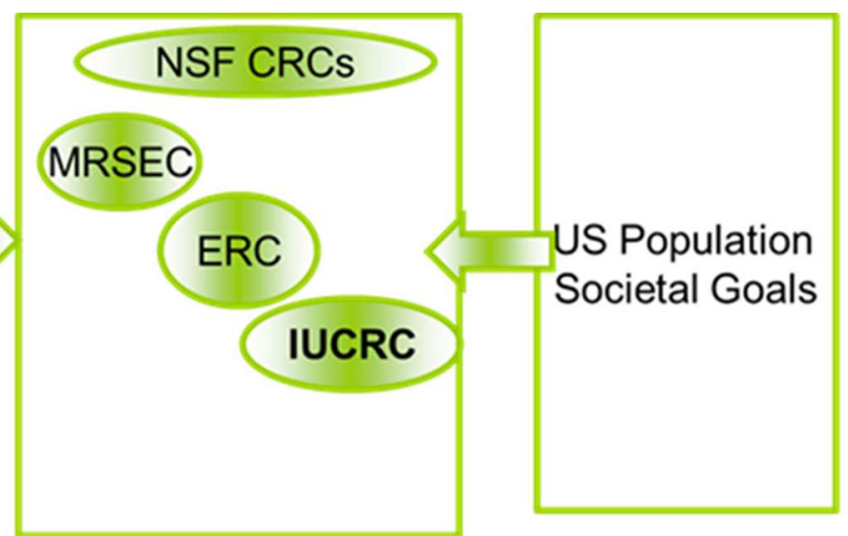

\section{Middle Level: Government Funded CRC Triple Helix structure}

Macro Level: National or Regional

Many studies have investigated technology transfer at the micro and macro levels [63][64]. Research at the micro level is focused on single-actors such as a university technology transfer office (TTO), research labs or individual firms. These studies only represent a partial stakeholder view and primarily use traditional metrics for evaluation such as papers, patents and licenses. Econometric studies are plentiful at the macro level. However, the aggregated data isn't useful to compare CRCs. Researchers have identified the lack of research for comparing CRCs as the "missing middle" [65].

Table 1 shows an example of some of the more highly cited articles by some of these leading authors and the journals where they are being published. Examination 
of the citations in these articles provided an additional source of references for the literature review.

Table $1 \quad$ CRC articles published in leading academic journals

\begin{tabular}{|l|l|l|l|}
\hline Author(s) & Title & Publication & Cited $^{*}$ \\
\hline $\begin{array}{l}\text { Etzkowitz, } \\
\text { Leydesdorff, }\end{array}$ & $\begin{array}{l}\text { The dynamics of innovation: From National Systems } \\
\text { and "mode 2" to a Triple Helix of university-industry- } \\
\text { government relations }\end{array}$ & $\begin{array}{l}\text { Research } \\
\text { Policy [4] }\end{array}$ & 4430 \\
\hline $\begin{array}{l}\text { Gray, Behrens, } \\
\text { Unintended consequences of cooperative research: } \\
\text { impact of industry sponsorship on climate for } \\
\text { academic freedom and other graduate student } \\
\text { outcomes }\end{array}$ & $\begin{array}{l}\text { Research } \\
\text { Policy [66] }\end{array}$ & 175 \\
\hline $\begin{array}{l}\text { Feldman, Feller } \\
\text { Bercovitz, } \\
\text { Burton 2002 }\end{array}$ & $\begin{array}{l}\text { Equity and the technology transfer strategies of } \\
\text { American research universities }\end{array}$ & $\begin{array}{l}\text { Management } \\
\text { Science [67] }\end{array}$ & 359 \\
\hline $\begin{array}{l}\text { Siegel, Waldman, } \\
\text { Link, 2003 }\end{array}$ & $\begin{array}{l}\text { Assessing the impact of organizational practices on the } \\
\text { relative productivity of university technology transfer } \\
\text { offices: An exploratory study }\end{array}$ & $\begin{array}{l}\text { Research } \\
\text { Policy [68] }\end{array}$ & 1035 \\
\hline $\begin{array}{l}\text { Carayannis, } \\
\text { Popescu, 2006 }\end{array}$ & $\begin{array}{l}\text { Technological learning for entrepreneurial } \\
\text { development (TL4ED) in the knowledge economy } \\
\text { (KE): Case studies and lessons learned }\end{array}$ & $\begin{array}{l}\text { Technovation } \\
\text { [69] }\end{array}$ & 147 \\
\hline $\begin{array}{l}\text { Boardman, } \\
\text { Corley, 2008 }\end{array}$ & $\begin{array}{l}\text { University research centers and the composition of } \\
\text { research collaborations }\end{array}$ & $\begin{array}{l}\text { Research } \\
\text { Policy[70] }\end{array}$ & 99 \\
\hline $\begin{array}{l}\text { Boardman, Gray, } \\
\text { Rivers 2010 }\end{array}$ & $\begin{array}{l}\text { The new science and engineering management: } \\
\text { cooperative research centers as government policies, } \\
\text { industry strategies and organizations }\end{array}$ & $\begin{array}{l}\text { Journal of } \\
\text { Technology } \\
\text { Transfer [58] }\end{array}$ & 44 \\
\hline
\end{tabular}

*Citation count reported using Google Scholar in July, 2015

\subsection{Program Evaluation Methods}

The evaluation method literature was synthesized into five (5) groups for further discussion:

1) quantitative econometric and statistical analysis,

2) case-based analysis,

3) social network analysis (SNA),

4) multiple criteria decision making (MCDM),

5) multi-attribute utility theory (MAUT). 
One comprehensive report by Ruegg \& Feller [38] that surveyed evaluation methods and models was particularly useful. The rest of this section reviews the evaluation methods in the literature by the five research method groupings.

Licensing performance is a common theme in the quantitative based literature. For example, Chukumba and Jensen [71] , examine how the characteristics of different actors affect licensing performance. Two findings provide evidence of a positive relationship between the importance of venture capital and licensing agreements and that engineering faculty was relatively more important than the other science based faculty. Anderson et. al. used licensing data to examine efficiency [72] and Kim took an in-depth look at the impact of lag time using similar data and metrics. Shane and Somaya [73] use the association of university technology transfer managers (AUTM) association data and patent litigation data to examine the effects on university licensing efforts [73].

The Feldman and Kelly study is different because it uses statistical analysis to test the strength of hypothesized relationships. This method is interesting because it can help to open up the "box" and take a look at the "middle". The survey data was coded as a bi-variate "yes" or "no" then tabulated and tested for statistical significance. Logistic regression was used to test the strength of the relationships [74].

The research method selected for a study depends upon the research problem being investigated and the organizational structure under analysis [75]. These 
studies are particularly useful at the micro, single-actor level, or macro, total-program level because they use a more consistent method that can be replicated by other researchers to verify and extend the results building convincing evidence about program impacts. These methods are particularly useful to justify the existence of a program and investigate if the total cost of the policy is beneficial to society. Table 2 shows some methods and findings; however, the results don't help to provide comparisons between centers.

Table 2 Quantitative based research in CRC literature

\begin{tabular}{|l|l|l|l|}
\hline Author Year & Purpose & Purpose/ Findings & Method \\
\hline $\begin{array}{l}\text { Cohen, } \\
\text { 1994 [76] }\end{array}$ & $\begin{array}{l}\text { Provide a } \\
\text { comprehensive } \\
\text { picture of IURCs }\end{array}$ & $\begin{array}{l}\text { Measurement of IURC impact } \\
\text { on technology advance }\end{array}$ & $\begin{array}{l}\text { Extensive survey-based } \\
\text { empirical study forming } \\
\text { the "Carnegie Mellon" } \\
\text { database }\end{array}$ \\
\hline $\begin{array}{l}\text { Cohen, } \\
\text { Walsh, } \\
\text { Nelson 2002 } \\
\text { [77] }\end{array}$ & $\begin{array}{l}\text { University and } \\
\text { government research } \\
\text { lab contribution to } \\
\text { industrial innovation }\end{array}$ & $\begin{array}{l}\text { System of simultaneous } \\
\text { equations links dependent } \\
\text { variables to firm/industry } \\
\text { level economic variables }\end{array}$ & $\begin{array}{l}\text { Survey-based approach } \\
\text { using Carnegie Mellon } \\
\text { data (1994) hypothesis- } \\
\text { based testing }\end{array}$ \\
\hline $\begin{array}{l}\text { Hall, Link, } \\
\text { [74] 2003 }\end{array}$ & $\begin{array}{l}\text { Investigating roles } \\
\text { and effects of } \\
\text { universities in ATP- } \\
\text { funded projects }\end{array}$ & $\begin{array}{l}\text { University involvement may } \\
\text { not speed up } \\
\text { commercialization as } \\
\text { partnerships may have more } \\
\text { basic research aspects. }\end{array}$ & $\begin{array}{l}\text { Survey-based study of } \\
\text { ATP-funded research } \\
\text { projects. } \\
\text { Multivariate regression } \\
\text { analysis }\end{array}$ \\
\hline $\begin{array}{l}\text { Chukumba, } \\
\text { Jensen 2005 } \\
\text { [71] }\end{array}$ & $\begin{array}{l}\text { Licensing } \\
\text { performance focused } \\
\text { at small business }\end{array}$ & $\begin{array}{l}\text { Licensing by universities with } \\
\text { larger venture capital, } \\
\text { engineering faculty relative } \\
\text { high importance }\end{array}$ & $\begin{array}{l}\text { Empirical, Game } \\
\text { theoretic model, } \\
\text { hypothesis testing }\end{array}$ \\
\hline $\begin{array}{l}\text { Feldman and } \\
\text { Kelley, 2006 } \\
\text { [78] }\end{array}$ & Knowledge spillover & $\begin{array}{l}\text { Testing hypothesis for } \\
\text { incentive effects of } \\
\text { government R\&D funding for } \\
\text { firms }\end{array}$ & $\begin{array}{l}\text { Empirical survey, 240 } \\
\text { completed, } \\
\text { multivariate regression }\end{array}$ \\
\hline
\end{tabular}

Cohen et. al. conducted an extensive survey-based nation-wide empirical study investigating the impact of university-industry-research centers (UIRCs) on 
technology advancement. As part of the study, they measured technology transfer outputs and outcomes. Realizing that patents, inventions and prototypes only capture a partial picture, they developed intermediate outcome measures including: improved existing products or processes, new products, new R\&D projects and new methods to make existing R\&D projects more efficient. The data was quantified, normalized and used to compute summary scores. They determined that "face-to-face interactions are the most important component of effective technology transfer from (university-industry research centers) UIRCs to industry" [[76] p 25]. This excellent study helps to understand UIRC outputs and outcomes.

None of the studies use quantitative methods to compare CRCs for performance. Two primary reasons are measurement error in the survey-based measures [77] and the opportunistic selection of model elements based upon the availability of data. Data collection is important. It takes time to identify, collect, verify clean and cure. This is one reason why some researchers form a model based upon data availability. For example, the Carnegie Mellon study took over three years and another study of the magnitude was not found that could be helpful to update the 1994 data set.

So, the focus on patents and licensing is understandable because of the availability of data; however, it is only a piece of the performance story. First, not all research results in patents. Next, researchers have found that only $17 \%$ of R\&D performing firms consider patents a moderately important source of the university 
to industry knowledge transfer [77]. The other problem with patent and licensing is a time lag that was addressed by Kim [63], who took a deeper look at this problem in his dissertation. Thus, researchers caution that studies limited on these metrics may seriously mis-represent the impact of a university-based ecosystem [79].

In summary, econometric and statistical methods are useful and appropriate at the micro "actor" level or the national level to look at a particular mechanism or the impact of a program; but, there isn't enough structured data available to provide a holistic picture required for CRC comparisons. "Most of what we know about cooperative research is communicated at a very aggregate level" [[66] p 194].

Other researchers have used survey methods and case studies to research center stakeholder values and evaluate individual centers. Peer review is a popular technique used for individual center evaluations [75]. For example, Boardman [80] surveyed researchers in IUCRCs to evaluate their research practices and others have used case studies to identify success factors [81]. Case studies help to answer why and how questions. They are useful at evaluating the performance of CRCs helping to explain why some succeed and others fail and to link outcomes to outputs for a particular center. This section will focus on the case study literature that emphasizes performance and comparison of two or more CRCs using performance metrics.

In a sense, all of the NSF IUCRC program evaluators publish case studies each year for each IUCRC because they use standardized, Level of Interest and Feedback Evaluation (LIFE), forms and questionnaires to collect qualitative data. 
Table 3 provides an example of some of the cased-based literature focused on IUCRC performance evaluation.

Table 3 Case-based research in CRC literature

\begin{tabular}{|l|l|l|l|}
\hline Author Year & Focus & Findings & Gaps \\
\hline $\begin{array}{l}\text { Gray et. al., } \\
\text { 2003 [82] }\end{array}$ & $\begin{array}{l}\text { IUCRC Evaluation } \\
\text { process }\end{array}$ & $\begin{array}{l}\text { Centers have been } \\
\text { extensively evaluated }\end{array}$ & $\begin{array}{l}\text { Comparative evaluation } \\
\text { missing or of low } \\
\text { quality }\end{array}$ \\
\hline $\begin{array}{l}\text { Corley, } \\
\text { Boardman, } \\
\text { Bozeman, } \\
\text { 2006 [2] }\end{array}$ & $\begin{array}{l}\text { Multi- } \\
\text { institutional } \\
\text { research } \\
\text { evaluation } \\
\text { implications }\end{array}$ & $\begin{array}{l}\text { Need organizational structure } \\
\text { or epistemic development of } \\
\text { the disciplines in the } \\
\text { collaborations }\end{array}$ & $\begin{array}{l}\text { More focus needed on } \\
\text { the design of } \\
\text { organizational systems. }\end{array}$ \\
\hline $\begin{array}{l}\text { Gray, } \\
\text { 2008[59] }\end{array}$ & $\begin{array}{l}\text { IUCRC Evaluation } \\
\text { Process }\end{array}$ & $\begin{array}{l}\text { Structured case reports } \\
\text { needed to include outcomes, } \\
\text { best practices and } \\
\text { breakthrough technologies }\end{array}$ & $\begin{array}{l}\text { Subjective data are non } \\
\text { comparable, coding } \\
\text { methods needed }\end{array}$ \\
\hline $\begin{array}{l}\text { Ramanathan } \\
\text { et. al. 2010 } \\
\text { [83] }\end{array}$ & $\begin{array}{l}\text { CETI IUCRC } \\
\text { Stakeholder } \\
\text { needs } \\
\text { assessment }\end{array}$ & $\begin{array}{l}\text { Agile design processes benefit } \\
\text { students to span boundaries }\end{array}$ & $\begin{array}{l}\text { Innovation outcomes } \\
\text { are typically } \\
\text { unmeasured }\end{array}$ \\
\hline $\begin{array}{l}\text { Scott, 2014 } \\
\text { [84] }\end{array}$ & $\begin{array}{l}\text { IUCRC break- } \\
\text { through } \\
\text { technologies }\end{array}$ & $\begin{array}{l}\text { IUCRCs need a structured way } \\
\text { to report breakthrough } \\
\text { technologies }\end{array}$ & $\begin{array}{l}\text { Inconsistency of impact } \\
\text { data. }\end{array}$ \\
\hline
\end{tabular}

Case studies are important because they can paint a detailed story and explain why events are happening tying inputs, activities, outputs and outcomes to impacts. Some of the limitations is the confidentiality of the information or the tendency to under or over report. There is also the problem of comparing centers to one another [84]. It is difficult to generalize from a case study creating opportunity for measurement error. While the IUCRC has developed and documented many case studies, the focus is on the individual center and not on the general comparison of centers in the program [2][59]. 
Social network analysis (SNA) is gaining importance in the literature [4][85]. Several researchers have used SNA methods, tools and techniques to investigate spillovers [86][87], co-authorship networks [88][89] and membership activity [14]. Structured data such as citations in the scientific databases and filings in patent databases can be mined using bibliometric techniques. Most of the researchers who use the citation of other firms' patents note that patents are not a perfect measure of innovative output [38], because they relate only to codified knowledge and there may be significant differences in patenting behavior between IUCRCs, firms, and technological domains.

However, this method shows promise and researchers are actively working to improve the problem of data availability and linkages. For example, Rafols et al. introduced a new method using bibilometric data to map areas of collaboration using network analysis methods [90]. Advances in scientific databases now allow for more sophisticated mapping and the spatial and geographic mapping methods are becoming more popular [91]. A sample of research from leading authors in this area is included in Table 4. 


\begin{tabular}{|l|l|}
\hline Author, year & Topic \\
\hline $\begin{array}{l}\text { Balconi and Laboranti } \\
\text { 2006 [86] }\end{array}$ & $\begin{array}{l}\text { University-industry interactions in applied research: The case of } \\
\text { microelectronics }\end{array}$ \\
\hline $\begin{array}{l}\text { Rafols, Porter, } \\
\text { Leydesdorff, 2009 [90] }\end{array}$ & $\begin{array}{l}\text { Science overlay maps: a new tool for research policy and library } \\
\text { management }\end{array}$ \\
\hline Porter Rafols, 2009 [92] & $\begin{array}{l}\text { Is science becoming more interdisciplinary? Measuring and } \\
\text { mapping six research fields over time }\end{array}$ \\
\hline $\begin{array}{l}\text { Abbasi and Altman, 2011 } \\
\text { [87] }\end{array}$ & $\begin{array}{l}\text { Correlation between Research Performance and Social Network } \\
\text { Analysis Measures Applied to Research Collaboration Networks }\end{array}$ \\
\hline Garner et. al. 2012 [93] & $\begin{array}{l}\text { Assessing research network and disciplinary engagement changes } \\
\text { induced by an NSF program }\end{array}$ \\
\hline $\begin{array}{l}\text { Leydesdorff, Carley, } \\
\text { Rafols 2013 [91] }\end{array}$ & $\begin{array}{l}\text { Global maps of science based on the new Web-of-Science } \\
\text { categories }\end{array}$ \\
\hline Abassi et. al. 2014 [94] & $\begin{array}{l}\text { Measuring social capital through network analysis and its } \\
\text { influence on individual performance }\end{array}$ \\
\hline
\end{tabular}

Even Elsevier is working to develop an international standard for research metrics. They have identified that the traditional citation metrics are inadequate to provide a multi-faceted approach [88]. In order to reach their vision in their new "Snowball" program, several metrics will need to be developed that aren't readily available now such as esteem, prestige or credit received from peers.

Several researchers have used multi-criteria decision making (MCDM) [49] [95] to consider different perspectives in their research. A multi-level decision model (MLDM) is a flexible method that can utilize both structured data and unstructured data by using methods that quantify the expert judgment. Saaty [96] introduced the Analytic Hierarchy Process (AHP), a popular MCDM method to deconstruct a problem into top-down levels of linked concepts. The Hierarchical Decision Model (HDM) is 
similar to the hierarchical structure of approaching problem and differs in the use of pair-wise comparisons to quantify element weights.

Hierarchical decision models (HDMs) were developed by Phan to evaluate the innovativeness of companies in the semi-conductor industry based upon output indicators [95] and by Tran to develop an index to measure the effectiveness of a technology transfer office (TTO) based upon fulfillment of the stated organizational mission [49]. These researchers measured a broader range of outcomes to include knowledge transfer beyond licensing. In Tran's research, a knowledge and technology transfer effectiveness index was developed to compare mechanisms for a particular university. This research is particularly interesting for this study because it provides precedence in the literature for using the HDM as an appropriate methodology as well as additional data to identify knowledge and technology transfer output elements.

The multi-attribute utility theory (MAUT) is another popular multi-criteria model that considers additive value for multiple objectives [97]. Because the AHP and the HDM involve a relative importance assessment procedure and use "a hierarchy to establish preferences and orderings" they are "sometimes classified as a MAUT approach" [[98]p 646]. The MAUT process considers the perspective of a decision maker through the use of utility functions or desirability curves.

Other strategic and scoring models have been used to study CRC evaluation such as Porter's diamond [99], the Kaplan-Norton Balanced Scorecard [100][101][102] and the knowledge management performance index (KPMI)[103]. 
Al-Ashaab et al. used the Balanced Scorecard method by developing a set of key performance indicators to evaluate UI cooperative research [100]. The balanced perspectives for evaluation included: competitiveness, sustainable development, innovation, strategic partnerships, human capital and internal business processes.

Perkman et al. evaluate UI success criteria with a staged model they developed that considers inputs, activities, outputs and outcomes [10]. This research identified success factors at different stages of maturity. However, the format of these models could introduce more non-structural type of errors than a multi-level decision model leaving room for additional sources of expert disagreement.

Other authors extend the case study method by applying frameworks. Using a structured process, they applied these frameworks to evaluate output indicators. Ruegg developed the composite performance rating system (CPRS) [39][38] for comparative project evaluation for the Advanced Technology Program. The CPRS assigns up to four (4) stars for selected characteristics. Summing the values will produce a total score for each project in a portfolio. While the pilot method selected indicators by data availability, several iterations of the process has led to valuable discussions and findings about using output indicators [39].

Carayannis et. al. extend the case-based approach to compare engineering research centers (ERCs) [5]. This work focused specifically on the intellectual capacity type of outputs. Additional dimensions of stakeholder perspective and time were discussed in this research. 
Rogers et. al. developed a framework to assess University-based ecosystems based upon eight dimensions of effectiveness [104]. He found that inputs were problematic because they led to identifying effectiveness by size. This is additional evidence that reinforces the decision to use normalized output indicators.

Geisler [9] developed The Metric of Process Outcomes as an approach to integrate output indicators in four different stages of the innovation process. In this process he developed indices to calculate an overall score. This method also groups indicators by normalized weights. National scoring systems such as the OECD, the U.S. NSF and the Japanese Science Indicators system (SCI) are discussed in a comprehensive book he published about science and technology metrics [20]. This seminal work is focused at the national level attempting to evaluate the economic impact on the economy. While demand for evaluation has increased [74][105][106], the evaluation methods and holistic approaches required for comparison are lacking [8][47].

\subsection{Science and Technology Indicators (STI)}

Identification of the "right" indicator(s) is not a new problem. In the 1960's the Organization for Economic and Co-operation and Development (OECD) began discussions about science and technology indicators (STI) [107]. The NSF became actively involved and published a set of science indicators (SI) to measure how strong the US was in science and technology [108]. Wanting to gain a better understanding of the impact of these indicators, the NSF funded research. Several studies found that 
heavy reliance on research expenditure data and patent statistics provided misleading results [109].

So, researchers continued to investigate correlation and use of the scientometric indicators [110]. In the 1990's, Grupp was one researcher promoting "technometrics" by investigating correlation between output indicators and different technology specification measurements such as patents and citations [111]. However, Katz and Martin cautioned about using co-authorship citation as a metric to measure collaboration. They found that many possible factors drove researchers to co-publish such as funding patterns, staffing, and mentoring. So, collaboration is difficult to define and measuring by co-authorship still only paints a partial picture [112]. Early publication and patent-based indicators continued to be criticized as researchers realized there was no "catch-all" criterion [113]. However, publication and citation analysis has become a traditional measure for research evaluation [110] enabling researchers to study focused areas of the performance problem.

Growth in investment has raised policy maker's attention towards the impact of CRCs publicly funded collaborative research projects [11][114]. For example, the Government Performance and Results Act (GPRA) of 1993 increased interest in "reforming the way we evaluate government research efforts" [[59] p 79] using science and technology indicators (SCIs)[19] that contributed to a heightened sense of "metric mania" [57]. 
Recognizing the need to measure multiple dimensions led researchers to investigate composite indicators and scoreboards. Using normalization techniques, researchers created formulas combining publication criteria to create new indicators [115]. Wagner and Leydesdorff describe an integrated impact indicator (I3) that solves some of the problems with using citation data [116]. Scoreboards, such as the OECD Science, Technology and Industry Scoreboard, and the NSF's National Science Board publish composite statistical scores at the macro level [117].

Eventually, policy makers began to take a larger system perspective [118] encouraging flexible approaches to be developed beyond the structured-based approach of bibliometric quantification. The federal agency in Japan, the National Institute of Science and Technology Policy (NISTEP), uses a similar method to research science and technology activity. Funding and support provided by the US National Bureau of Economic Research (NBER) has contributed to Porter's efforts to map innovative cluster development [119], providing data sets for researchers at the macro (regional and national) level. The NIH and NSF continue to heavily invest in systems that help measure the impact of programs at a national level as evidenced by the emergence of new federal R\&D data systems such as the STAR METRICS suite of tools [48].

Table 5 identifies research focused on finding the "right" metrics providing some background on the development of CRC performance evaluation metrics. 


\begin{tabular}{|l|l|}
\hline Author, Year & Purpose/Findings \\
\hline $\begin{array}{l}\text { Bozeman and } \\
\text { Corley, 2004 }\end{array}$ & $\begin{array}{l}\text { Investigate the impact of collaborative research in CRCs on human } \\
\text { capital [120]. }\end{array}$ \\
\hline Leydesdorff, 2005 & $\begin{array}{l}\text { Evolution of scienometrics and use of citation indexes for research } \\
\text { evaluation [110]. }\end{array}$ \\
\hline $\begin{array}{l}\text { Freeman and } \\
\text { Soete, 2009 }\end{array}$ & $\begin{array}{l}\text { Continuous and rapid evolution of science and technology innovation } \\
\text { systems requires new performance measurement indicators [121]. }\end{array}$ \\
\hline $\begin{array}{l}\text { Rafols, Porter and } \\
\text { Leydesdorff, 2009 }\end{array}$ & $\begin{array}{l}\text { New dynamic approach to locate collaborative research through } \\
\text { mapping [90] }\end{array}$ \\
\hline $\begin{array}{l}\text { Schmoch, } \\
\text { Schubert and } \\
\text { Jansen, 2010 }\end{array}$ & $\begin{array}{l}\text { Scientific performance evaluation requires a balanced set of metrics } \\
\text { and a multi-dimensional approach [122]. }\end{array}$ \\
\hline $\begin{array}{l}\text { Waltman et. al., } \\
\text { 2011 }\end{array}$ & $\begin{array}{l}\text { Combination techniques to create a "crown" indicator using } \\
\text { bibliometric data [115]. }\end{array}$ \\
\hline $\begin{array}{l}\text { Wagner, et. al., } \\
\text { 2011 }\end{array}$ & $\begin{array}{l}\text { NSF commissioned study to identify interdisciplinary research output } \\
\text { indicators found progress with methods and call for more research } \\
\text { and development before metrics can adequately evaluate } \\
\text { performance[123] }\end{array}$ \\
\hline $\begin{array}{l}\text { Piva and Rossi- } \\
\text { Lamastra, 2013 }\end{array}$ & $\begin{array}{l}\text { Towards developing a system of indicators to evaluate U/I } \\
\text { performance that currently do not exist [124] }\end{array}$ \\
\hline
\end{tabular}

Nowadays, researchers generally agree that measuring the performance of a GUI CRC requires a multi-dimensional and balanced approach using output indicators [5]. Both direct and indirect methods of technology transfer must be considered [125]. Bozeman and Corley [120] conducted a study using data from 451 researchers at US CRCs investigating the impact of cooperative research on human capital.

Wagner et. al. argue that this is not simply a multi-disciplinary problem; but rather it is an interdisciplinary one meaning the research output is more than the sum of its parts [123]. Outputs go beyond the research component to consider cognitive and social aspects. This supports Geels contention that this is a multi-levelperspective (MLP) problem [31]. The development and need for indicators for 
performance evaluation continues to evolve. In general, researchers agree that a holistic set of new performance indicators are required [110][115][124].

Prominent organizational theorists emphasize the first step in clarifying the construct is to identify all of the elements in the domain of organizational effectiveness and then determine how they are related [126][127][128]. Therefore, literature was examined to review many different CRC programs to select an appropriate domain for the organizational effectiveness problem. "While the OECD launched the idea of indicators, it is to the NSF that we owe the development of the field" [[107] p 687]. Thus, the discussion turns back towards the NSF IUCRC program model.

\subsection{NSF IUCRC program}

The NSF IUCRC model is one type of GUI CRC. The model was developed to transfer "know-how" in the form of organizational structure and best management practices from the NSF to a director and managing research staff at an established IUCRC. Through research projects and other IUCRC activities, technical knowledge and technology is transferred from researchers to industry members and their companies. Researches focused on IUCRC evaluation include: Gray, Boardman and Rivers.

The NSF IUCRC program was selected as the domain of organizational effectiveness for this research based upon the longevity and formalized structure of the program. Currently there are 66 centers spanning 175 different university sites 
[8][58]. While even more have graduated from the NSF's program, they still utilize the model. So, the NSF IUCRC program model has been replicated multiple times. Not unlike a business franchise model, the NSF IUCRC program has developed their brand of social technology in the form of operational mechanisms making the domain appropriate for this research study. Researchers have also identified the IUCRC program model as one of the most successful technology transfer mechanisms [9].

\subsubsection{NSF Background}

The National Science Foundation (NSF) is the US federal agency that is dedicated to the support of fundamental research and education for science and engineering disciplines. It was established in 1950 through a bill signed by President Truman. The organization was structured with a Director and a twenty-four (24) member Science Board. The charter of the NSF remained through Sputnik, the Vietnam War, and a period of economic crisis.

"In the early 1980s, the research agenda began to shift to domestic technology transfer" [[57] p 639]. This also coincides with the time that the IUCRC program was formally launched (1980) by the NSF to improve the linkage between industry and university for cooperative research [8]. Today, the NSF funds several different science and engineering research center programs and projects. Figure 3 captures how some of these programs are more focused on basic research and others on applied research. Funding is targeted at the micro level through grant programs such as: Accelerating 
Innovation Research (AIR) and Small Business Innovation Research (SBIR). Funding is targeted at the middle level through CRCs.

Figure 3 NSF Programs

Macro Level National Programs

Middle Level CRCs

Micro Level Single Entities

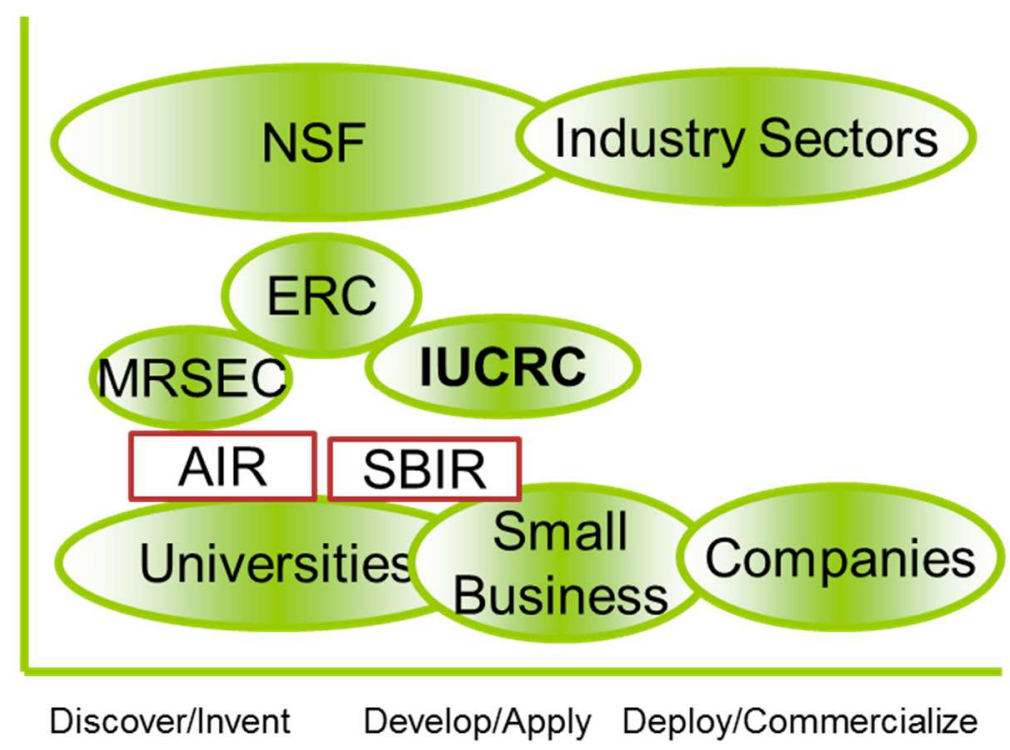

The distinction between basic research and applied research is an important aspect of a CRC's mission. For example, Engineering Research Centers (ERCs) and Materials Research Science and Engineering Centers (MRSECs) focus more on basic research while IUCRCs emphasize more on applied research. Crow and Bozeman found tracing the impact of basic research to be especially difficult and that industrial R\&D spends little on basic research [129]. Figure 3 shows how the IUCRC model is more aligned with applied research that translates more directly to industry in the form of commercialization. 


\subsubsection{Mission Specifications}

The IUCRC program encourages multidisciplinary collaborative research between one or more universities and industry member firms. Using a hybrid organizational structure that allows for flexibility [62], the research is selected by an Industrial Advisory Board (IAB) and conducted collaboratively between university faculty, student researchers and industry partners [130].

In 1988, an informative guide was published to facilitate development and management of IUCRCs that outlines the program and clarified the mission through three objectives:

1) To pursue fundamental engineering and scientific research having industrial relevance.

2) To produce graduates who have a broad, industrially oriented perspective in their research and practice.

3) To accelerate and promote the transfer of knowledge and technology between university and industry [[62] p 23]."

In 1993, “the NSF's IUCRC program had 53 centers spanning 78 universities in the United States, with over 700 participating companies and agencies" [[55] p 39].

\subsubsection{Organizational Mechanisms}

IUCRCs may take different forms and vary by participation number and levels, center goals and processes, and outputs [114]. However, there is a formal organizational model with specified policies, processes and procedures for management and evaluation. The model was intentionally designed so the NSF could 
transfer management "know-how" and expertise to IUCRC members. Central to the selection of the NSF IUCRC program as the unit of analysis for this study is the clear organizational structure and consistent application of operational mechanisms.

Figure 4 shows how new IUCRCs can be structured to include more academic partners in a complex, multi-university organizational structure. The frame on the left shows a typical single university organizational chart; whereas, the frames on the right show multiple partnerships. Seven (7) of the IUCRCs have only one (1) university partner [[62] p 62].

Figure $4 \quad$ IUCRC organizational structures

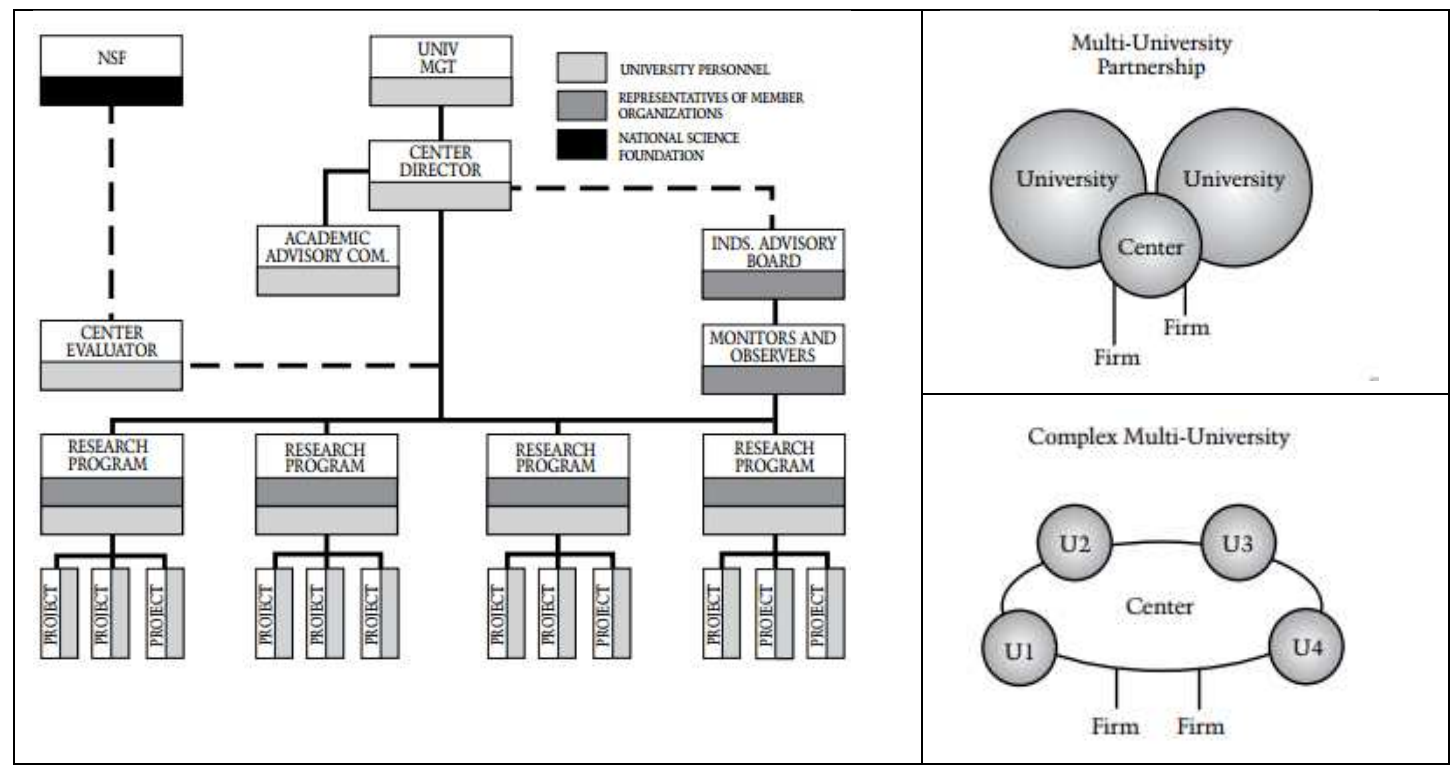

As of today, the IUCRC model has been replicated more than 100 times [84]. The most complex IUCRC, focused on advanced foundry systems, has ten (10) university partners. The NSF policy and incentives has gradually shifted towards 
supporting multi-discipline, multi-site IUCRC structures [41][131][132] and away from single-site centers. Table 6 [62] describes the IUCRC model by operational mechanisms and characteristics.

Table $6 \quad$ IUCRC characteristics

\begin{tabular}{|l|l|}
\hline \multicolumn{1}{|c|}{ Characteristics } & \multicolumn{1}{c|}{ Description } \\
\hline Formal membership agreement & Includes unique scope and shared interest agreements \\
\hline Partners & University, industry, other organizations \\
\hline Shared research agenda & Objectives, goals and a roadmap \\
\hline Shared IP & Formal agreement \\
\hline Center Director & Tied to a University [62], diverse [133] \\
\hline Primary Funding Source & Industry members structured min. funding: \$30k from 10 \\
\hline Evaluation & 2x/year reporting, independent formal evaluation \\
\hline Graduate Students & Required involvement \\
\hline Structural Requirements & Funding, organizational, management, reporting \\
\hline
\end{tabular}

Formal partnership agreements are required for membership. These documents include the scope of the research projects and shared interest agreements that help to clarify intent. There are multiple stakeholders that include the NSF, the university, the center director, researchers, students and industry. Formal documents and management practices require regular reports and roadmaps. Other management practices and structural requirements help to establish an IUCRC through its' formation. For example, the funding structure requires that industrial advisory board (IAB) members pay yearly dues.

\subsubsection{Formal Evaluation Program}

Performance appraisal is important to the practice of CRC management to understand and maximize the impact of their research findings [134]. While 
supporting and evaluating centers is very expensive, performance evaluation is a best management practice [94] and required by policy when federal funds are involved. According to a White House memorandum [135], funding agencies, academic leadership, and industry must manage their portfolios in an objective, evidence-based manner to address science and technology priorities of our nation and increase the productivity of our research institutions.

The NSF has recognized the importance of a formal evaluation program by continuously supporting a project established at North Carolina State University for the purpose of evaluating IUCRCs. Their website clearly states the primary purpose:

1) To help NSF and local centers objectively evaluate their impact by documenting I/UCRC outcomes and accomplishments

2) To promote continuous improvement by giving actionable, timely, databased (formally collected and observational) feedback, analysis and advice to NSF and local centers;

3) To identify and communicate information about I/UCRC best practices to NSF and local centers. (www.ncsu.edu/iucrc, 2016)

The evaluation program is also structured and formalized with established policies, processes and procedures to address program inputs, activities, outputs, outcomes and impacts. Independently contracted NSF evaluators collect data using tools and templates established by the NSF IUCRC evaluation program. Both qualitative and qualitative data are collected. Evaluators help center directors define, develop and populate metrics. For example, customer satisfaction can be difficult to measure. Information for this type of measure is typically recorded on a Level of 
Interest and Feedback Evaluation (LIFE) form [62]. The IUCRC evaluation program typically includes:

- "submitting a yearly Evaluator Report detailing the center's progress

- conducting exit interviews when members leave the center, and

- administering and analyzing an annual process and outcome questionnaire to IAB members" [62]

\subsection{Gaps in Literature}

Despite the research interest and financial support for program evaluation, literature shows that current outputs and metrics are insufficient [58][130] and evaluation continues to be extremely challenging [136]. Through a synthesis of literature, researchers generally agree on three causes for the limitations and gaps: the complexity of the ecosystem, poor agreement on the "right" outputs and metrics and lack of available time-series data and the quality of the data [137].

"Collaborative Research Centers are heterogeneous in nature varying widely in missions often including creation of fundamental knowledge commercialization of technologies, education of next generation of researchers and promotion of economic development" [15 p1]. So, the disparity in the unit of analysis makes efforts to evaluate and compare GUI CRCs challenging [138]. Boardman and Gray agree finding a lack of definitional consensus and variety of organizational structures and mission specifications to be contributing factors to the problem.

Basically, "improved methods are needed for program evaluation" [[39] p 11], because of the flexibility and variety in the ecosystem. Even when the unit of analysis 
can be clarified, other researchers have pointed to the problem of understanding what indicators are required to measure performance.

Table 7 provides additional supporting evidence to the problem of identifying what to measure and how to measure it. Author identified challenges support the three leading gaps: complexity, lack of data, and inadequacy of traditional indicators.

\section{Table $7 \quad$ Performance evaluation gaps in CRC literature}

\begin{tabular}{|c|c|c|}
\hline Reference & Findings & Theme \\
\hline Adams et. al, 2004 & $\begin{array}{l}\text { More and better "panel data" needed to answer other } \\
\text { IUCRC impact questions. }\end{array}$ & $\begin{array}{l}\text { Lack of } \\
\text { available data }\end{array}$ \\
\hline $\begin{array}{l}\text { Freeman and } \\
\text { Soete, } 2009\end{array}$ & $\begin{array}{l}\text { "Research on STI (science and technology initiative) } \\
\text { indicators appears today as challenging as ever"[[121] } \\
\text { p529]. }\end{array}$ & Complexity \\
\hline $\begin{array}{l}\text { Boardman and } \\
\text { Gray, } 2010\end{array}$ & $\begin{array}{l}\text { "CRCs are inherently complex and therefore a challenging } \\
\text { phenomenon to understand" [[6] p 5]. }\end{array}$ & Complexity \\
\hline $\begin{array}{l}\text { Roessner, } \\
\text { Manrigue, and } \\
\text { Park, } 2010\end{array}$ & $\begin{array}{l}\text { Lack of a "standardized performance criteria" and "exclusive } \\
\text { reliance on quantifiable data" provides misleading results } \\
\text { [139]. }\end{array}$ & $\begin{array}{l}\text { Traditional } \\
\text { indicators } \\
\text { inadequate }\end{array}$ \\
\hline $\begin{array}{l}\text { Schmoch et al., } \\
2010\end{array}$ & $\begin{array}{l}\text { "Scientific performance should not be measured by a one- } \\
\text { dimensional metric such a publication, since it is a multi- } \\
\text { dimensional phenomenon" [[122] p2]. }\end{array}$ & $\begin{array}{l}\text { Traditional } \\
\text { indicators } \\
\text { inadequate }\end{array}$ \\
\hline $\begin{array}{l}\text { Palomares- } \\
\text { Montero and } \\
\text { Garcia-Aracil, } 2011\end{array}$ & $\begin{array}{l}\text { "It is difficult to obtain valid and reliable data and the } \\
\text { results of evaluation processes depend on the quality of the } \\
\text { information available. There is a lack of disaggregated data } \\
\text { to enable comparison among disciplines, and data often are } \\
\text { not sufficiently firm, resulting in indicators that provide } \\
\text { inaccurate results" [[140] p353]. }\end{array}$ & $\begin{array}{l}\text { Lack of } \\
\text { available data }\end{array}$ \\
\hline Graham, 2013 & $\begin{array}{l}\text { "Many experts regarded commonly used research } \\
\text { commercialization metrics (number of spin-offs, licensing } \\
\text { revenue, etc.) as unreliable indicators of long-term } \\
\text { capability to support of develop a vibrant innovation } \\
\text { ecosystem"[[141] p i]. }\end{array}$ & $\begin{array}{l}\text { Traditional } \\
\text { indicators } \\
\text { inadequate }\end{array}$ \\
\hline $\begin{array}{l}\text { Penfield et. al., } \\
2014\end{array}$ & $\begin{array}{l}\text { "These 'traditional' bibliometrics techniques can be } \\
\text { regarded as giving only a partial picture of full impact with } \\
\text { no link to causality [134]. }\end{array}$ & $\begin{array}{l}\text { Traditional } \\
\text { indicators } \\
\text { inadequate }\end{array}$ \\
\hline Abbasi et al. 2014 & $\begin{array}{l}\text { "Collecting network data has its own limitations" and lack of } \\
\text { other types of data prevents performance comparisons } \\
{[[94] \text { p72]. }}\end{array}$ & $\begin{array}{l}\text { Lack of } \\
\text { available data }\end{array}$ \\
\hline
\end{tabular}


Metrics can be used to compare and differentiate the performance of different organizations. Some organizations produce outputs more efficiently than others or at higher quality levels. Effective use of metrics can help organizations to achieve superior performance outcomes. However, Freeman and Soete argue on the basis of their 40 years of indicators work that "STI [science and technology] indicators that were important last century may no longer be so relevant today and indeed may even be positively misleading" [[121] p588]. Researchers have found that a GUI CRC is a complex ecosystem [60]; not a "trivial machine, with a defined input-output ratio" [15]. So, metrics are important; but, which ones are appropriate?

Publications and patents are common outputs of university research projects. Publications typically represent the output of earlier-stage, basic research while patents are typically more indicative of applied research [17]. These traditional outputs are easily quantified with bibliometrics data and have been used in many studies. However, researchers have cautioned that "exclusive reliance on quantifiable data" provides misleading results [139] because they only provide a partial picture [134]. Others have cautioned that traditional measures are simply the "wrong" metrics [14][15].

Knowledge transfer and integration also requires understanding of social dynamics and networks. Emerging research in social network analysis and metrics such as betweenness centrality and diversity are promising; but, the use and interpretation is difficult [123]. In a recent, empirical research study involving 
multiple experts the results concluded that "identifying a set of metrics to evaluate the performance of a university-based ecosystem was a considerable challenge" [[141] 4].

The third group discusses challenges attempting to tie the metrics to the outputs and outcomes because more and better quality data are needed to answer impact type of questions [137]. Some of the available aggregated data was found to be of poor quality leading to inaccurate results [[140]p353]. In general, researchers agree that "due to non-availability of data we are unable to measure" performance of research centers. Researchers are specifically asking for time series membership data [137] and network data [89] that is disaggregated [140].

In summary, performance measurement calls for a comprehensive [72], multi-dimensional approach considering multiple perspectives. This problem requires boundary-spanning criteria because there are many constituent groups who have a stake placing different values on outputs and outcomes. Different perspectives can lead to disagreement about the mission and value of the outputs. For example, different institutional norms govern public and private knowledge [79] [136]. Even when agreement is reached, stakeholder perspectives are expected to shift over time. Literature is calling for more research to examine the effectiveness of the CRC organization and the impact of their activities and outputs [52]. 


\section{CHAPTER 3: RESEARCH APPROACH}

\subsection{Research Problem}

As societal problems become increasingly complex, more emphasis is being placed on multi-disciplinary cooperative research approaches to solve them. Federally funded CRCs receive over $\$ 5$ billion in federal funding[59] for support and evaluation. Because CRC's have been recognized as an effective mechanism for translational research they are important; but, performance comparison is still somewhat of a challenge. Where formal evaluation programs exist, the methods are typically resource intensive. Results are typically focused on a single center or at the program level[59]. Outcome evaluation studies "have tended to focus on technology transfer outcomes to industry"[[59] p 77].

With limited resources, policy makers must be diligent at attempting to make objective and increasingly transparent funding decisions. Decision support tools that can evaluate a holistic set of metrics can compare the performance of centers against a mission. Without the help of such tools, policy makers are ill equipped to make transparent and objective decisions. They need to know if their program really makes a difference "compared to no program or an alternative one" [[59] p 78] and how to improve with scarce resources.

Government continues to support cooperative research centers because they provide competitive advantage at a national level; however, sustainable performance requires evaluation. Performance evaluation not only provides insight to improve 
management effectiveness; it is also a federal mandate. So, effective and efficient GUI CRCs are important to policy makers, center directors, industrial board members and the public.

Despite the importance an increasing investment, a set of holistic output indicators are missing. Missing also are decision support tools and methods to help make performance measurement more cost effective. While there are many excellent studies investigating organizational and program performance, they are primarily focused at the micro and macro levels leaving a gap in the middle level. Where researchers have attempted to evaluate this level, they caution that limitations in data paint a partial picture making comparison of centers difficult.

The number and variety of CRCs varies widely. This disparity makes identification of the unit of analysis difficult. So, there is not a generalizable model, holistic set of metrics with data to populate them, or a system available to measure performance for center comparison.

\subsection{Research Scope and Objectives}

This study presents a new holistic approach that allows for comparison of NSF science and engineering research centers multiple CRCs. NSF Science of Science Innovation Policy (SciSIP) program representatives validated the research gap and importance of the topic through a successful grant proposal review process. Validating the literature gap, one evaluator wrote: "These centers can vary considerably in the science they support, their structure, and ultimately their strengths. 
Where one center may make considerable progress in research, another may instead succeed best at producing excellent scientists. Agencies have long struggled with how to evaluate such centers, given their complexity." Evidence also supports the importance of the topic. "Evaluating such centers remains difficult and often subjective, yet federal science agencies continue to invest considerable resources in them."

Multiple IUCRCs are used to test and analyze the model's ability to calculate a valid and appropriate performance evaluation score. An expert's review of the case study results validates the generalizability of the model.

This research has four objectives:

1) To define a set of outputs that paints a balanced-holistic picture

2) To develop a framework and metrics that gauge the performance evaluation of these outputs toward meeting the objectives

3) To evaluate the performance with required data

4) To introduce a new method for CRC performance comparison extending the literature

Figure 5 maps the gaps to research questions that were developed to support the research objectives. 
Figure $5 \quad$ Research gaps, objectives and questions

\section{GAPS $\Longrightarrow$ OBJECTIVES $\Longrightarrow$ QUESTIONS}

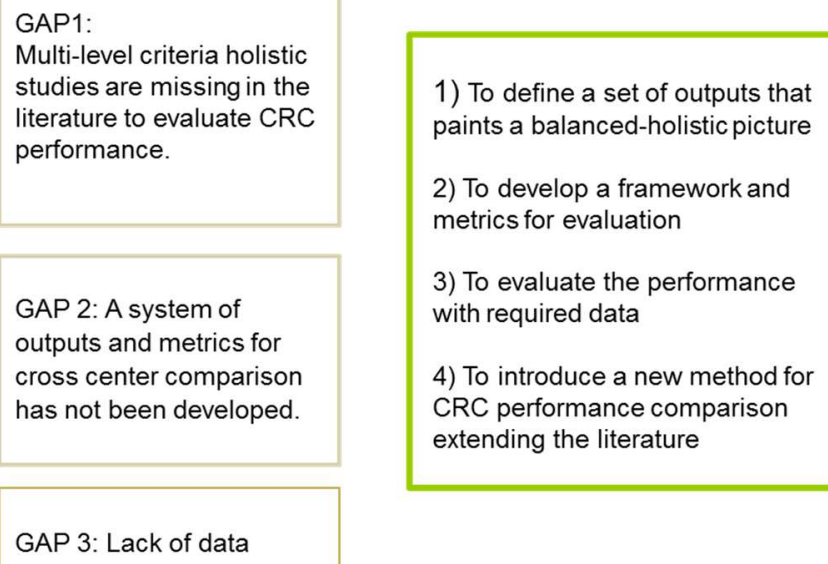

1) To define a set of outputs that paints a balanced-holistic picture

2) To develop a framework and metrics for evaluation

3) To evaluate the performance with required data

4) To introduce a new method for CRC performance comparison extending the literature

What is the most appropriate framework for comparative performance evaluation of CRCs?

Which CRC program should be used to test the model?

How is that program characterized (operational mechanisms)?

What outputs are necessary/sufficient for a holistic evaluation?

How can a score be used to improve management performance of a center?

How are the metrics developed and normalized?

How can bias be minimized?

How reliable are the results?

\subsection{Multi Criteria Decision Problem}

Policy makers have the fiscal responsibility to make objective based decisions that are transparent to the public. When units of analysis are too complex to characterize and data are unavailable, they must base their decisions on experience and subjective data. CRC performance should be measured using multi-dimensional criteria because this is a "multi-dimensional phenomenon" [[122] p2]. The literature review, previously discussed in Chapter 2 that examines methods used to study CRC performance evaluation, is summarized in Figure 6. The multi-criteria decision making (MCDM) method is appropriate for this research problem because the complexity of the ecosystem makes the construct difficult to define requiring expert 
input. The flexibility of the method can handle both qualitative and quantitative data allowing for a holistic approach.

\section{Figure 6 Comparison of research methods}

\begin{tabular}{|l|l|l|l|l|}
\hline Challenge & $\begin{array}{l}\text { Statistical } \\
\text { Methods }\end{array}$ & Case & SNA & Multi-Criteria \\
\hline $\begin{array}{l}\text { Complexity } \\
\text { Limitations }\end{array}$ & $\begin{array}{l}\text { Typically linear } \\
\text { regression type } \\
\text { of problems. } \\
\text { Does not handle } \\
\text { multiple } \\
\text { perspectives }\end{array}$ & $\begin{array}{l}\text { Provides answers } \\
\text { to what, how and } \\
\text { linkages between } \\
\text { outputs, outcomes } \\
\text { and impacts. Not } \\
\text { reproducible }\end{array}$ & $\begin{array}{l}\text { Does not handle } \\
\text { multiple } \\
\text { perspectives. } \\
\text { Structured data } \\
\text { set partial } \\
\text { picture. }\end{array}$ & $\begin{array}{l}\text { Requires } \\
\text { experts. Difficult } \\
\text { to define. }\end{array}$ \\
$\begin{array}{l}\text { Aggregated } \\
\text { score. }\end{array}$ \\
\hline Metrics & $\begin{array}{l}\text { Traditional, } \\
\text { partial picture }\end{array}$ & $\begin{array}{l}\text { Non-standard, } \\
\text { descriptive, not } \\
\text { measured }\end{array}$ & $\begin{array}{l}\text { Traditional, } \\
\text { partial picture }\end{array}$ & $\begin{array}{l}\text { Expert defined } \\
\text { Desirability } \\
\text { function }\end{array}$ \\
\hline Datatative, & $\begin{array}{l}\text { Citation based } \\
\text { descriptive }\end{array}$ & Flexible \\
\hline quantitative & Fibmetric & \\
\hline
\end{tabular}

Understanding that organizational effectiveness is a construct rather than a concept [126] helps to explain why a multi-criteria decision making tool is appropriate for this type of a problem. In the organizational theory literature, Steers [127] and other researchers [128] discuss the importance of using a framework to link decision criteria [142]. Concepts are abstractions defined and measured by characteristics. Higher-level abstractions are often difficult to characterize and measure requiring construction of different concepts.

Multi-criteria, multi-level models are useful when decisions are complex and require judgment between multiple alternatives. They present an appropriate method for this study for several reasons: 
1) They are flexible, decision support tools that can be used to quantify expert judgment. These methods can handle both qualitative and quantitative data.

2) The hierarchical methods allow for decomposition of a complex decision problem into a hierarchy of smaller sub-problems for independent analysis. The elements of the hierarchy can relate to any aspect of the decision problem under investigation.

3) There is a precedence in the literature. The methods have been used in other research studies to explore complex, multi-dimensional problems [49][95][143][144].

Researchers have used many different hierarchical frameworks in multidimensional decision models. While there are many popular multi-criteria methods, the multi-attribute utility theory, analytic hierarchy process and hierarchical decision model methods are highlighted because they are discussed more frequently in the CRC program evaluation literature.

The ability to capture decision maker preferences through utility functions is an advantage of the MAUT method. The structured hierarchical approach used by the AHP method to decompose a problem using linked levels of decision criteria aligns closely with the organizational theory literature making it an appropriate framework for this type of problem. The HDM is similar to the AHP in the structured approach to breaking down a problem and capturing expert judgment data using pair-wise comparisons. However, it differs because it provides more input flexibility and a 
robust method for consistency analysis. Specifically, the AHP uses a nine point scale and the HDM uses constant sum, direct ratio or absolute values.

\subsection{Expert Judgment}

Literature provides strong evidence for the use of expert panels in complex decision making problems where quantitative data are not available [143]. In this research, expert panels are used to complete three different functions involved in the model development process: validation of concepts, quantification of elements to establish weights and desirability curve development. Experts were again asked to participate in criterion-related validity by responding to results of a case study.

This section will discuss the importance and need for expert judgment and the role they play to validate the model and results of this research. It outlines critical issues when working with experts, describes how experts were selected and formed into panels, delineates the methods used to collect data and describes how the data was cured before the generalizable model was finalized.

\subsubsection{Validation}

Expert judgment is a key component in this research approach. Table 8 shows how experts are used to validate the model content and construct and also to conduct criterion-related validity [[49]p71] . 
Table $8 \quad$ Summary of evaluation tests

\begin{tabular}{|l|l|l|}
\hline Validity & What is measured & Methods \\
\hline Construct & $\begin{array}{l}\text { The degree to which a measure relates } \\
\text { to expectations formed from theory for } \\
\text { hypothetical construct }\end{array}$ & $\begin{array}{l}\text { Judgmental, } \\
\text { Correlation, } \\
\text { Convergent-discrimination } \\
\text { Factor analysis } \\
\text { Multitrait-multimethod }\end{array}$ \\
\hline Content & $\begin{array}{l}\text { Degree to which the content of the } \\
\text { items adequately represents the } \\
\text { universe of all relevant items under } \\
\text { study }\end{array}$ & Judgmental \\
\hline $\begin{array}{l}\text { Criterion- } \\
\text { related }\end{array}$ & $\begin{array}{l}\text { Degree to which the criterion can } \\
\text { capture the true value of the variable }\end{array}$ & $\begin{array}{l}\text { Judgmental, } \\
\text { Correlation }\end{array}$ \\
\hline
\end{tabular}

A five-step structured process is used to get the best results and minimize bias [145]: 1) Criteria development, 2) identification, 3) selection, 4) panel formation, 5) judgment extraction. It is also used to describe critical issues considered while working with experts.

Criteria must be developed not only for the domain under investigation but also for the expert qualifications[146]. Experts must be knowledgeable about the domain, have a reputation for high quality expertise [147], as well as the ability to make assessments. Failure to select appropriate experts has created problems for many studies [148]. Researchers emphasize the importance of relevant training and experience [149].

Many definitions of expertise are based upon a social role or believability. But, just because someone holds a certain position doesn't make them an expert. For example, are the experts qualified for the panel based upon a role and the years of 
service in that role, or are they selected based upon demonstrated performance? Panel criteria have considered both. It is important to establish criteria before creating a list of experts to avoid introducing unnecessary bias into the panel and allowing for a balanced perspective.

When identifying experts and forming panels it is important to consider that different perspectives are required at different levels in the model. Inherent in the organizational design of a collaborative research center are perspective differences among the multiple stakeholders. In this study, Panel 1 experts require a strong grasp of policies that support technology transfer mechanisms. Insight about how the NSF IUCRC program strategically fits into the national technology planning process is also important. Specific criteria required to validate and quantify NSF IUCRC program objectives include: technology planning expertise at the national level as well as direct IUCRC program management experience.

NSF IUCRC program directors and the Principal Investigator for the NSF IUCRC evaluation project were identified as qualified experts for judging the level 2 decision critera. Experts judging criteria at level 3 in the model require expertise in program evaluation and a managerial and organizational perspective. Many of the NSF IUCRC program evaluators were identified using the online NSF center directory.

Literature reviews, citation analysis and snowball were other methods used to identify experts. Mining bibliometrics data [50] is often used to locate leading authors in the field. Seventeen (17) authors were identified as leading in the field 
because they had published or co-published 3 or more of the papers obtained from the literature search or their citation count was high. Citation analysis was an effective means to select leading authors. Authors with more than 50 citation counts on at least one published journal article in the NSF IUCRC literature are an example of invited participants.

Social network analysis (SNA) is an effective method to search for experts who have co-authored or facilitated some of the NSF IUCRC meetings. Background information on experts and their contact information was obtained by searching the web and collecing CVs to fill in missing data. Citation analysis of the NSF literature extended this method revealing additional experts and leaders in the domain. Snowball methods were also used by asking experts during the invitation process for names of other experts. A total of 208 experts were identified through these various methods.

\subsubsection{Research design}

A structured research approach that was designed to guide this research is shown in Figure 7. 
Figure $7 \quad$ Research Approach

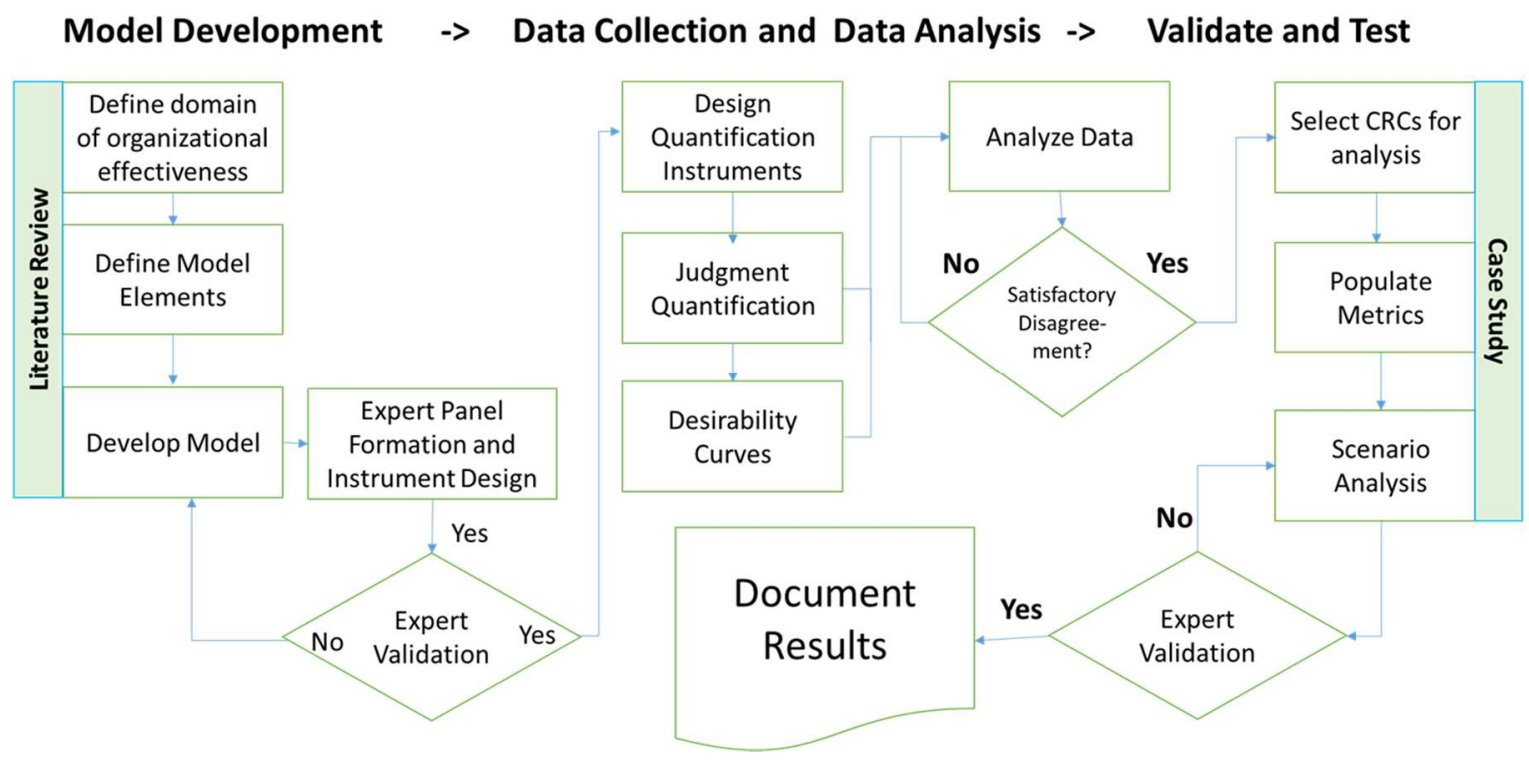

Literature reviews were conducted to identify and define the elements required to clarify the domain of organizational effectiveness and establish an appropriate hierarchical framework that could be adapted to link these concepts together constructing a generalizable model. Literature identified objectives, goals and outputs as three types of elements required to measure the degree to which centers perform relative to the program's mission. A generalizable model, developed by linking the decision criteria, was presented to experts for validation of the content and construction. 


\subsubsection{HDM as a framework}

Cleland and Kocaoglu introduced a framework that is well-suited for this performance evaluation problem based upon mission-objectives-goals-strategiesactivities (MOGSA) [150]. When the problem is broken into a hierarchical structure [151], experts can judge a series of elements through pairwise comparisons. Each element is organized into a different level in the model and linked to the other elements creating the hierarchical structure. Figure 8 shows how the MOGSA framework was adapted to create a generalizable four (4) level model for this performance evaluation problem.

Figure $8 \quad$ Generalized hierarchical framework

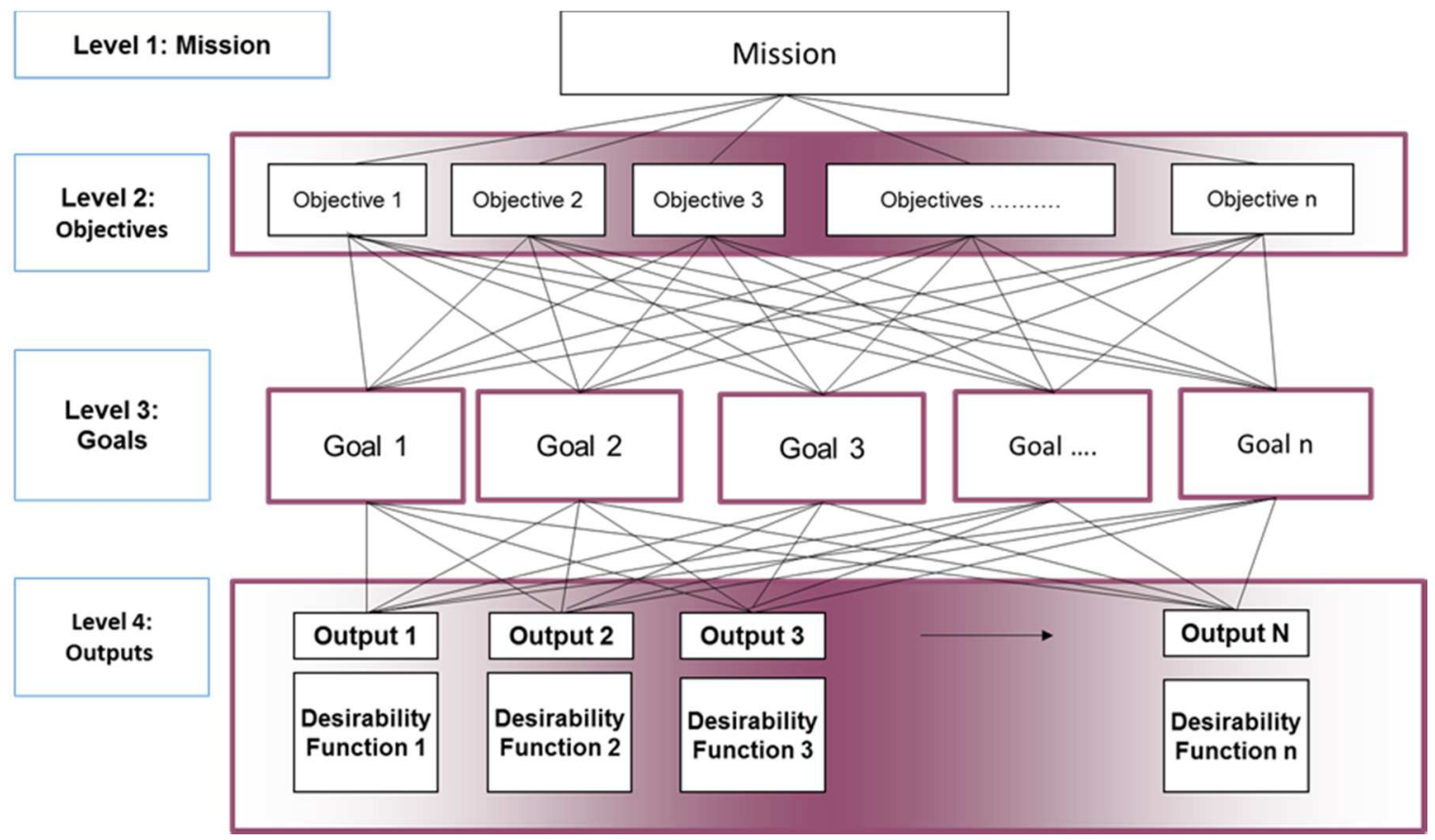


The purpose of the model (decision objective) is placed at the top of the mission-oriented framework. Organizational objectives fill the second level. Goals are placed at the third level and output indicators used to measure the goals fill in the $4^{\text {th }}$ level. Thus, the mission of the model is a performance evaluation score that determines the degree to which objectives measured by a balanced set of output indicators contributes to the IUCRC program's mission.

It makes sense that different outputs are not valued the same. Some may contribute to performance more or less than others. The value of relative outputs towards the mission is determined by experts. Mean scores of experts in each panel are then quantified to develop weights for each element. It also makes sense that producing different output quantities meeting different quality standards will provide different results.

Tran [49] included desirability curves to evaluate the effectiveness of university-based technology transfer offices establishing precedence in the literature for this method. Because more is not always better and scales are not absolute, curves reflecting desired output quantity and/or quality are developed. Inclusion of utility curves incorporates some of the benefits previously described in the MAUT literature.

Equation 1 shows how a performance effectiveness value (E) can be calculated using multiple criteria (c) for any number of (I) alternatives (a) under comparison. 


\section{Equation 1 Performance effectiveness value}

$$
\mathrm{E}\left(\mathrm{a}_{\mathrm{i}}\right)=\sum_{l=1}^{L} \sum_{k=1}^{K} \sum_{j=1}^{J} O_{l} G_{k}^{l} C_{j k}^{k} d(m, j k) \quad \text { for } \mathrm{i}=1, \ldots, \mathrm{I}
$$

Where:

$\mathrm{E}\left(\mathrm{a}_{\mathrm{i}}\right)=$ Effectiveness value for alternative $\mathrm{I}$,

$O_{l} \quad=\quad$ the degree to which objective $\boldsymbol{l}$ contributes towards center performance.

$G_{k}^{l} \quad=$ the relative contribution of goal $\boldsymbol{k}$ under objective $\boldsymbol{l}$ towards performance.

I $=\quad$ Number of alternatives under comparative evaluation,

$\mathrm{J}=\quad$ Number of outputs,

$\mathrm{K}=\quad$ Number of goals,

$\mathrm{L}=\quad$ Number of objectives,

$\mathrm{d}\left(m_{i}, j k\right) \quad=\quad$ Desirability of performance metric of alternative $(i)$ for $j$ th criterion under goal $(k)$,

$\boldsymbol{C}_{j k}^{k}=\quad$ Relative importance of criterion $(j k)$ under goal $(k)$.

\subsubsection{Expert panel configuration}

This study uses a two-phased research design where thirty-seven selected experts were formed into five (5) different panels to validate then quantify decision elements. Several experts met the criteria for multiple panels and were motivated to participate on them. Experts in the sixth panel were asked to validate and quantify desired metrics. 
There are many reasons why a small sub-set of identified experts are selected for a study. Some may simply no longer be active in the domain and others may not be willing or have the time to participate. There could also be the matter of balance and screening. For example, of the 208 identified experts, 167 invitations were sent. Authors who did not qualify as leading and experts who were no longer involved with the NSF IUCRC program or actively conducting research are examples of why experts were removed from the list. Steps were taken to verify qualifications and understand the motivation of potential panel members such as collection and review of curricula vitaes (CVs).

Active participation by conducting research, teaching or chairing student theses or dissertation committees are indications of an expert who is current. Experts may become outdated if they have not been engaged in the field for a period of time. An expert should be willing and able to participate for the duration of the study. Experts interested in the research and have time to actively engage are more likely to provide higher quality data.

Letters of introduction by highly respected domain experts or committee members followed by a personalized invitation may solicit more interest. Both of these approaches were effectively used to connect with experts. Examples of research instruments in Appendix A that were developed for this research include: invitations (Appendix A-1), consent forms (Appendix A-2) and letters of support (Appendix A-3), web-based data validation (Appendix A-4) and quantification (Appendix A-5) 
instruments. Figure 9 represents a sample of a few of the research instruments

designed and used in this study. A complete list is included in Appendix A-6.

Figure $9 \quad$ Research Instruments

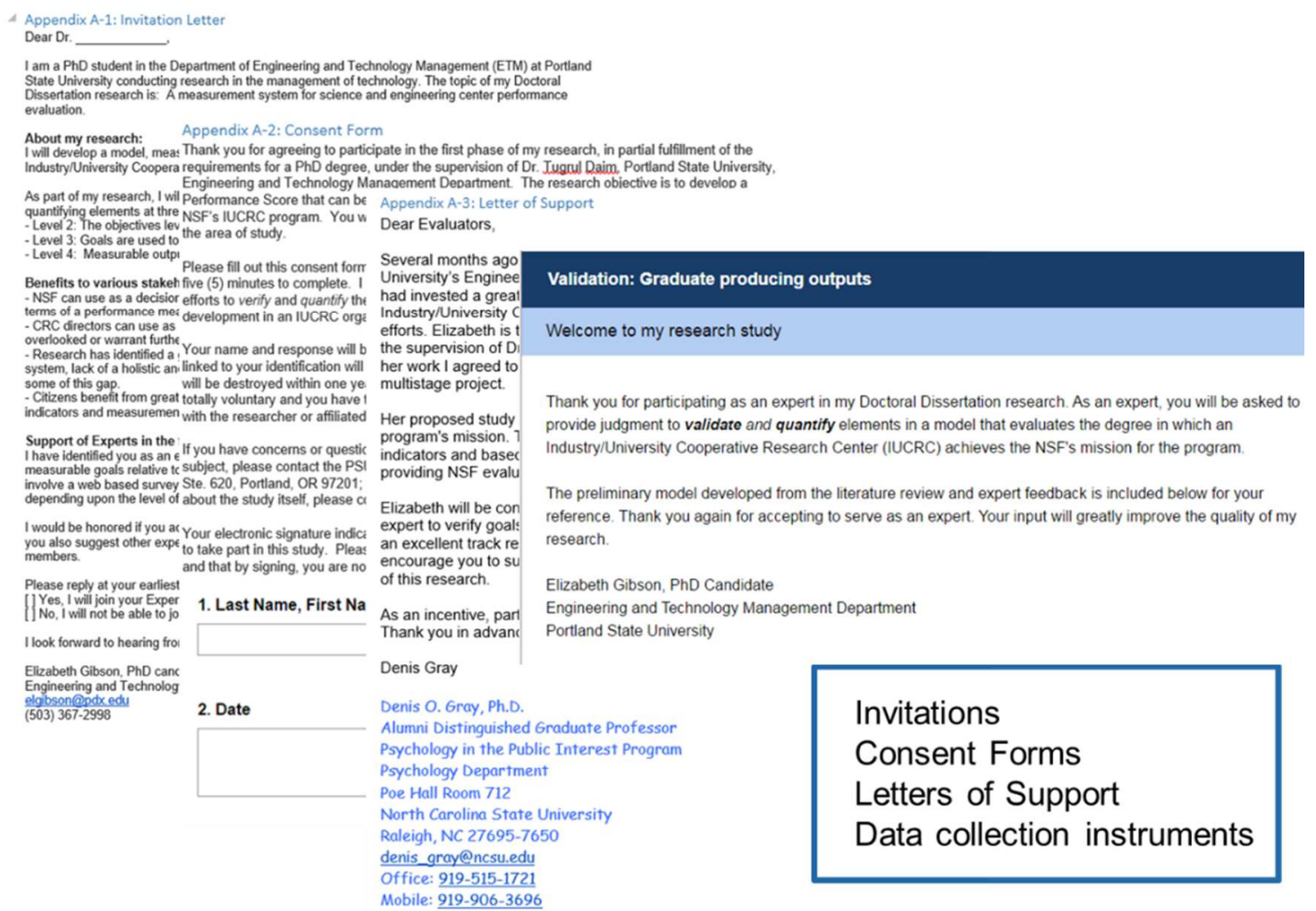

Table 9 shows how a balanced perspective is represented in the affiliation and background columns. Appendix B-2 provides titles of expert participants by an alphabetized affiliation listing. 
Table 9 Selected expert background

\begin{tabular}{|c|c|c|c|}
\hline Expert \# & Affiliation & Title & Background \\
\hline 1 & NSF Program & NSF Program Manager & NSF \\
\hline 2 & North Carolina State U & Professor/Director & $\mathrm{C}$ \\
\hline 3 & Ohio State U & Professor & $\mathrm{R}$ \\
\hline 4 & NSF IUCRC & NSF Project Manager & $\mathrm{R}$ \\
\hline 5 & NSF Consultant & Evaluator IUCRC & $\mathrm{R}$ \\
\hline 6 & Iowa State & Assoc. Prof/Evaluator & NSF \\
\hline 7 & University of Washington & Professor/Evaluator & $\mathrm{R}$ \\
\hline 8 & Palo Alto & Assoc. Prof/Evaluator & NSF \\
\hline 9 & U of California, Berkeley & Professor/Director & $\mathrm{C}$ \\
\hline 10 & University of Florida & Evaluator IUCRC & NSF \\
\hline 11 & Grand Valley state U & VP/Evaluator & $\mathrm{R}$ \\
\hline 12 & $\mathrm{U}$ of Colorado, Boulder & CoDirector IUCRC & C \\
\hline 13 & North Carolina State U & Director IUCRC & $\mathrm{C}$ \\
\hline 15 & SUNY Buffalo & Director IUCRC & $\mathrm{C}$ \\
\hline 16 & Arizona State U & IUCRC staff & $\mathrm{C}$ \\
\hline 17 & Univ of Bufalo & Director IUCRC & $\mathrm{C}$ \\
\hline 18 & U of Arizona & Director IUCRC & $\mathrm{C}$ \\
\hline 19 & Virginia Tech & Director IUCRC & $\mathrm{C}$ \\
\hline 20 & Oregon State Univ & Director IUCRC & $\mathrm{C}$ \\
\hline 21 & Virginia Tech & Director IUCRC & $\mathrm{C}$ \\
\hline 22 & UC Davis & Director IUCRC & C \\
\hline 23 & Brigham Young Univ & Director IUCRC & C \\
\hline 24 & U of Arkansas & Director IUCRC & $\mathrm{C}$ \\
\hline 25 & U of Tennessee, Knoxville & CoDirector IUCRC & $\mathrm{C}$ \\
\hline 26 & U of California, Santa-Cruz & Center Executive & $\mathrm{C}$ \\
\hline 27 & Boise State & Evaluator IUCRC & NSF \\
\hline 28 & North Texas & Professor/Assoc Director & $\mathrm{C}$ \\
\hline 29 & Georgetown U & Director IUCRC & C \\
\hline 30 & U of Washington & Director IUCRC & $\mathrm{C}$ \\
\hline 31 & University of Tennessee & Evaluator IUCRC & NSF \\
\hline 32 & Purdue U & Professor/Evaluator & NSF \\
\hline 33 & George Washington U & Professor & $\mathrm{R}$ \\
\hline 34 & Arizona State U & Professor & $\mathrm{R}$ \\
\hline 35 & Univ of Georgia & Evaluator IUCRC & NSF \\
\hline 36 & Clarkson U & Director IUCRC & $\mathrm{C}$ \\
\hline 37 & Purdue U & Ass Prof/Assist. Dir & $\mathrm{C}$ \\
\hline
\end{tabular}

Expert numbers were assigned in order that consent forms were received. Many of the experts have multiple titles. The title column is not a complete representation of an expert's experience as many experts fill multiple roles. The primary background 
qualifying the expert for the study was classified as a regular or contracted employee of the NSF (NSF), a leading researcher (R), or a center director, co-director or executive (C).

Each panel was configured to consider a balanced perspective to minimize bias and encourage a richer and more diverse pool of data (Appendix B-2). Care must be taken to protect anonymity of individual judgments[50]; identifying information was removed as it was recorded. Figure 10 shows how overlap in the panels occurs because experts may serve in multiple functions: validation and model development, quantification or development of the utility functions (desirability curves).

\section{Figure 10 Expert functions}

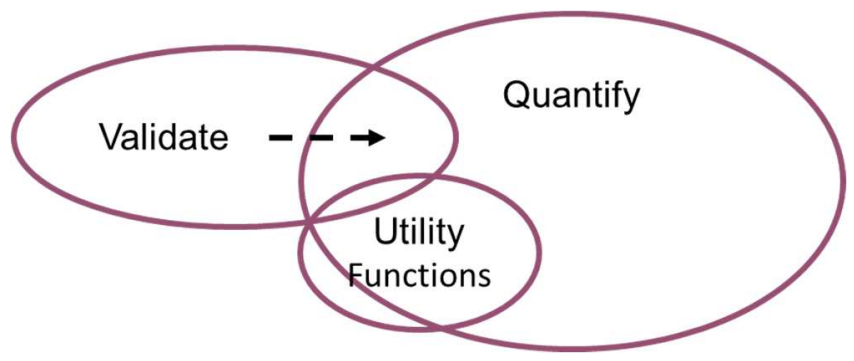

Panel criteria and configuration data can be found in Appendix B. Column 1 in Figure 11 shows how the thirty-seven (37) experts were configured into six (6) panels. Columns 2 and 3 discuss how experts were asked to validate and quantify different levels of decision criteria. 
Figure 11 Panel configurations (Appendix B-1)

\begin{tabular}{|c|c|c|c|c|}
\hline ID \# & $\begin{array}{l}\text { Phase } 1 \text { (P1): Validate } \\
\text { content and construct. }\end{array}$ & $\begin{array}{l}\text { Phase } 2 \text { (P2): Data } \\
\text { collected to quantify } \\
\text { elements. }\end{array}$ & $\begin{array}{l}\text { Expert Panel } \\
\text { Qualifications }\end{array}$ & $\begin{array}{l}\text { Research Instruments and Data Collection } \\
\text { Methods }\end{array}$ \\
\hline $\begin{array}{l}1 \\
P 1(2) \\
P 2(1)\end{array}$ & $\begin{array}{l}\text { Validation of construct } \\
\text { and content of level } 2 \text { : } \\
\text { political. }\end{array}$ & $\begin{array}{l}\text { Quantification of } \\
\text { objectives at the political } \\
\text { level of the model. }\end{array}$ & $\begin{array}{l}\text { NSF IUCRC directors } \\
\text { (past/present) NSF IUCRC } \\
\text { Project Director }\end{array}$ & $\begin{array}{l}\text { Phone Interview: open-ended and closed- } \\
\text { ended questions for quantification and } \\
\text { qualitative contextual data later used for } \\
\text { scenario analysis }\end{array}$ \\
\hline $\begin{array}{l}2 \\
P 1(9) \\
P 2(8)\end{array}$ & $\begin{array}{l}\text { Validation of construct } \\
\text { and content at the } \\
\text { organizational level. }\end{array}$ & $\begin{array}{l}\text { Quantification of goals at } \\
\text { the organizational level } \\
\text { of the model. }\end{array}$ & $\begin{array}{l}\text { NSF IUCRC program } \\
\text { evaluations. Leading researchers } \\
\text { in the field. }\end{array}$ & \multirow{4}{*}{$\begin{array}{l}\text { Four instruments were developed for each } \\
\text { panel group for phase } 1(\mathrm{P} 1) \text { to validate } \\
\text { elements respective to each groups } \\
\text { perspective. Another set of instruments were } \\
\text { developed for phase } 2(\mathrm{P} 2) \text { to extract pair- } \\
\text { wise comparison data for quantification } \\
\text { P1) Binary checklist (agree/ disagree) with } \\
\text { open text box for additional qualitative data. } \\
\text { P2) Survey requesting pair-wise comparisons } \\
\text { with drop-down box allowing for numerical } \\
\text { selection of values }[1,99] \text {. }\end{array}$} \\
\hline $\begin{array}{l}3 \\
P 1(8) \\
P 2(14)\end{array}$ & $\begin{array}{l}\text { Validate sub-criteria } \\
\text { outputs relative to } \\
\text { parent goals. }\end{array}$ & $\begin{array}{l}\text { Quantify outputs relative } \\
\text { to goals characterizing } \\
\text { objective } 1 \text { (research). }\end{array}$ & $\begin{array}{l}\text { NSF evaluation members, } \\
\text { Leading researchers }\end{array}$ & \\
\hline $\begin{array}{l}4 \\
\text { P1(11) } \\
\text { P2(13) }\end{array}$ & $\begin{array}{l}\text { Validate sub-criteria } \\
\text { outputs relative to } \\
\text { parent goals. }\end{array}$ & $\begin{array}{l}\text { Quantify outputs relative } \\
\text { to goals characterizing } \\
\text { objective } 2 \text { (students). }\end{array}$ & $\begin{array}{l}\text { NSF IUCRC Center directors } \\
\text { (past/present), Leading } \\
\text { researchers }\end{array}$ & \\
\hline $\begin{array}{l}5 \\
P 1(9) \\
P 2(15)\end{array}$ & $\begin{array}{l}\text { Validate sub-criteria } \\
\text { outputs relative to } \\
\text { parent goals. }\end{array}$ & $\begin{array}{l}\text { Quantify outputs relative } \\
\text { to goals characterizing } \\
\text { objective } 3 \text { (KTT). }\end{array}$ & $\begin{array}{l}\text { Leading researchers, Center } \\
\text { directors/co-directors, IAB } \\
\text { Members, KTT experts }\end{array}$ & \\
\hline $\begin{array}{l}6 \\
\text { P1(4) } \\
\text { P2(4) }\end{array}$ & $\begin{array}{l}\text { Validate metrics and } \\
\text { data sources available } \\
\text { for desirability curves. }\end{array}$ & $\begin{array}{l}\text { Quantify "goodness" } \\
\text { data to develop } \\
\text { desirability curves. }\end{array}$ & $\begin{array}{l}\text { NSF Evaluators, leading authors } \\
\text { respective to perspective: coop. } \\
\text { research, IUCRC student, or KTT. }\end{array}$ & $\begin{array}{l}\text { Phone Interviews: Acceptance of metric and } \\
\text { context, subjective data to qualify statements } \\
\text { for quantification of desirability values. Email. }\end{array}$ \\
\hline
\end{tabular}

For example, experts in panel 2 validated and quantified goals relative to each of the three (3) objectives. Qualifications for each of the panels and the data collection methods used are also discussed. Separate judgment quantification instruments were created for each of the functions: validation, quantification and desirability curve development. The expert panel formation process also considered how different perspectives are required at three (3) different levels. Figure 12 shows how the first two panels were configured. Individual identify was not maintained in the reporting of panel results. For example, the generic identifier of E1 for panel 1 is not tied to E1 of panel 2 . 
Figure 12 Expert panel 1 and 2 configurations

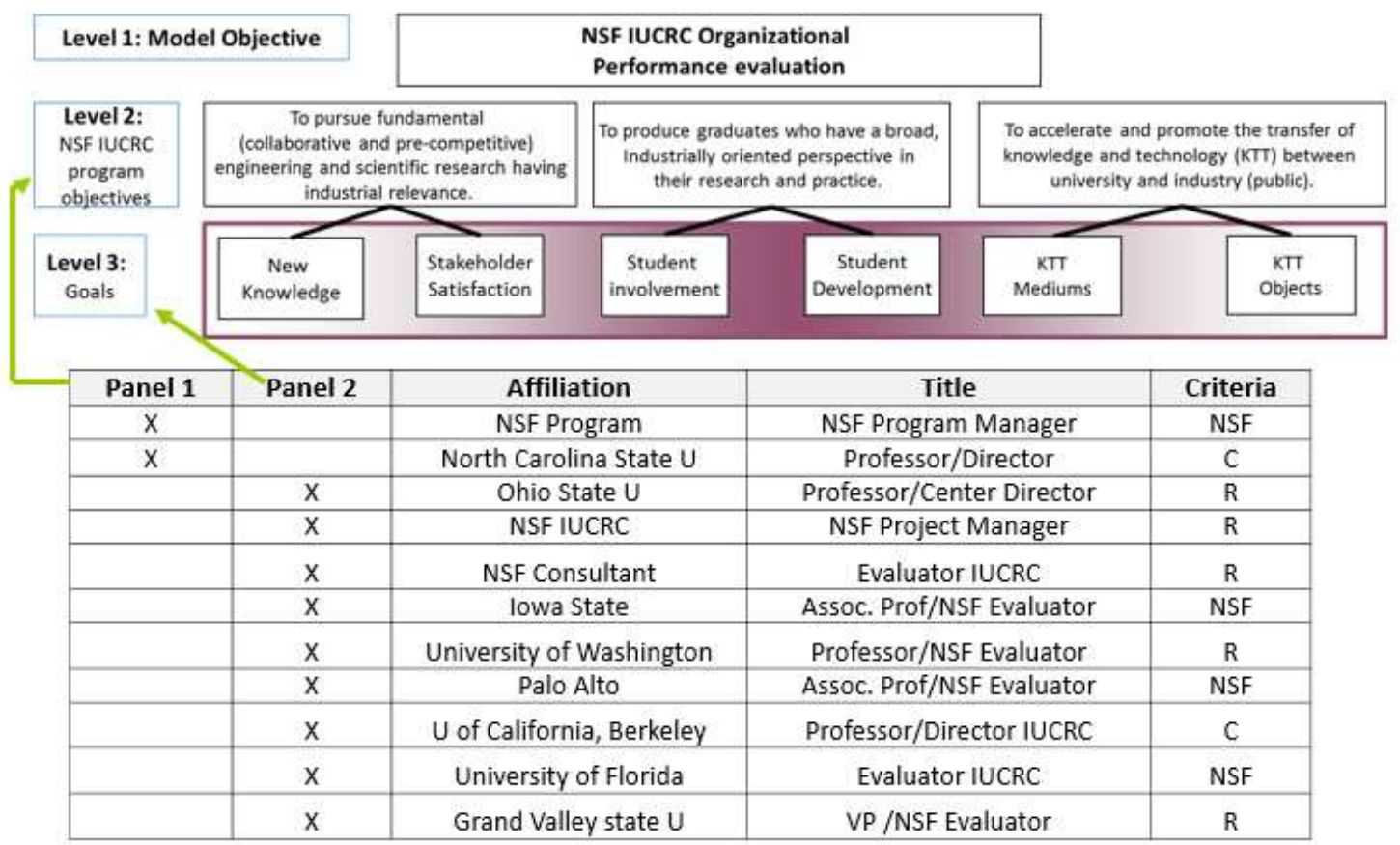

Criteria Key: $\mathrm{R}=$ Leading Researcher, $\mathrm{C}=$ IUCRC Center Director

Upon formation of the panels, experts received consent forms and data collection commenced.

\subsubsection{Data collection approach}

Powerful techniques have been developed for eliciting knowledge and judgments from experts. Judgment is the key input for many decision analysis models as well as management problems [147]. Delphi is a popular method used in many domains and has become increasingly popular in foresight activities and research studies [145][148][152][153][154][155][156]. This method uses a series of surveys 
and intervals of controlled feedback to encourage participation and collaboration from different stakeholder perspectives [152][154][157].

The Delphi method and the Hierarchical Decision Model (HDM) are combined [95][158] using expert panels to validate the model content and construct. This is similar to how other researchers have combined these methods to validate surveys used to study technology acquisition in many industries including: high-tech [159], health care [160] and agriculture [161].

The Delphi method was used in Phase 1 to validate the content and construct of the model. Using an iterative solicitation process, expert opinion was extracted through well-defined questions resulting in binary yes/no acceptance of elements to determine the "right" decision criteria. Strengths of this method include the wide acceptance of a transparent process by experts that yields a concrete consensus of answers. The drawbacks include the opportunity for decision bias [28] and the method discourages out of the box results [35] as experts tend to converge towards the middle through the iterative nature of the process.

Phone interviews were conducted with experts at the policy level (panel 1 level 2). For all other panels, a research instrument was developed providing experts with a binary checklist to agree or disagree with each of the concepts. An online validation instrument was used to collect binary "yes/no" acceptance data. Full data sets are provided in Appendix C. An open text box was provided asking experts to share additional comments. The qualitative data was analyzed. The validation 
process was repeated following the Delphi method until expert agreement met or exceeded 80\% [49] consensus.

After the model was validated by the experts, phase 2 required expert judgment to quantify the elements. Experts were presented with pair-wise comparisons through a carefully designed online judgment quantification instrument and asked to value element A versus B by selecting an integer value, exclusive range from 0 to 100 (inclusive $[1,99]$ ). Research instruments used to collect quantification data and data collected from the experts are reproduced in Appendix D.

The HDM uses the constant-sum method of allocating a total of 100 points between two of the model elements at a given time. Distributing the points compares relative importance of the two elements with respect to the parent element by which the two lower elements are linked. The subjective values of the two elements are then calculated and normalized to obtain the relative importance value of each element in a ratio scale. The process results in the overall relative contribution of each element with respect to the objective of the decision model. 


\subsubsection{Data analysis methods}

Quantified data was analyzed for inconsistency and disagreement. When presented with multiple decisions, expert judgment data typically reflects a small amount of inconsistency. For example, if an expert judges $A$ to be twice as important as $\mathrm{B}$, and $\mathrm{B}$ to be equally important as $\mathrm{C}$, then to be cardinally consistent they should also judge A to be twice as important as C. An example of ordinal consistency can be explained using the variables $\mathrm{A}, \mathrm{B}$, and $\mathrm{C}$. If an expert judges $\mathrm{A}$ to be more important than B and if they judge B to be more important than $A$, they will maintain ordinal consistency if they also judge A to be more important than C.

The process used to measure consistency first used the HDM 2.0 software to calculate inconsistency of each expert and compare the value against a $10 \%$ threshold. The HDM software $\subseteq$, available at the Department of Engineering and Technology Management at Portland State University, used the arithmetic mean of the standard deviation to calculate inconsistency as shown in Equation 2.

Equation 2 Expert inconsistency formula used by HDM software@[49]

$$
\text { Inconsistency }=\frac{1}{n} \sum_{i=1}^{n} \sigma_{i}
$$

Specifically, for any number of elements an expert completes pair-wise comparisons creating a vector consisting of values for $n$ ! orientations. Literature 
provides evidence that researchers have compared this calculation against a threshold of 0.1 for validity [49][95].

For each inconsistency value that exceeded the threshold of 0.10 , a more robust examination of consistency is warranted. Recently, Abbas [162] introduced a new calculation using the root-sum of the variances (RSV) instead of the sum of the standard deviations. This measure, shown in equation 3 , considers the number of pairwise comparisons made by the expert.

\section{Equation 3 Expert inconsistency using RSV formula}

$$
\text { Inconsistency }(R S V)=\sqrt{\sum_{i=1}^{n} \sigma_{i}^{2}}
$$

The collaborative research center ecosystem is complex and rich with diversity that fosters multiple perspectives leading to disagreements. A common statistical technique used by researchers to measure levels of disagreement is the Intraclass Correlation Coefficient (ICC). The ICC is somewhat of a guideline based upon the degree to which a number of experts are in agreement on a relative number of elements. The data were analyzed using established thresholds, means and standard deviations. For this study, a disagreement calculation (d) above a threshold of $10 \%$ ( $d \geq 0.10$ ) was associated with higher disagreements [12][95]. All expert 
panel data was also evaluated for disagreement among the experts using the process shown in figure 13. Each value calculated by the HDM 2.0@ software that exceeded the threshold of $10 \%$ was further examined using hierarchical agglomerative clustering (HAC). Analysis of expert disagreement is a particularly important part of this research.

Figure 13 Disagreement analysis framework

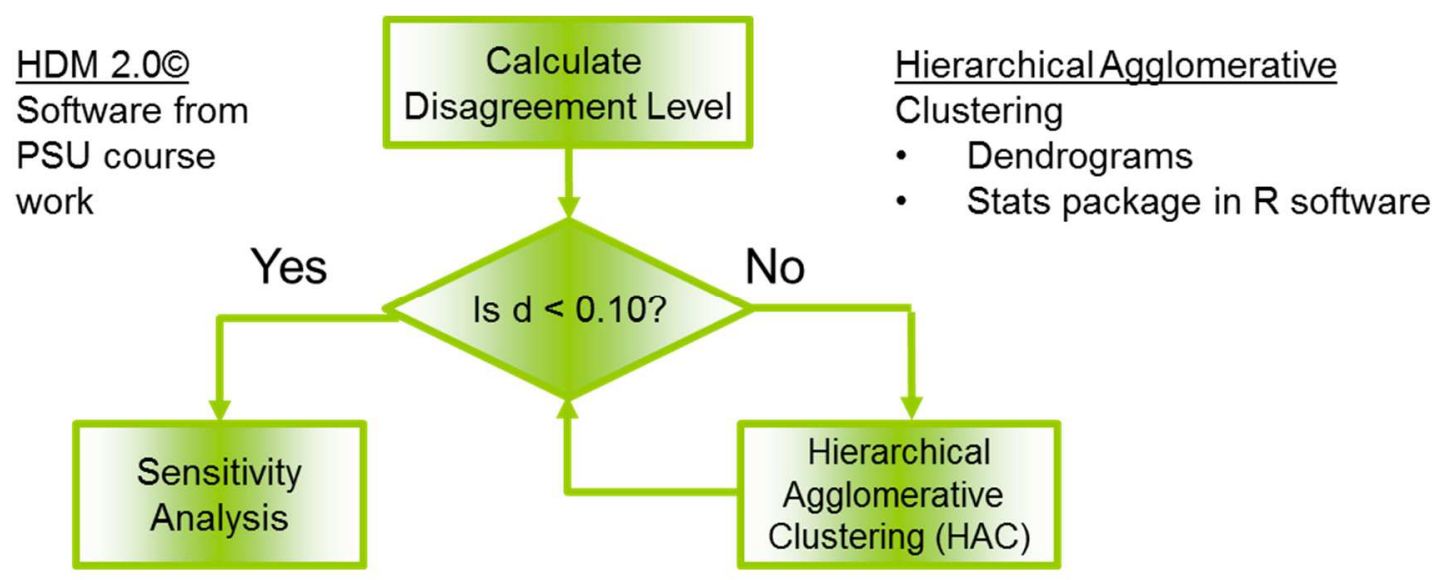

The hierarchical agglomerative clustering (HAC) technique uses dendrograms that visually depict sub-clusters of expert data. Disagreement values were calculated for each sub-cluster and compared against the threshold until the disagreement level was satisfied.

Hierarchical agglomerative clustering (HAC) techniques allow disagreement to be analyzed by examining similarities and differences among expert sub-groups. The method uses a bottom-up algorithm that starts with a single expert data document then successively merges pairs of clusters until all documents are used. 
The hclust function in the $R$ program's stats package were used to develop the dendrograms. RStudio and the knitr package was used to document the source code.

A series of scenarios were developed to investigate how different clusters of decision makers might impact the model. By simply replacing the weights of the decision elements in the generalizable model with the weights of the mean of different sub-cluster one-at-a-time (OAT) a gross level sensitivity analysis was conducted examining the impact to the decision alternatives.

This method is appropriate because the NSF is more concerned about transparency in the decision making than "rack and stacking" IUCRCs against each other in a benchmark type of a study. The benefits of this tool are for transparency in decision making and understanding how to improve versus competing to be the best. By design, centers may have valid and appropriate reasons to differentiate, focusing on different areas in order to be unique.

\subsubsection{Case studies}

Six case studies were developed to illustrate how the model calculates a score and how these scores can be used to conduct a comparative analysis. The Wood Based Composites (WBC) center was used to illustrate how the model works to calculate a performance score by collecting data and populating $100 \%$ of the metrics. 
While the comparative study that was developed for criterion related validity used all six of the centers, only data obtained from secondary sources was used. These results were presented to experts to determine the degree to which the model effectively reflected the actual performance of each center. 


\section{CHAPTER 4: $\quad$ HDM DEVELOPMENT}

The hierarchical decision model (HDM) provides a flexible, hierarchical structure for decision analysis. The purpose of the model is to determine the degree to which an IUCRC meets the program's mission. It is a generalizable model that outputs a performance evaluation score for an IUCRC in the program by evaluating a holistic set of metrics.

At the top of the model, the objective is the organizational effectiveness score. At level 2, the NSF IUCRC program objectives specify the mission of the program. Organizational goals, relative to each of the objectives populate level 3. The outputs, indicators and desirability curves in level 4 are used to describe and measure each of the goals. The rest of the chapter clarifies and links the decision elements showing how the generalizable model is constructed.

\subsection{Objectives}

Literature finds the NSF IUCRC program's mission has long been specified by three objectives:

1. To pursue fundamental (collaborative and pre-competitive) engineering and scientific research having industrial relevance.

2. To produce graduates who have a broad, industrially oriented perspective in their research and practice.

3. To accelerate and promote the transfer of knowledge and technology between university and industry (public) ([62]p 23).

These objectives, outlined in what has become known as "the purple book", have stood the test of time with little modification. However, literature does offer 
some debate and clarification of concepts. Researchers agree that increasingly complex problems require a multi-disciplinary approach. Recognizing this need, the US government has responded mandating that federally supported cooperative research centers be problem focused rather than discipline focused [163]. Some researchers argue that these policies may have allowed the pendulum to swing too far [79], placing potentially successful pre-competitive university research at risk. Regardless of the debate, the NSF IUCRC program has become a key policy lever for translational research. Each of the three objectives to pursue fundamental research, produce graduates and transfer knowledge and technology is discussed.

\subsubsection{Pursuit of fundamental research}

While the development of collaborative, pre-competitive research [164] has been a part of the program's mission since inception [62], NSF policy makers have started to increase incentives towards broader cooperation among university partners [10]. Today, the program is promoting boundary spanning activities through an increased number of cooperative partnerships and multi-disciplinary science [132]. Since the early 1990's, the IUCRC solicitations have increased incentives for multi-site IUCRCs [165]. A program expert confirmed that a lower threshold for multi-site membership agreements will likely continue. Today, the minimum threshold for a multi-site proposer is $\$ 350 \mathrm{~K}$ while single-site membership requires \$400K per year. 
There is historical precedence for NSF policy makers to encourage cooperative, pre-competitive research. It has been attributed to be a main factor in the development of high technology clusters such as Silicon Valley [166] and Austin, Texas [53]. Collaboration is often awkward and less efficient for researchers [5]. The most common configuration for an IUCRC project team has been found to be "one faculty scientist working with one or two graduate students from the same academic discipline" [[132] p3]. One reason is "collaborative research exposes both sides to a certain degree of vulnerability to exploitation" [[167] p605]. There must be clear and compelling reasons for members to conduct collaborative research. Therefore, further policy incentives may be required to bridge the cultural divide and increase trust [168].

So, it is not surprising that information obtained from the expert validation process suggested qualifying or changing the language in the first objective of "fundamental research" to include the concepts of "cooperative and pre-competitive." What has changed is the shift in emphasis for industrial relevant research that is not only cooperative but also pre-competitive serving both the emerging public as well as private needs [101]. 


\subsubsection{Producing graduates}

An IUCRC requires graduate student involvement [62]. Funding and scholarships provide graduate students opportunities to complete research towards a thesis or dissertation making programs more attractive [66]. Students gain experience and acquire knowledge through a cooperative and industry-oriented approach to conducting research. Measuring human development and intellectual capacity is often subjective. Ultimately, the responsibility falls on the center director. Therefore, it is important to configure panels that validate outputs and goals for producing graduate students with experts who have experience as a center director.

\subsubsection{Knowledge and technology transfer (KTT)}

Knowledge and technology transfer (KTT) is a complex construct, spanning boundaries [101] with many definitions. Roessner provides a simple definition of KTT as "the movement of know-how, technical knowledge, or technology from one organizational setting to another" [[45] p31]. The facilitation of knowledge and technology transfer [4] is key to achieving the NSF IUCRC's mission as stated in the third objective: to accelerate and promote the transfer of knowledge and technology between university and industry [[62] p23] that benefits the public [78][139][169].

\subsection{Goals and Outputs}

Each of the three objectives are further characterized by two measurable goals. "New knowledge" and "stakeholder satisfaction" were identified as appropriate goals for 
measuring how fundamental research is pursued and how satisfied stakeholders are with this pursuit. Likewise, literature identifies that graduates are best produced when students are involved and developed. The Delphi method was particularly helpful to identify goals that measure the degree to which knowledge and technology transfer outputs contribute towards the mission.

Knowledge and technology transfer is a complex construct making it difficult to define and measure [76]. Bozeman agrees stating "whether technology transfer or knowledge transfer, a perpetual challenge is demarcating the transfer object from its environment" [[57] p 629]. He provides some guidance for this study with his "Contingent Effectiveness Model of Technology Transfer" where the effectiveness literature is classified into five (5) dimensions [[57] p 637]. The framework, adapted specifically to the NSF IUCRC program literature, is shown in Table 10. 
Table 10 Dimensions of KTT for an IUCRC

\begin{tabular}{|l|l|l|}
\hline Dimension & IUCRC Focus & Description [[57] p637] \\
\hline Transfer agent & $\begin{array}{l}\text { The IUCRC seeking to transfer the } \\
\text { technology. }\end{array}$ & $\begin{array}{l}\text { University partners and IAB member } \\
\text { firms are joined through contractual } \\
\text { agreements to form an IUCRC. }\end{array}$ \\
\hline $\begin{array}{l}\text { Transfer } \\
\text { medium }\end{array}$ & $\begin{array}{l}\text { The vehicle, formal or informal by } \\
\text { which the technology is transferred. }\end{array}$ & $\begin{array}{l}\text { Person-to-person, formal literature, } \\
\text { copyright, license, CRADAs, etc. }\end{array}$ \\
\hline $\begin{array}{l}\text { Transfer } \\
\text { object }\end{array}$ & $\begin{array}{l}\text { The content and form of what is } \\
\text { transferred, the transfer entity. }\end{array}$ & $\begin{array}{l}\text { New methods, new processes, } \\
\text { technological devices, know-how and } \\
\text { specific characteristics of each. }\end{array}$ \\
\hline $\begin{array}{l}\text { Transfer } \\
\text { recipient }\end{array}$ & $\begin{array}{l}\text { The organization or institution } \\
\text { receiving the transfer object. }\end{array}$ & $\begin{array}{l}\text { IAB member firm, public, other IUCRC } \\
\text { partners }\end{array}$ \\
\hline $\begin{array}{l}\text { Demand } \\
\text { environment }\end{array}$ & $\begin{array}{l}\text { Domain factors pertaining to the } \\
\text { need for the transferred object. }\end{array}$ & $\begin{array}{l}\text { Interest in technology, market price } \\
\text { for technology, substitutability, etc. }\end{array}$ \\
\hline
\end{tabular}

Experts agreed that two of these goals determine the degree ito which knowledge and technology are transferred in an IUCRC: transfer media and transfer objects.

\subsubsection{New knowledge}

A key aspect of the NSF IUCRC program is that new knowledge is pursued in a collaborative setting. In the broadest sense of the program, all research projects are collaborative because they require an industrial sponsor. However, both literature and experts emphasize the importance of configuring collaborative projects to include researchers from multiple firms and multiple disciplines. The concepts of industrial relevant, pre-competitive, and collaborative research are further discussed to clarify the degree to which new knowledge contributes towards fundamental research. 
The concept of industrial relevance has broadened over time and shifted in the literature towards multi-disciplinary science. Complexity of today's problems are driving a team science approach that requires multi-organizational as well as interinstitutional collaboration [2]. Gray [59] and other researchers [170] discuss the increased value of a team science approach. "Large cross-disciplinary scientific teams are becoming increasingly prominent in the conduct of research" [[164] p1]. Some IUCRC's are even demonstrating support of a multi-disciplinary science trend by emphasizing the approach in their organizational mission statements [132]. Outputs for relevant research include new knowledge [171] and stakeholder satisfaction [82].

"The program was designed to spur pre-competitive R\&D" among firms [[172]p 8]. Pre-competitive refers to research conducted jointly by usually competing companies [131]. So, rather than measuring the amount of new knowledge generated, it is important to the mission that new knowledge benefits extend beyond a single firm. Therefore, experts deemed that collaborative research extends beyond two or more researchers from a single-site working together to solve an industry supported problem within an IUCRC. The goal of new knowledge measures how research is conducted and who receives the benefit and the amount generated is captured through the objective and goals that measure knowledge and technology transfer (KTT). 
The emphasis towards multi-disciplinary and multi-site collaboration has also increased in literature as summarized in Table 11. Through the validation process, experts clarified that "patents are explicitly NOT a part of the IUCRC program" because they discourage pre-competitive research.

Table 11 Literature identified new knowledge outputs

\begin{tabular}{|l|l|l|}
\hline New Knowledge & IUCRC focused description & Reference \\
\hline $\begin{array}{l}\text { Scientific Co- } \\
\text { publications }\end{array}$ & $\begin{array}{l}\text { Co-authorship. The IUCRC literature } \\
\text { emphasizes authors to be affiliated with } \\
\text { different organizations. }\end{array}$ & $\begin{array}{l}{[21][38][40][41][42]} \\
{[43][44][48][51]}\end{array}$ \\
\hline $\begin{array}{l}\text { Patents and co- } \\
\text { patenting }\end{array}$ & Multiple firms listed as owners. & $\begin{array}{l}{[17][37][40][41][43]} \\
{[44][54]}\end{array}$ \\
\hline $\begin{array}{l}\text { Cooperative } \\
\text { research projects }\end{array}$ & $\begin{array}{l}\text { Researchers affiliated with multiple } \\
\text { organizations. Multi-disciplinary } \\
\text { research has been recently emphasized } \\
\text { in the IUCRC and team science literature. }\end{array}$ & $\begin{array}{l}{[4],[37][38][40][41]} \\
{[45][50][51][53][59]}\end{array}$ \\
\hline
\end{tabular}

\subsubsection{Stakeholder satisfaction}

When government takes an active role in university-industry relations, literature has referred to these structures as a government-university-industry (GUI) model [5] or the "Triple Helix" [173]. An IUCRC is a GUI, or Triple Helix type of structure because the NSF represents the government stakeholder, there is at least 1 university partner and multiple firms represent industry in the form of an industrial advisory board (IAB). This complex university-based ecosystem must balance the needs of these various stakeholders. 
The satisfaction of each primary group must be considered; however, this is somewhat of a challenge because often there are competing needs. For example, researchers seeking tenure may be motivated to publish and become frustrated if an IAB member lobbies for publication to be delayed. Some IAB members may be short sighted and not appreciate the nature of pre-competitive research, instead being more focused on solving an immediate problem facing their company. Industrial advisory board (IAB) members can be satisfied in an IUCRC that is not performing well if they are getting more benefit from the research. So, it is important to consider the trade-offs among the three primary stakeholder groups.

"An empowered I/U champion at the industrial firm" [[174] p 42] plays a pivotal role in assessing the firm's satisfaction. “A firm's I/U champion is uniquely positioned to ensure that industry-university relationships properly leverage each organization's skills knowledge and resources" [[174]p 45]. However, finding the decision maker in an IAB member's company may be somewhat elusive [125]. They may reside in different departments and may not be the IAB member who attends the meetings. "Limited knowledge regarding factors within the organization that determine decision outcomes" [[125]p7] coupled with the difficulty of finding the decision maker renders surveys impractical. Fortunately, Gray provides some help finding membership renewal to be a good proxy for IAB member satisfaction of relevant research [175]. 


\subsubsection{Student involvement}

Student support and funding [83] were identified as output elements in the literature. Experts noted these outputs to be highly collinear creating problems for the model. They were removed during phase 1 for model validation of the content as they failed to achieve the 75\% tolerance level for expert agreement [95].

There was some debate about student involvement, participation and engagement at IAB meetings. Some IAB meetings have allowed members to attend using electronic communications. With advances in today's communication technologies such as video conferencing, some consider remote attendance at meetings as sufficient. However, researchers have found the value of long-distance participation to be limited [132]. While distance participation is counted in the metric, it is heavily discounted in the desirability curve based upon expert opinion.

\subsubsection{Student development}

Literature identifies many different outputs of student development. Some of these include number of courses taken, number of degrees earned, number of projects completed, papers written and presentations given. The IUCRC program is concerned about the type of research and presentations. Students will receive degrees whether they conducted industry-related research or not. Therefore, conducting research in IUCRC sponsored research projects or presenting information about this research are 
specific to this program and experts did not validate the number or type of degrees earned.

\subsubsection{KTT media}

Bozeman describes a KTT medium as the vehicle, formal or informal by which the technology is transferred [57]. He used this model in 2000 to organize a review of the literature. Tran applied this model to study the effectiveness of knowledge and technology transfer from a transfer agent defined as the university to a transfer recipient defined as an industrial firm. His study brought the literature review current by covering the period from the 2000 Bozeman study forward to 2013 [49]. Through a rigorous study he was able to determine the relative importance of both KTT media and objects towards the performance of a university. This literature was included for review to help identify goals and KTT outputs. The results of the literature review are presented in Table 12. 
Table $12 \quad$ Literature identified KTT media

\begin{tabular}{|c|c|c|}
\hline KTT media & IUCRC focused description & References \\
\hline Papers & $\begin{array}{l}\text { Publications in peer-reviewed } \\
\text { journals are traditionally recognized } \\
\text { outputs of KTT. }\end{array}$ & $\begin{array}{l}{[21][38][40][41][42][43]} \\
{[44][48][51][176]} \\
{[177][81][178][93]}\end{array}$ \\
\hline Reports & Research reports & {$[44][51]$} \\
\hline $\begin{array}{l}\text { Conference } \\
\text { presentations }\end{array}$ & & $\begin{array}{l}{[5][38][40][42][43][44]} \\
{[45][51][53][54]}\end{array}$ \\
\hline $\begin{array}{l}\text { Workshops, } \\
\text { classes }\end{array}$ & $\begin{array}{l}\text { Attendance at IUCRC directors } \\
\text { meetings and IAB meetings, } \\
\text { workshops. }\end{array}$ & $\begin{array}{l}{[5][44][45][53]} \\
{[77][179][180][176][1]} \\
{[136][66]}\end{array}$ \\
\hline $\begin{array}{l}\text { Informal } \\
\text { meetings }\end{array}$ & $\begin{array}{l}\text { Informal meetings, one-on-one } \\
\text { discussions or small informal groups }\end{array}$ & {$[38][41][42][44]$} \\
\hline $\begin{array}{l}\text { Professional } \\
\text { networks: } \\
\text { Editors, } \\
\text { Professional } \\
\text { Organization } \\
\text { officers, Boards }\end{array}$ & $\begin{array}{l}\text { Editorships and members in scientific } \\
\text { advisory boards and officers of } \\
\text { professional organizations improve } \\
\text { linkages and the profile of the } \\
\text { organization. Editors often find } \\
\text { knowledgeable referees who agree to } \\
\text { review papers, officers organize } \\
\text { conferences and meetings. }\end{array}$ & $\begin{array}{l}{[43][51][53][122][8]} \\
{[176][181][172]} \\
{[182][175][5]}\end{array}$ \\
\hline $\begin{array}{l}\text { Graduate hires, } \\
\text { fellowships }\end{array}$ & Graduates hired into the industry & $\begin{array}{l}{[5][38][40][41][43][44]} \\
{[48][50][53][58][59]}\end{array}$ \\
\hline Co-supervising & $\begin{array}{l}\text { Supervisors from multiple sites or } \\
\text { multiple organizations }\end{array}$ & {$[38][40][43][45]$} \\
\hline $\begin{array}{l}\text { Personnel } \\
\text { exchange }\end{array}$ & $\begin{array}{l}\text { Focus on student internships, } \\
\text { mentorships. }\end{array}$ & $\begin{array}{l}\text { [41], [43] [44] [51] [53] [54] } \\
{[57][75][183][184][77][185]} \\
{[186][49][187][188][85][8]}\end{array}$ \\
\hline $\begin{array}{l}\text { Consulting } \\
\text { services }\end{array}$ & $\begin{array}{l}\text { Secondary focus on scientific faculty } \\
\text { contracted by IAB member firm to } \\
\text { facilitate commercialization of } \\
\text { technology. }\end{array}$ & $\begin{array}{l}{[5][37][38][41][42][43]} \\
{[44]} \\
{[45][46][53][54]}\end{array}$ \\
\hline $\begin{array}{l}\text { Shared } \\
\text { resources }\end{array}$ & $\begin{array}{l}\text { Examines not only alternative uses of } \\
\text { resources but also possible impacts on } \\
\text { the mission such as improved human } \\
\text { capital for conducting future research }\end{array}$ & $\begin{array}{l}{[38][43][44][53]} \\
{[112][177][132][189]}\end{array}$ \\
\hline
\end{tabular}

KTT media supported by literature include personnel exchanges, demonstrations, papers and professional networks. Shared knowledge and idea generation [165] transferred at networking and informal events are difficult to 
evaluate. However, attending and participating in these events are often cited as a key transfer medium. The distinction between knowledge generation and knowledge transfer is important. When students, faculty or industry members conduct research they are creating knowledge whereas when they are teaching or taking a course they become containers for knowledge.

\subsubsection{KTT objects}

KTT objects provide the form and document the content of what is transferred. Some examples of this transfer entity include new products or services, new methods or processes and patents. In an IUCRC, focus is placed on a technological breakthrough or advance such as: "significant process improvements, new process or techniques, and new or improved products or services that resulted either directly from, or was indirectly stimulated by the center's research program" (Scott, 2014). The NSF has published a set of Compendiums that catalogue peer reported breakthrough technologies. Table 13 identifies KTT objects found in literature.

Table 13 Literature identified KTT objects

\begin{tabular}{|l|l|l|}
\hline KTT Objects & IUCRC focused description & References \\
\hline Licenses & $\begin{array}{l}\text { Traditional indicators long used in the literature } \\
\text { to measure technology transfer. Often an } \\
\text { indicator of intent to commercialize the } \\
\text { technology. }\end{array}$ & $\begin{array}{l}{[17][37][40][41][43]} \\
{[44][46][50][51][54]} \\
{[56][59]}\end{array}$ \\
\hline New products & $\begin{array}{l}\text { Focus on pre-competitive and collaborative. } \\
\text { Beneficial to industry (beyond 1 company) } \\
\text { New methods or } \\
\text { procesess }\end{array}$ & $\begin{array}{l}{[8][191][4][174][168]} \\
{[130]} \\
\text { compendium of breakthrough technologies } \\
\text { IUCRC [190]. }\end{array}$ \\
\hline
\end{tabular}




\subsection{Metrics}

Link shares how "research evaluation is an art; not a science" [[192]p 451]. He summarizes that using measurable outputs are appropriate, complete and replicable. They are appropriate because they can be counted and evaluated independent of time [95].

Metrics established for each of the outputs listed as sub-criteria for the relative goals were tested for the ability to be populated with realistic data in a timely manner (SMART) before being validated by experts. For example, a mathematical formula that calculates a value when populated by objective data is an ideal way to specify a value. The use of quantitative metrics for program evaluation is not only a best practice; it is also mandated for federally funded programs through the Government Performance and Results Act. Specifying a metric can be challenging, especially when qualitative data must be used to populate the metric.

Table 14 describes the outputs that were presented to experts and validated. The parent element for each output is a relative goal that is identified in column 1 . While metrics were presented to experts to help clarify and describe each output indicator, each metric was re-examined during the development and quantification of desirability curves by another set of experts in panel 6. It was at this point where the output of mentorships was removed because experts expressed concern about the ability to capture data to populate the metric. 
Table 14 Output decision elements with proposed metrics

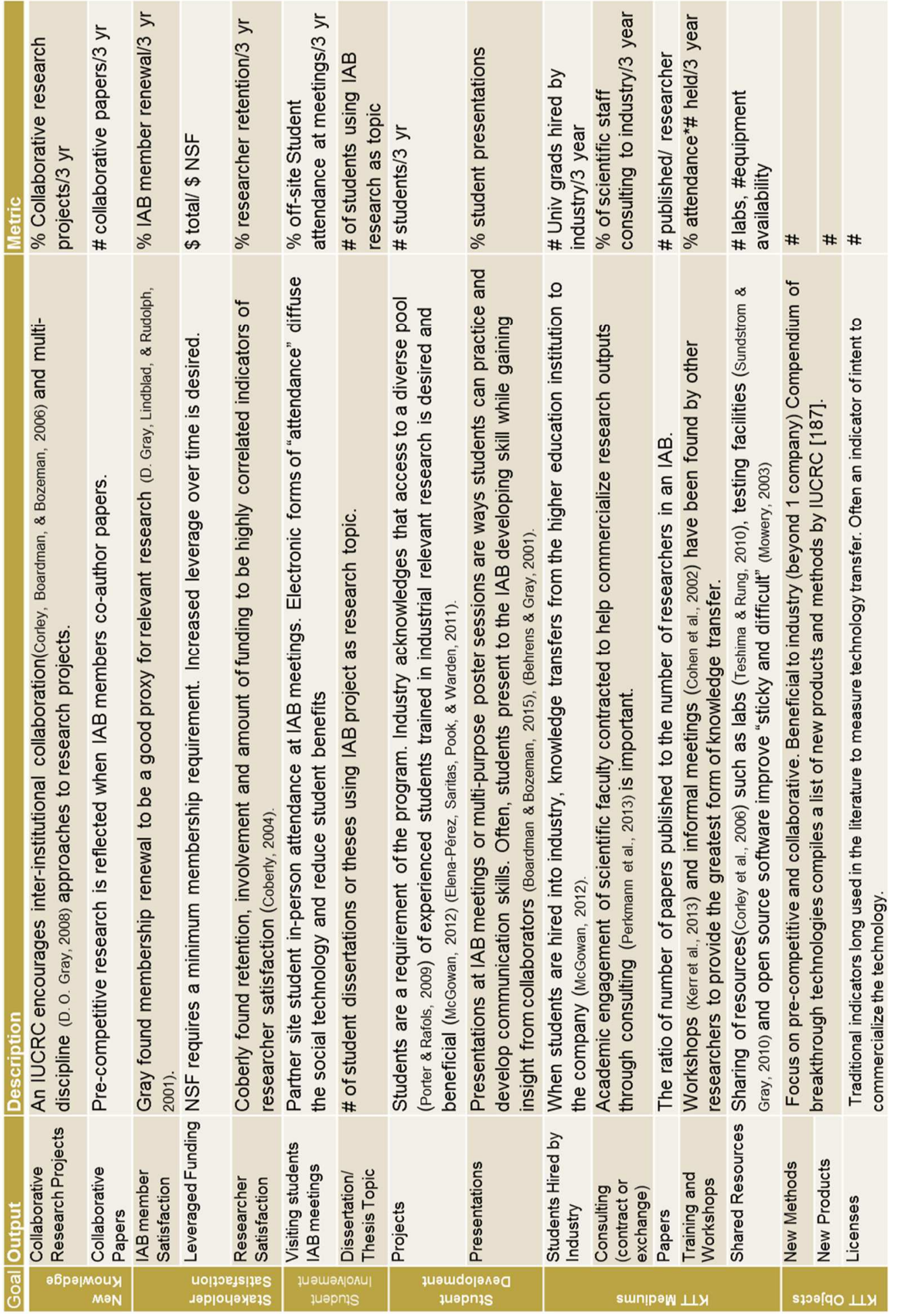




\subsection{Desirability Curve Development}

Expert judgment is also used to validate and quantify desirability curves for each metric. Kocaoglu [137] provides some insight into this concept explaining that experts' judgment about these values represent how good or desirable the output is to the decision maker. Therefore, a key qualification for experts selected to form panel 6 is that they are decision makers.

Development of a desirability curve is a method to convert either qualitative or quantitative data used for measuring a decision element to a scaled quantitative value. Understanding the desired or ideal value for a metric is important. The relationship of values for different metrics may scale differently. Comparing desired values against a consistent scale normalizes the values.

So, what goal is desirable for each of the outputs? In a complex ecosystem, stakeholders may provide conflicting judgment about these values. For example, IAB membership renewal rates are used to measure IAB member satisfaction. If experts agree that some turn-over is normal and a desired retention is $80 \%$ or better, $40-50 \%$ retention may or may not be judged to be half as good. A $60 \%$ retention may signify a tipping point or problem.

In an IUCRC, how much partnership is ideal? If one IUCRC has three (3) directors/co-directors are six (6) partners twice as good or nine partners (9) three times as good? It is important to establish relative usefulness for each of the metrics. 
Appendix E shows an illustration for developing desirability curves that was share with experts.

Metrics and desirability curves are presented relative to each of the six goals. Tables 15 - 20 present output indicators and discuss metrics that characterize each of the six respective goals: new knowledge, stakeholder satisfaction, student involvement, student development, KTT media and KTT objects. Figures 14 - 19 show the respective desirability curves. Appendix E-2 provides the source data used to develop the curves.

Table 15 New knowledge characterization

\begin{tabular}{|c|c|c|c|c|}
\hline Goal & Output & Description & Metric & Desirability Range \\
\hline \multirow{2}{*}{ 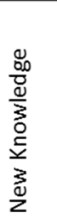 } & $\begin{array}{l}\text { Collaborative } \\
\text { Research Projects }\end{array}$ & $\begin{array}{l}\text { An IUCRC encourages inter-institutional } \\
\text { collaboration(Corley, Boardman, \& Bozeman, 2006) and } \\
\text { multi-discipline (D. O. Gray, 2008) approaches to } \\
\text { research projects. }\end{array}$ & $\begin{array}{l}\% \text { Collaborative } \\
\text { research projects } / 3 \mathrm{yr}\end{array}$ & $\begin{array}{l}0 \%<=\mathrm{n}<=100 \% \\
\text { Single-site, multi- disciplined } \\
\text { based or } \\
\text { multi-site projects }\end{array}$ \\
\hline & $\begin{array}{l}\text { Collaborative } \\
\text { Papers }\end{array}$ & $\begin{array}{l}\text { Pre-competitive research is reflected when IAB } \\
\text { members co-author papers. }\end{array}$ & $\begin{array}{l}\% \text { collaborative } \\
\text { papers } / 3 \mathrm{yr}\end{array}$ & $\begin{array}{l}0 \%<=\mathrm{n}<=100 \% \\
2 \text { or more university } \\
\text { partners or } 2 \text { or more firms }\end{array}$ \\
\hline
\end{tabular}

Collaborative research projects require more than one scientist and student(s) from the same site in the same discipline to be counted. According to an expert, "same site multi-disciplinary project teams are slightly more desirable because they don't have expenses associated with distance" for synchronous collaborations. However, for simplification the configurations were judged equally desirable by the experts and only numbers of collaborative (multi-organization or multi-discipline) research projects were counted. 
While many IUCRCs report all projects are collaborative because they are conducted by a researcher affiliated with a university and sponsored by an industrial member, experts would ideally like to see at least $80 \%$ of the collaborative projects to be configured with multi-disciplinary researchers or multiple organizations beyond the sponsor.

Figure 14 Desirability curves for new knowledge outputs

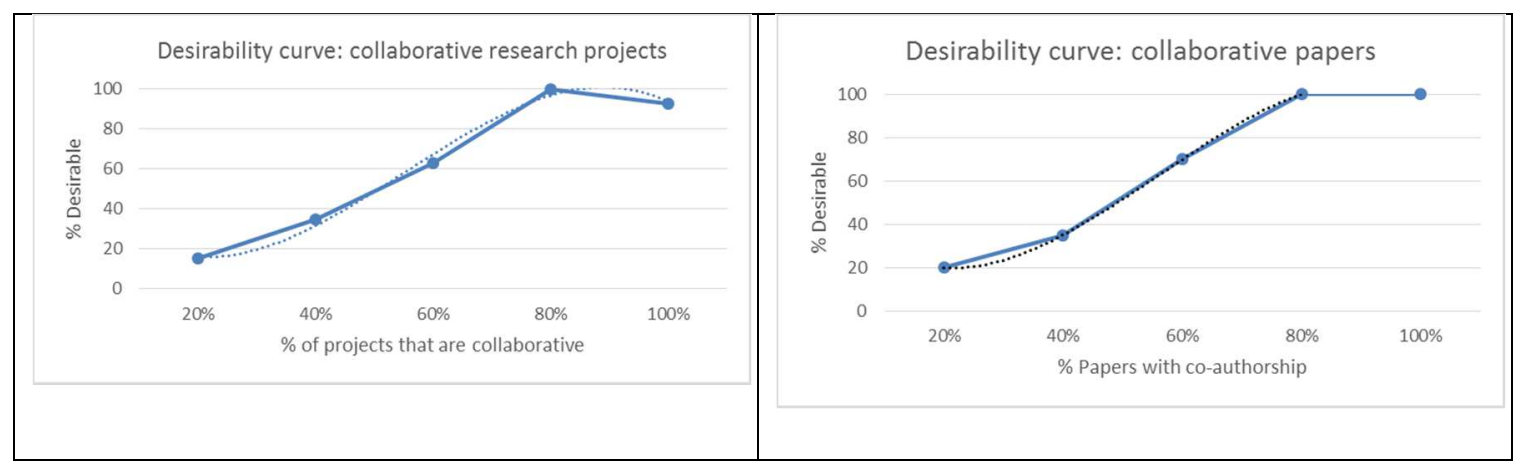

A collaborative paper requires two (2) or more organizations as co-authors. These can be different universities or a university and an IAB firm. Literature finds that repeated co-publications improves trust [89][92] required for pre-competitive research. Co-authorship networks develop and increase value as structural capital is developed. Databases can be mined to understand the configuration of linkages using social network analysis techniques. Relational capital also increases as the relationships developed through the social interactions facilitates knowledge creation [93] and better research outcomes [94]. 
There are many benefits to collaborative research; however, there are many reasons not to co-author including legal considerations, ownership, timing, availability or simply interest.

Table 16 Stakeholder satisfaction characterization

\begin{tabular}{|c|c|c|c|}
\hline Goal & Output & Description & Metric \\
\hline \multirow{3}{*}{ 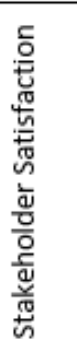 } & $\begin{array}{l}\text { IAB member } \\
\text { Satisfaction }\end{array}$ & $\begin{array}{l}\text { Gray found membership renewal to be a good proxy for } \\
\text { relevant research (D. Gray, Lindblad, \& Rudolph, 2001). }\end{array}$ & $\begin{array}{l}\text { \% IAB member } \\
\text { renewal } / 3 \mathrm{yr}\end{array}$ \\
\hline & $\begin{array}{l}\text { Leveraged } \\
\text { Funding }\end{array}$ & $\begin{array}{l}\text { NSF requires a minimum membership requirement. } \\
\text { Increased leverage over time is desired. The NSF } \\
\text { encourages funding sources beyond memberships. }\end{array}$ & \$ Total/ \$ NSF/ 3 yr \\
\hline & $\begin{array}{l}\text { Researcher } \\
\text { Satisfaction }\end{array}$ & $\begin{array}{l}\text { Coberly found retention, involvement and amount of } \\
\text { funding to be highly correlated indicators of researcher } \\
\text { satisfaction (Coberly, 2004). Churn detects } \\
\text { dissatisfaction. }\end{array}$ & $\begin{array}{l}\% \text { average churn/ } 3 \\
\mathrm{yr}\end{array}$ \\
\hline
\end{tabular}

Membership renewal takes place when an existing member renews their membership. Researchers have correlated Industrial Advisory Board (IAB) member satisfaction with the relevance of the research program. In a regression study investigating member satisfaction, researchers found "relevance not general quality, appears to be paramount" [[175] p253] for membership renewal decisions. This implies, if an IAB member perceives the research projects are relevant, they are more likely to pay their dues and retain their membership status.

Leveraged Funding: The initial response to this was the higher leverage the better. Ideally, an IUCRC will mature and graduate from the NSF IUCRC program sustaining the social technology embedded in the operational mechanisms of the center. Therefore, the leveraged ratio of funding that an IUCRC receives from all sources other than the NSF IUCRC program to the funding the NSF provides was 
determined to range from 0 to $n>10$. Once an IUCRC has gained industrial support exceeding a leveraged factor of 10 , the NSF may prefer to graduate them from the program allowing for a reallocation of resources to help newer IUCRCs form. Therefore, a leveraged value of 8 was judged equivalent to a center with a significantly higher leveraged value such as 20 .

Researcher satisfaction: Pre-eminent scientists attract high quality students and are instrumental in conducting fruitful research. Coberly conducted extensive research to find retention, involvement and amount of funding to be significant indicators of researcher satisfaction [193]. While the formal evaluation program has conducted recent surveys to collect researcher satisfaction data, many experts warned about the use of this data. Instead, churn was established as a proxy. 


\section{Figure 15 Desirability curves for stakeholder satisfaction outputs}

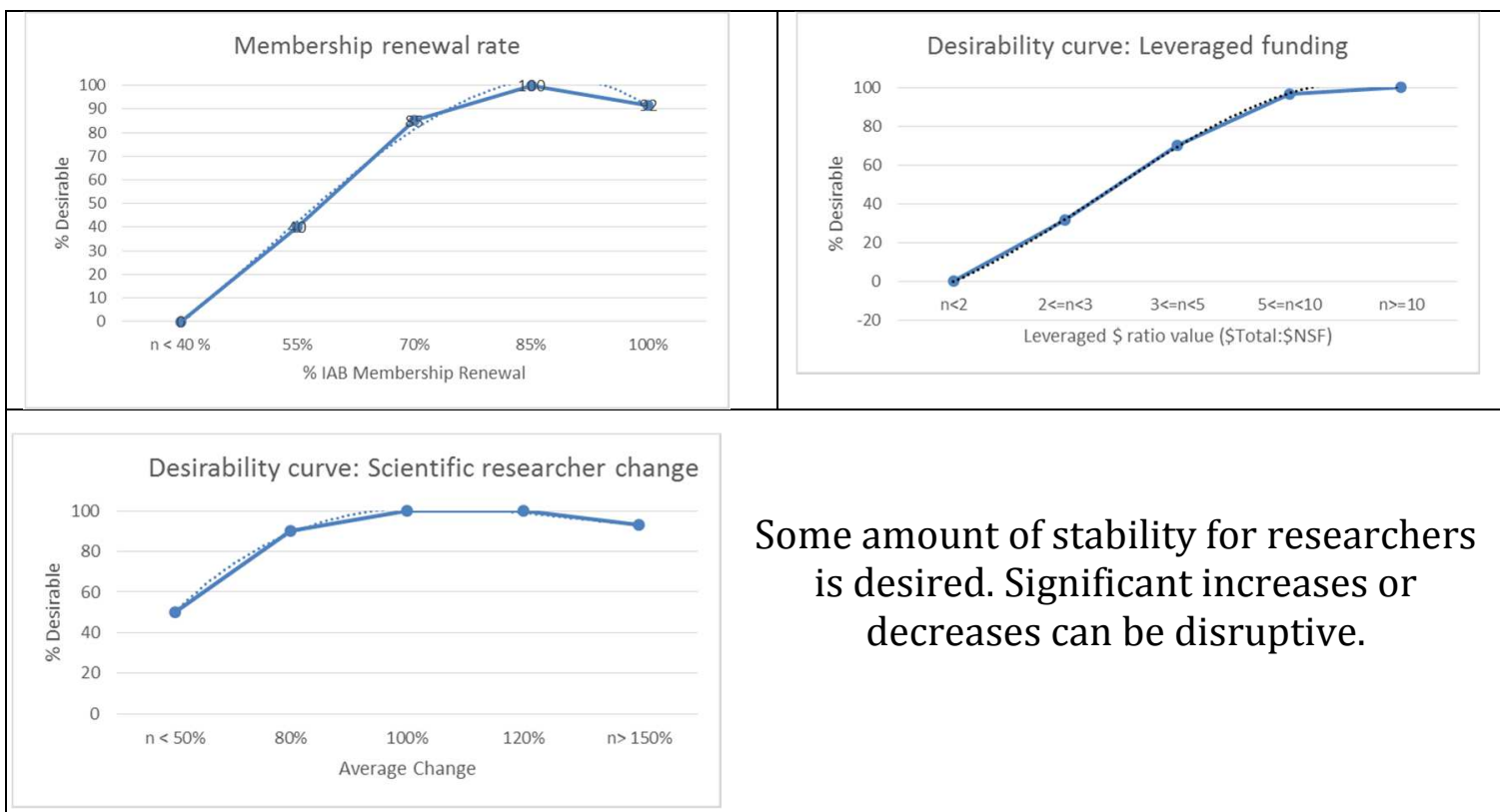

Notice how the curve in the upper left hand corner of figure 15 for membership renewal rate shows the most desirable rate to be about $85 \%$. One reason is that some change in membership is expected and good. Experts expressed the importance of growing the membership base. However, they also noted by design some of the smaller firms are expected to have limited retention and be replaced by others. For example, firms subsidized by programs such as the Small Business Innovation Research (SBIR) program have funding for a limited time-period and then simply run out of funds as the grant expires.

Different members join for different reasons. Some join to "check-it-out" and see what the program is all about. Therefore, there is some value in having firms drop out; as in the case of small firms being replaced in the SBIR program. Experts noted 
this "absolute" counting of smaller and larger firms was not ideal noting there may be "cause for concern if two of your larger stable members drop but limited concern if two firms in the SBIR program are not able to renew. " The type of IAB member firm may play a role in the indicator. Therefore, on average, it is desirable for most of the IAB members to renew; but, smaller firms are not expected to continue renewal and the curve slightly dips at the right end of the scale.

Table 17 Student involvement characterization

\begin{tabular}{|l|l|l|l|l|}
\hline Goal & Output & Description & Metric & DC Range \\
\hline & $\begin{array}{l}\text { Visiting students } \\
\text { IAB meetings }\end{array}$ & $\begin{array}{l}\text { Partner site student in-person attendance } \\
\text { at IAB meetings. Electronic forms of } \\
\text { "attendance" diffuse the social technology } \\
\text { and reduce student benefits }\end{array}$ & $\begin{array}{l}\text { \% off-site Student } \\
\text { attendance at } \\
\text { meetings/3 yr }\end{array}$ & $0<=\mathrm{n}<=100$ \\
\hline $\begin{array}{l}\text { Student dissertations or theses using IAB } \\
\text { project as research topic. }\end{array}$ & $\begin{array}{l}\text { Avg \# of students } \\
\text { using IAB research as } \\
\text { topic/3 yr }\end{array}$ & $0<=\mathrm{n}<=9+$ \\
\hline
\end{tabular}

Figure 16 Desirability curves for student involvement outputs

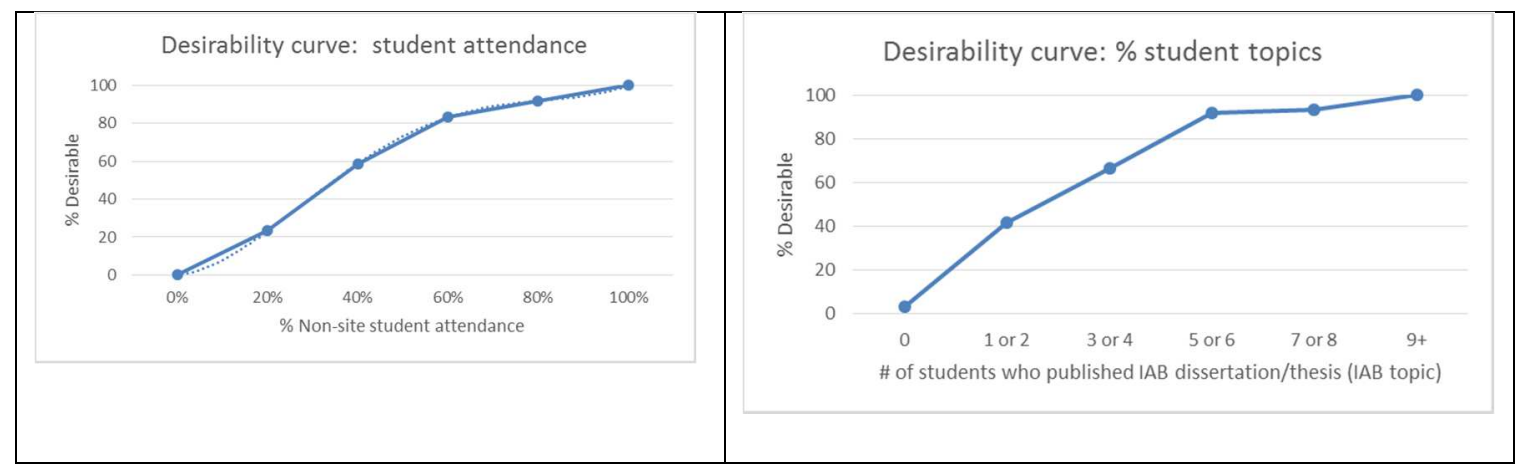




\section{Table 18 Student development characterization}

\begin{tabular}{|c|c|c|c|c|}
\hline Coal & Output & Description & Metric & DC Range \\
\hline \multirow{2}{*}{ 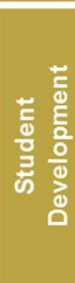 } & Projects & $\begin{array}{l}\text { Students are a requirement of the program. Industry acknowledges that } \\
\text { access to a diverse pool (Porter \& Rafols, 2009) of experienced students } \\
\text { trained in industrial relevant research is desired and beneficial (McGowan, } \\
2012 \text { ) (Elena-Pérez, Saritas, Pook, \& Warden, 2011). }\end{array}$ & $\begin{array}{l}\text { Students: } \\
\text { research } \\
\text { scientist ratio }\end{array}$ & $0<\mathrm{n}<=5+$ \\
\hline & $\begin{array}{l}\text { Presen- } \\
\text { tations }\end{array}$ & $\begin{array}{l}\text { Presentations at IAB meetings or multi-purpose poster sessions are ways } \\
\text { students can practice and develop communication skills. Often, students } \\
\text { present to the IAB developing skill while gaining insight from collaborators } \\
\text { (Boardman \& Bozeman, 2015), (Behrens \& Gray, 2001). }\end{array}$ & $\begin{array}{l}\% \text { of students } \\
\text { who } \\
\text { presented/year }\end{array}$ & $0<=\mathrm{n}<=100$ \\
\hline
\end{tabular}

Figure 17 Desirability curves for student development outputs

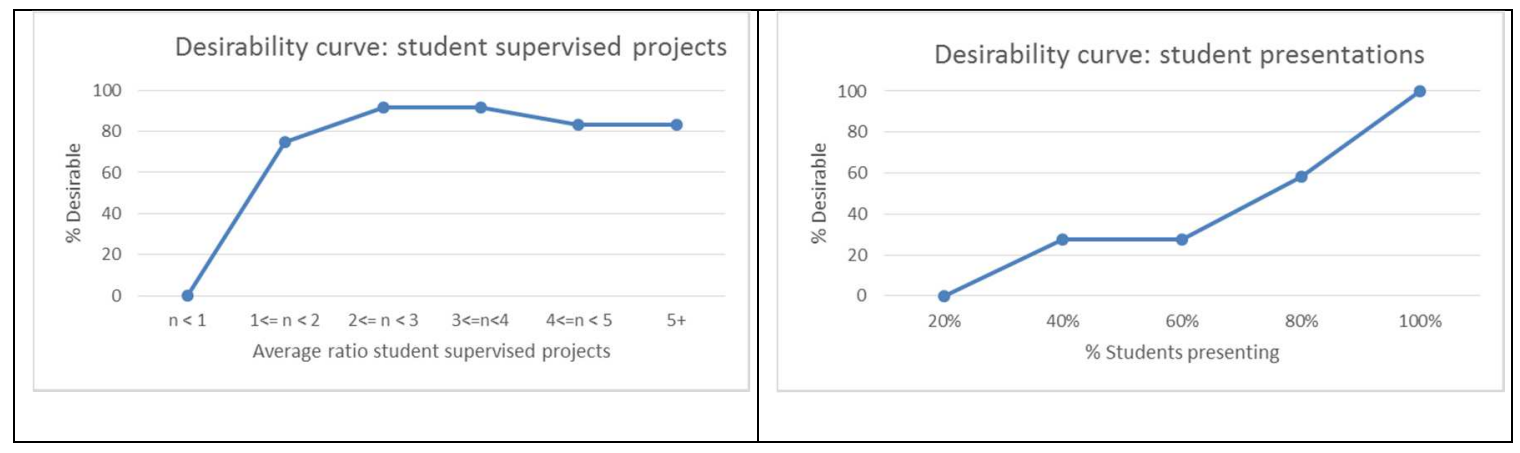

Knowledge and technology transfer (KTT) is a complex construct, spanning boundaries [101] with many definitions. Roessner provides a simple definition of KTT as "the movement of know-how, technical knowledge, or technology from one organizational setting to another" ([45] p31). The facilitation of knowledge and technology transfer [4] is key to achieving the NSF IUCRC's mission as stated in the third objective: to accelerate and promote the transfer of knowledge and technology between university and industry ([62] p23) that benefits the public [78][139] [169]. 
However, the complexity of this construct makes it difficult to define and measure [76]. Bozeman agrees stating "whether technology transfer or knowledge transfer, a perpetual challenge is demarcating the transfer object from its environment"([57] p 629). He provides some guidance for this study with his "Contingent Effectiveness Model of Technology Transfer" where outputs are classified for KTT transfer as media and objectives ([57] p 637).

Bozeman describes a KTT medium as the vehicle, formal or informal, by which the technology is transferred [57]. KTT media supported by literature include personnel exchanges, demonstrations, papers and professional networks. KTT objects provide the form and document the content of what is transferred. Some examples of this transfer entity include new products or services, new methods or processes and patents.

Researchers have examined personnel exchange as a common medium for knowledge and technology transfer [8] [49][57][75] [77][85][183][184][185][186] [187][188]. In an IUCRC, students are a focus and the output of students hired by industry is defined by the average number of university graduates hired by industry per year. In the definition, industry expands beyond the firms holding memberships in the associated IUCRC.

Academic engagement of scientific faculty contracted to help commercialize research outputs is also important [180]. Papers are a common medium used to share 
knowledge [81][93][176][177][178] and were supported by the expert data. The metric considers all publications in journals and conference proceedings. While members holding key positions as editors or conference organizers were identified in the literature as a KTT medium [5][8][122][172][175][176][181][182] this output was not supported by the expert validation data and was removed.

\section{Table $19 \quad$ KTT media characterization}

\begin{tabular}{|c|c|c|c|}
\hline Goal & Output & Description & Metric \\
\hline \multirow{5}{*}{ 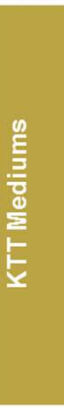 } & $\begin{array}{l}\text { Students } \\
\text { Hired by } \\
\text { Industry }\end{array}$ & $\begin{array}{l}\text { Percentage of students hired in industry where they can apply knowledge received } \\
\text { through the IUCRC experience. When students are hired into industry, knowledge } \\
\text { transfers from the higher education institution to the company (McGowan, 2012). }\end{array}$ & $\begin{array}{l}\text { Avg \# Univ grads } \\
\text { hired by industry/3 } \\
\text { year }\end{array}$ \\
\hline & $\begin{array}{l}\text { Consulting } \\
\text { (contract or } \\
\text { exchange) }\end{array}$ & $\begin{array}{l}\text { Academic engagement of scientific faculty contracted to help commercialize } \\
\text { research outputs through consulting (Perkmann et al., 2013) is important. }\end{array}$ & $\begin{array}{l}\% \text { of scientific staff } \\
\text { consulting to } \\
\text { industry/3 year }\end{array}$ \\
\hline & Papers & The ratio of number of papers published to the number of researchers in an IAB. & \# papers/ researcher \\
\hline & $\begin{array}{l}\text { Training and } \\
\text { Workshops }\end{array}$ & $\begin{array}{l}\text { Workshops (Kerr et al., 2013) and informal meetings (Cohen et al., 2002) provide } \\
\text { the greatest form of knowledge transfer. }\end{array}$ & $\begin{array}{l}\% \text { attendance } \# \\
\text { held } / 3 \text { year }\end{array}$ \\
\hline & $\begin{array}{l}\text { Shared } \\
\text { Resources }\end{array}$ & $\begin{array}{l}\text { Sharing of resources(Corley et al., 2006) such as labs (Teshima \& Rung, 2010), } \\
\text { testing facilities (Sundstrom \& Gray, 2010) and open source software sites } \\
\text { improves "sticky and difficult" (Mowery, 2003) transfer of technical knowledge. }\end{array}$ & $\begin{array}{l}\text { Shared equipment or } \\
\text { lab (infrastructure) }\end{array}$ \\
\hline
\end{tabular}


Figure 18 Desirability curves for KTT media

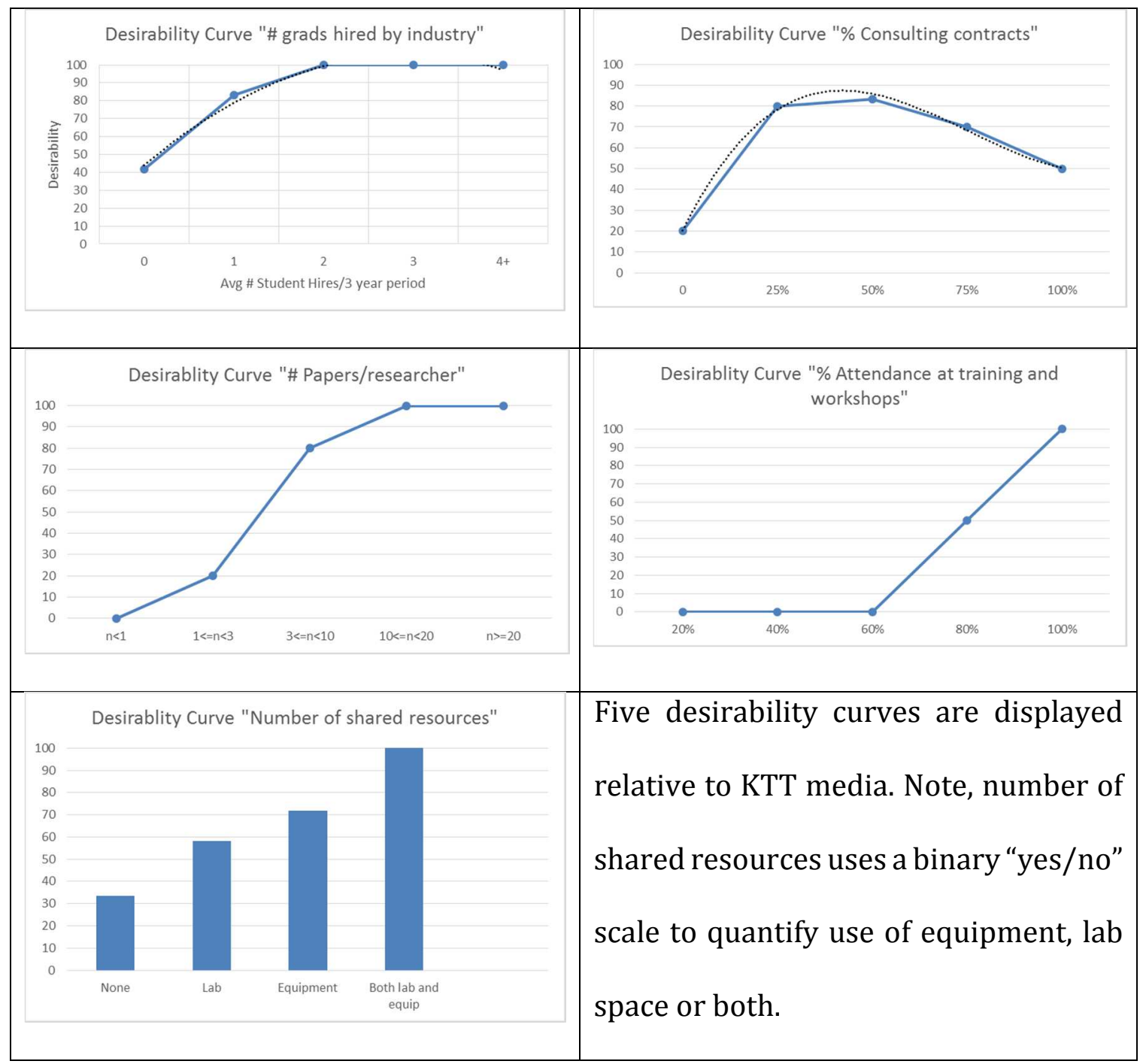

The transfer objects new products, new methods or processes are discussed in scientific journals [8][191][4][174][168][130] and tracked in a compendium of breakthrough technologies published by the NSF. 
Table 20 KTT objects characterization

\begin{tabular}{|l|l|l|l|}
\hline Goal & Output & Description & Metric \\
\hline \multirow{3}{*}{} & $\begin{array}{l}\text { New } \\
\text { Products }\end{array}$ & $\begin{array}{l}\text { Developing new technology [124] with } \\
\text { the aim to transfer new products, } \\
\text { technologies or processes [167]. }\end{array}$ & \# new products \\
\cline { 2 - 4 } & $\begin{array}{l}\text { New } \\
\text { Methods or } \\
\text { processes }\end{array}$ & $\begin{array}{l}\text { \# new methods or } \\
\text { processes }\end{array}$ \\
\cline { 2 - 4 } & Licenses & $\begin{array}{l}\text { Licenses indicate intention of use. By } \\
\text { design of the partnership agreement, all } \\
\text { members share the intellectual property } \\
\text { unless exclusive rights are granted. }\end{array}$ & \# licenses granted \\
\cline { 2 - 4 } & & &
\end{tabular}

Figure 19 Desirability curves for KTT object outputs

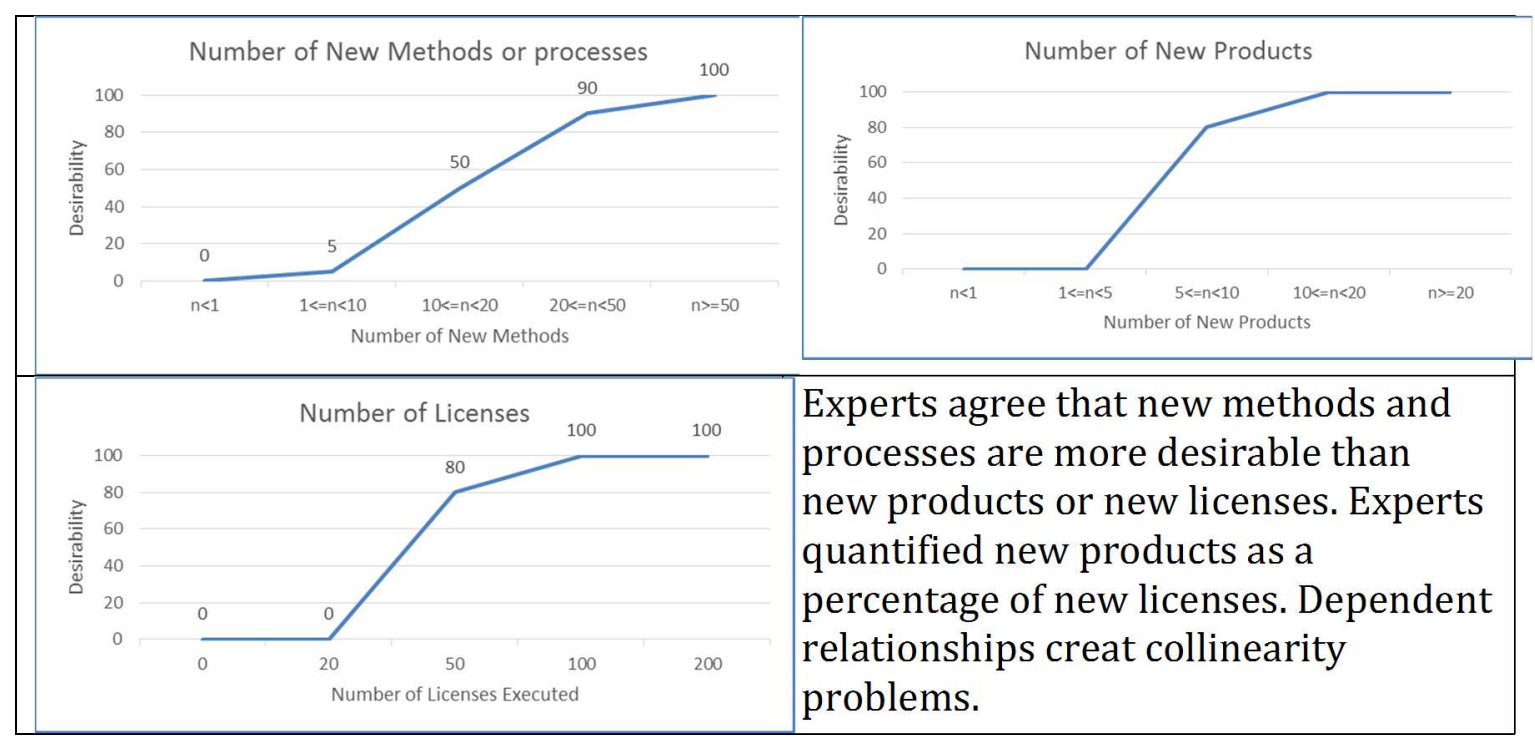




\section{CHAPTER 5: FINALIZING THE MODEL}

Finalization of the generalizable performance evaluation model is discussed in the following sections: expert validation of the model content and construct, expert quantification of the relative decision criteria importance and curing the data to establish final weights. In phase 2, experts quantified the relative importance of each element. Therefore, an important part of this research is development and validation of the model with NSF IUCRC domain experts.

\subsection{Model Validation}

It is important to carefully select outputs [124] that not only "fit" the mission specifications but are also aligned with the social technology characterizing the NSF IUCRC program. Experts provided qualitative input regarding the ability of decision elements to represent the uniqueness of the NSF IUCRC program. Then, experts judged each element providing quantitative binary acceptance data. Elements were accepted when an $80 \%$ agreement level was reached by the panel of experts [49].

Appendix C shows how three objectives (Appendix C-1), six goals (Appendix C-2) and seventeen (17) of twenty-four outputs (Appendix C-3) were validated and accepted into the model because they were accepted by at least $80 \%$ of the experts [49]. The validation of goals and outputs required an iterative process. 
Figure 20 shows how the validated elements were linked together to develop the HDM. Three (3) objectives fill level 2, six (6) goals fill level 3 and seventeen (17) outputs specified by desirability curves fill level four 4 .

Figure 20 Validated HDM

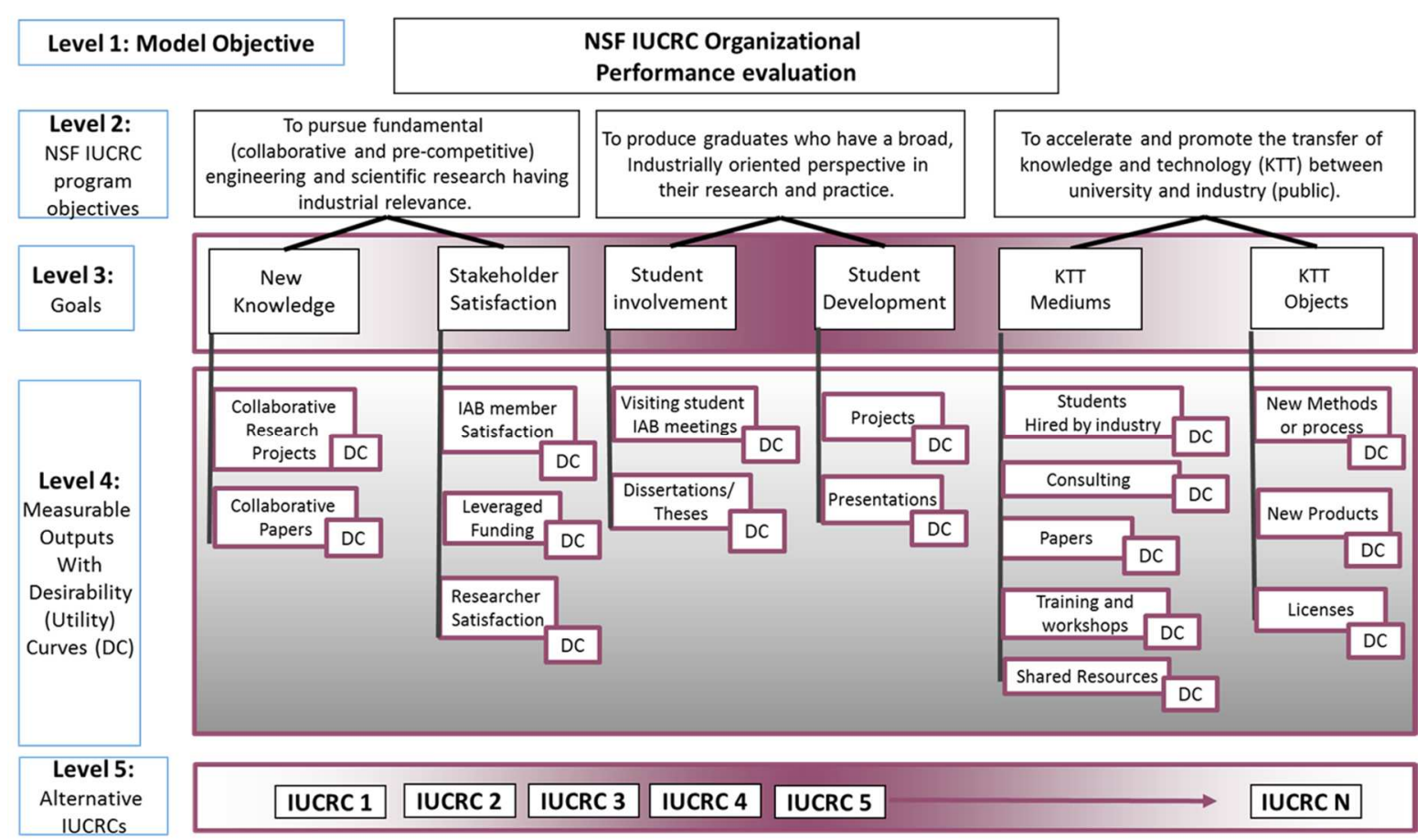

\subsection{Data Collection and Quantification}

The pairwise comparison technique was used for the quantification process for each decision elements. The number of pairwise comparisons is calculated using equation 5; where $\mathrm{N}$, the number of pair-wise comparisons, is dependent upon $\mathrm{n}$ number of elements. 


\section{Equation 4 Number of pair-wise comparisons}

$$
\mathrm{N}=\frac{\mathrm{n}(\mathrm{n}-1)}{2}, \quad \text { for } \mathrm{n}>0
$$

For example, if a group has 5 elements (as outputs relative to KTT media), the number of pairwise comparisons that are asked to be completed is $(5 * 4) / 2=10$.

Judgment quantification instruments (Appendix A-5) were designed, developed and administered to each panel of experts to collect pairwise comparison data. The raw data tables are provided in Appendix D. Data was then entered into the HDM (c) 2.0 software to complete the quantification calculations and inconsistency and disagreement measures. A screen shot shows the ten pairwise comparisons for KTT media in Appendix D-3.

\subsection{Inconsistency}

This research applied different measurement methods to examine expert inconsistency in the quantification data. First, all expert data was examined for inconsistency using the average standard deviation method that was calculated by the HDM 2.0@ software. All measures were compared against a threshold tolerance of $10 \%$. Inconsistencies at or above the tolerance threshold were further examined using the root-sum of the variances (RSV) method [162].

One high inconsistency measure occurred in the data that asked experts to provide pairwise comparison judgments for KTT medium outputs relative to the goal of transferring knowledge and technology. Figure 21 shows that expert 9 has an inconsistency value of 0.26 and expert 2 is at the threshold of $10 \%$. 
Figure $21 \quad$ Inconsistent expert data

\section{Inconsistency $0.26>0.1$ threshold}

\begin{tabular}{|c|c|c|c|c|c|c|}
\hline KTT Medium & Stu Hires & Consulting & Papers & Training & $\begin{array}{c}\text { Shared } \\
\text { Resources }\end{array}$ & Inconsistency \\
\hline E1 & 0.31 & 0.21 & 0.03 & 0.19 & 0.25 & 0.06 \\
\hline E2 & 0.12 & 0.06 & 0.18 & 0.39 & 0.26 & 0.1 \\
\hline E3 & 0.38 & 0.12 & 0.15 & 0.19 & 0.15 & 0.03 \\
\hline E4 & 0.29 & 0.11 & 0.16 & 0.27 & 0.17 & 0.02 \\
\hline E5 & 0.62 & 0.11 & 0.05 & 0.1 & 0.11 & 0.05 \\
\hline E6 & 0.36 & 0.18 & 0.2 & 0.12 & 0.13 & 0.04 \\
\hline E7 & 0.36 & 0.11 & 0.11 & 0.16 & 0.26 & 0.01 \\
\hline E8 & 0.28 & 0.28 & 0.18 & 0.18 & 0.08 & 0.04 \\
\hline E9 & 0.03 & 0.15 & 0.37 & 0.39 & 0.06 & 0.26 \\
\hline E10 & 0.32 & 0.07 & 0.21 & 0.21 & 0.18 & 0.01 \\
\hline E11 & 0.34 & 0.22 & 0.12 & 0.18 & 0.14 & 0.03 \\
\hline E12 & 0.29 & 0.19 & 0.19 & 0.19 & 0.13 & 0 \\
\hline E13 & 0.23 & 0.19 & 0.14 & 0.3 & 0.13 & 0 \\
\hline Mean & 0.3 & 0.15 & 0.16 & 0.22 & 0.16 & \\
\hline Minimum & 0.03 & 0.06 & 0.03 & 0.1 & 0.06 & \\
\hline Maximum & 0.62 & 0.28 & 0.37 & 0.39 & 0.26 & \\
\hline Std. Deviation & 0.13 & 0.06 & 0.08 & 0.09 & 0.06 & \\
\hline Disagreement & & & & & & 0.075 \\
\hline
\end{tabular}

Instead of using a fixed measure of $10 \%$, Abbas [162] provides a method to determine an acceptable level of inconsistency for a certain number of decision elements for a specified confidence level. The decision variables in this case include the five different knowledge and technology transfer media: student hires, consulting, papers published, training and workshops and shared resources. Abbas explains in his research how the fixed $10 \%$ threshold limit is increasingly conservative as the number of decision elements increase from the range of 3 elements to 12 elements. He found the $10 \%$ threshold to be quite conservative when experts were asked to make comparative judgment involving 5 elements [162]. Therefore, the data for E2 was accepted into the study. 
Expert 9 however calculated at .26 using the HDM(C) 2.0 software. Expert inconsistency can signify a problem with the judgment quantification instrument, or an opportunity to uncover new information. Therefore, the inconsistent data for expert 9 was further examined for consistency using the RSV method.

After normalizing values for a stratified sample from the 120 orientations (5!) the mean, standard deviation and variance were calculated for each of the five decision elements. The stratified sample method used randomly selected orientations beginning with $\mathrm{A}$, then $\mathrm{B}$, then $\mathrm{C}$, then $\mathrm{D}$, then $\mathrm{E}$, corresponding to the 5 decision elements. The normalized values were calculated as a basis for finding the mean, standard deviation and variance. Approximately 50 samples were selected in this manner. An example showing how the results in Table 21 were calculated using stratified sampling is included in Appendix F.

Table 21 Mean, Std Deviation and variance for Expert 9 data

\begin{tabular}{|l|l|l|l|l|l|}
\hline Formula & Stu Hires & Consulting & Papers & Training & Shared Resources \\
\hline Mean & 0.03 & 0.15 & 0.37 & 0.38 & 0.06 \\
\hline Std Deviation & 0.15 & 0.24 & 0.34 & 0.34 & 0.13 \\
\hline Variance & 0.02 & 0.06 & 0.12 & 0.11 & 0.02 \\
\hline
\end{tabular}

Equations 6 and 7 show how inconsistency was measured using the standard deviation method and the RSV method respectively

\section{Equation 5 Expert 9 Inconsistency using standard deviation method}

$$
\begin{aligned}
& \text { Inconsistency }=\sqrt{\frac{1}{5}\left((.15)^{2}+(.24)^{2}+(.34)^{2}+(.34)^{2}+(.13)^{2}\right)} \\
& \text { Inconsistency }=0.264(\mathrm{STD})
\end{aligned}
$$


Equation 6 Expert 9 Inconsistency using RSV

$$
\begin{aligned}
& \text { Inconsistency }=\sqrt{.02+.06+.12+.11+.02} \\
& \text { Inconsistency }=0.574(\mathrm{RSV})
\end{aligned}
$$

Using figure 22, the RSV inconsistency level of .574 is above the tolerance threshold limit of .26. This method is appropriate because an approximation is adequate to compare against the threshold found on the curve. So, the discordant data set is rejected because it fails to achieve the required consistency.

Figure 22 Inconsistency threshold for 5 decision elements ([162] p 99)

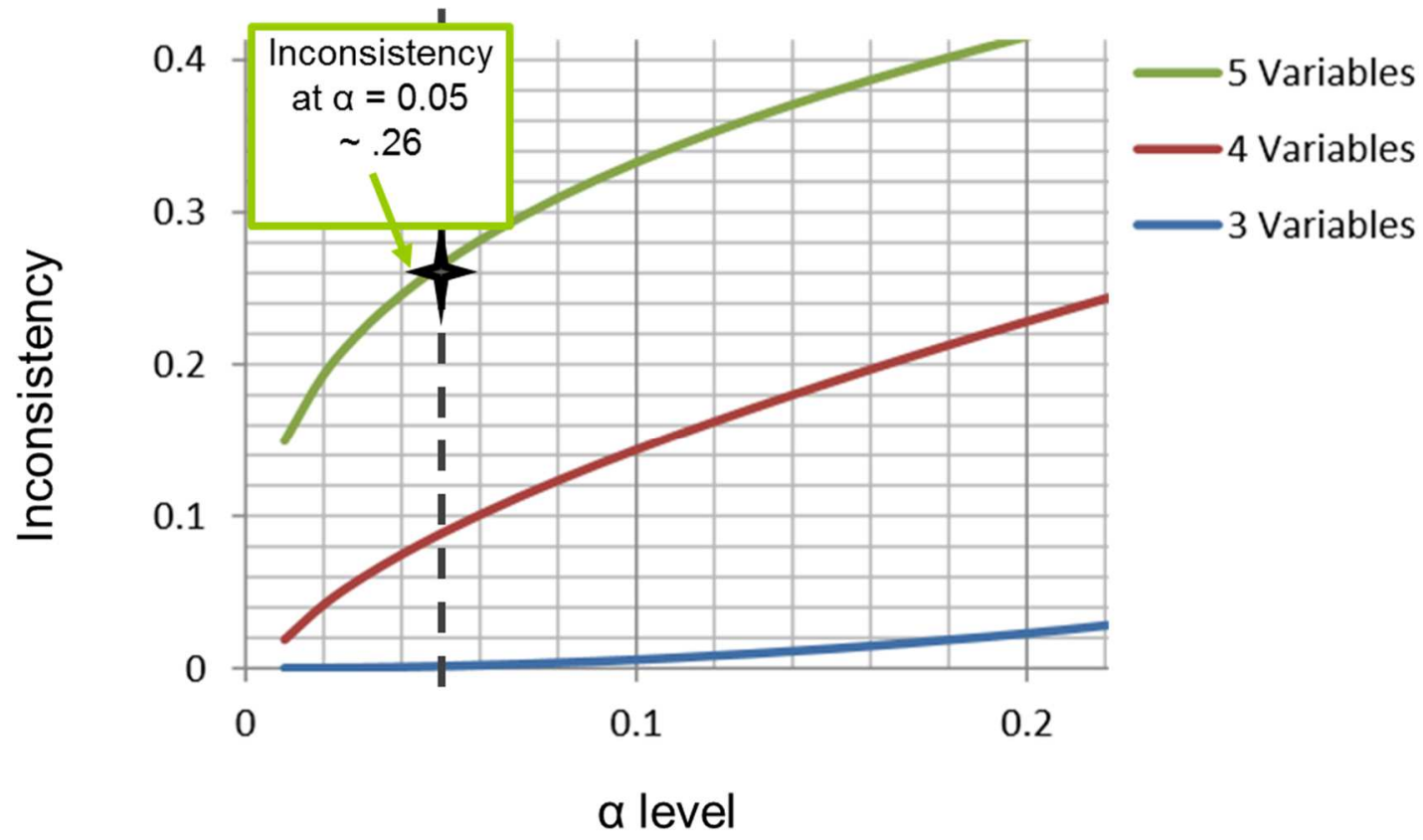

Notice how several of the decision elements were valued at a 99 or a 1 . The judgment quantification instrument provided instructions for experts to enter a weight of 1 when judging an element to have a negligible contribution towards the degree to 
which an IUCRC performs against the programs mission. In this expert's opinion, the data show that they judged student hires and shared resources to be insignificant because a value of 1 was provided relative to another paired element.

\subsection{Disagreement Analysis}

Experts disagree for many reasons. Disagreements can stem from a rich diversity of opinions, or a structural mis-understanding of the problem. Mumpower and Stuart describe how disagreement among experts' judgments of scientific and technical may stem from different sources including: difference in relative importance, difference in functional linkages, and difference in bias (p195). Analyzing the cause for difference can lead to valuable information.

Figure 23 reflects the areas of disagreement selected for further analysis by panel and focus area because the levels were above a set threshold of $10 \%$. Highlighted elements, in the right of figure 23 , show that 7 of 10 data sets reflected disagreement levels above the threshold. 
Figure 23 Disagreement levels among experts

\begin{tabular}{|l|c|}
\hline Panel \#: Focus & Disagreement \\
\hline 1: Objectives & 0.000 \\
\hline 2: Research Goals & 0.172 \\
\hline 2: Student Goals & 0.119 \\
\hline 2: KTT Goals & 0.132 \\
\hline 3: New Knowledge & 0.147 \\
\hline 3: Stakeholder Sat. & 0.126 \\
\hline 4: Student Involvement & 0.169 \\
\hline 4: Student Development & 0.140 \\
\hline 5: KTT Mediums & 0.059 \\
\hline 5: KTT Objects & 0.089 \\
\hline
\end{tabular}

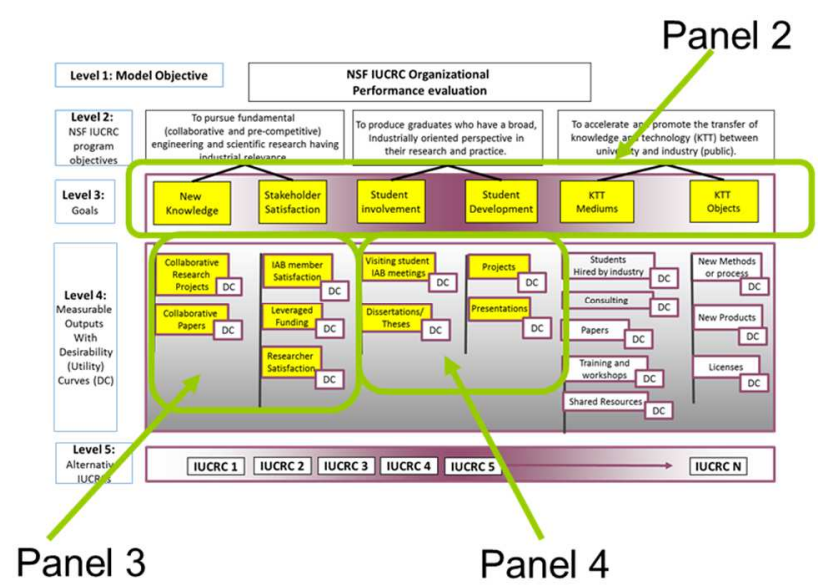

Panel 2 experts, configured with NSF IUCRC evaluators, project managers and a center director, were asked to quantify pairwise comparisons of goals relative to each objective. This group of experts was selected for their strength in managerial aspects of the NSF IUCRC program as well as their knowledge about program evaluation. Most of the participating experts have some background as NSF IUCRC evaluators and all were generous with their time and information. Each set of data for panel 2 was above the disagreement threshold of 0.10 ; so, hierarchical agglomerative clustering analysis (HAC) was conducted eventually resolving in satisfactory disagreement levels.

Appendix G shows how the dendrograms were developed and the data that was used to analyze the disagreement. Excerpts from the knitted output R program are included as well as disagreement tables calculated using the HDM software package for each disagreement analyzed. 


\subsubsection{Level 3 HAC: Goals}

Experts conducted pair-wise comparisons between new knowledge and stakeholder satisfaction relative to the first objective about pursuing fundamental research. The disagreement value of 0.172 was above the threshold and the data was selected for analysis using the hierarchical agglomerative clustering (HAC) techniques. Figure 24 depicts the cluster dendrogram and new disagreement levels.

Figure 24 HAC: new knowledge vs. stakeholder satisfaction

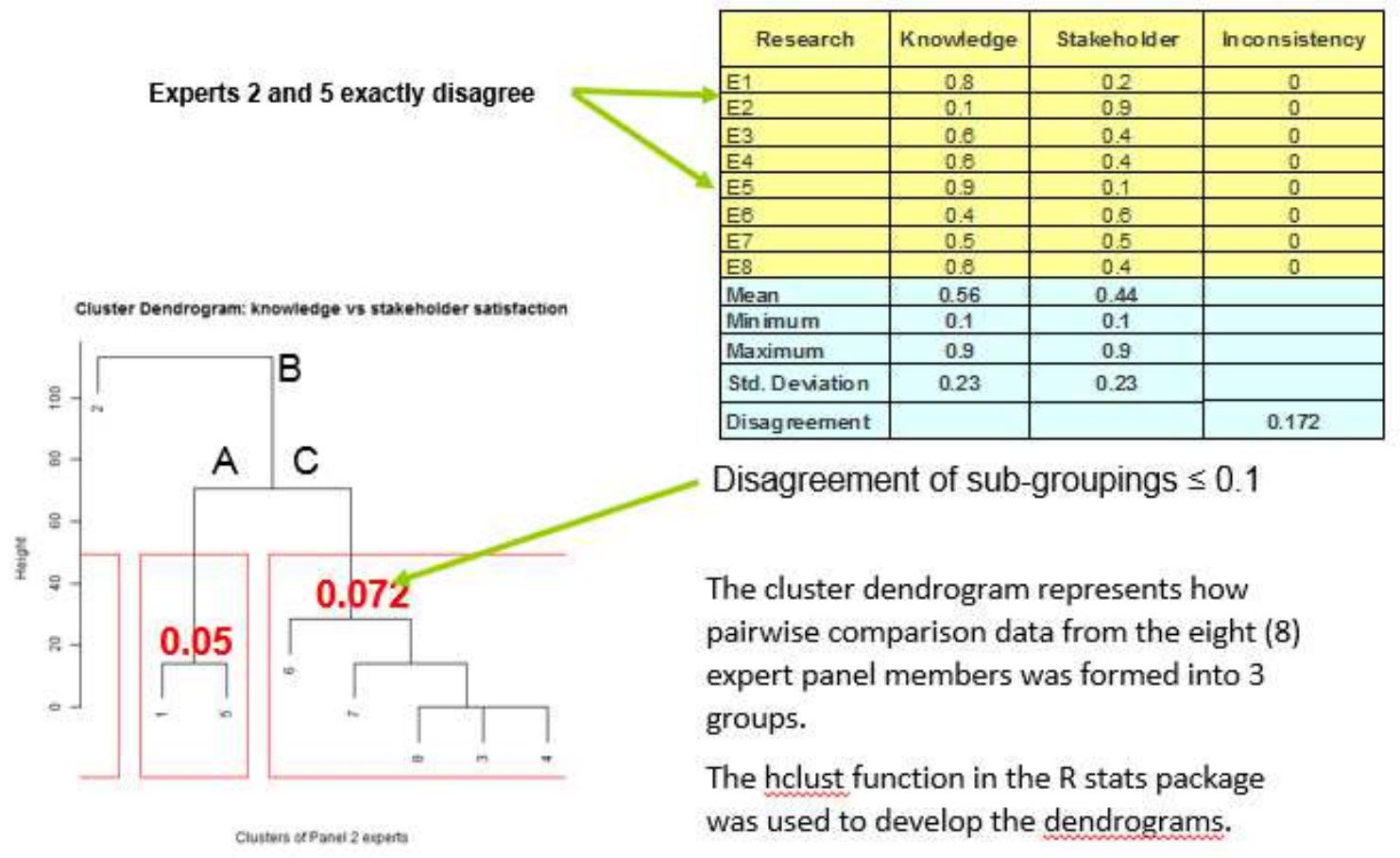

Note how each of the sub-groups disagreement is below the $10 \%$ threshold. Further analysis using the F-Test shows that the probability of disagreement can be 
rejected at the sub-cluster level. Therefore, the sub-clusters have a strong probability that a random amount of disagreement would be rejected.

In group A, experts 1 and 5 strongly favored new knowledge over stakeholder satisfaction. However, expert 2 in group B was even stronger in the other direction favoring stakeholder satisfaction over new knowledge. Group C had a more balanced perspective about the relative importance showing only slight favoritism towards new knowledge.

Panel 2 experts, judging the relative importance of student involvement versus student development towards objective 2, showed a 0.119 level of disagreement. Disagreement levels were re-calculated for each cluster as shown in the dendrogram in Figure 25. Both sub-clusters measure a disagreement level below the $10 \%$ threshold. Group A clearly values student involvement over student development and group B rates them as relatively equal in importance towards contribution to the organizational mission. 
Figure 25 HAC: student involvement vs. development

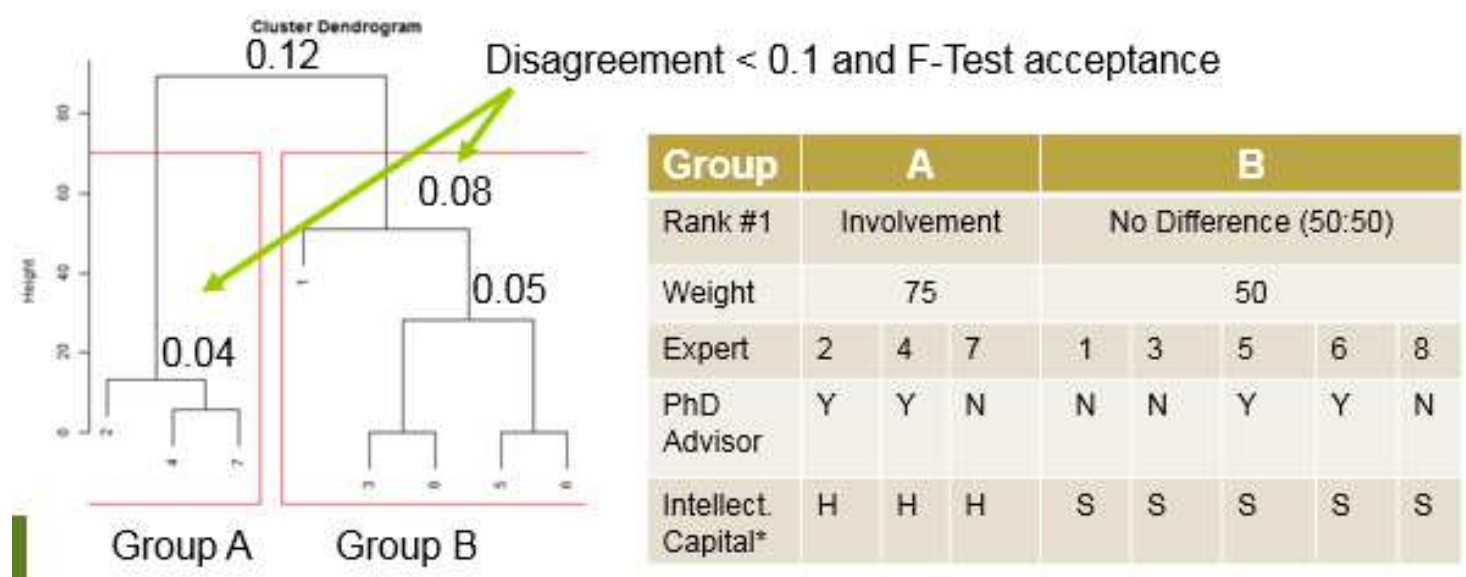

Involvement provides a higher contribution to center performance

-Intellectual Capital: Human, Relational, Structural (Carayanis, et. al., 2014)

The F-Test shows that Group A has a low probability of disagreement being rejected for randomness. Experts have different levels of experience and expertise with students. Further data was collected to determine the background and experience level for each expert in their capacity of student advising and expertise and research interest in intellectual capital.

In an attempt to find a pattern to test a possible causal relationship, a search was conducted in the ProQuest dissertations and theses global database to determine the background of each expert with regards to advising students. Using the advanced search, the expert's name was entered into the "advisor" field. Experts listed as a student advisor on a student thesis or dissertation were coded as "Y/N". The number 
of publications is also shown in table 22. For this example, no pattern was detected in relation to student advising.

Table 22 Expert background: student involvement and development

\begin{tabular}{|c|c|c|c|c|c|}
\hline Expert \# & Advisor & Bias & \# Pub & $\begin{array}{l}\text { IC focused } \\
\text { research }\end{array}$ & $\begin{array}{l}\text { Intellectual capital research } \\
\text { focus }\end{array}$ \\
\hline 1 & Y & D & 14 & Y & Structural/Human capital \\
\hline 2 & Y & I & 5 & Y & Human capital \\
\hline 3 & N & -- & 0 & N & Structural \\
\hline 4 & Y & I & 5 & N & Human capital \\
\hline 5 & Y & I & 27 & Y & Structural capital \\
\hline 6 & Y & I & 24 & Y & Structural capital \\
\hline 7 & N & I & 0 & Y & Human capital \\
\hline 8 & N & -- & 0 & Y & Structural capital \\
\hline
\end{tabular}

Figure 26 shows how group B experts reported a bias towards KTT media versus KTT objects as more effective towards achieving KTT.

Figure 26 HAC: KTT media vs. KTT objects

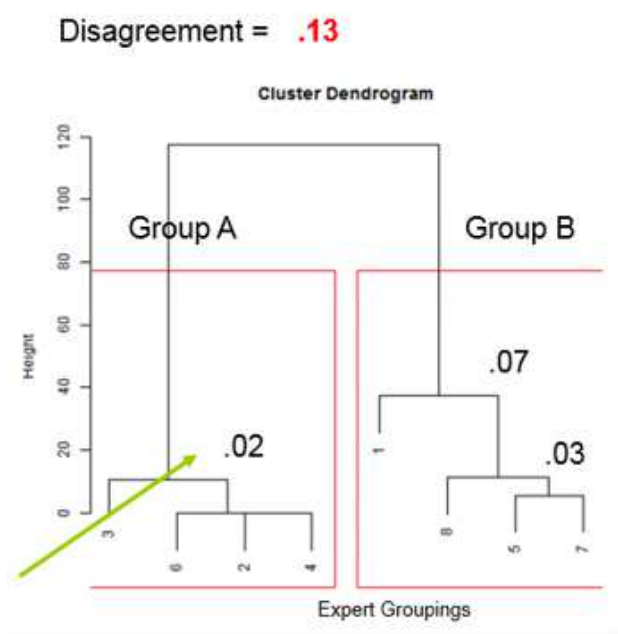




\subsubsection{Level 4 HAC: Outputs}

The panels at level 4 were slightly larger with more focus during selection and formation on balanced perspectives. At this perspective level, panels were configured with leading researchers, center directors, program evaluators and IAB executive directors.

Figure 27 shows the dendrogram for expert disagreement evaluating relative importance between collaborative projects and collaborative papers.

Figure 27 HAC: new knowledge outputs

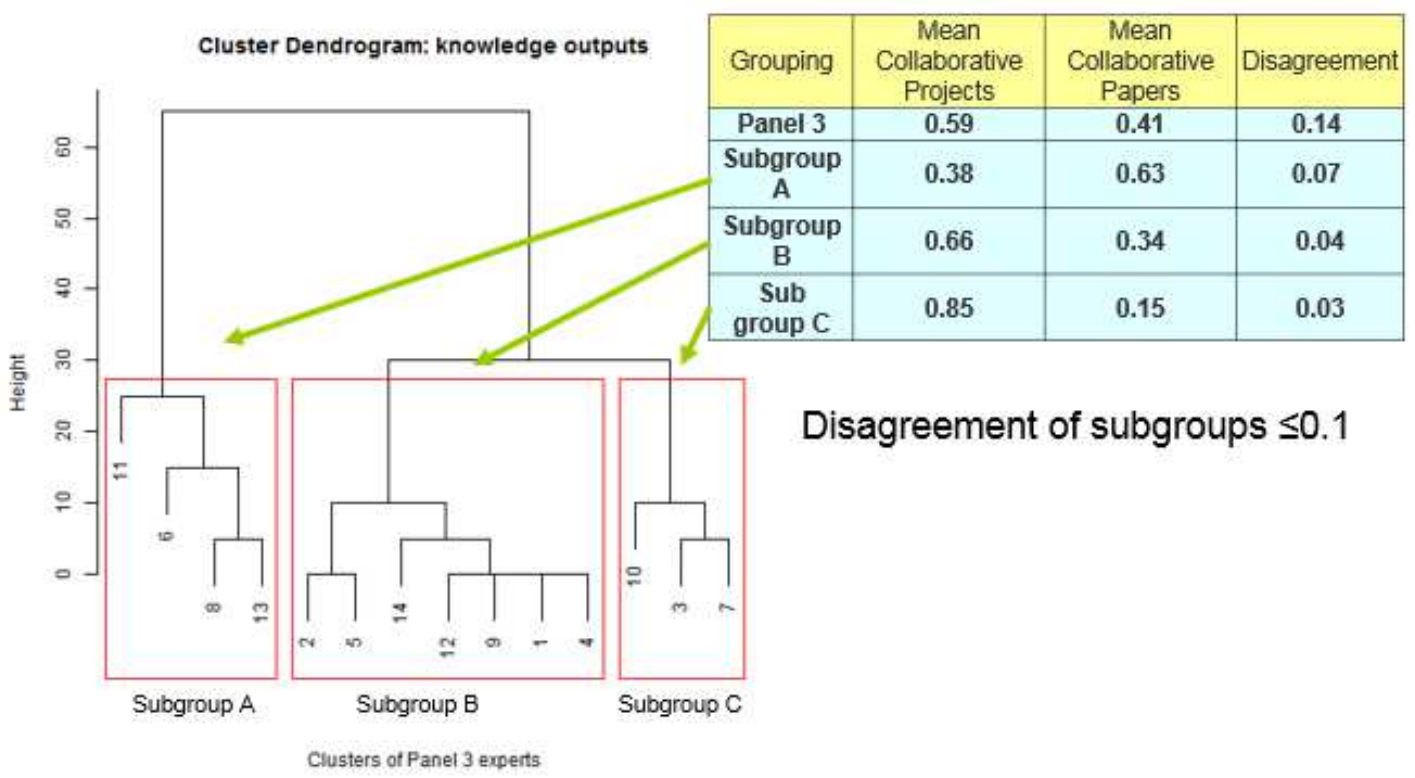

The ordinal disagreement between subgroup $A$ and subgroups $B$ and $C$ is important. Group A believes collaborative papers to be relatively more important and groups B and C lean towards collaborative projects showing ordinal disagreement. The initial results for stakeholder satisfaction show different groups favored each of 
the different alternatives. Group A judged researcher satisfaction to be of primary importance. Group B was very certain that the NSF and the measurement proxy of leveraged funding was the primary stakeholder to keep satisfied and groups C and D thought the IAB members were the most important.

Figure 28 HAC: stakeholder satisfaction outputs

\section{Cluster analysis for Stakeholder Satisfaction}

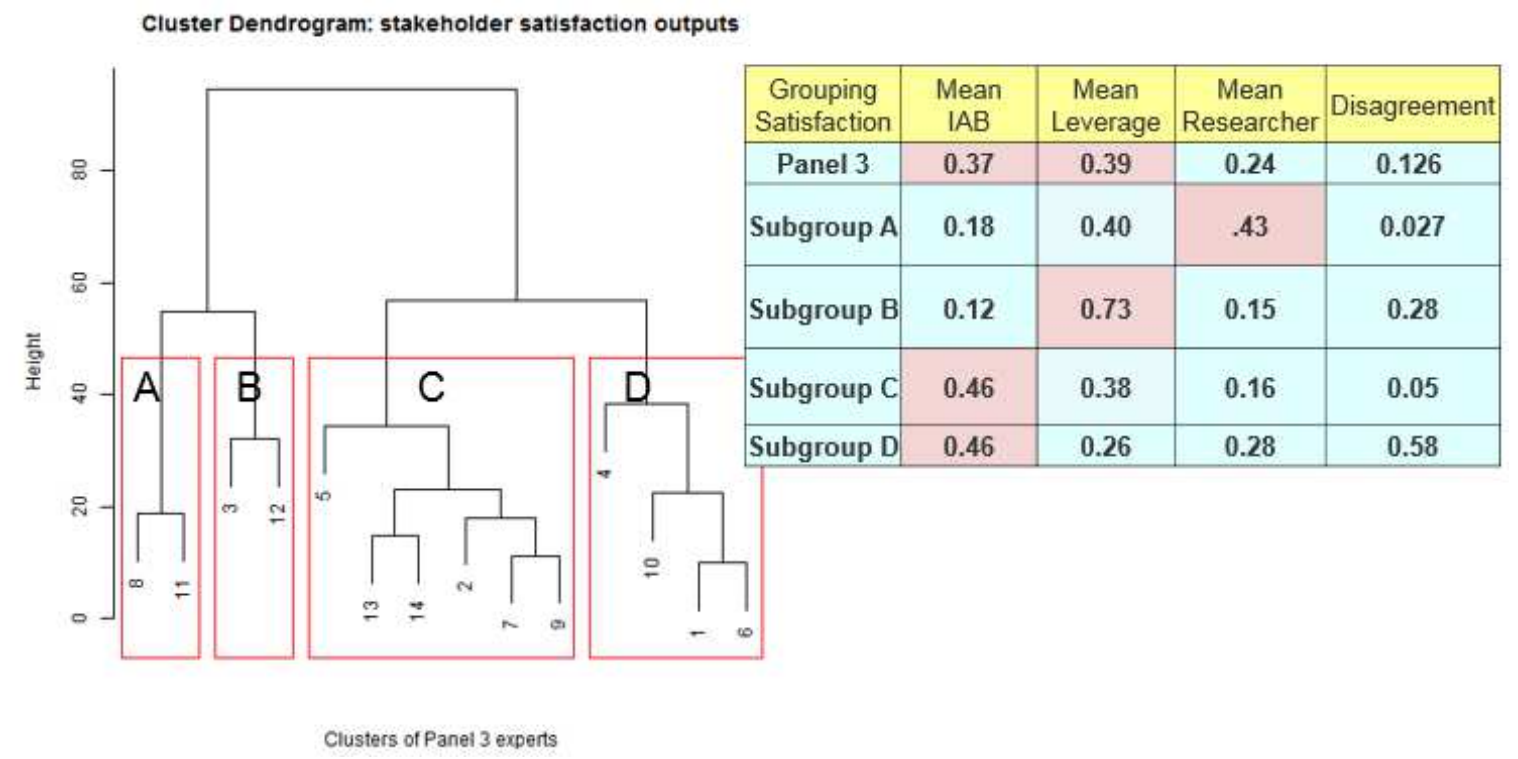

The next area of disagreement is the relative importance of visiting student attendance at IAB meetings vs thesis and dissertation topics. 


\section{Cluster Analysis for Student Involvement}

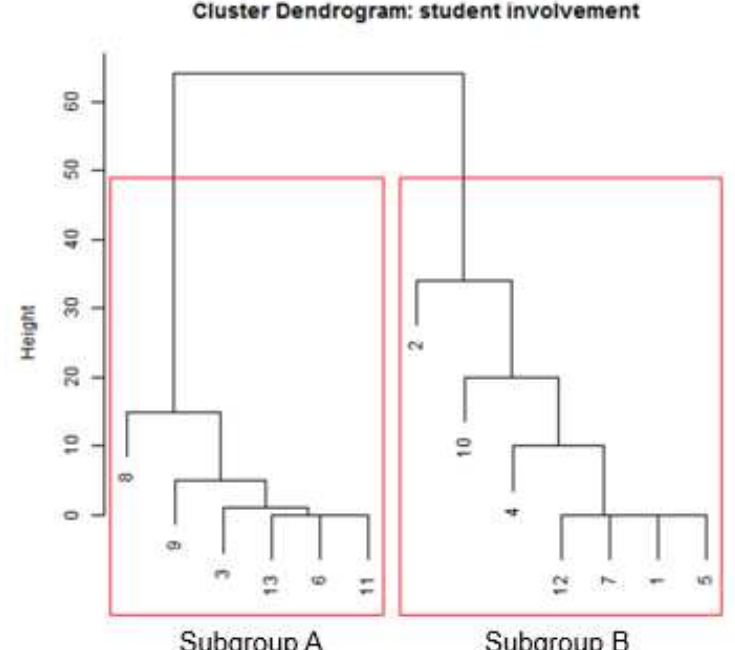

Subgroup A
Subgroup B

Clusters of Panel 4 experts

\begin{tabular}{|c|c|c|c|}
\hline $\begin{array}{c}\text { Grouping } \\
\text { involvement }\end{array}$ & $\begin{array}{c}\text { Mean } \\
\text { Meetings }\end{array}$ & $\begin{array}{c}\text { Mean } \\
\text { Topics }\end{array}$ & Disagreement \\
\hline Panel 3 & 0.38 & 0.62 & 0.126 \\
\hline Subgroup A & 0.19 & 0.81 & 0.031 \\
\hline Subgroup B & 0.53 & 0.47 & 0.078 \\
\hline
\end{tabular}

Group A agreed closely that students choosing $\mathrm{IAB}$ research as the topics in their dissertation or theses projects contributed more than offsite student meeting attendance.

Group B shows they are relatively equal with meeting attendance being slightly more important.

Group A consistent with group's ordinal values.

There is an ordinal difference between subgroup A and B. Experts in subgroup A strongly believe that students who choose IAB research as the topic in their $\mathrm{PhD}$ dissertation research or Master's thesis demonstrate more involvement than the percentage of off-site students who attend IAB meetings. The probability of subgroup A disagreeing on this point are low as shown by the disagreement value and confirmed by the F-Test. 
Data was collected to examine the level of engagement each expert had as a student advisor. The ProQuest data base for dissertations and theses was searched by advisor. The results are shown in table 23 .

Table 23 Student advisors

\begin{tabular}{|c|c|c|c|c|c|}
\hline Expert \# & Advisor & \# students & Topic & Group SI & Group SD \\
\hline 1 & $\mathrm{~N}$ & 0 & 50 & $\mathrm{~B}$ & $\mathrm{~B}$ \\
\hline 2 & $\mathrm{Y}$ & 42 & 26 & $\mathrm{~B}$ & $\mathrm{C}$ \\
\hline 3 & $\mathrm{Y}$ & 24 & 79 & $\mathrm{~A}$ & $\mathrm{C}$ \\
\hline 4 & $\mathrm{Y}$ & 7 & 40 & $\mathrm{~B}$ & $\mathrm{~A}$ \\
\hline 5 & $\mathrm{~N}$ & 0 & 50 & $\mathrm{~B}$ & $\mathrm{C}$ \\
\hline 6 & $\mathrm{~N}$ & 0 & 80 & $\mathrm{~A}$ & $\mathrm{~B}$ \\
\hline 7 & $\mathrm{Y}$ & 7 & 50 & $\mathrm{~B}$ & $\mathrm{C}$ \\
\hline 8 & $\mathrm{Y}$ & 7 & 90 & $\mathrm{~A}$ & $\mathrm{C}$ \\
\hline 9 & $\mathrm{~N}$ & 0 & 75 & $\mathrm{~A}$ & $\mathrm{C}$ \\
\hline 10 & $\mathrm{Y}$ & 3 & 26 & $\mathrm{~B}$ & $\mathrm{C}$ \\
\hline 11 & $\mathrm{Y}$ & 36 & 80 & $\mathrm{~A}$ & $\mathrm{~B}$ \\
\hline 12 & $\mathrm{~N}$ & 0 & 50 & $\mathrm{~B}$ & $\mathrm{~A}$ \\
\hline 13 & $\mathrm{Y}$ & 3 & 80 & $\mathrm{~A}$ & $\mathrm{~B}$ \\
\hline
\end{tabular}

Every expert who leaned towards topics also valued projects higher. However, the reverse does not hold true. A center director who was identified in the most dissertation or theses publications judged attendance and not publications to contribute more towards the NSF IUCRC program's mission. 
Figure $30 \quad$ HAC: Student development outputs

\section{Cluster analysis for Student Development}

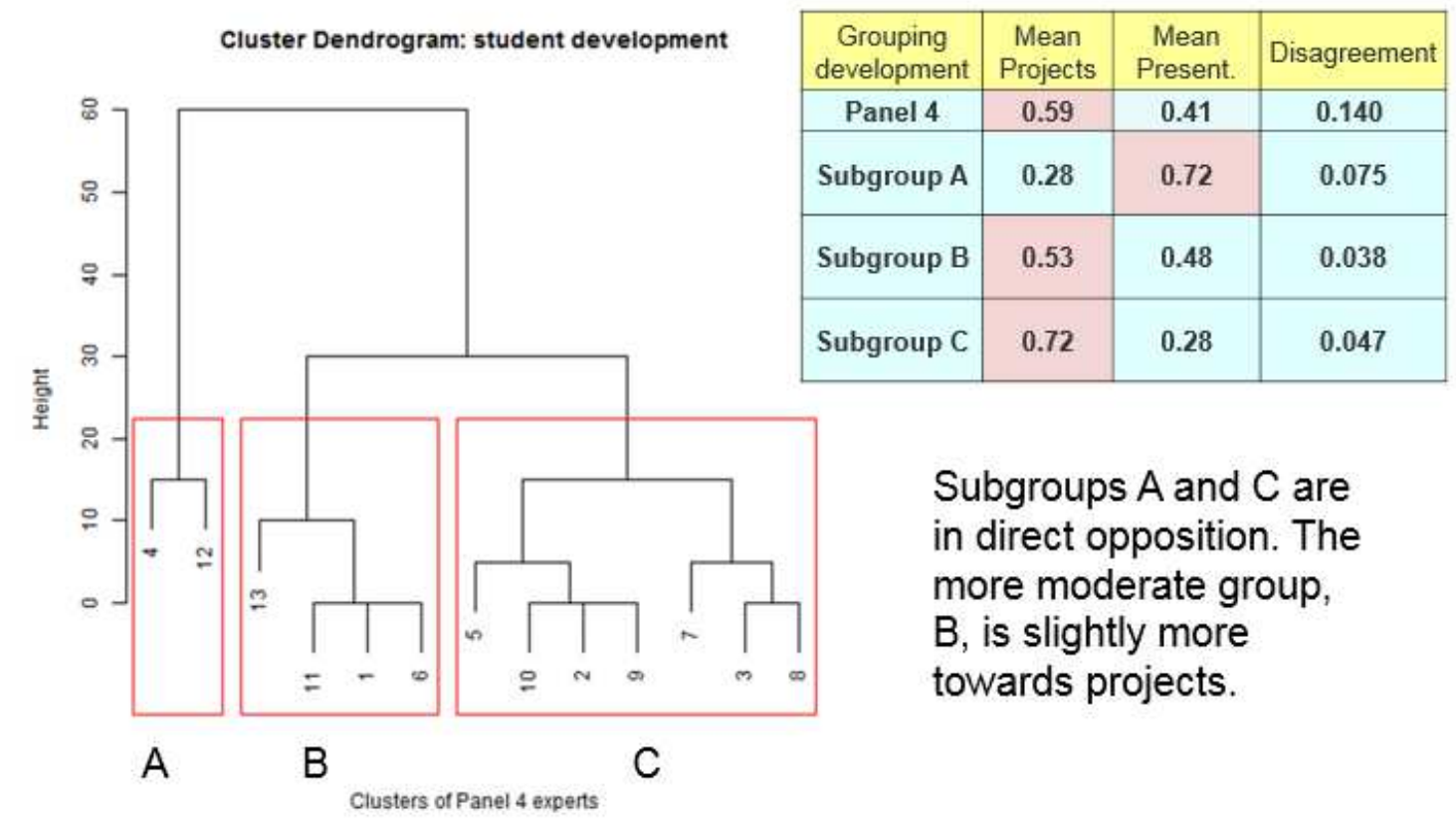

\subsection{Finalized HDM}

After the data was cleaned and cured, final weights were quantified for each of the elements. Figure 31 shows the finalized decision element weights on the generalizable model. 
Figure 31 Generalized HDM for IUCRC performance evaluation

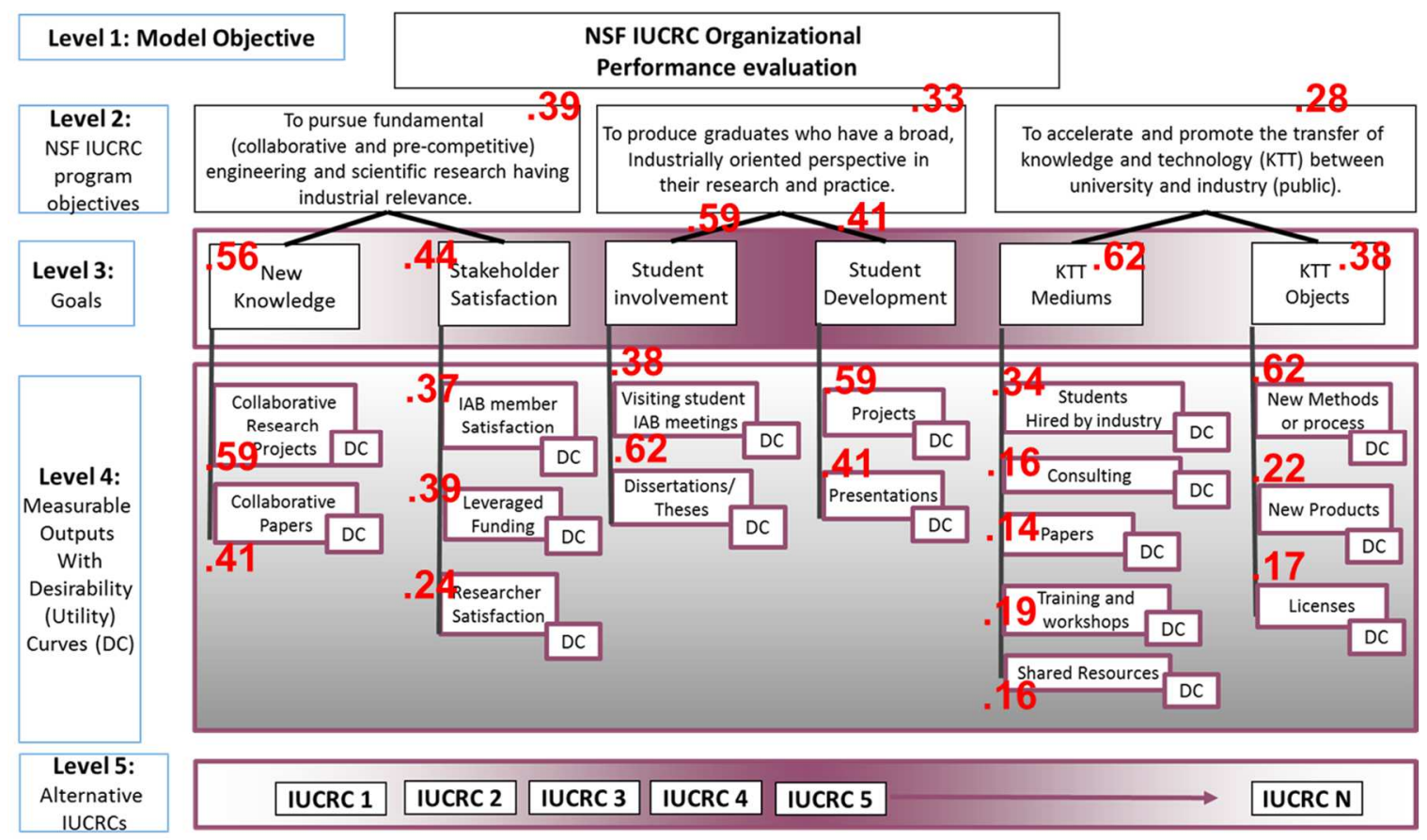

Note the low weighted values for papers and licenses relative to KTT media. These are two of the more popular indicators used to evaluate knowledge and technology transfer. These results support recent cautionary statements found in the literature about using traditional indicators [116][123]. One particularly insightful and extensive study conducted by Graham [141] found the "easy to measure" metrics such as licenses place an "over-riding focus on faculty-generated IP" (p 12). Furthermore, many experts believe this has negatively impacted "long-term strategic industry collaborations" (p 12). Further discussion is presented in Chapter 7. 


\section{CHAPTER 6: CASE STUDIES}

Case studies are developed to illustrate how the model works and to conduct criterion-related validation. Criterion-related validation enlists the help of an expert to evaluate the degree to which the model reflects actual performance. Data collected for six selected centers was used to populate the metrics, find respective desirability values and calculate scores for each of the alternative centers. Analysis of the results were presented to an expert. The discussion for this chapter is organized into four sections:

Section 1 Identifies the alternate IUCRCs selected as case studies. Background is provided to introduce each of the six IUCRCs used to test the performance of the model.

Section 2 illustrates how data was collected and used to calculate a performance evaluation score. Actual data collected for the WBC is provided in Appendix H.

Section 3 calculates and compares performance evaluation scores for each of the selected IUCRCs and analyzes the results. Strengths and suggested areas for improvement are presented. Scores are normalized after removing some of the metrics that did not have data for all of the centers.

Section 4 conducts one at a time (OAT) sensitivity analysis to explore the impact of expert disagreement on the results. 


\subsection{IUCRC Selection}

Of the 54 centers actively participating in the NSF IUCRC program since 2010, six (6) were selected as case studies. Currently, the NSF evaluation process uses postaction control to determine the success of completed outputs and outcomes. These reports help to justify the center research program to NSF, member firms, and other parts of the university. One output of the formal NSF IUCRC evaluation project is a yearly structural information (SI) report. The reports published in 2012-2015 contain most of the key data for the case studies [194].

Sixteen new centers were reported in the earliest report. Screening questions were developed to select appropriate centers for comparison. Ten centers were eliminated because they did not meet the criteria. Figure 32 provides a graphical representation showing how six (6) currently active IUCRC alternatives were selected. 
Figure 32 Identification and selection of IUCRC alternatives

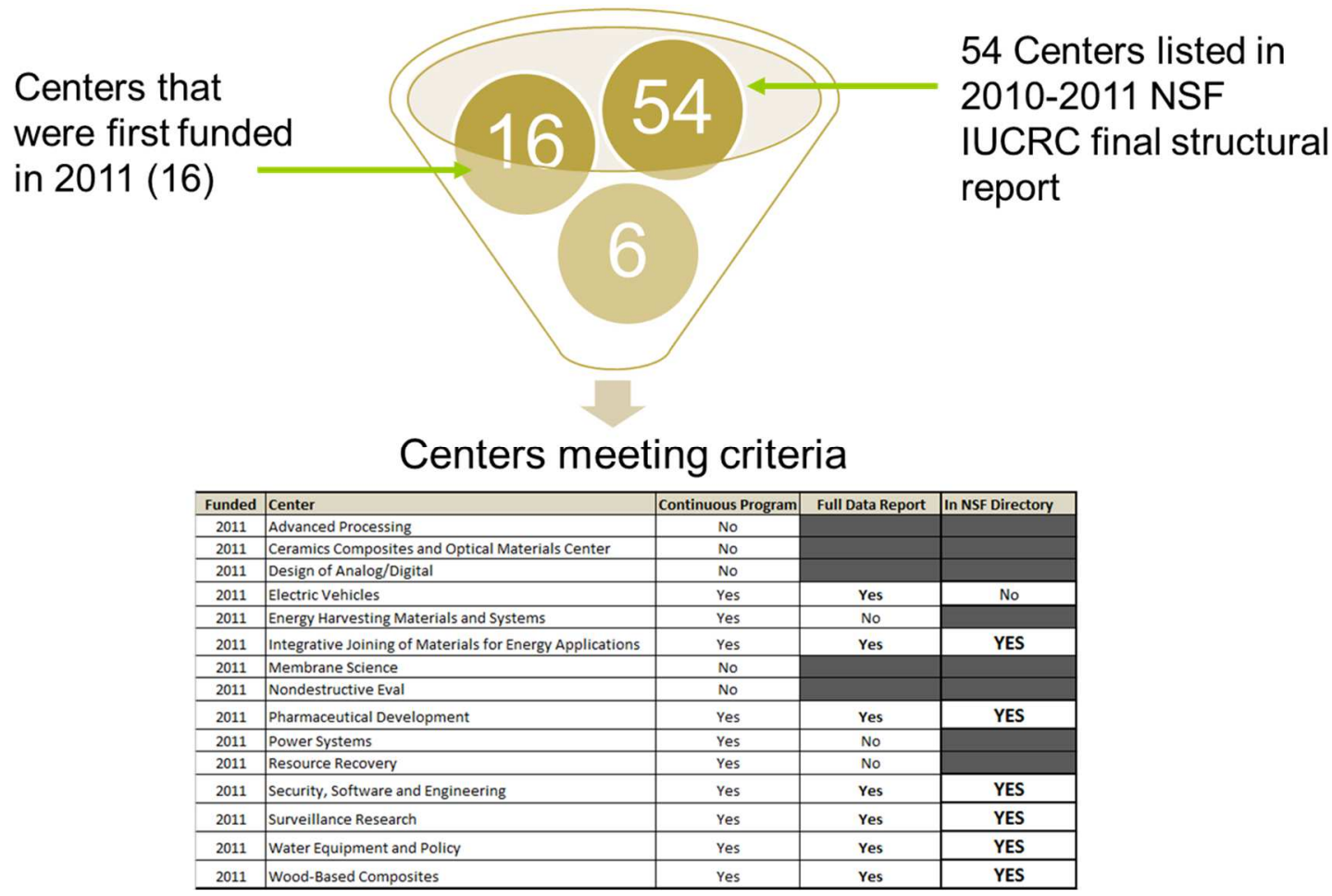

The following questions were used to select IUCRCs:

1) Was a proposal submitted for NSF IUCRC program funding in 2010 ?

2) Was the proposal recommended for receipt of a first round funding award?

3) Is there available data to populate the metrics?

4) Is the IUCRC currently listed in the online NSF IUCRC directory?

While sixteen centers were initially funded in 2011, some were re-formed having previously participated in the program. These centers were removed from the list. Table 24 introduces the IUCRCs that are used for illustration and criterion-related validation: Integrative Joining of Materials for Energy Applications (Ms2JIC), Center 
for Pharmaceutical Development (CPD), Security and Software Engineering Research Center (S²ERC), Center for Surveillance Research (CSR), Water Equipment Policy (WEP) and Wood-Based Composites (WBC) centers.

Table $24 \quad$ IUCRC alternatives

\begin{tabular}{|c|c|c|c|l|}
\hline Center & Domain & NSF Funded 2011 \# Sites & Partner Site Locations \\
\hline Ma2JIC & Energy and Environment & $\$ 291,000$ & 4 & $\begin{array}{l}\text { Ohio State, Univ of Wisconsin, } \\
\text { Leghigh, Colo School of Mines }\end{array}$ \\
\hline CPD & Health and Safety & $\$ 135,000$ & 2 & Georgia IT, U of Kentucky \\
\hline S2ERC & $\begin{array}{c}\text { Information, Communication, } \\
\text { Computing }\end{array}$ & $\$ 191,000$ & 2 & Ball State, lowa State \\
CSR & $\begin{array}{c}\text { Information, Communication, } \\
\text { Computing }\end{array}$ & $\$ 142,982$ & 2 & Ohio State, Wright State U \\
\hline WEP & Energy and Environment & $\$ 151,000$ & 2 & U of Wisconsin, Marquette U \\
\hline WBC & Advanced Materials & $\$ 135,000$ & 2 & Virginia Tech, Oregon State U \\
\hline
\end{tabular}

NSF IUCRC 2010-2011 Structural Information, Final report.

Upon formation, IUCRCs are classified into one of nine technology domains: 1) Advanced Electronics, 2) Advanced Manufacturing, 3) Biotechnology, 4) Advanced Materials, 5) Civil Infrastructure Systems, 6) Energy \& Environment, 7) Health \& Safety, 8) System Design \& Simulation and 9) Information Communication \& Computing. Centers respond to NSF requests for proposals (RFPs). The mean award amount for these six centers was just under $\$ 175,000$ which is a typical seed funding amount. The grand mean for all centers supported in fiscal year 2010-2011 was $\$ 220,653$ [195]. This amount is small because centers are required to have a minimal amount of industrial endorsement to be accepted into the program. According to the 
report, 4 of the 6 centers were successful in collecting membership dues meeting the formation threshold of $\$ 300,000$.

In the next 6 sections, each center is introduced in a one-page summary. Figures 33 - 38, identify the missions and show descriptive statistics including the number of: industry member companies, funded NSF IUCRC university partners, research faculty from the partner universities, students and other participating universities for each of the respective centers: Ma²JIC, CPD, S2ERC, CSR, WEP and WBC. Supporting data for each of the case profiles are included in Appendix H. Appendix H-1 shows how the centers were selected and Appendix H-2 provides the details behind the aggregated center resource statistics. 


\subsubsection{Integrative Joining of Materials for Energy Applications}

The Integrative Joining of Materials for Energy Applications (Ma²JIC), also known as the Manufacturing and Materials Joining Innovation Center is a collaborative research center with four partner universities: Ohio State University, Lehigh University, Colorado School of Mines and the University of Tennessee. At some point since the acceptance of the center's proposal in September, 2010 the University of Wisconsin was replaced by the University of Tennessee. It is the only center in the group that was originally formed with more than 2 university partners. The center is led by Director Londono at Ohio State University and co-directors from each of the partner sites.

Figure 33 Manufacturing \& Materials Joining Innovation Center (Ma² JIC)

$\mathrm{Ma}^{2} \mathrm{JIC}$ Jolning Innovation Cente Joining Innovation Cente

\section{Manufacturing \& Materials Joining} Innovation Center

Their mission is to advance the science and technology of advanced manufacturing as it applies to materials joining.

31 Industry Member Companies

11 Research Faculty

26 Student Participants (2013-2014 structural report)

4 University Partners (1 replaced)

https://ma2jic.osu.edu/
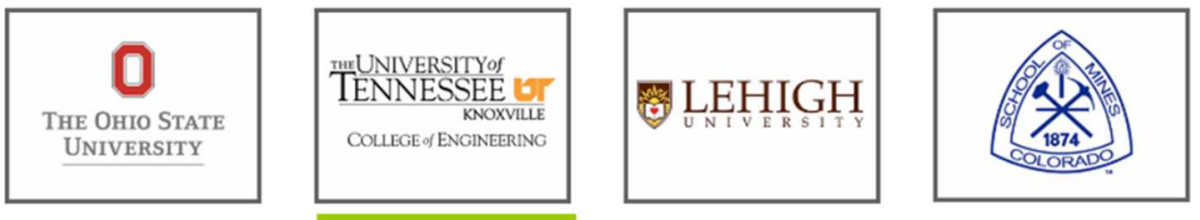


\subsubsection{Center for Pharmaceutical Development}

The Center for Pharmaceutical Development (CPD) is a collaborative research center with two partner universities: Georgia Institute of Technology (lead) and the University of Kentucky. The center is led by Director Bommarius at Georgia Institute of Technology with Co-director Munson at the University of Kentucky and Vice-Chair of the IAB Smith who is affiliated with Allergan. Note that while 2 university partners show on the official NSF IUCRC website, 3 other university sites participate in conducting the collaborative research projects: Emory University, University of Kansas and Duquesne University.

\section{Figure 34 Center for Pharmaceutical Development}

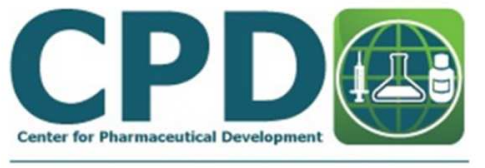

\section{Center for Pharmaceutical Development}

Their mission is to create more selective and robust biological and chemical catalysts, to develop methods for stabilizing drugs and vaccines, and to design new techniques for nondestructive evaluations of pharmaceutical products.

5 Industry Member Companies

17 Research Faculty

14 Student Participants (2013-2014 structural report)

2 University Partners

3 other participating universities http://cpd.gatech.edu/

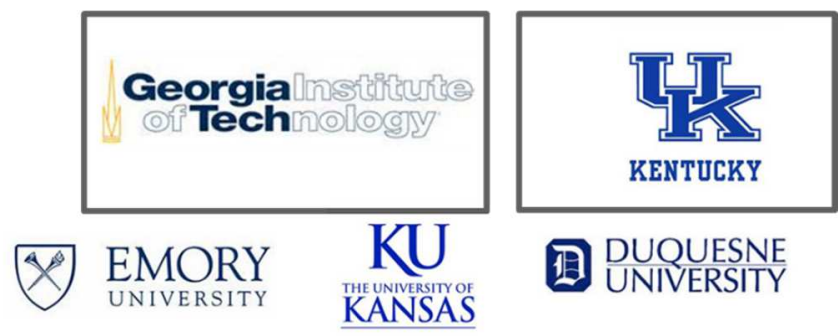




\subsubsection{Security and Software Engineering Research Center}

The Security and Software Engineering Research Center (S²ER) is a collaborative research center with three partner universities and nine other university partners. Director Zage at Ball State University receives support from Managing Director Stineburg, Site Directors Burger and Clancy and coordinators from each of the sites. This center has the greatest number of resources and student participation of the six case studies.

Figure 35 Security and Software Engineering Research Center

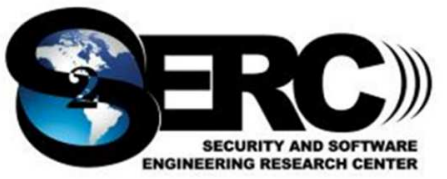

\section{Security and Software Engineering Research Center (S²ERC)}

Their mission is to conduct a program of applied and basic research on cybersecurity, software security, system security and software engineering problems to enable technology gains in member organizations.

28 Industry Member Companies

9 Research Faculty

28 Student Participants (2013-2014 structural report)

3 University Partners

9 Other Participating Universities

http://serc.net/
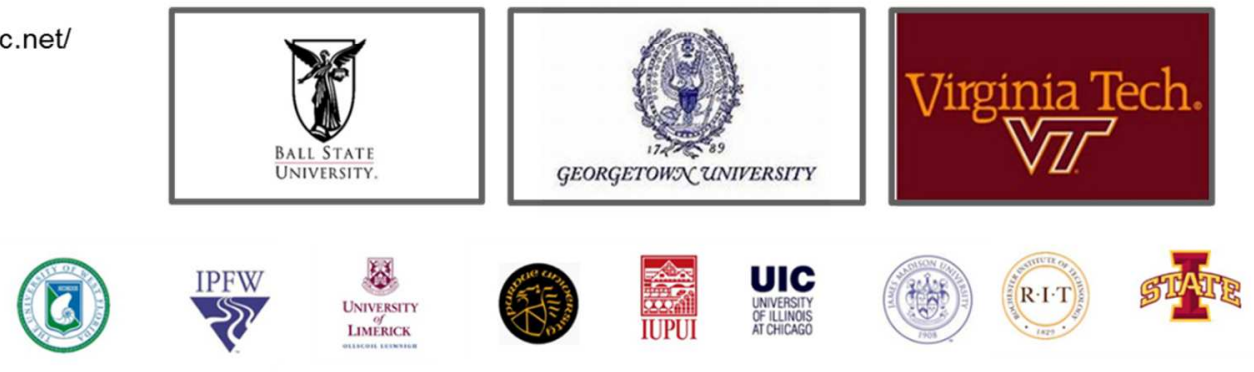


\subsubsection{Center for Surveillance Research}

The Center for Surveillance Research (CSR) is a collaborative research center with two partner universities: Ohio State University (lead) and Wright University with participation from 2 other university research sites. This well-funded center has the fewest number of industrial companies. IAB members include the US Airforce research lab and the US Army research lab.

Figure 36 Center for Surveillance Research

\section{G. Center For SuRVELLANCE}

Their mission is to advance the body-of-knowledge for modern surveillance systems. The inherent multidisciplinary nature of surveillance systems means that the Center includes researchers from a broad spectrum of expertise, including, sensor phenomenology, signal and image processing, machine learning, sensor technology (e.g., radar, acoustic, chemical/biological, etc.), and human factors.

6 Industry Member Companies

16 Research Faculty

11 Student Participants (2013-2014 structural report)

2 University Partners

2 Other participating universities

https://csr.osu.edu/

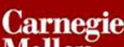

Mellon

University

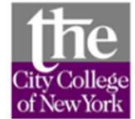

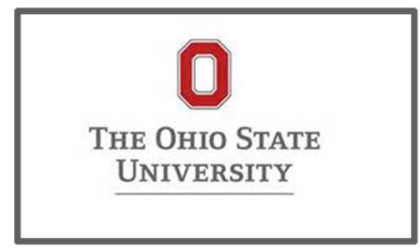

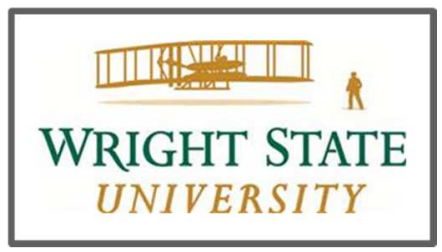




\subsubsection{Water Equipment \& Policy Research Center}

The Water Equipment and Policy Center (WEP) is strategically located with its primary site at the University of Wisconson-Milwaukee adjacent to Lake Michigan. partner site, at Marquette University is also situated in the Great Lakes Region. Of the six case studies, this center received the greatest federal $(\$ 600,671)$ and state funding $(\$ 300,000)$ contributions. This center acts as a catalyst for synthesizing the region's assets towards water related research.

Figure 37 Water Equipment and Policy Research Center

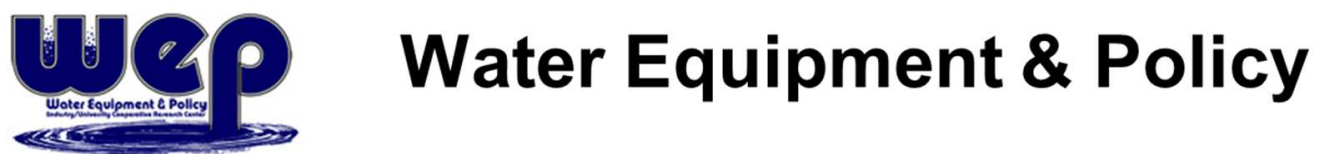

Their research focuses on creating new sensors and devices, novel materials, innovative systems, and water policies that will help change the way the world manages its acutely stressed water resources.

15 Industry Member Companies

19 Research Faculty

17 Student Participants (2013-2014 structural report)

2 University Partners

http://www4.uwm.edu/
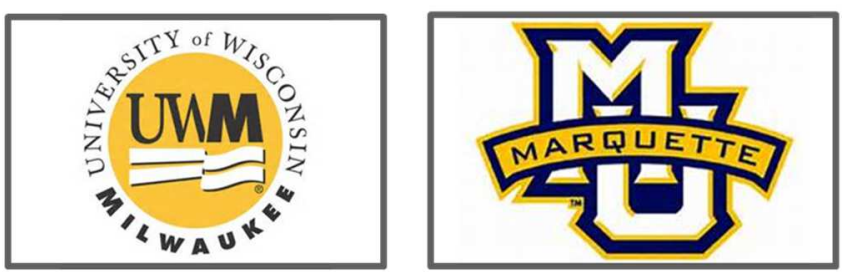


\subsubsection{Wood-Based Composites Center}

The mission of the Wood-Based Composites Center (WBC) is to advance the science and technology of wood-based composite materials. While the center was formed with only 2 partner universities, it has grown to informally include four more. Of the six centers, the WBC has the most data transparency about students. On their website (wbc.vt.edu) the center discusses goals that include attracting students to careers in the wood-based composites and adhesion industries by providing "intellectual exchange and interaction among professionals and students."

Figure 38 Wood-Based Composites Center

\section{WR: Wood-Based Composites Center}

Their mission is to advance the science and technology of wood-based composite materials.

15 Industry Member Companies

10 Research Faculty

23 Student Participants (2013-2014 structural report)

2 University Partners

4 Other Participating Universities

wbc.vt.edu
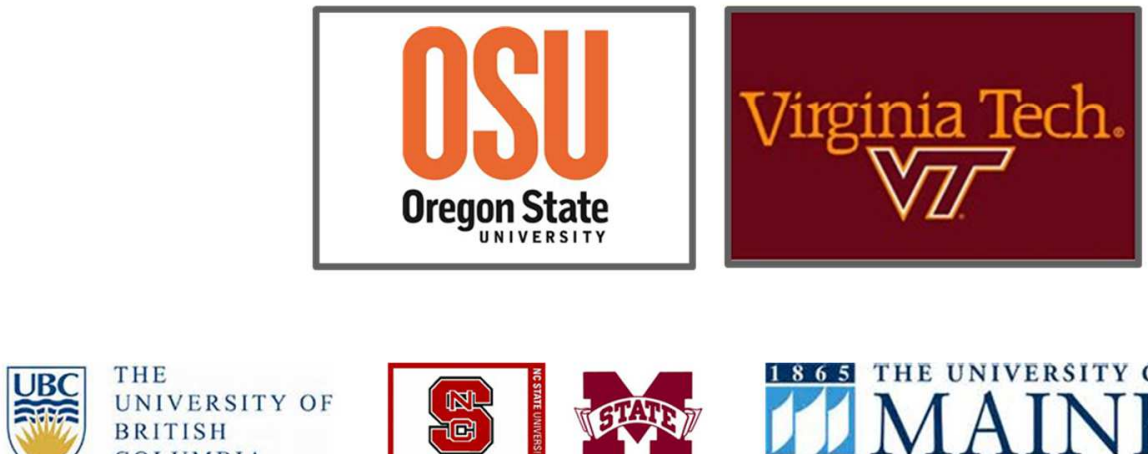

BRITISH

COLUMBIA

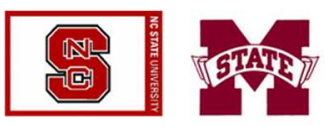

MANN 


\subsection{Illustration case: WBC}

The Wood-Based Composites (WBC) center is used to illustrate how secondary data are collected and metrics are populated and used to calculate a score. The WBC was selected as the case to illustrate the method because they were the only center where all data was available. The data collection approach proposed using five secondary data sources: center websites, NSF IUCRC structural information reports, center minutes, the NSF Compendium of Breakthrough Technologies and the ProQuest Database for theses and dissertations. Minutes were not available. Attendance records were collected for two of the centers by contacting the center evaluators.

Appendix H-1 identifies the secondary sources proposed to collect data for population of the metrics. Each IUCRC is contractually required to maintain a website. Information about collaborative projects and background information on researchers and configurations of projects was obtained from specific IUCRC websites. The structural information reports from 2010 - 2014 were used for most of the descriptive statistics. Data regarding attendance was collected from NSF evaluators for two of the centers. The other requests for information received either no response or re-direction. The Compendium of Breakthrough Technologies provided data regarding new methods and processes.

The ProQuest database was searched to identify theses and dissertations published by students with advisors affiliated with IUCRC research projects. A 
content analysis was conducted on the abstract and acknowledgement section of each identified student thesis or dissertation to ascertain if the research topic was aligned with an IAB research topic.

Obtaining the minutes was somewhat challenging because these documents are not publicly available. Some contain confidential information and are they not required to be submitted to the formal NSF evaluation project. Specific industry information may be confidential for many centers. For example, a project scoring sheet that shares monetary values could be confidential for some centers (Appendix $H-4)$.

Data required to evaluate the first criterion requires a list of research projects and the research team configurations. For this example, current data are used because the NSF provides aggregated data that was difficult to correlate with the center website. Appendix H-5 lists current and past WBC research projects, shows how they are configured and which projects are recorded with a binary "yes/no" value. If the research in the center was being conducted by a researcher in another participating university the value was marked yes. One-third of the projects are being conducted with researchers beyond a single funded NSF partner site. Of the fifteen research projects only one is includes researchers from both Oregon State University and Virginia Tech, the two NSF funded partner sites. 
There were no changes required from the proposed data collection approach to populate metrics for the next four criteria. The values were calculated using data available on the NSF IUCRC evaluation project website.

Attendance by research faculty and students at the bi-annual IAB meetings was difficult to obtain because the minutes of the meetings were not available. The site website was mined to disaggregate the NSF reported data as shown in Table 25. Approximately fifteen industry members, fourteen scientific research faculty and fifteen student researchers participate in the semiannual (biannual) IAB meetings. Ten of the faculty are affiliated with the partner university sites and four are affiliated with the other four participating universities.

Table $25 \quad$ WBC description (wbc.vt.edu)

\begin{tabular}{|l|l|l|l|}
\hline University Partners & Industry Members* & Faculty Role & Contact \\
\hline Oregon State Univ. & Arauco North America & Director & C. Frazier \\
University of British Columbia & Arclin & Co-Director & F. Kamke \\
*University of Maine & Ashland & Managing & \\
*Mississippi State Univ. & Boise Cascade & Director & L. Caudill \\
North Carolina State Univ. & Columbia Forest Products & Researcher & R. Lemaster \\
Virginia Tech & Fraunhofer WKI Institute & Researcher & L. Zhenglun \\
& Georgia-Pacific Chemical & Researcher & L. Muszynski \\
& Henkel Corporation & Researcher & J. Nairn \\
& Hexion & Researcher & L Schimleck \\
& LP Building Products & Researcher & J Simonsen \\
& Oxiquim & Researcher & A Sinha \\
& Queensland (Australia) Gov. & Researcher & G. Smith \\
& Solenis & Researcher & R. Smith \\
& States Industries & Researcher & G. Velarde \\
& Willamette Valley Co & Researcher & A. Zink-Sharp \\
\hline
\end{tabular}

*Currently listed on the WBC website (wbc.vt.edu, 2016) 
Several NSF evaluators responded to specific questions about attendance numbers. Therefore, the data for the WBC was obtained from evaluator reported statistics for metrics related to criteria 6, 8 and 12 (Appendix H-5).

Percent of topics measures student involvement. This information is not reported by the NSF. Therefore, the ProQuest dissertation/theses database was mined for research faculty funded by the WBC acting as advisors. Appendix H-6 lists student dissertations and theses by advisor. Only two of the documents were found within the funding years of the center. Each acknowledgment section was reviewed and both topics and student authors were compared against present and past research project configurations. Neither student acknowledged the WBC and neither student was listed as a researchers associated with any IAB research project resulting in a value of zero.

\subsubsection{Data populated metrics}

The metric $(m)$ for each of seventeen output criteria $\left(c_{j}\right)$ relative to a parent goal $\left(g_{k}\right)$ is populated with data calculating a score for the WBC. Thus, the metric for the $1^{\text {st }}$ criterion under the $1^{\text {st }}$ goal with respect to the $1^{\text {st }}$ objective can be represented as $\left(m_{W B C}, c_{1,1}\right)$.

The metric for collaborative papers is used to illustrate how the data from the NSF database can be collected to obtain an actual value. Equation 8 uses data collected from the last three available NSF Structural Information (SI) reports to calculate the 
value for the 3 year average percent of collaborative papers. In this case no collaborative papers were reported being published over the 3 year period.

Equation 7 Collaborative papers

$$
\text { collaborative papers }=\frac{(0+0+0)}{3} * 100 \%
$$

A second example is shown by calculating the percent of IAB members renewing their membership. Equation 9 shows how the number of members who renew is calculated using the NSF SI data.

\section{Equation 8 IAB member renewal}

$$
I A B \text { member renewal }=(\# \text { members starting }-\# \text { of members left })
$$

Equation 9 uses this formula to calculate a metric value for IAB member satisfaction using the percent of members who renew.

\section{Equation 9 Percent member renewal}

$$
\begin{gathered}
\% \text { member renewal }=(\# \text { IAB member renew }) /(\# \text { starting }) \\
(m, \% \text { member renewal })=\frac{\left[\left(\frac{8}{8}\right)+\left(\frac{8}{9}\right)+\left(\frac{9}{11}\right)\right]}{3} * 100=90.2 \%
\end{gathered}
$$

The results of the data collection for each metric, $(m, j k)$, are presented in Table 26. The metric and its relative $j$ th criterion are identified in the first two columns followed by the resulting value obtained from the listed data source. 


\begin{tabular}{|c|c|c|c|c|}
\hline$j$ & Metric & Value & Data Source & Approach used \\
\hline 1 & $\begin{array}{l}\text { \% collaborative } \\
\text { projects }\end{array}$ & .33 & $\begin{array}{l}\text { Center website } \\
\text { wbc.vt.edu }\end{array}$ & $\begin{array}{l}\text { Current number of collaborative } \\
\text { project configurations/Total number } \\
\text { of projects listed }\end{array}$ \\
\hline 2 & $\begin{array}{l}\text { \# of collaborative } \\
\text { papers }\end{array}$ & 0 & $\begin{array}{l}\text { NSF } \\
\text { www.ncsu.edu/ } \\
\text { iucrc/ }\end{array}$ & $\begin{array}{l}\text { Average number of collaborative } \\
\text { papers published as recorded } / 3 \\
\text { years }\end{array}$ \\
\hline 3 & $\begin{array}{l}\text { \% IAB member } \\
\text { renewal }\end{array}$ & .90 & NSF & $\begin{array}{l}\text { Calculated } 3 \text { year average using } \\
\text { (members renewed)/ } \\
\text { members starting }\end{array}$ \\
\hline 4 & $\begin{array}{l}\text { Leverage funding } \\
\text { ratio }\end{array}$ & 3.83 & NSF & $\begin{array}{l}\text { Calculated } 3 \text { year average using total } \\
\text { funding/NSF IUCRC funding }\end{array}$ \\
\hline 5 & $\begin{array}{l}\text { \% research faculty } \\
\text { (RF) change }\end{array}$ & 1.11 & NSF & $\begin{array}{l}3 \text { year average change for Current } \\
\text { number RF/past year number RF }\end{array}$ \\
\hline 6 & $\begin{array}{l}\% \text { student meeting } \\
\text { attendance }\end{array}$ & .33 & $\begin{array}{l}\text { NSF IUCRC } \\
\text { evaluator }\end{array}$ & $\begin{array}{l}\text { Averaged for } 2 \text { IAB meetings (\# non- } \\
\text { site students/\# total non-site } \\
\text { students) }\end{array}$ \\
\hline 7 & \% students topics & 0 & $\begin{array}{l}\text { ProQuest } \\
\text { database }\end{array}$ & $\begin{array}{l}3 \text { year average (\# dissertations or } \\
\text { theses published/\# students) }\end{array}$ \\
\hline 8 & $\begin{array}{l}\text { Student } \\
\text { supervision ratio }\end{array}$ & 1.2 & NSF & $\begin{array}{l}\text { Calculated } 3 \text { year average } \\
\text { students/RF }\end{array}$ \\
\hline 9 & $\begin{array}{l}\% \text { Students } \\
\text { presented }\end{array}$ & 0.14 & $\begin{array}{l}\text { NSF IUCRC } \\
\text { evaluator }\end{array}$ & $\begin{array}{l}\text { \# students who presented/\# } \\
\text { students }\end{array}$ \\
\hline 10 & \# Students hired & 2 & NSF & 3 year average students hired \\
\hline 11 & \% RF contracts & 0.07 & NSF & $\begin{array}{l}3 \text { year average RF contracts using in- } \\
\text { kind personnel support }\end{array}$ \\
\hline 12 & $\begin{array}{l}\text { \# Papers } \\
\text { published }\end{array}$ & 0.63 & NSF & $\begin{array}{l}3 \text { year average papers } \\
\text { published/researcher }\end{array}$ \\
\hline 13 & $\begin{array}{l}\% \mathrm{RF} \text { meeting } \\
\text { attendance }\end{array}$ & 8.87 & $\begin{array}{l}\text { NSF IUCRC } \\
\text { evaluator }\end{array}$ & $\begin{array}{l}2 \mathrm{mtg} \text {. average: \# RF attending IAB } \\
\text { meeting/\# total RF }\end{array}$ \\
\hline 14 & $\begin{array}{l}\text { Shared resources } \\
\text { available }\end{array}$ & Both & NSF & $\begin{array}{l}\text { Binary “yes/no" availability of } \\
\text { facilities or equipment }\end{array}$ \\
\hline 15 & $\begin{array}{l}\text { \# New Methods or } \\
\text { Processes }\end{array}$ & 1 & $\begin{array}{l}\text { NSF } \\
\text { Compendium }\end{array}$ & $\begin{array}{l}\text { \# reported in recent past } \\
\text { Compendium }\end{array}$ \\
\hline 16 & \# New Products & 0 & $\begin{array}{l}\text { NSF } \\
\text { Compendium }\end{array}$ & $\begin{array}{l}\text { \# reported in recent past } \\
\text { Compendium }\end{array}$ \\
\hline 17 & \# New Licenses & 0 & NSF evaluator & $\begin{array}{l}\text { Calculated proxy: Dependent value } \\
\text { based upon new products }\end{array}$ \\
\hline
\end{tabular}

In several cases the data collection approach used was different from what had been

proposed (Appendix H-3) because the data was not available in the NSF IUCRC database and had to be obtained elsewhere. 


\subsubsection{Desirability values}

The value of each metric $(m, j k)$ is standardized using a desirability function. The illustration for the percent of IAB member renewal is continued to show how a desirability curve can be used to standardize a value $\mathrm{d}(m, j k)$, for each respective decision criteria.

The desirability function developed using expert data (Appendix E) for membership renewal shows that experts find it is desirable to have about $85 \%$ of the members renew. Figure 39 shows how the calculated value of a $90 \%$ renewal rate is very close to a value $100 \%$ desired by the experts. In fact, it is closer to $100 \%$ than if every member had renewed. Experts expect some turn-over because some smaller companies are sponsored by the SBIR program. While it may be concerning when larger long-term IAB members do not renew, turn-over of smaller SBIR sponsored organizations is desired.

Figure $39 \mathrm{WBC}$ value for \% membership renewal results

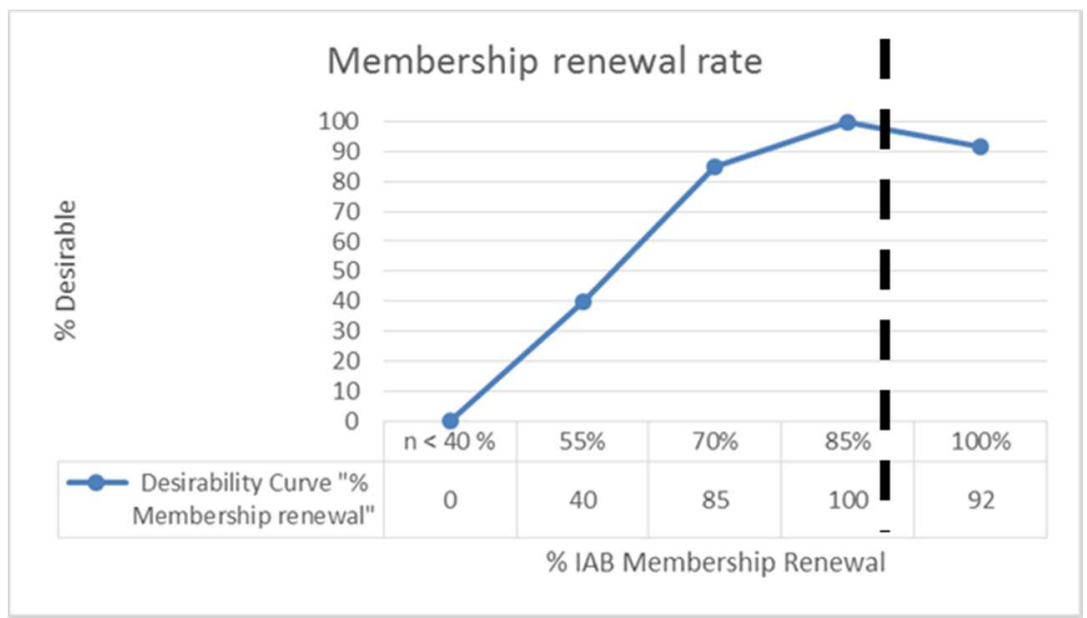


Using the table data to calculate the value represented on the desirability curve is shown in the following equation.

Equation 10 Desirability value for membership renewal

$\frac{92-100}{100-85}=\frac{x}{90}, \quad x=-4.8$
$92 \%-(-4.8 \%)=96.8 \%$

Therefore, the desirability value for WBC's metric for measuring membership satisfaction (c3) relative to the goal of stakeholder satisfaction (g2) is recorded as $\mathrm{d}\left(\operatorname{mwBC}_{w}, c_{3,2}\right)=.97$. Table 27 shows the results for each of the decision criteria desirability values. 
Table 27 WBC Metrics and desirability values

\begin{tabular}{|l|c|c|}
\hline Output decision element & Metric Value $(\boldsymbol{m}, \boldsymbol{j} \boldsymbol{k})$ & $\begin{array}{c}\text { Desirability curve value } \\
d(m, j k)\end{array}$ \\
\hline Collaborative Projects & 0.33 & 0.28 \\
\hline Collaborative Papers & 0.00 & 0.00 \\
\hline IAB Member Satisfaction & 0.90 & 0.97 \\
\hline Leveraged Funding & 3.83 & 0.70 \\
\hline Researcher Satisfaction & 1.11 & 1.00 \\
\hline Student Mtg. Attendance & 0.52 & 0.73 \\
\hline Student Research Topic & 0.00 & 0.03 \\
\hline Student Research Project & 1.20 & 0.75 \\
\hline Student Presentations & 0.14 & 0.25 \\
\hline Student Hires & 2.00 & 1.00 \\
\hline Consulting & 0.07 & 0.37 \\
\hline Papers Published & 0.63 & 0.80 \\
\hline Training and Workshops & 0.69 & 0.75 \\
\hline Shared Resources & Both & 1.00 \\
\hline New Methods or Processes & 1.00 & 1.00 \\
\hline New Products & 0.00 & 0.50 \\
\hline Licenses & 0.00 & 0.50 \\
\hline
\end{tabular}

\subsubsection{Calculating performance evaluation}

A final score can be calculated by summing the product of the values found for each $d(m, j k)$ and the decision element's $\left(C_{j k}^{k}\right)$ weight $\left(w_{j}\right)$. 
Equation 11 shows the expression used to calculate the sum the products of the two vectors.

Equation 11 Performance evaluation score

$$
\sum_{j=1}^{17}\left[w_{j} * d(m, j k)\right]
$$

Table 28 reflects the results of applying the expression identified in equation 11.

Table 28 Calculated Performance Evaluation Score

\begin{tabular}{|l|c|r|r|}
\hline Output Contribution & Weights & \multicolumn{1}{l|}{$d(m, j k)$} & \multicolumn{1}{|c|}{ Product } \\
\hline C. Research Projects & 0.14 & 0.28 & 0.039 \\
\hline C. Research Papers & 0.08 & 0.00 & 0.000 \\
\hline IAB Member Sat & 0.06 & 0.97 & 0.058 \\
\hline Leveraged Funding & 0.07 & 0.70 & 0.049 \\
\hline Researcher Sat. & 0.04 & 1.00 & 0.040 \\
\hline Visiting Students & 0.07 & 0.73 & 0.051 \\
\hline Student Topics & 0.12 & 0.03 & 0.004 \\
\hline Student Projects & 0.08 & 0.75 & 0.060 \\
\hline Student Presentations & 0.05 & 0.25 & 0.012 \\
\hline Student Hires & 0.06 & 1.00 & 0.060 \\
\hline Consulting & 0.03 & 0.37 & 0.011 \\
\hline Papers & 0.02 & 0.80 & 0.016 \\
\hline Training and Workshops & 0.04 & 0.75 & 0.030 \\
\hline Shared Resources & 0.03 & 1.00 & 0.030 \\
\hline New Methods/Proc. & 0.07 & 1.00 & 0.070 \\
\hline New Products & 0.02 & 0.50 & 0.010 \\
\hline Licenses & 0.02 & 0.50 & 0.010 \\
\hline Sum of the Product & & & 0.550 \\
\hline
\end{tabular}


The shaded values represent the higher weighted decision elements. While this model has seventeen decision criteria notice how the top 2 account for $25 \%$ of the performance contribution. This means the decision criteria are not linearly related and that the method is able to separate more important elements from the ones that contribute towards the organizational performance to a lesser degree.

The data for this center shows there were no theses or dissertations published by students using topics from the IAB center during the last 3 years of the center's operation (Appendix H-6). Therefore, the corresponding desirability value was .03. Encouraging just 1 student to select an IUCRC topic as the topic for their Phd dissertation research or Master's Thesis would reflect a desired value of .42 resulting in an additive score of 0.05 instead of the current value of 0.004 .

On the other hand, increased emphasis, expenditure in time and resources on improving licensing would only improve the score by $1 \%$. 


\subsection{IUCRC Comparative Analysis}

Comparing performance of centers is somewhat of a challenge because they operate in different technology domains under different partnership structures with different stakeholders. Therefore, the criterion-related scores can only be estimates that must be validated by an expert. Minutes that were originally identified in the data collection approach to populate four (4) of the metrics (visiting student attendance, student presentations, training and workshops and licenses) were not obtained.

For consistency, these metrics were removed. The performance effectiveness values for the six selected IUCRCs were then calculated by summing the product of each of the 13 output metrics and desirability curve values. The removed values required normalization of the scores for an easier comparison.

The top contributing outputs, highlighted in Table 29 show how straightforward it is to identify areas of strength and those needing improvement. For example, while experts judged the highest contributing output to be collaborative projects, none of the centers are achieving the experts' desired value of having $80 \%$ of the research projects configured as multi-site or multi-disciplined science teams. The data suggests that each center should provide more focus on collaborative research projects.

While all centers have research projects that are sponsored by an IAB member, most of the project teams are not configured to include multi-partner, multiorganization or multi-disciplined researchers. Experts explicitly defined 
collaborative research as extending beyond industry sponsorship of 1 or 2 researchers and students affiliated with a single university department. However, research shows that "the simplest configuration for an IUCRC project team - one faculty scientist working with one or two graduate students from the same academic discipline - has been the most common" [[132] p 3].

Table 29 IUCRC performance evaluation scores

\begin{tabular}{|l|c|c|c|c|c|c|c|}
\hline Output Contribution & Weights & Ma2IC & CPD & S $^{2}$ ERC & CSR & WEP & WBC \\
\hline C. Research Projects & 0.14 & 0.03 & 0.00 & 0.00 & 0.00 & 0.00 & 0.05 \\
\hline C. Research Papers & 0.08 & 0.02 & 0.00 & 0.02 & 0.00 & 0.06 & 0.00 \\
\hline IAB Member Sat & 0.06 & 0.06 & 0.06 & 0.06 & 0.06 & 0.06 & 0.06 \\
\hline Leveraged Funding & 0.07 & 0.07 & 0.05 & 0.05 & 0.07 & 0.05 & 0.05 \\
\hline Researcher Sat. & 0.04 & 0.04 & 0.04 & 0.04 & 0.04 & 0.04 & 0.04 \\
\hline Student Topics & 0.12 & 0.12 & 0.05 & 0.08 & 0.00 & 0.00 & 0.00 \\
\hline Student Projects & 0.08 & 0.07 & 0.07 & 0.04 & 0.06 & 0.06 & 0.06 \\
\hline Student Hires & 0.06 & 0.03 & 0.06 & 0.06 & 0.03 & 0.03 & 0.06 \\
\hline Consulting & 0.03 & 0.03 & 0.03 & 0.02 & 0.02 & 0.02 & 0.01 \\
\hline Papers & 0.02 & 0.01 & 0.01 & 0.01 & 0.01 & 0.00 & 0.02 \\
\hline Shared Resources & 0.03 & 0.00 & 0.00 & 0.00 & 0.00 & 0.00 & 0.00 \\
\hline New Methods/Proc. & 0.07 & 0.00 & 0.00 & 0.00 & 0.00 & 0.00 & 0.00 \\
\hline Shared Resources & 0.03 & 0.03 & 0.01 & 0.02 & 0.01 & 0.01 & 0.03 \\
\hline New Methods/Proc. & 0.07 & 0.04 & 0.07 & 0.07 & 0.07 & 0.04 & 0.07 \\
\hline New Products & 0.02 & 0.01 & 0.01 & 0.01 & 0.01 & 0.01 & 0.01 \\
\hline & 0.82 & 0.56 & 0.46 & 0.47 & 0.37 & 0.38 & 0.45 \\
\cline { 2 - 8 } & 1 & 0.68 & 0.56 & 0.57 & 0.46 & 0.46 & 0.55 \\
\hline Standardized Data & & & & & & & \\
\hline
\end{tabular}

The scores are not intended to identify a top "winner" and a "loser". Rather, they are a means to provide transparency in metrics and decisions about where to focus resources or identify areas for improvement. For example, all centers in the top half earned higher performance scores towards developing students. All of the top 3 
scoring centers had students who published dissertations or theses with IAB research as their topics and research faculty as their advisors and that none of the centers scoring in the bottom half produced these any of these outputs.

The CSR, WEP and WBC could each achieve a 5\% improvement by encouraging just one student to select IAB research as their dissertation or thesis topic. Most of these types of output are attributed to just one or two researching professors who advise the bulk of the students in any particular IUCRC. This information could be helpful to a Center Director or Dean when looking to hire the next research faculty. Not all professors have the same demonstrated skill to mentor graduate students.

The results indicate that the Ma2IC (0.63) is leading in performance. A key contributing output is the number of students engaged in IUCRC research projects. Research project data collected from center websites is recorded in appendix H-8. Appendix H-9 shows the results from a content analysis of the Compendium of Breakthrough technologies to summarize data used to count new methods and new products. The rest of the data used to populate the metrics can be found in the NSF IUCRC database. Analysis starts by first examining the outputs that contribute the highest degree towards the IUCRC program's mission. Analysis of the outputs can lead to recommendations for improvement or a shift in focus. Table 30 summarizes the highest contributors to the center's performance and indicates areas for improvement. 
Table $30 \quad$ Output analysis summary

\begin{tabular}{|l|l|l|l|}
\hline Rank & Center & Highest contributing outputs & Improve \\
\hline 1 & S2ERC & $\begin{array}{l}\text { Student topics, new methods, } \\
\text { collaborative papers }\end{array}$ & Collaborative research projects \\
\hline 2 & CPD & $\begin{array}{l}\text { Methods, Student projects, } \\
\text { Leveraged funding }\end{array}$ & $\begin{array}{l}\text { Collaborative research projects and } \\
\text { student topics }\end{array}$ \\
\hline 3 & Ma2JIC & $\begin{array}{l}\text { Student topics, IAB member } \\
\text { satisfaction, Student projects }\end{array}$ & $\begin{array}{l}\text { Collaborative research projects and } \\
\text { collaborative research papers }\end{array}$ \\
\hline 4 & WBC & $\begin{array}{l}\text { New methods, Student hires, } \\
\text { student projects, IAB member } \\
\text { sat., Leveraged funding }\end{array}$ & $\begin{array}{l}\text { Student topics and collaborative } \\
\text { research projects }\end{array}$ \\
\hline 5 & WEP & $\begin{array}{l}\text { Collaborative papers, Leveraged } \\
\text { funding, Student projects }\end{array}$ & $\begin{array}{l}\text { Student topics and collaborative } \\
\text { research projects }\end{array}$ \\
\hline 6 & CSR & $\begin{array}{l}\text { New methods, student projects, } \\
\text { IAB member sat and leveraged } \\
\text { funding }\end{array}$ & $\begin{array}{l}\text { Student topics and collaborative } \\
\text { research projects }\end{array}$ \\
\hline
\end{tabular}

Further analysis of the relative scores allows for specific recommendations for each center. This can be useful for a center to understand why they may be scoring relatively lower than their peer group and what actions they could take to make some realistic improvements towards organizational performance.

For example, the Manufacturing and Materials Joining Innovation Center has demonstrated effectiveness in promoting students. This center has the most students using IAB center topics for their dissertations or theses. Thus, an increased focus in that area won't significantly improve their performance effectiveness score. However, if they were more intentional about how they configured their research project teams, their performance score could be significantly increased.

Instead of assigning one researcher at one site to each sponsored project, the teams could be readily expanded at the same university site to include researchers in different disciplines. For example, at the Ohio State University, the Welding 
Engineering program is housed in the Department of Materials Science and Engineering. However, faculty collaborate in other interdisciplinary research as the technology has different industry applications including power, construction, aerospace, automotive, consumer products, etc. Therefore, on projects where multisite collaboration may be cost prohibitive, same-site multi-discipline project team configurations may be an innovative way to increase collaboration.

Two specific recommendations could improve the score for Ma2JIC from a 0.63 to 0.71 , bringing it to the level of the top performer in the group. Data shows that 7 of 25 projects are configured with multi-site or multi-discipline teams of researchers. By doubling the number to be 14 of the 25 projects, the metric would show that $60 \%$ of their projects were being conducted using collaborative configurations. The desirability value for this value is $70 \%$. Therefore, 70 percent of the corresponding weighted decision criteria value (.08) is .056 which is an increase of 0.035 before rounding.

Table 31 shows how a reasonable set of actions taken by each center can improve their performance evaluation score. 
Table $31 \quad$ Performance improvement recommendations

\begin{tabular}{|c|c|c|c|c|c|c|}
\hline \multirow[t]{2}{*}{ Center } & \multirow{2}{*}{$\begin{array}{l}\text { Pre- } \\
\text { Score }\end{array}$} & \multirow[t]{2}{*}{$c_{j}$} & \multirow[t]{2}{*}{ Suggested Improvement } & \multicolumn{2}{|c|}{ Contribution } & \multirow{2}{*}{$\begin{array}{l}\text { New } \\
\text { Score }\end{array}$} \\
\hline & & & & Current & Impact & \\
\hline \multirow[t]{2}{*}{$\mathrm{Ma}^{2} \mathrm{JIC}$} & \multirow[t]{2}{*}{0.68} & 1 & $\begin{array}{l}\text { Increase multi-site/multi-discipline } \\
\text { research project configurations from } 7 \\
\text { to } 14 \text { of } 25 \text {. }\end{array}$ & 0.05 & +.04 & \multirow[t]{2}{*}{0.76} \\
\hline & & 2 & $\begin{array}{l}\text { Increase co-publications from } 5 \text { to } 9 \text { of } \\
15 .\end{array}$ & 0.02 & +.04 & \\
\hline \multirow[t]{2}{*}{ CPD } & \multirow[t]{2}{*}{0.56} & 1 & $\begin{array}{l}\text { Increase multi-site/multi discipline } \\
\text { research projects from } 0 \text { to } 5 \text { of } 12 \text {. }\end{array}$ & 0.02 & +.06 & \multirow[t]{2}{*}{0.64} \\
\hline & & 2 & $\begin{array}{l}\text { Support student interest in selecting } \\
\text { IUCRC topics for dissertation or thesis } \\
\text { by } 2 \text { students }\end{array}$ & .06 & +.02 & \\
\hline $\mathrm{S}^{2} \mathrm{ERC}$ & 0.57 & 1 & $\begin{array}{l}\text { Increase multi-site/multi-discipline } \\
\text { research project configurations. } \\
\text { Currently with } 0 \text { of } 22 \text { they should } \\
\text { increase to } 50 \% \text { multi-site or multi- } \\
\text { disciplined research project teams. }\end{array}$ & .02 & +.06 & 0.63 \\
\hline \multirow[t]{2}{*}{ CSR } & \multirow[t]{2}{*}{0.46} & 1 & $\begin{array}{l}\text { Encourage } 1 \text { student to select an IAB } \\
\text { research project as their dissertation } \\
\text { or thesis topic. }\end{array}$ & 0 & +.05 & \multirow[t]{2}{*}{0.58} \\
\hline & & 2 & $\begin{array}{l}\text { Increase collaborative configuration } \\
\text { from } 0 \text { to } 6 \text { of nine projects. Increase } \\
\text { to } 60 \% \text {. }\end{array}$ & .02 & +.06 & \\
\hline \multirow[t]{2}{*}{ WEP } & \multirow[t]{2}{*}{0.46} & 1 & $\begin{array}{l}\text { Encourage } 1 \text { student to select an IAB } \\
\text { research project as their dissertation } \\
\text { or thesis topic. }\end{array}$ & 0 & +.05 & \multirow[t]{2}{*}{0.57} \\
\hline & & 2 & $\begin{array}{l}\text { Increase collaborative configuration } \\
\text { from } 0 \text { to } 0 \text { of } 11 \text { projects. Increase to } \\
60 \% \text {. }\end{array}$ & .02 & +.06 & \\
\hline \multirow[t]{2}{*}{ WBC } & \multirow[t]{2}{*}{0.55} & 1 & $\begin{array}{l}\text { Encourage } 1 \text { student to select an IAB } \\
\text { research project as their dissertation } \\
\text { or thesis topic. }\end{array}$ & 0 & +.05 & \multirow[t]{2}{*}{0.65} \\
\hline & & 2 & Projects $4 / 14$ increase to $70 \%$. & .05 & +.05 & \\
\hline
\end{tabular}

Collection of data to populate this metric uncovered some unanticipated relationships. For example, the WBC data for student topics revealed that the most prolific dissertation advisor and chair at both IUCRC partner sites Virginia Tech 
(Frazier) and Oregon State University (Kamke), had played these roles before the formation of this young IUCRC. This leads to questions about how promotions to center director may impact student topic outcomes.

Further examination of the data shows how the model can help with decision scenarios. What if a passionate researcher who was also excellent at advising students encouraged 5 students to publish dissertations or theses with IUCRC topics at the WBC? The result would be that they could be peer with the highest scoring center.

Other questions may come from further analysis of this data set. For example, Kamke was listed as an advisor on several student dissertations and theses at Virginia Tech before being listed as an advisor for a student at Oregon State University in 2009. How does this finding impact the degree to which collaborative research was conducted? Was there a single site center at Virginia Tech before Kamke moved to Oregon State? Some of the research is listed as projects on the site indicate this may have been the case. See Appendix H-7 for supporting data.

The indicators may also show to social connections among the researchers and their institutions. For example, Sinha who published a thesis related to current IAB research projects for the WBC in 2010 now appears to have joined the faculty at Oregon State University as a researcher (Sinha, 2010). This dissertation was not counted, as the center did not officially enter the NSF IUCRC program until 2011. 
As shown, a strength of the model is that the more important decision criteria can be identified and their impact can be analyzed relatively quickly. This can be a powerful aid to managers and policy makers. However, what happens to the model when experts disagree about the decision criteria? This model and these values are subjective and not absolute. There are many reasons for differences. Some centers may have more difficulty with intellectual property issues because of their technology domain; they may instead focus on development of students. Efforts such as these could be diminished with this pure benchmarking approach.

\subsection{Sensitivity Analysis}

Many decisions are time and condition dependent. We thus need to examine the model's quality and validity as decision elements change. Common reasons for changes could be a shift in the political make-up of the US Congress or a change in the IUCRC director. Groups of evaluators could change or different groups could be in disagreement about a particular element. Carayannis et al. discusses how an IUCRC must navigate a "complex, multi-layered strategic environment" and "manage three different levels of relationships [[5] p 612]."

There are different methods that can be used to conduct sensitivity analysis. A method that was developed by Chen and Kocaoglu [133][134] uses a mathematical deduction approach to examine the flexibility and robustness of the results under any changing conditions. Sensitivity analysis could be done at any level or for any element 
of the HDM decision model to understand how responsive the decision is to any possible changes in the relative values of the objectives or the criteria/sub-criteria.

For this research, disagreements among experts as to the relative importance of different decision elements towards the performance of an IUCRC is an area of particular interest. A very simple local analysis, requiring direct substitution of one criterion's weight at a time (OAT) [196], was used to record the difference in the score. This brute-force method further investigates the impact of different expert group decisions by selecting nine (9) of the scenarios where HAC analysis showed significant cardinal or ordinal disagreement.

This local method does not constitute a robust or reliable approach for resolving distributed disagreement since the output is not linearly related to the decision criteria. However, it allows specific disagreements to be identified and analyzed in terms of impact on the output performance evaluation scores. Few decision criteria contribute towards most of the performance. Specifically six decision criteria: research projects $(14 \%)$, student topics $(12 \%)$, student projects $(8 \%)$, collaborative publications (8\%), new methods $(7 \%)$ and leveraged funding $(7 \%)$ of the 17 contribute approximately 56\% towards the evaluation score. Thus, $35 \%$ of the criteria contribute towards $56 \%$ of the effective performance. This method is able to separate where disagreement is more or less important.

This method is also acceptable because the goal is not to pick the best. Highlighting critical areas of disagreement could provide direction for policy makers 
to help with policy clarification. Therefore, the OAT method conducts direct replacement of nine (9) disagreement scenarios (B - J) identified by the HAC analysis as shown in Table 32.

Table 32 Scenario examples

\begin{tabular}{|l|l|l|l|}
\hline Scenario & Decision Criteria & Mean values & Substitution \\
\hline B & New knowledge vs Stakeholder satisfaction & $56: 44$ & $77: 23$ \\
\hline C & New knowledge vs Stakeholder satisfaction & $56: 44$ & $53: 47$ \\
\hline D & Student Involvement vs Development & $59: 41$ & $75: 25$ \\
\hline E & Student Involvement vs Development & $59: 41$ & $50: 50$ \\
\hline F & KTT medium vs KTT object & $62: 38$ & $75: 25$ \\
\hline G & Collaborative projects vs Col. Papers & $59: 41$ & $38: 63$ \\
\hline H & $\begin{array}{l}\text { Stakeholder satisfaction outputs - } \\
\text { IAB:NSF:Researcher }\end{array}$ & $37: 39: 24$ & $18: 40: 43$ \\
\hline I & $\begin{array}{l}\text { Stakeholder satisfaction outputs - } \\
\text { IAB:NSF:Researcher }\end{array}$ & $37: 39: 24$ & $12: 73: 15$ \\
\hline J & $\begin{array}{l}\text { Stakeholder satisfaction outputs - } \\
\text { IAB:NSF:Researcher }\end{array}$ & $37: 39: 24$ & $46: 38: 16$ \\
\hline
\end{tabular}

Therefore, The OAT method was used to simply substitute the mean values for each scenario and record the difference in the output performance evaluation scores. Appendix I provides the data table used for the sensitivity analysis. Scenarios were not developed for visiting student attendance at IAB meetings because data was not available.

Scenarios F, H, and J are of little interest reflecting minimal difference in the top contributing decision elements. Figure 40 shows how scenarios D, G and I resulted in an ordinal difference in the highest weighted decision criteria. 
Figure 40 Performance evaluation scores

\begin{tabular}{|c|c|c|c|c|c|c|c|c|c|c|}
\hline Output Contribution & Data & B & $\mathrm{C}$ & D & $\mathrm{E}$ & $\mathrm{F}$ & G & H & 1 & J \\
\hline C. Research Projects & 0.14 & 0.18 & 0.12 & 0.13 & 0.13 & 0.13 & 0.08 & 0.13 & 0.13 & 0.13 \\
\hline C. Research Papers & 0.08 & 0.12 & 0.08 & 0.09 & 0.09 & 0.09 & 0.14 & 0.09 & & 0.09 \\
\hline IAB Member Sat & 0.06 & 0.03 & 0.07 & 0.06 & 0.06 & 0.06 & 0.06 & 0.03 & 0.02 & 0.08 \\
\hline Leveraged Funding & 0.07 & 0.03 & 0.07 & 0.07 & 0.07 & 0.07 & 0.07 & 0.07 & 0.13 & 0.07 \\
\hline Rese archer Sat. & 0.04 & 0.02 & 0.04 & 0.04 & 0.04 & 0.04 & م0A & 0.07 & 0.03 & 0.03 \\
\hline Visiting Students & 0.07 & 0.07 & 0.07 & 0.09 & 0.06 & 0.07 & 0.07 & 0.07 & 0.07 & 0.07 \\
\hline Student Topics & 0.12 & 0.12 & 0.12 & 0.15 & 0.10 & 0.12 & 0.12 & 0.12 & 0.12 & 0.12 \\
\hline Student Projects & 0.08 & 0.08 & 0.08 & 0.05 & 0.10 & 0.08 & 0.08 & 0.08 & 0.08 & 0.08 \\
\hline Student Presentations & 0.05 & 0.06 & 0.06 & 0.03 & 0.07 & 0.06 & 0.06 & 0.06 & 0.06 & 0.06 \\
\hline Student Hires & 0.06 & 0.06 & 0.06 & 0.06 & 0.06 & 0.07 & 0.06 & 0.06 & 0.06 & 0.06 \\
\hline Consulting & 0.03 & 0.03 & 0.03 & 0.03 & 0.03 & 0.03 & 0.03 & 0.03 & 0.03 & 0.03 \\
\hline Papers & 0.02 & 0.02 & 0.02 & 0.02 & 0.02 & 0.03 & 0.02 & 0.02 & 0.02 & 0.02 \\
\hline Training and Workshops & 0.04 & 0.04 & 0.04 & 0.04 & 0.04 & 0.04 & 0.04 & 0.04 & 0.04 & 0.04 \\
\hline Shared Resources & 0.03 & 0.03 & 0.03 & 0.03 & 0.03 & 0.04 & 0.03 & 0.03 & 0.03 & 0.03 \\
\hline New Methods/Proc. & 0.07 & 0.07 & 0.07 & 0.07 & 0.07 & 0.04 & 0.07 & 0.07 & 0.07 & 0.07 \\
\hline New Products & 0.02 & 0.02 & 0.02 & 0.02 & 0.02 & 0.02 & 0.02 & 0.02 & 0.02 & 0.02 \\
\hline Licenses & 0.02 & 0.02 & 0.02 & 0.02 & 0.02 & 0.01 & 0.02 & 0.02 & 0.02 & 0.02 \\
\hline Key & 1st & 2nd & 3 rd & 4th & 5th & & & & & \\
\hline
\end{tabular}

In scenario D, experts felt that student involvement contributed to a much higher degree towards the mission than student development. Replacing the mean weights for student involvement vs student development with a $75 \%$ bias towards student involvement changed the cardinal value of collaborative research projects from the highest ranking decision element to second place. The impact of scenarios D, G and I are further explored using all six case studies. 


\section{CHAPTER 7: DISCUSSION}

In this chapter, the results of the model development and validation process are analyzed. The results of the case study are summarized and the process used for criterion-related validation with experts is discussed.

First, experts validated the model's content and construct through a structured Delphi process. Next, expert review of the case study results determined that the model is appropriate and generalizable. Table 33 adapts a framework to summarize how the research design used expert judgment to evaluate results for content validity, construct validity and criterion-related validity [197].

Table $33 \quad$ Validation results

\begin{tabular}{|l|l|l|l|}
\hline $\begin{array}{l}\text { Research } \\
\text { Validation }\end{array}$ & $\begin{array}{l}\text { Test description for } \\
\text { this research }\end{array}$ & Methods & Results \\
\hline $\begin{array}{l}\text { Content } \\
\text { Validity }\end{array}$ & $\begin{array}{l}\text { The degree to which } \\
\text { the content adequately } \\
\text { describes the NSF } \\
\text { IUCRC mission. }\end{array}$ & $\begin{array}{l}\text { Delphi process during } \\
\text { model development. } \\
\text { Experts validated } \\
\text { content and construct } \\
\text { when 80\% agreement } \\
\text { was reached. Criteria } \\
\text { and linked relationships } \\
\text { were validated [49]. }\end{array}$ & $\begin{array}{l}\text { Experts validated 17 of } \\
\text { the decision criteria } \\
\text { identified by literature. }\end{array}$ \\
\cline { 4 - 4 } & $\begin{array}{l}\text { Elements linked } \\
\text { together creating the } \\
\text { logic in a hierarchical } \\
\text { construction. }\end{array}$ & $\begin{array}{l}\text { Proxy metrics } \\
\text { developed for several } \\
\text { indicators for lack of } \\
\text { data. }\end{array}$ \\
\hline related & $\begin{array}{l}\text { Degree to which the } \\
\text { criterion can capture } \\
\text { the true value of the } \\
\text { IUCRC's performance. }\end{array}$ & $\begin{array}{l}\text { Expert review of case } \\
\text { study analysis and } \\
\text { results. }\end{array}$ & $\begin{array}{l}\text { Experts were in } \\
\text { general agreement } \\
\text { with the results from } \\
\text { the case study and } \\
\text { determined the model } \\
\text { is appropriate and } \\
\text { generalizable. }\end{array}$ \\
\hline
\end{tabular}




\subsection{Decision criteria}

Experts validated the decision criteria and relative linkages for each criteria presented from the literature review. Seventeen of twenty-four decision elements were validated by experts and linked together to construct a four-level decision model. The tolerance level of $80 \%$ for accepting elements into the model was used based upon precedence in a similar research study [49]. While other levels for acceptance have been documented in the literature such as $2 / 3 \mathrm{rds}$ agreement [95][97], the more stringent level was warranted and helped elicit expert data for improved clarification of the metrics.

Each criterion was validated by experts when an $80 \%$ agreement level was met. At level 2 in the HDM, the first objective was modified to clarify that fundamental research is also collaborative and pre-competitive. The objectives, defined by Gray and Walters in a guide for directors published in 1998 [62], have been modified several times. However, this well-known "purple book" is still used and referenced today.

The official NSF website shares a different set of objectives and goals. The objectives read:

- To promote research programs of mutual interest

- To contribute to the nation's research infrastructure base

- To enhance the intellectual capacity of the engineering or science workforce through the integration of research and education, and 
- To facilitate technology transfer.

These objectives are followed by statements to achieve these goals by:

- Contributing to the nation's research enterprise by developing longterm partnerships among industry, academe, and government;

- Leveraging NSF funds with industry to support graduate students performing industrially relevant pre-competitive research;

- Expanding the innovation capacity of our nation's competitive workforce through partnership between industries and universities; and

- Encouraging the nation's research enterprise to remain competitive through active engagement with academic and industrial leaders throughout the world.

(http://www.nsf.gov/eng/iip/iucrc/about.jsp)

These statements would be very difficult to break down into a hierarchical model as they integrate concepts at the objective and goal levels. There was general expert support for the three objectives from the "purple book". Experts agree that there has been ongoing discussion over the years about the objectives. The one most debated is the third objective, knowledge and technology transfer. This objective has been narrowed on the NSF's website lending more emphasis towards direct commercialization by removing the word "knowledge." This focus shift is not 
supported in the current literature stream or by the experts in this study. Rather, literature emphasizes the importance of knowledge and technology transfer because indirect transfer is often overlooked [106].

\subsection{Balanced set of relative indicators}

In discussing the weighted values of the decision elements, one expert shared they have "been concerned for some time about the over emphasis of using licensing and papers as indicators." Specifically, several experts stressed that "knowledge and technology transfer is not about the short-term gain of licenses or products developed by one firm, it's really about the long term impact of students who make their career in the field."

This model accurately reflects this point of view. For example, a large amount of time and resources spent on acquiring additional licenses would not make as much impact on a center's performance score as encouraging more students towards theses or dissertation topics related to IUCRC research projects.

Experts were not surprised that student topics contributed a high degree towards student involvement. "Students who are more involved typically have a personal motive and interest beyond the research project. It's the students who are willing to work at home, continuing to conduct research that are the most engaged." Some students working as research assistants participate in the center as more of a job. 
Experts believe a significant role can be played by university graduates hired into the field and by new methods for accelerating and promoting knowledge and technology transfer. These results make sense because graduates have the

opportunity to provide a long term impact to the field. This perspective was supported by the judgment provided by the expert panels reflected in student hires contributing approximately $6 \%$ towards the mission.

The inconsistency analysis provided both new insights and disagreement. For instance, one expert argued that this may not be a fair indicator: "Inclusion of a metric for student hires may be problematic because there is a high percentage of International students." Therefore, some IUCRCs may have participating students who are legally not able to accept a position in a company if one was extended. They further qualified their argument expressing concern about possible screening practices that could be encouraged as a result of too much focus in this area. While the expert data uncovered some findings that may be of interest to policy makers and NSF IUCRC directors, a debate about the mission or objectives of the NSF program is beyond the scope of this dissertation. Instead the goal here has been to measure the degree to which centers are meeting the mission as currently defined.

\subsection{Metrics}

The development of several of the metrics required an iterative process. For example, some experts felt that all projects were "collaborative" because industry sponsored research was part of the organizational design. They argued that this 
measure would offer little differentiation. Others, expressed concern about the lack of definitional consensus arguing that collaboration goes beyond a single-site configured team sponsored by a single organization. Therefore, several iterations describing the metric was required before definitional consensus was reached with the expert panel contributing to the development of the metrics and desirability functions.

Upon describing the metric as counting only multi-site or multi-disciplined configured research teams, one expert suggested differentiating and measuring multi-site from multi-organizational. A review of site research faculty CVs in several of the case studies showed all researchers at a site were affiliated with the same departments. Therefore, the metric remained. In general, all experts agree that "collaborative projects is probably one area that has not be given enough focus."

\subsection{Case study results}

The Wood-Based Composites IUCRC was used to illustrate how a performance evaluation score is calculated using the model. One strength of the model is that decision criteria contributing to a higher degree towards the organizational performance can be readily identified. The case showed how improvement in outputs for the more heavily weighted decision elements could significantly improve performance.

Experts agreed the model provides an easy tool to evaluate different decision scenarios. For example, the case of the WBC shows that by increasing the number of 
students publishing dissertations and/or theses based on IUCRC topics and configuring more teams with multi-disciplinary scientists or multiple organizations the center could possibly improve their score by $20 \%$. Experts generally agreed that these areas were "probably the most overlooked" in the current evaluation program.

Six centers were analyzed for organizational effectiveness. Analysis identified strengths and suggested areas for improvement. These results indicate that centers emphasizing collaborative projects and affirmatively supporting students who are interested in selecting IUCRC research projects as the topics for their PhD dissertation research or Master theses can improve the degree to which they are performing against the program's mission. Sorensen and Chambers agree "it is time to shift academic technology metrics away from the primary focus on measuring patents and money to a more balanced metric focused on the mission of the research institution, which is making access to knowledge available [[198] p 537] ."

\subsection{Disagreement impact}

Expert disagreement was found to have little overall impact as performance value differences were investigated one at a time in a case study of six IUCRCs. However, measuring and analyzing higher levels of disagreement can aid program directors to clarify policies and program objectives. Using data from clusters defined in the previous HAC analysis, data was replaced and compared against the generalized model to determine if there would be a change in ordinal ranking of the outputs. The data for the results shown in Table 34 is provided in Appendix I-3. 
Table $34 \quad$ Case scenarios tested for sensitivity

\begin{tabular}{|l|l|l|l|l|l|l|}
\hline & Ma2JIC & CPD & \multicolumn{1}{|l|}{ S $^{2}$ ERC } & CSR & WEP & \multicolumn{1}{l|}{ WBC } \\
\hline Scenario D & 0.68 & 0.46 & 0.48 & 0.42 & 0.45 & 0.53 \\
\hline Scenario G & 0.69 & 0.47 & 0.49 & 0.43 & 0.49 & 0.52 \\
\hline Scenario I & 0.68 & 0.45 & 0.46 & 0.42 & 0.43 & 0.52 \\
\hline Scenario A (Mean) & 0.69 & 0.47 & 0.47 & 0.43 & 0.44 & 0.55 \\
\hline
\end{tabular}

Seven of ten panels exhibited levels of disagreement at or above the tolerance threshold for further analysis. Conducting HAC analysis revealed some interesting patterns between the cluster groups and among the experts. By systematically replacing different sets of cluster data where experts disagreed, the model identified order changes in the rankings of each alternative.

Of the nine different scenarios, none made an ordinal difference in the performance score calculations for the 6 IUCRCs in the case study.

The analysis will allow policy/decision maker(s) to:

- $\quad$ Conduct scenario analysis

- $\quad$ Assess the flexibility of the decision model for disagreement

- Identify the most critical and the most sensitive elements in the model

- Understand the impact of changing priorities or group disagreement

- $\quad$ Build a more transparent decision making process 


\subsection{Summary}

In general, experts validated the results of the case study and provided a basis of interest for continued study. Specific responses include:

- The model is "well constructed."

- "It really is about pre-competitive, collaborative research"

Experts found the results interesting and "did not find anything particularly concerning." They also agreed that "one area the evaluation program has probably overlooked is collaborative research projects and the configuration of the teams." The finding that all centers should focus on collaborative projects and multi-disciplined research configurations was validated.

Focus on the KTT object of new methods or KTT medium of student hires would both contribute a relatively high degree towards the objective to accelerate and promote the transfer of knowledge and technology.

More encouragement of students to select IAB project research as the topic for their dissertations and theses could improve a center's effectiveness towards promoting students with broad industrial knowledge. It also indicates that all IUCRCs should pay attention to increasing attempts to configure multi-firm or multidisciplinary research teams. Successful collaboration requires innovative leadership, the development of people, and the willingness of stakeholders to tolerate innovative tactics. 
Additional expert input was obtained through a proposal process for this dissertation research. Representatives from the NSF Science of Science \& Innovation Policy (SciSIP) program provided additional comments.

"Many federal science agencies support large centers of research around a single scientific problem. These centers can vary considerably in the science they support, their structure, and ultimately their strengths. Where one center may make considerable progress in research, another may instead succeed best at producing excellent scientists. Agencies have long struggled with how to evaluate such centers, given their complexity."

Concluding with:

"Dissemination of the model will be important."

Upon completion of the criterion-related validity, a "brute-force" [196] sensitivity analysis was conducted by creating scenarios to further investigate expert disagreement about the decision criteria.

Expert response validated the generalizable model as a reasonable and valid approach to aid decision makers for funding decisions and priority setting for centers. The method presents " $a$ straightforward attempt to model research center effectiveness that could be applied to many other government-sponsored programs" having "widespread applicability for federal investment for research center programs."

Experts validated the results and ranking; but, were more interested in the ability of the model to ascertain criteria that were relatively more important towards 
the mission. Specifically, they thought the transparency the model provided towards each outputs' contribution added value to the field. The discussion about how each center could improve was of interest and generally validated. Experts were not surprised that collaborative projects was a highly ranked decision element.

Experts are interested in extending the study: "Can you broaden your sample to include other CRC programs so that your results are more generalizable"? 


\section{CHAPTER 8: Conclusions}

This research was able to successfully meet the original objectives set forth at the beginning of this dissertation. While this research was successful at taking a step towards closing the gaps identified in the literature, many still remain. Limitations included use of subjective data, development of proxy metrics and partial data sets. Future research opportunities are plentiful in this area including extensions to other NSF and NIH CRC and other types of CRC programs, methods for more robust sensitivity analysis, longitudinal studies to examine possible forecasting models for program sustainability and integration with proposal evaluation studies.

Increasingly important is the need for inter-disiplinary and interorganizational collaborative research. Recognizing this need, the US National Science Foundation (NSF) has responded with funding and programmatic support for cooperative science and engineering research centers (CRCs). While evidence shows these centers are effective mechanisms for fundamental research, student development and knowledge and technology transfer; challenges remain to effectively measure and compare the performance of these organizations.

Organizational effectiveness is a difficult construct. Using the HDM, concepts were identified, validated by experts and linked together to construct a generalizable model. Transparency in how the decision variables impact the final performance scores was demonstrated by analyzing how a center could turn their performance 
upside-down by focusing on fewer than $20 \%$ of the outputs. Understanding where to shift resources can be a powerful decision aid to center directors. In one case example, it was demonstrated how the WBC center could obtain a significant performance increase by re-configuring project teams to include multi-disciplinary researchers and advising students towards completion of dissertation or theses using IAB projects as topics.

Centers were comparatively analyzed providing specific recommendations. The results were presented to an expert for criteria-related validity. The expert review validated the model and the results. The generalizability of the model was validated for the IUCRC program and interest was expressed for a broadened study to make the model even more generalizable.

\subsection{Contributions}

This research begins to fill some of the gaps identified in literature. First, a system of outputs and metrics were presented from a balanced perspective. The hierarchical decision model (HDM) was introduced as a measurement system using both quantitative and qualitative metrics. The holistic study was validated using a 3phased validation approach: 1) concept and content validation, 2) construct validation and 3) criterion-related validation. The criterion-related validity involved expert review of the results from a comparison of the performance of six case studies.

This research adds value to the field by offering a generalizable model and

measurement system to compare performance of NSF science and engineering 
centers. It provides a new scoring method to compare and evaluate different IUCRCs. NSF center evaluators can then use these scores as a decision support tool for additional funding decisions and center managers can use these scores to analyze their portfolios in an objective, evidence-based manner increasing the achievement of their research objectives.

The study effectively defined a set of output indicators painting a balancedholistic picture of the NSF IUCRC program meeting the first objective of this research. While the generalizable model was only tested using the NSF IUCRC program, the model provides a new scoring method to compare and evaluate different IUCRCs in different programs.

Objective two was also accomplished by developing a framework and metrics for evaluation. Therefore, a new method for CRC performance comparison was introduced into the literature stream. This research begins to close the gap for cross CRC comparison by developing a generalizable model and a system for cross-center performance evaluation. The gap originally identified through literature was validated by experts. Gray agrees, "virtually all CRC outcome evaluation has been ad hoc, program-level evaluation studies" and that "these studies have tended to focus on technology transfer outcomes to industry"([59] p78).

The next contribution follows as a result of the first by disseminating the model and results of the study for improved assessment in the NSF IUCRC program. This study tested the model and the method by evaluating six (6) alternative IUCRCs. 
Many studies question if the traditional bibliometric indicators are the "right ones" and caution that they paint a "partial picture"[123]. The results of this research provide supporting evidence to this stream of literature by finding that new methods contribute significantly higher towards knowledge and technology transfer objectives than licenses.

Federally funded CRCs are required to have transparency in their decision making processes. This research provides a new method that highlights disagreements helping to drive discussions and transparent decision making processes.

Representatives for the NSF SciPSI program remarked through an evaluation of this research agree that "the need for understanding IUCRCs is important. They are a key policy lever used by the government to enhance translational research." "Evaluating such centers remains difficult and often subjective, yet federal science agencies continue to invest considerable resources in them." (NSF SciPHI program proposal evaluators)

This study benefits the research community by applying a flexible approach that combines qualitative and quantitative output indicators. Additional insight will be gained about the importance and use of output indicators. This holistic approach demonstrates a generalizable model that provides comparison among cooperative research centers. 


\subsection{Risks and Limitations}

Risks and limitations of the research design include:

1) The subjective research approach is based on the use of expert panels. While a strict process approach is defined to improve the reliability of the data, the nature of the methodology allows for inconsistent expert responses, the possibility of bias and expert disagreement. Applying proper data cleaning and treatment techniques and rigorous attention to a structured process is important. While this is a limitation it is also a strength. The level of disagreement can be further analyzed using cluster analysis techniques highlighting policy clarification opportunities.

These limitations were acknowledged and steps were taken to solicit a balanced set of experts versed in the domain. Letters of support were written to leverage the network of the NSF project director for the IUCRC evaluation program. Selection and formation of panels was careful and thoughtful. Strict adherence to the Delphi process was used in phase 1 to obtain input unique to the IUCRC organizational model.

2) Generalizability of the model is context dependent based upon the mission specifications of a program. Upon establishing the validity of the framework and methodology, follow-on research is proposed to extend the sample size to include other programs for evaluation not only within a program but also for evaluation of CRC performance when operating under different organizational structures. 
3) For several of the metrics, data was missing or difficult to obtain. Data mining tools are starting to close this gap by making data easier to mine and collect. However, in several cases either a metric was developed as a proxy to measure an output or an absolute metric was used. Ideally, complete sets of reliable, time-series data could be collected to populate the metrics for every alternative in the program. A strength in using the NSF IUCRC program is the availability of data. The problem becomes worse for centers without formal evaluation programs.

\subsection{Future Research}

A primary output of this research is identification of multiple areas for future investigation. Validation of the generalizable model suggests the model can be extended to other CRC programs within the NSF, NIH and possibly other national or international CRC sponsored programs. Another NSF SciSIP program proposal reviewer asked: "Can you broaden your sample to include other CRC programs so that your results are more generalizable"?

Because the method is tested using centers in the NSF IUCRC program, outputs specific to this program are used to determine the degree to which centers achieve this program's objectives. Future research could extend the findings completing a broader study by including comparisons to other types of CRC's. While the NSF IUCRC program has uniquely reinforced social-technology in the form of organizational mechanisms and structure, "the goals of the IUCRC program are quite similar to center programs at NIH, and likely across Federal science agencies." This supports the validity 
of the method and would require additional research to validate content specific to other studies.

A follow-up longitudinal study could investigate decision impact and correlation with sustainable centers. The possibility of a forecasting model that predicts sustainability potential of centers could be an area for future research.

Another possibility is to use a more robust method for sensitivity analysis. The one-method-at a time (OAT) is a brute-force means to investigate the difference in the score if different groups of experts were making the decision. Analysis of variance (ANOVA) methods aim to decompose the variance when all inputs are varied. For example, application of Chen's algorithm [143] for sensitivity analysis could help determine the robustness of the generalizable model. This would give a more comprehensive understanding of the impact of disagreement among decision makers. 


\section{REFERENCES}

[1] C. Boardman and B. Bozeman, "Academic faculty as intellectual property in university-industry research alliances," Econ. Innov. New Technol., no. 2, pp. 118, 2015.

[2] E. A. Corley, P. C. Boardman, and B. Bozeman, "Design and the management of multi-institutional research collaborations: Theoretical implications from two case studies," Res. Policy, vol. 35, pp. 975-993, 2006.

[3] C. Boardman and B. Ponomariov, "A preliminary assessment of the potential for 'team science' in DOE Energy Innovation Hubs and Energy Frontier Research Centers," Energy Policy, vol. 39, no. 6, pp. 3033-3035, 2011.

[4] H. Etzkowitz and L. Leydesdorff, "The dynamics of innovation: from National Systems and 'Mode 2' to a Triple Helix of university-industry-government relations," Res. Policy, vol. 29, no. 2, pp. 109-123, Feb. 2000.

[5] E. Carayannis, M. Del, G. Maria, R. Della, E. Carayannis, M. Del, G. Maria, R. Della, M. Villasalero, F. Campanella, M. Rosaria, D. Peruta, M. Del Giudice, and M. Villasalero, "Managing the intellectual capital within government-universityindustry R\&D partnerships," J. Intellect. Cap., vol. 15, no. 4, pp. 611-630, 2014.

[6] C. Boardman and D. Gray, "The new science and engineering management: cooperative research centers as government policies, industry strategies, and organizations," J. Technol. Transf., vol. 35, pp. 445-459, 2010.

[7] Y. S. Lee, "The Sustainability of University-Industry Research Collaboration," J. Technol. Transf., vol. 25, pp. 111-133, 2000.

[8] D. O. Gray, D. Rivers, and G. Vermont, "Measuring the Economic Impacts of the NSF Industry / University Cooperative Research Centers Program: A Feasibility Study," Arlington, Virginia, 2012.

[9] E. Geisler, "Benchmarking inter-organisational technology cooperation: the link between infrastructure and sustained performance," Int. J. Technol. Manag., vol. 25, no. 8, pp. 675-702, 2003.

[10] M. Perkmann, A. Neely, and K. Walsh, "How should firms evaluate success in university-industry alliances? A performance measurement system," $R D$ Manag., vol. 41, no. 2, pp. 202-216, 2011.

[11] B. Bozeman, D. Fay, and C. P. Slade, "Research collaboration in universities and academic entrepreneurship: The-state-of-the-art," J. Technol. Transf., vol. 38, pp. 1-67, 2013.

[12] P. H. Phan and D. S. Siegel, "The Effectiveness of University Technology Transfer," Found. Trends® Entrep., vol. 2, no. 2, pp. 77-144, 2006.

[13] A. N. Link and D. S. Siegel, "University-based technology initiatives: Quantitative and qualitative evidence," Res. Policy, vol. 34, no. 3, pp. 253-257, 2005.

[14] Y. Motoyama, J. Konczal, J. Bell-masterson, and A. Morelix, "Think Locally , Act 
Locally : Building a Robust Entrepreneurial Ecosystem," 2014.

[15] T. Wallner and M. Menrad, "Extending the innovation ecosystem," Proceedings. IXXII ISPIM Conf. Hamburd, Ger., pp. 1 - 9, 2004.

[16] D. O. Gray, O. Leonchuk, L. C. McGowen, and T. Michaelis, "2012-2013 Process Outcome Survey Results descriptive statistics compiled from industry and faculty surveys," Raleigh, North Carolina State University, 2014.

[17] L. I. Schultz, "Measuring the Activities of Collaborative Research Centers," Proc. 17th Int. Conf. Sci. Technol. Indic., vol. 2, pp. 743-755, 2012.

[18] R. N. Kostoff, "Systematic acceleration of radical discovery and innovation in science and technology," Technol. Forecast. Soc. Change, vol. 73, no. 8, pp. 923936, Oct. 2006.

[19] R. N. Kostoff, "Science and Technology Metrics," Arlington, Virginia, 2005.

[20] E. Geisler, The metrics of science and technology. Greenwood Publishing Group, 2000.

[21] K. Weigand, T. Flanagan, K. Dye, and P. Jones, "Collaborative foresight: Complementing long-horizon strategic planning," Technol. Forecast. Soc. Change, vol. 85, pp. 134-152, Jun. 2014.

[22] H. Grupp and H. A. Linstone, "Around the Globe Resurrection and New Paradigms," Technol. Forecast. Soc. Chang., vol. 94, pp. 85-94, 1999.

[23] B. R. Martin, "The origins of the concept of 'foresight' in science and technology: An insider's perspective," Technol. Forecast. Soc. Change, vol. 77, no. 9, pp. 1438-1447, Nov. 2010.

[24] J. F. Coates, "The future of foresight-A US perspective," Technol. Forecast. Soc. Change, vol. 77, no. 9, pp. 1428-1437, Nov. 2010.

[25] J. Calof and J. Smith, "The integrative domain of foresight and competitive intelligence and its impact on R\&D management," R\&D Manag., vol. 40, no. 1, pp. 31-39, Dec. 2009.

[26] A. Alsan and M. A. Oner, "An integrated view of foresight: integrated foresight management model," Foresight, vol. 5, no. 2, pp. 33-45, 2003.

[27] E. Major, D. Asch, and M. Cordey-Hayes, "Foresight as a core competence," Futures, vol. 33, no. 2, pp. 91-107, Mar. 2001.

[28] P. Ecken, T. Gnatzy, and H. von der Gracht, "Desirability bias in foresight: Consequences for decision quality based on Delphi results," Technol. Forecast. Soc. Change, vol. 78, no. 9, pp. 1654-1670, Nov. 2011.

[29] Y. Yokoo and K. Okuwada, "Identifying expected areas of future innovation by combining foresight outputs," Foresight, vol. 15, no. 1, pp. 6-18, 2013.

[30] R. A. Slaughter, "Foresight beyond strategy: Social initiatives by business and government," Long Range Plann., vol. 29, no. 2, pp. 156-163, Apr. 1996.

[31] F. W. Geels, "Ontologies, socio-technical transitions (to sustainability), and the multi-level perspective," Res. Policy, vol. 39, no. 4, pp. 495-510, May 2010.

[32] R. Rohrbeck, "Harnessing a network of experts for competitive advantage : technology scouting in the ICT industry," R\&D Manag., pp. 169-180, 2010. 
[33] R. Rohrbeck and S. Kaab, "Collaborative business modelling for systemic and sustainability innovations," Int. J. Technol. Manag., vol. 63, no. 1/2, pp. 4-23, 2013.

[34] V. Chavez, "Creative enterprise as a solution vector for twenty first century problems," Technol. Forecast. Soc. Change, vol. 80, no. 2, pp. 191-193, Feb. 2013.

[35] H. Masum, J. Ranck, and P. A. Singer, "Five promising methods for health foresight," Foresight, vol. 12, no. 1, pp. 54-66, 2010.

[36] F. Alkemade and R. Suurs, "Patterns of expectations for emerging sustainable technologies," Technol. Forecast. Soc. Change, vol. 79, no. 3, pp. 448-456, Mar. 2012.

[37] F. W. Geels, "From sectoral systems of innovation to socio-technical systems," Res. Policy, vol. 33, no. 6-7, pp. 897-920, Sep. 2004.

[38] R. Ruegg and I. Feller, A Toolkit for Evaluating Public R\&D Investment. Gaithersburd, MD: National Institute of Standards and Technology, NIST GCR 03-857, 2003.

[39] R. Ruegg, "Bridging from Project Case Study to Portfolio Analysis in a Public R \& D Program, NIST GCR 06-891," Gaithersburg, MD, 2006.

[40] J. M. Miller, "Universities, Industry, and government in collaboration: a review of the literature on research centers," Available SSRN 1932959, pp. 1-36, 2009.

[41] L. Georghiou and J. Cassingena Harper, "Rising to the challenges-Reflections on Future-oriented Technology Analysis," Technol. Forecast. Soc. Change, vol. 80, no. 3, pp. 467-470, Mar. 2013.

[42] L. Georghiou and M. Keenan, "Evaluation of national foresight activities: Assessing rationale, process and impact," Technol. Forecast. Soc. Change, vol. 73, no. 7, pp. 761-777, Sep. 2006.

[43] E. Gibson, "Supporting Sustainable technology cluster development: a performance measurement problem," in PICMET 2015, 2015, pp. 1-16.

[44] B. Martin and R. Johnston, "Technology Foresight for Wiring Up the National Innovation System Experiences in Britain , Australia , and New Zealand," Technol. Forecast. Soc. Chang., vol. 60, no. 1999, pp. 37-54, 1999.

[45] J. D. Roessner, "Review of Progress in quantitative nondestructive evaluation," Rev. Prog. Quant. Nondestruct. Eval., vol. 12, pp. 31-39, 1998.

[46] D. Siegel, D. Waldman, and A. Link, "Assessing the impact of organizational practices on the productivity of university technology transfer offices: An exploratory study," Cambridge, 7256, 1999.

[47] L. Georghiou and D. Roessner, "Evaluating technology programs: tools and methods," Res. Policy, vol. 29, pp. 657-678, 2000.

[48] M. H. Cragin, L. Nichols, M. Simon, and S. M. Watts, "Measuring science: Emerging tools for analysis of federal R\&D investments," Proc. ASIST Annu. Meet., vol. 49, no. 1, 2012.

[49] T. A. Tran, "Strategic Evaluation of University Knowledge and Technology Transfer Effectiveness," Portland State University, 2013. 
[50] T. U. Daim, G. Rueda, H. Martin, and P. Gerdsri, "Forecasting emerging technologies: Use of bibliometrics and patent analysis," Technol. Forecast. Soc. Change, vol. 73, no. 8, pp. 981-1012, Oct. 2006.

[51] D. K. R. Robinson, L. Huang, Y. Guo, and A. L. Porter, "Forecasting Innovation Pathways (FIP) for new and emerging science and technologies," Technol. Forecast. Soc. Change, vol. 80, no. 2, pp. 267-285, Feb. 2013.

[52] E. G. Carayannis and M. von Zedtwitz, "Architecting gloCal (global-local), realvirtual incubator networks (G-RVINs) as catalysts and accelerators of entrepreneurship in transitioning and developing economies: lessons learned and best practices from current development and business incubation ," Technovation, vol. 25, no. 2, pp. 95-110, Feb. 2005.

[53] R. W. Smilor, D. V Gibson, and G. Kozmetsky, "Creating the Technopolis : High Technology Development in Austin , Texas," Bus. Ventur., pp. 49-67, 1989.

[54] D. 0. Gray, L. Tornatzky, L. McGowen, and E. Sundrome, "Research Center Sustainability and Survival: Case Studies of Fidelity, Reinvention and Leadership of Industry/University Cooperative Research Centers," vol. 0631414, p. 93, 2012.

[55] C. Boardman, D. Gray, and D. Rivers, Cooperative research centers and technical innovation: Government policies, industry strategies and organizational dynamics, 1st ed. New York: Springer-Verlag New York, 2013.

[56] J. Cunningham, P. O'Reilly, C. O'Kane, and V. Mangematin, "The inhibiting factors that principal investigators experience in leading publicly funded research," $J$. Technol. Transf., vol. 39, pp. 93-110, 2014.

[57] B. Bozeman, "Technology transfer and public policy: a review of research and theory," Res. Policy, vol. 29, pp. 627-655, 2000.

[58] D. O. Gray, C. Boardman, and D. Rivers, "The new science and engineering management: cooperative research centers as intermediary organizations for government policies and industry strategies," in Cooperative research centers and technical innovation, New York: Springer, 2013, pp. 3-33.

[59] D. O. Gray, "Making team science better: Applying improvement-oriented evaluation principles to evaluation of coorperative research centers," New Dir. Eval., no. 118, pp. 107-114, 2008.

[60] R. Adner and R. Kapoor, "Value creation in innovation ecosystems: how the structure of technological interdependence affects firm performance in new technology generations," Strateg. Manag. J., vol. 31, pp. 306-333, 2010.

[61] K. Borner, N. Contractor, H. J. Falk-Krzesinski, S. M. Fiore, K. L. Hall, J. Keyton, B. Spring, D. Stokols, W. Trochim, and B. Uzzi, "A Multi-Level Systems Perspective for the Science of Team Science," Sci. Transl. Med., vol. 2, pp. 24-49, 2010.

[62] D. O. Gray and S. G. Walters, Managing the industry/university cooperative research center: A guide for directors and other stakeholders. Columbus: Battelle Press, 1998.

[63] J. Kim, "Performance characteristic of US academic research," Portland State 
University, 2012.

[64] L. Cassia, A. De Massis, M. Meoli, and T. Minola, "Entrepreneurship research centers around the world: research orientation, knowledge transfer and performance," J. Technol. Transf., pp. 376-392, Feb. 2013.

[65] M. Muro and B. Katz, "The new cluster moment: how regional innovation clusters can foster the next economy," Brookings Institution, no. Sept, 2010.

[66] T. R. Behrens and D. O. Gray, "Unintended consequences of cooperative research: Impact of industry sponsorship on climate for academic freedom and other graduate student outcome," Res. Policy, vol. 30, pp. 179-199, 2001.

[67] M. Feldman, I. Feller, J. Bercovitz, and R. Burton, "Equity and the Technology Transfer Strategies of American Research Universities," Manage. Sci., vol. 48, no. June 2015, pp. 105-121, 2002.

[68] D. S. Siegel, D. Waldman, and A. Link, "Assessing the impact of organizational practices on the relative productivity of university technology transfer offices : an exploratory study," Res. Policy, vol. 32, pp. 27-48, 2003.

[69] E. G. Carayannis, D. Popescu, C. Sipp, and M. Stewart, "Technological learning for entrepreneurial development (TL4ED) in the knowledge economy (KE): Case studies and lessons learned," Technovation, vol. 26, no. 4, pp. 419-443, Apr. 2006.

[70] P. C. Boardman and E. A. Corley, "University research centers and the composition of research collaborations," Res. Policy, vol. 37, no. Feb, pp. 900913, 2008.

[71] C. Chukumba and R. Jensen, "University Invention, Entrepreneurship, and Start-Ups," Natl. Bur. Econ. Res., 2005.

[72] T. R. Anderson, T. U. Daim, and F. F. Lavoie, "Measuring the efficiency of university technology transfer," Technovation, vol. 27, no. 5, pp. 306-318, May 2007.

[73] S. Shane and D. Somaya, "The effects of patent litigation on university licensing efforts," J. Econ. Behav. Organ., vol. 63, pp. 739-755, 2007.

[74] B. Hall, A. Link, and J. Scott, "The Review of Economics and Statistics," Rev. Econ. Stat., vol. 85, no. 2, pp. 485-491, 2003.

[75] D. Hicks, "Performance-based university research funding systems," Res. Policy, vol. 41, no. 2, pp. 251-261, 2012.

[76] W. Cohen, R. Florida, and W. Goe, "University-Industry Research Centers in the United States." Center for Economic Development, H. John Heinz III School of Public Policy and Management, Carnegie Mellon University, 1994.

[77] W. M. Cohen, R. R. Nelson, and J. P. Walsh, "Links and Impacts: The Influence of Public Research on Industrial R\&D," Manage. Sci., vol. 48, no. June 2015, pp. 123, 2002.

[78] M. P. Feldman and M. R. Kelley, "The ex ante assessment of knowledge spillovers: Government R\&D policy, economic incentives and private firm behavior," Res. Policy, vol. 35, pp. 1509-1521, 2006. 
[79] A. Geuna and A. Muscio, "The governance of university knowledge transfer: A critical review of the literature," Minerva, vol. 47, pp. 93-114, 2009.

[80] P. C. Boardman, "Government centrality to university-industry interactions: University research centers and the industry involvement of academic researchers," Res. Policy, vol. 38, pp. 1505-1516, 2009.

[81] B. L. Ponomariov and P. C. Boardman, "Influencing scientists' collaboration and productivity patterns through new institutions: University research centers and scientific and technical human capital," Res. Policy, vol. 39, no. 5, pp. 613624, 2010.

[82] D. O. Gray and H. J. Steenhuis, "Quantifying the benefits of participating in an industry university research center: An examination of research cost avoidance," Scientometrics, vol. 58, no. 2, pp. 281-300, 2003.

[83] J. Ramanathan, R. Ramnath, M. J. Herold, and B. J. R. Wierwille, "An agile translation process for complex innovations: An industry/university cooperative research center case study," Proc. - Front. Educ. Conf. FIE, pp. 15321538, 2013.

[84] C. S. Scott, Compendium 2014. Raleigh, N.C.: NSF, 2014.

[85] M. Perkmann and K. Walsh, "University-industry relationships and open innovation: Towards a research agenda," Int. J. Manag. Rev., vol. 9, no. 4, pp. 259-280, 2007.

[86] M. Balconi and A. Laboranti, "University-industry interactions in applied research: The case of microelectronics," Res. Policy, vol. 35, pp. 1616-1630, 2006.

[87] A. Abbasi and J. Altmann, "On the Correlation between Research Performance and Social Network Analysis Measures Applied to Research Collaboration Networks," 2011 44th Hawaii Int. Conf. Syst. Sci., pp. 1-10, 2011.

[88] E. Y. Li, C. H. Liao, and H. R. Yen, "Co-authorship networks and research impact: A social capital perspective," Res. Policy, vol. 42, no. 9, pp. 1515-1530, 2013.

[89] A. Abbasi, K. S. K. Chung, and L. Hossain, "Egocentric analysis of co-authorship network structure, position and performance," Inf. Process. Manag., vol. 48, no. 4, pp. 671-679, 2012.

[90] I. Rafols, A. L. Porter, and L. Leydesdorff, "Science overlay maps: a new tool for research policy and library management," J. Am. Soc. Inf. Sci. Technol., vol. 61, no. 9, pp. 1871-1887, 2009.

[91] L. Leydesdorff, S. Carley, and I. Rafols, "Global maps of science based on the new Web-of-Science categories," Scientometrics, vol. 94, no. 2, pp. 589-593, 2013.

[92] A. L. Porter and I. Rafols, "Is science becoming more interdisciplinary? Measuring and mapping six research fields over time," Scientometrics, vol. 81, no. 3, pp. 719-745, 2009.

[93] J. G. Garner, A. L. Porter, N. C. Newman, and T. a. Crowl, "Assessing research network and disciplinary engagement changes induced by an NSF program," Res. Eval., vol. 21, no. 2, pp. 89-104, 2012. 
[94] A. Abbasi, R. T. Wigand, and L. Hossain, "Measuring social capital through network analysis and its influence on individual performance," Libr. Inf. Sci. Res., vol. 36, no. 1, pp. 66-73, 2014.

[95] K. Phan, "Innovation Measurement: A Decision Framework to Determine Innovativeness of a Company," Portland State University, 2013.

[96] T. L. Saaty, "How to make a decision: The analytic hierarchy process," Eur. J. Oper. Res., vol. 48, no. 1, pp. 9-26, Sep. 1990.

[97] I. Iskin, "An Assessment Model for Energy Efficiency Program Planning in Electric Utilities: Case of Northwest U.S.," Portland State University, 2014.

[98] J. Wallenius, J. S. Dyer, P. C. Fishburn, R. E. Steuer, S. Zionts, K. Deb, J. S. Dyer, P. C. Fishburn, and R. E. Steuer, "Multiple Criteria Decision Making, Multiattribute Utility Theory: Recent Accomplishments and What Lies Ahead Multiple Criteria Decision Making , Multiattribute Utility Theory: Recent Accomplishments and What Lies Ahead," Manage. Sci., no. June 2016, 2008.

[99] H. Y. Wu, Y. K. Lin, and C. H. Chang, "Performance evaluation of extension education centers in universities based on the balanced scorecard," Eval. Program Plann., vol. 34, no. 1, pp. 37-50, 2011.

[100] A. Al-Ashaab, M. Flores, A. Doultsinou, and A. Magyar, "A balanced scorecard for measuring the impact of industry-university collaboration," Prod. Plan. Control, vol. 22, no. 5-6, pp. 554-570, 2011.

[101] A. Comacchio, S. Bonesso, and C. Pizzi, "Boundary spanning between industry and university: the role of Technology Transfer Centres," J. Technol. Transf., vol. 37, no. 6, pp. 943-966, Aug. 2011.

[102] M.-Y. Chen, M.-J. Huang, and Y.-C. Cheng, "Measuring knowledge management performance using a competitive perspective: An empirical study," Expert Syst. Appl., vol. 36, no. 4, pp. 8449-8459, 2009.

[103] K. C. Lee, S. Lee, and I. W. Kang, "KMPI: Measuring knowledge management performance," Inf. Manag., vol. 42, pp. 469-482, 2005.

[104] E. M. Rogers, B. J. Hall, M. Hashimoto, M. Steffensen, L. Kristen, M. K. Timko, and K. L. Speakman, "Technology Transfer from University-Based Research Centers," J. Higher Educ., vol. 70, no. 6, pp. 687-705, 1999.

[105] R. J. W. Tijssen, "Universities and industrially relevant science: Towards measurement models and indicators of entrepreneurial orientation," Res. Policy, vol. 35, pp. 1569-1585, 2006.

[106] D. S. Siegel, D. A. Waldman, L. E. Atwater, and A. N. Link, "Toward a model of the effective transfer of scientific knowledge from academicians to practitioners: qualitative evidence from the commercialization of university technologies," $J$. Eng. Technol. Manag., vol. 21, no. 1-2, pp. 115-142, 2004.

[107] B. Godin, "The emergence of S\&T indicators: Why did governments supplement statistics with indicators?," Res. Policy, vol. 32, no. 4, pp. 679-691, 2003.

[108] B. Godin, "The obsession for competitiveness and its impact on statistics: The construction of high-technology indicators," Res. Policy, vol. 33, no. 8, pp. 1217- 
1229, 2004.

[109] K. Pavitt, "R \& D , patenting and innovative activities A statistical exploration," Sci. Policy Res., 1982.

[110] L. Leydesdorff, "Evaluation of research and evolution of science indicators," Curr. Sci., vol. 89, no. 9, pp. 1510-1517, 2005.

[111] H. Grupp, "The measurement of technical performance of innovations by technometrics and its impact on established technology indicators," Res. Policy, vol. 23, no. 2, pp. 175-193, 1994.

[112] J. S. Katz and B. R. Martin, "What is research collaboration?," Res. Policy, vol. 26, no. 1, pp. 1-18, 1997.

[113] H. Grupp and M. E. Mogee, "Indicators for national science and technology policy: How robust are composite indicators?," Res. Policy, vol. 33, no. 9, pp. 1373-1384, 2004.

[114] J. C. Hayton, S. Sehili, and V. Scarpello, "Why do firms join consortial research centers? An empirical examination of firm, industry and environmental antecedents," J. Technol. Transf., vol. 35, pp. 494-510, 2010.

[115] L. Waltman, N. J. Van Eck, and A. V. Leeuwen, "Towards a new crown indicator : Some theoretical considerations," J. Informetr., vol. 5, no. 1, pp. 37-47, 2011.

[116] C. S. Wagner and L. Leydesdorff, "An Integrated Impact Indicator: A new definition of 'Impact' with policy relevance," Res. Eval., vol. 21, no. 3, pp. 183188, 2012.

[117] Scibiolmed, A. K. Das, P. Arora, and S. Bhattacharya, "Webliography of STI indicator databases and related publications," J. Scientometr. Res., vol. 1, no. 1, p. 1, 2012.

[118] P. Aghion, P. a. David, and D. Foray, "Science, technology and innovation for economic growth: Linking policy research and practice in 'STIG Systems,"' Res. Policy, vol. 38, no. 4, pp. 681-693, May 2009.

[119] M. Delgado, M. E. Porter, and S. Stern, "Clusters, convergence and economic performance," Cambridge, MA, 18250, 2012.

[120] B. Bozeman and E. Corley, "Scientists' collaboration strategies: Implications for scientific and technical human capital," Res. Policy, vol. 33, no. 4, pp. 599-616, 2004.

[121] C. Freeman and L. Soete, "Developing science, technology and innovation indicators: What we can learn from the past," Res. Policy, vol. 38, no. 4, pp. 583589, May 2009.

[122] U. Schmoch, T. Schubert, D. Jansen, R. Heidler, and R. von Görtz, "How to use indicators to measure scientific performance: a balanced approach," Res. Eval., vol. 19, no. 1, pp. 2-18, 2010.

[123] C. S. Wagner, J. D. Roessner, K. Bobb, J. T. Klein, K. W. Boyack, J. Keyton, I. Rafols, and K. Börner, "Approaches to understanding and measuring interdisciplinary scientific research (IDR): A review of the literature," J. Informetr., vol. 5, pp. 1426, 2011. 
[124] E. Piva and C. Rossi-Lamastra, "Systems of indicators to evaluate the performance of university-industry alliances: a review of the literature and directions for future research," Meas. Bus. Excell., vol. 17, no. June, pp. 40-54, 2013.

[125] D. Rivers, "Final Report: Social and Human Capital Impacts of the I / UCRC Program on Faculty Directors," vol. 0631414, 2012.

[126] R. E. Quinn and J. Rohrbaugh, "A Spatial Model of Effectiveness Criteria: Towards a Competing Values Approach to Organizational Analysis," Manage. Sci., vol. 29, no. 3, pp. 363-377, 2014.

[127] R. M. Steers, "Problems in the Measurement of Organizational Effectiveness," Adm. Sci. Sci., vol. 10, no. 4, pp. 546-558, 1975.

[128] K. Cameron, "Measuring Organizational Effectiveness in Institutions of Higher Education," Adm. Sci. Q., vol. 23, no. December, pp. 604-632, 1978.

[129] M. Crow and B. Bozeman, Limited by Design-R\&D Laboratories in the O.S. National Innovation System. New York: Columbia University Press, 1998.

[130] L. McGowan, "Program sustainability for cooperative research centers: A longitudinal analysis," North Carolina State University, 2012.

[131] M. Perkmann, A. Neely, and K. Walsh, "AIM Research Working Paper Series How should firms evaluate success in university-industry alliances? A performance measurement system I S S N : 1744 - 000 9," 2010.

[132] E. Sundstrom and D. O. Gray, "Fostering Team Science: Innovative leadership practices in NSF Industry/University Research Cooperative Centers," in Triple Helix VIII: International Conference on Government, University \& Industry Linkages, 2010, no. October, pp. 20-22.

[133] NSF, "Industry \& University Cooperative Research Program (I/UCRC)," NSF 13594, 2013.2 [Online]. Available: http://www.nsf.gov/pubs/2013/nsf13594/nsf13594.htm. [Accessed: 16-Feb2015].

[134] T. Penfield, M. J. Baker, R. Scoble, and M. C. Wykes, "Assessment, evaluations, and definitions of research impact: A review," Res. Eval., vol. 23, no. 1, pp. 21$32,2014$.

[135] White House Office of Management and Budget, "Science and Technology Priorities for the FY 2011 Budget," Memoranda 2009: M-09-27, 2011. [Online]. Available: www.whitehouse.gov/omb/memoranda_2009. [Accessed: 16-Feb2015].

[136] J. Bruneel, P. D’Este, and A. Salter, “Investigating the factors that diminish the barriers to university-industry collaboration," Res. Policy, vol. 39, no. 7, pp. 858-868, 2010.

[137] J. D. Adams, E. P. Chiang, and K. Starkey, "Industry-University Cooperative Research Centers," J. Technol. Transf., vol. 26, pp. 73-86, 2001.

[138] D. Stokols, K. L. Hall, B. K. Taylor, and R. P. Moser, "The Science of Team Science. Overview of the Field and Introduction to the Supplement," Am. J. Prev. Med., 
vol. 35, pp. 77-89, 2008.

[139] D. Roessner, L. Manrique, and J. Park, "The economic impact of engineering research centers: preliminary results of a pilot study," J. Technol. Transf., vol. 35, pp. 475-493, 2010.

[140] D. Palomares-Montero and a. Garcia-Aracil, "What are the key indicators for evaluating the activities of universities?," Res. Eval., vol. 20, no. 5, pp. 353-363, 2011.

[141] R. Graham, "Technology Innovation Ecosystem Benchmarking Study: Key findings from Phase 1," 2013.

[142] R. E. Quinn, J. Rohrbaugh, and J. Rohrbaugh, "A competing values approach to organizational effectiveness," Public Product. Rev., vol. 5, no. 2, pp. 122-140, 1981.

[143] H. Chen and D. F. Kocaoglu, "A sensitivity analysis algorithm for hierarchical decision models," Eur. J. Oper. Res., vol. 185, pp. 266-288, 2008.

[144] J. L. Mumpower and T. R. Stewart, "Expert Judgement and Expert Disagreement," Think. Reason., vol. 2, no. February 2015, pp. 191-212, 1996.

[145] B. B. Brown, "Delphi process: a methodology used for the elicitation of opinions of experts," ASTME Vectors, no. February, pp. 1-15, 1968.

[146] M. J. Clayton, "Delphi: a technique to harness expert opinion for critical decision-making tasks in education," Educ. Psychol., vol. 17, no. February 2015, pp. 373-386, 1997.

[147] F. Bolger and G. Wright, "Assessing the quality of expert judgment," Decis. Support Syst., vol. 11, pp. 1-24, 1994.

[148] C. Okoli and S. D. Pawlowski, "The Delphi method as a research tool: an example, design considerations and applications," Inf. Manag., vol. 42, pp. 1529, 2004.

[149] J. S. Grant and L. L. Davis, "Selection and use of content experts for instrument development.," Res. Nurs. Health, vol. 20, pp. 269-274, 1997.

[150] D. I. Cleland and D. F. Kocaoglu, Engineering Management. New York: McGrawHill, 1981.

[151] T. L. Saaty, "Decision making with the analytic hierarchy process," Int. J. Serv. Sci., vol. 1, no. 1, p. 83, 2008.

[152] B. Förster and H. von der Gracht, "Assessing Delphi panel composition for strategic foresight - A comparison of panels based on company-internal and external participants," Technol. Forecast. Soc. Change, vol. 84, pp. 215-229, May 2014.

[153] J. Keller and H. a. von der Gracht, "The influence of information and communication technology (ICT) on future foresight processes - Results from a Delphi survey," Technol. Forecast. Soc. Change, vol. 85, pp. 81-92, Jun. 2014.

[154] M. Hilbert, I. Miles, and J. Othmer, "Foresight tools for participative policymaking in inter-governmental processes in developing countries: Lessons learned from the eLAC Policy Priorities Delphi," Technol. Forecast. Soc. Change, 
vol. 76, no. 7, pp. 880-896, Sep. 2009.

[155] C.-Y. Hung, W.-Y. Lee, and D.-S. Wang, "Strategic foresight using a modified Delphi with end-user participation: A case study of the iPad's impact on Taiwan's PC ecosystem," Technol. Forecast. Soc. Change, vol. 80, no. 3, pp. 485497, Mar. 2013.

[156] C. Markmann, I.-L. Darkow, and H. von der Gracht, "A Delphi-based risk analysis - Identifying and assessing future challenges for supply chain security in a multi-stakeholder environment," Technol. Forecast. Soc. Change, vol. 80, no. 9, pp. 1815-1833, Nov. 2013.

[157] M. R. Geist, "Using the Delphi method to engage stakeholders: A comparison of two studies," Eval. Program Plann., vol. 33, pp. 147-154, 2010.

[158] D. Kocaoglu and N. Gerdsri, "A Quantitative Model for the Strategic Evaluation of Emerging Technologies," PICMET '04 Conf. Proc. CD-ROM, 2004.

[159] T. U. Daim and D. F. Kocaoglu, "Exploring technology acquisition in Oregon, Turkey and in the U.S. electronics manufacturing companies," J. High Technol. Manag. Res., vol. 19, pp. 45-58, 2008.

[160] K. B. Eden, "Selecting information technology for physicians' practices: a crosssectional study.," BMC Med. Inform. Decis. Mak., vol. 2, p. 4, 2002.

[161] P. Gerdsri and D. Kocaoglu, "A Systematic Approach to Developing National Technology Policy and Strategy for Emerging Technologies: A Case Study of Nanotechnology for Thailand 's Agriculture Industry," in PICMET '09 - 2009 Portland International Conference on Management of Engineering \& Technology, 2009, pp. 447-461.

[162] M. Abbas, "Consistency Analysis for Judgment Quantification in Hierarchical Decision Model," Portland State University, 2016.

[163] B. Bozeman and C. Boardman, "The NSF Engineering Research Centers and the University-Industry Research Revolution: A Brief History Featuring an Interview with Erich Bloch," J. Technol. Transf., vol. 29, pp. 365-375, 2004.

[164] K. L. Hall, D. Stokols, B. a. Stipelman, A. L. Vogel, A. Feng, B. Masimore, G. Morgan, R. P. Moser, S. E. Marcus, and D. Berrigan, "Assessing the value of team science: A study comparing center- and investigator-initiated grants," Am. J. Prev. Med., vol. 42, no. 2, pp. 157-163, 2012.

[165] D. Gray, E. Sundstrom, L. G. Tornatzky, and L. McGowen, "When Triple Helix unravels: A multi-case analysis of failures in industry-university cooperative research centres," Ind. High. Educ., vol. 25, no. 5, pp. 333-345, 2011.

[166] A. Gambardella and A. Saxenian, "Outcomes: Cluster Formation in the New Silicon Valleys," Ind. Corp. Chang., vol. 10, no. 4, pp. 835-860, 2001.

[167] M. Hemmert, L. Bstieler, and H. Okamuro, "Bridging the cultural divide: Trust formation in university-industry research collaborations in the US, Japan, and South Korea," Technovation, vol. 34, no. 10, pp. 605-616, Oct. 2014.

[168] S. C. Betts and M. D. Santoro, "Somewhere between markets and hierarchies: Controlling industr," Acad. Strateg. Manag. J., vol. 10, no. 1, pp. 19-25, 2011. 
[169] M. Devine, T. James, and T. Adams, "Government supported industry-university research centers: Issues for successful technology transfer," J. Technol. Transf., vol. 12, no. 1, pp. 27-37, 1987.

[170] C. Boardman and B. Ponomariov, "Management knowledge and the organization of team science in university research centers," J. Technol. Transf., vol. 39, pp. 75-92, 2012.

[171] D. Rivers and D. O. Gray, "Evaluating cooperative research centers: a strategy for assessing proximal and distal outcomes and associated economic impacts," in Handbook on the theory and practice of program evaluation, A. Link and N. Vonortas, Eds. Hemdon, VA: Edward Elgar Publishing Inc., 2013, pp. 1-424.

[172] D. Rivers, "To Join or Not to Join: Individual and Sub-organizational Factors Affecting Industry Membership in University-based Cooperative Research Centers," 8th Int. Triple Helix Conf., 2010.

[173] L. Leydesdorff and M. Meyer, "The Triple Helix of university - industry government relations," Scientometrics, vol. 58, no. 2, pp. 191-203, 2003.

[174] M. D. Santoro and S. C. Betts, "Making industry-university partnerships work," Res. Manag., vol. 45, pp. 42-46, 2002.

[175] D. Gray, M. Lindblad, and J. Rudolph, "Industry-University Research Centers: A Multivariate Analysis of Member Retention," J. Technol. Transf., vol. 26, pp. 247$254,2001$.

[176] M. Gaughan and E. Corley, "Science faculty at US research universities: The impacts of university research center-affiliation and gender on industrial activities," Technovation, vol. 30, no. 3, pp. 215-222, 2010.

[177] P. C. Boardman and E. A. Corley, "University research centers and the composition of research collaborations," Res. Policy, vol. 37, no. 2, pp. 900-913, 2008.

[178] E. Geisler, "Measuring the Contributions of Knowledge Management Systems To the Strategic Competitiveness of Organizations: a Review and a Model," Int. J. Innov. Technol. Manag., vol. 07, no. 02, pp. 89-107, 2010.

[179] E. Geisler, "The metrics of knowledge: Mechanisms for preserving the value of managerial knowledge," Bus. Horiz., vol. 50, pp. 467-477, 2007.

[180] M. Perkmann, V. Tartari, M. McKelvey, E. Autio, A. Broström, P. D’Este, R. Fini, A. Geuna, R. Grimaldi, A. Hughes, S. Krabel, M. Kitson, P. Llerena, F. Lissoni, A. Salter, and M. Sobrero, "Academic engagement and commercialisation: A review of the literature on university-industry relations," Res. Policy, vol. 42, no. 2, pp. 423-442, 2013.

[181] H. Etzkowitz, "The norms of entrepreneurial science: cognitive effects of the new university-industry linkages," Res. Policy, vol. 27, pp. 823-833, 1998.

[182] W. Tsai, "Knowledge Transfer in Intraorganizational Networks : Effects of Network Position and Absorptive Capacity on Business Unit Innovation and Performance," Acad. Manag. J., vol. 44, no. 5, pp. 996-1004, 2015.

[183] J. E. Tyler, "Redeploying Bayh-Dole: Beyond Merely doing good to optimizing 
the potential in results of taxpayer-funded research," J. Technol. Transf., vol. 38, pp. 911-929, 2013.

[184] J. a Pertuzé, E. S. Calder, M. Edward, and W. a Lucas, "Best Practices for Collaboration Best Practices for Industry- University," MIT Sloan Manag. Rev., vol. 41, no. 51416, pp. 83-90, 2010.

[185] J. D. Rogers and B. Bozeman, "Basic research and the success of federal labindustry partnerships," J. Technol. Transf., vol. 22, no. 3, pp. 37-47, 1997.

[186] K. Blind, K. Cuhls, and H. Grupp, "Current Foresight Activities in," Technol. Forecast. Soc. Change, vol. 60, no. 1, pp. 15-35, Jan. 1999.

[187] K. Philpott, L. Dooley, C. O'Reilly, and G. Lupton, "The entrepreneurial university: Examining the underlying academic tensions," Technovation, vol. 31, no. 4, pp. 161-170, Apr. 2011.

[188] B. Bozeman and C. Boardman, "Academic Faculty in University Research Centers: Neither Capitalism's Slaves nor Teaching Fugitives," J. Higher Educ., vol. 84, no. 1, pp. 88-120, 2013.

[189] S. Chai and W. Shih, "Bridging science and technology through academicindustry partnerships," Res. Policy, vol. 45, no. 1, pp. 148-158, 2016.

[190] Roessner, "Outcomes and Impacts of the State / Industry- University Cooperative Research Centers ( S / Iucrc ) Program," 2000.

[191] D. Gray, D. Rivers, L. McGowen, L. Leonchuck, and T. Michaelis, "SBIR/STTR Supplemental Opportunity in I/UCRCs," Arlington, Virginia, 2014.

[192] A. N. Link, "The use of literature-based innovation output indicators for research evaluation," Small Bus. Econ., vol. 7, no. 6, pp. 451-455, 1995.

[193] B. M. Coberly, "Faculty satisfaction and organizational commitment with industry-university research centers," North Carolina State University, 2004.

[194] D. Gray, L. McGowen, and S. DeYoung, "FINAL Report: 2010-2011 Structural Information," Raleigh, N.C., 2012.

[195] S. E. Gray, Denis O., McGowen, L, DeYoung, "NSF IUCRC 2010-2011 Structural Information Final Report," Raleigh, 2011.

[196] A. Van Griensven, T. Meixner, S. Grunwald, and T. Bishop, "A global sensitivity analysis tool for the parameters of multi-variable catchment models," J. Hydrol., vol. 324, pp. 10-23, 2006.

[197] N. J. Sheikh, Y. Park, and D. F. Kocaoglu, "Assessment of Solar Photovoltaic Technologies Using Multiple Perspectives and Hierarchical Decision Modeling : Manufacturers Worldview," pp. 491-497, 2014.

[198] J. Sorensen and D. A. Chambers, "Evaluating academic technology transfer performance by how well access to knowledge is facilitated -- defining an access metric," J. Technol. Transf., vol. 33, no. 5, pp. 534-547, 2008. 


\section{APPENDICES}

Appendix A: Research Instruments

Appendix A-1: Invitation Letter

Dear Dr.

I am a PhD student in the Department of Engineering and Technology Management (ETM) at Portland State University conducting research in the management of technology. The topic of my Doctoral Dissertation research is: $A$ measurement system for science and engineering center performance evaluation.

About my research:

I will develop a model, measurement process and metrics for measuring the degree to which an Industry/University Cooperative Research Center (IUCRC) contributes to the NSF program's mission.

As part of my research, I will have Expert Panels help me construct a decision model by validating and quantifying elements at three levels:

- Level 2: The objectives level specifies the mission of the program

- Level 3: Goals are used to characterize and quantify the relative objectives

- Level 4: Measurable outputs are developed relative to each goal

\section{Benefits to various stakeholders:}

- NSF can use as a decision support tool to evaluate a group of IUCRCs requesting $2^{\text {nd }}$ round funding in terms of a performance measurement score based upon a holistic set of output indicators.

- CRC directors can use as a decision support tool to evaluate which goals and objectives are being overlooked or warrant further focus.

- Research has identified a gap in performance evaluation for CRCs due to the complexity of the eco-system, lack of a holistic and balanced set of indicators and available data. This study helps to close some of this gap.

- Citizens benefit from greater transparency in decision making through the use of quantified output indicators and measurement techniques.

\section{Support of Experts in the field:}

I have identified you as an expert in the field to participate in the verification and quantification of measurable goals relative to NSF IUCRC objectives. If you agree to be 
an Expert for this panel, it will involve a web based data collection instrument that will take around 5 minutes to complete. There will be 2-3 instruments depending upon the level of agreement between the experts that will be used to obtain your judgment.

I would be honored if you accept my invitation and join my expert panels, and will appreciate it greatly if you also suggest other experts in NSF IUCRC performance evaluation as potential Expert Panel members.

Please reply at your earliest convenience with one of the following responses:

[ ] Yes, I will join your Expert Panels

[ ] No, I will not be able to join your Expert Panels

I look forward to hearing from you,

Elizabeth Gibson, PhD candidate

Engineering and Technology Management Department, PSU

elgibson@pdx.edu

(503) 367-2998 


\section{Appendix A-2: Consent Form}

Thank you for agreeing to participate in the first phase of my research, in partial fulfillment of the requirements for a PhD degree, under the supervision of Dr. Tugrul Daim, Portland State University, Engineering and Technology Management Department. The research objective is to develop a Performance Score that can be used to evaluate science and engineering centers participating in the NSF's IUCRC program. You were selected as a participant due to your qualifications and experience in the area of study.

Please fill out this consent form and proceed to provide your judgment. The assessment should take approximately five (5) minutes to complete. I value your input and appreciate your support of my research efforts to validate and quantify the measurable outputs relative to the goals of student support and student development in an IUCRC organizational structure.

Your name and response will be kept confidential and will not be shared with any third party. Any data linked to your identification will be stored in a secured place only accessible by the researcher. The data will be destroyed within one year after the completion of the study. Participation in the research study is totally voluntary and you have the right to withdraw at any time, and without affecting your relationship with the researcher or affiliated institutes.

If you have concerns or questions about your participation in this study, or your rights as a research subject, please contact the PSU Office of Research Integrity, 1600 SW 4th Ave, Market Center Building, Ste. 620, Portland, OR 97201; phone: (503) 725-2227 or 1 (877) 480-4400. If you have any questions about the study itself, please contact Elizabeth Gibson at elgibson@pdx.edu (503) 367-2998. 
Your electronic signature indicates that you have read and understand the information above and agree to take part in this study. Please note that you may withdraw your consent at any time without penalty, and that by signing, you are not waiving any legal claims, rights, or remedies.

\section{Last Name, First Name}

\section{Date}


Appendix A-3: Letter of Support

Dear Evaluators,

Several months ago I was approached by a doctoral candidate at Portland State University's Engineering and Technology Management program, Elizabeth Gibson, who had invested a great deal of time and effort into understanding NSF's Industry/University Cooperative Research Center (IUCRC) program and past evaluation efforts. Elizabeth is trying to complete her dissertation on the IUCRC program, under the supervision of $\mathrm{Dr}$. Tugrul (Daim), and I was sufficiently impressed by the quality of her work I agreed to facilitate access to individuals who could serve as raters in her multistage project.

Her proposed study examines the degree to which an IUCRC contributes to the program's mission. The research defines a balanced set of measurable output indicators and based on input from experts, uses them to create a performance score providing NSF evaluators and IUCRC directors with a decision support tool.

Elizabeth will be contacting you in the next few days to request your participation as an expert to verify goals and output elements in the model. The IUCRC program has had an excellent track record of facilitating student research efforts in the past and I encourage you to support this project, as your expertise will greatly improve the quality of this research.

As an incentive, participants will have early access to the survey results Thank you in advance.

Denis Gray

Denis O. Gray, Ph.D.

Alumni Distinguished Graduate Professor

Psychology in the Public Interest Program

Psychology Department

Poe Hall Room 712

North Carolina State University

Raleigh, NC 27695-7650

denis_gray@ncsu.edu

Office: 919-515-1721

Mobile: 919-906-3696

PI, NSF IUCRC Evaluation Project

www.ncsu.edu/iucrc 


\section{Appendix A-4: Web based validation instrument}

\section{Validation: Graduate producing outputs}

Welcome to my research study

Thank you for participating as an expert in my Doctoral Dissertation research. As an expert, you will be asked to provide judgment to validate and quantify elements in a model that evaluates the degree in which an Industry/University Cooperative Research Center (IUCRC) achieves the NSF's mission for the program.

The preliminary model developed from the literature review and expert feedback is included below for your reference. Thank you again for accepting to serve as an expert. Your input will greatly improve the quality of my research.

Elizabeth Gibson, PhD Candidate

Engineering and Technology Management Department

Portland State University

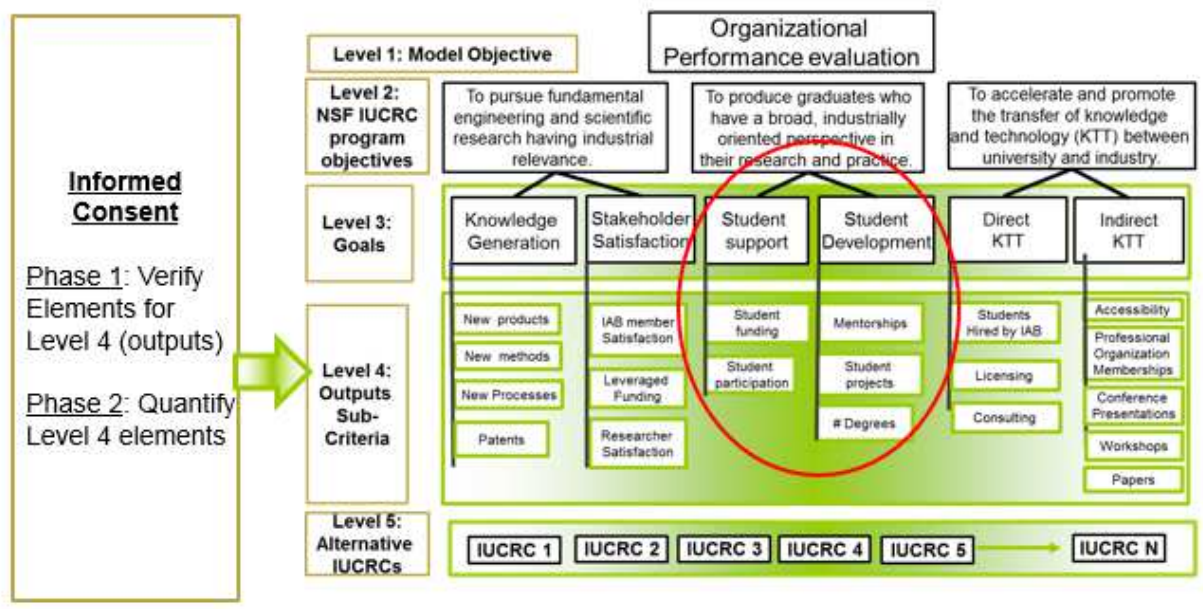


Appendix A-5: Web based judgment quantification instrument

\section{Quantification of NSF IUCRC outputs}

Welcome to phase 2 of my research study

Thank you for participating as an expert in my Doctoral Dissertation research.

The purpose of my model is to determine the degree in which an Industry/University Cooperative Research Center (IUCRC) achieves the mission specified by the NSF's IUCRC program. The three objectives shown at level 2 in the model specify the NSF IUCRC program's mission. The goals in level 3, have been verified and quantified by a panel of experts from an organizational perspective. In this study you will be asked to quantify the relative importance of each output (level 4) towards a respective goal.

The HDM provided below for your reference incorporates the results of the expert data collected from Phase 1 (model verification) of this study.

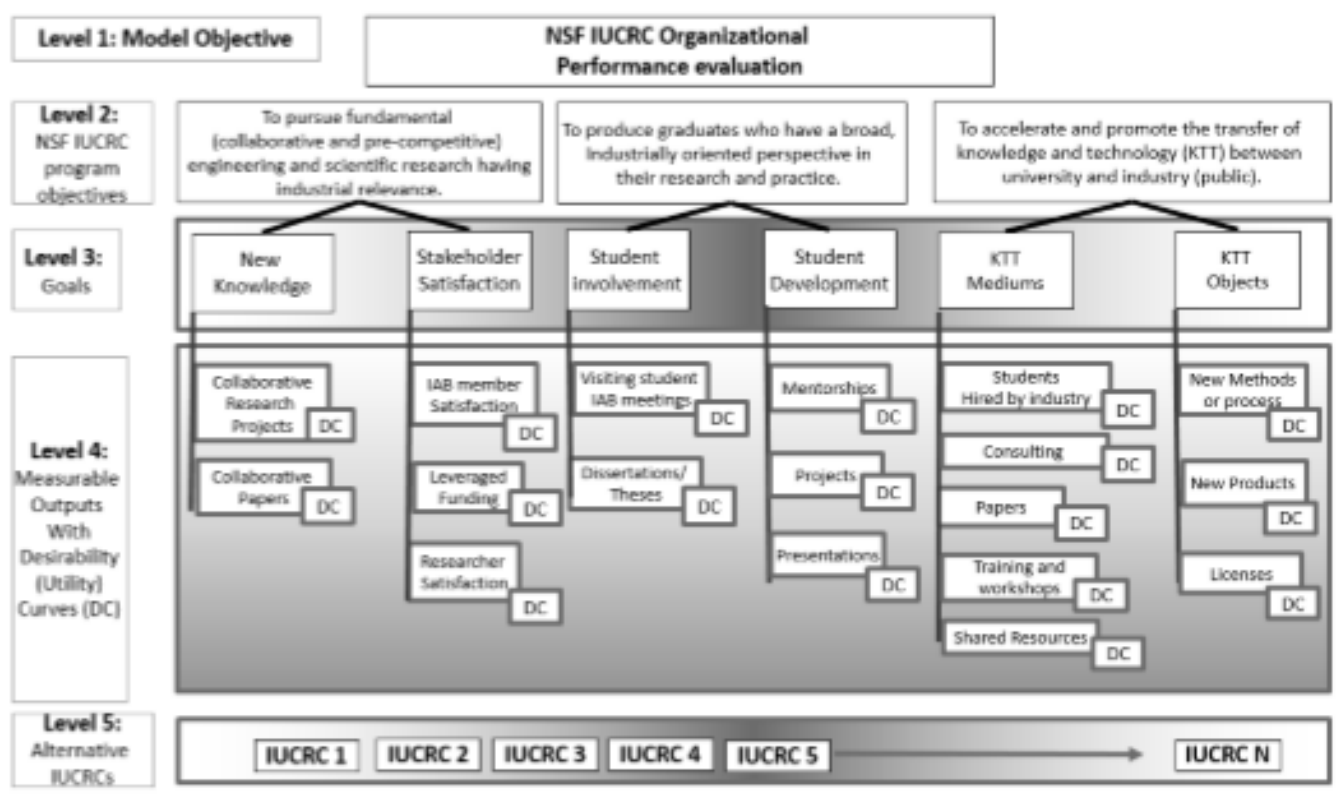

The full instrument is available from the author. 
Appendix A-6: Table of research instruments

\begin{tabular}{|c|c|c|c|}
\hline Instrument & Purpose & Data Collected & Method \\
\hline $\begin{array}{l}\text { Expert } \\
\text { Invitation }\end{array}$ & $\begin{array}{l}\text { Determine willingness of } \\
\text { experts to serve }\end{array}$ & $\begin{array}{l}\text { Binary acceptance } \\
\text { data. Check yes/no. }\end{array}$ & Personalized email \\
\hline $\begin{array}{l}\text { Consent } \\
\text { Form }\end{array}$ & $\begin{array}{l}\text { Full research disclosure. } \\
\text { Compliance with Institute } \\
\text { Review Board standards. }\end{array}$ & $\begin{array}{l}\text { Electronic signature } \\
\text { and date. }\end{array}$ & $\begin{array}{l}\text { Fillable open text box } \\
\text { attached to form. Binary } \\
\text { entry in MS Excel. }\end{array}$ \\
\hline $\begin{array}{l}\text { Criteria } \\
\text { Validation of } \\
\text { Objectives }\end{array}$ & $\begin{array}{l}\text { Validation of construct and } \\
\text { content of level } 2 \text { : political. } \\
\text { Data used to develop final } \\
\text { model for data collection. }\end{array}$ & $\begin{array}{l}\text { Transcript of phone } \\
\text { conversation. }\end{array}$ & $\begin{array}{l}\text { Open-ended questions to } \\
\text { acquire context, background } \\
\text { and scenario considerations. }\end{array}$ \\
\hline $\begin{array}{l}\text { Goal } \\
\text { criterion } \\
\text { Validation }\end{array}$ & $\begin{array}{l}\text { Validation of construct and } \\
\text { content at the organizational } \\
\text { level. Data used to develop } \\
\text { final model for data collection. }\end{array}$ & $\begin{array}{l}\text { Binary checklist (agree/ } \\
\text { disagree) with open } \\
\text { text box for additional } \\
\text { qualitative data. }\end{array}$ & $\begin{array}{l}\text { Survey Monkey email based } \\
\text { tool. Acceptance with } \% / 4 \\
\text { expert agreement. }\end{array}$ \\
\hline $\begin{array}{l}\text { Goal } \\
\text { criterion } \\
\text { Validation }\end{array}$ & $\begin{array}{l}\text { Validation of construct and } \\
\text { content at the organizational } \\
\text { level. Data used to develop } \\
\text { final model for data collection. }\end{array}$ & $\begin{array}{l}\text { Transcript of phone } \\
\text { conversations. }\end{array}$ & $\begin{array}{l}\text { Closed-ended questions for } \\
\text { acceptance of specific goals. } \\
\text { Opened-ended questions to } \\
\text { collect qualitative data. }\end{array}$ \\
\hline $\begin{array}{l}\text { Output } \\
\text { criterion } \\
\text { Validation }\end{array}$ & $\begin{array}{l}\text { Validation of construct and } \\
\text { content at the technical level. } \\
\text { Data used to develop final } \\
\text { model for data collection. }\end{array}$ & $\begin{array}{l}\text { Binary checklist (agree/ } \\
\text { disagree) with open } \\
\text { text box for additional } \\
\text { qualitative data. }\end{array}$ & $\begin{array}{l}\text { Survey Monkey email based } \\
\text { tool. Acceptance with } \% / 4 \\
\text { expert agreement. }\end{array}$ \\
\hline $\begin{array}{l}\text { Data } \\
\text { collection } 1\end{array}$ & $\begin{array}{l}\text { Quantification of objectives at } \\
\text { the political level of the model. }\end{array}$ & Pair-wise comparisons & $\begin{array}{l}\text { Closed-ended questions } \\
\text { during phone interview. }\end{array}$ \\
\hline $\begin{array}{l}\text { Data } \\
\text { collection } 2\end{array}$ & $\begin{array}{l}\text { Quantification of goals at the } \\
\text { organizational level of the } \\
\text { model. }\end{array}$ & Pair-wise comparisons & $\begin{array}{l}\text { Survey Monkey email based } \\
\text { tool and phone interviews. }\end{array}$ \\
\hline $\begin{array}{l}\text { Data } \\
\text { collection } \\
\text { instruments } \\
(3-5)\end{array}$ & $\begin{array}{l}\text { Quantification of goals at the } \\
\text { technical level of the model. }\end{array}$ & $\begin{array}{l}\text { Pair-wise comparisons } \\
\text { of output criterion } \\
\text { provides quantitative } \\
\text { weights. }\end{array}$ & $\begin{array}{l}\text { Three (3) different } \\
\text { quantification instruments } \\
\text { were administered in } \\
\text { accordance with experts' } \\
\text { perspective and panel } \\
\text { membership: research, } \\
\text { student, KTT. }\end{array}$ \\
\hline $\begin{array}{l}\text { Data } \\
\text { collection } 6\end{array}$ & $\begin{array}{l}\text { Validation and quantification of } \\
\text { desirability curves for each } \\
\text { output criterion. }\end{array}$ & $\begin{array}{l}\text { Acceptance of metric } \\
\text { and context, } \\
\text { background and } \\
\text { qualifying statements } \\
\text { for quantification of } \\
\text { desirability values. } \\
\text { Quantified desirability } \\
\text { values of metrics. }\end{array}$ & $\begin{array}{l}\text { Closed-ended questions to } \\
\text { determine acceptance of } \\
\text { metric and desirability } \\
\text { values. Open-ended } \\
\text { questions to allow experts } \\
\text { to share and qualify their } \\
\text { judgment. Qualitative data } \\
\text { transcribed for content } \\
\text { analysis. }\end{array}$ \\
\hline
\end{tabular}


Appendix B: Expert Panels

Appendix B-1: Panel Configurations
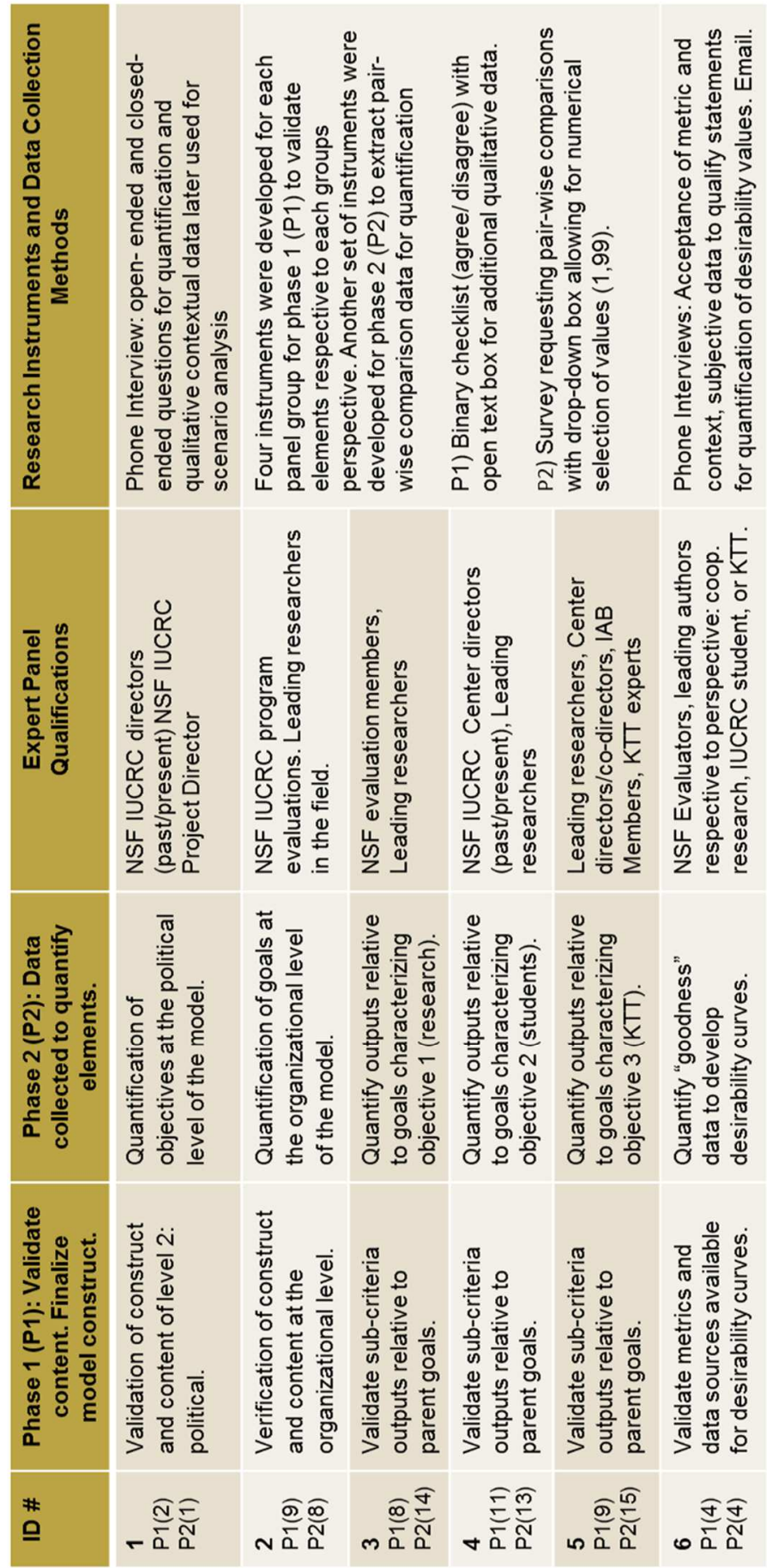
Appendix B-2: Expert Background

\begin{tabular}{|l|l|}
\hline \multicolumn{1}{|c|}{ Affiliation } & \multicolumn{1}{c|}{ Title } \\
\hline Arizona State U & IUCRC staff \\
\hline Arizona State U & Professor \\
\hline Boise State & Evaluator IUCRC \\
\hline Brigham Young Univ & Director IUCRC \\
\hline Clarkson U & Director IUCRC \\
\hline George Washington U & Professor \\
\hline Georgetown U & Director IUCRC \\
\hline Grand Valley state U & VP/Evaluator \\
\hline Iowa State & Dept Chair/Evaluator \\
\hline North Carolina State U & Professor/Director \\
\hline North Carolina State U & Director IUCRC \\
\hline North Texas & Professor/Assoc Director \\
\hline NSF Consultant & Evaluator IUCRC \\
\hline NSF IUCRC & NSF Project Manager \\
\hline NSF Program & NSF Program Manager \\
\hline Ohio State U & Professor \\
\hline Oregon State Univ & Director IUCRC \\
\hline Purdue U & Professor/Evaluator \\
\hline Purdue U & Ass Prof/Assist. Dir \\
\hline SUNY Buffalo & Director IUCRC \\
\hline SUNY Buffalo & Director IUCRC \\
\hline U of Arizona & Director IUCRC \\
\hline U of Arkansas & Director IUCRC \\
\hline U of California, Berkeley & Professor/Director \\
\hline U of California, Santa-Cruz & Center Executive \\
\hline U of Colorado, Boulder & CoDirector IUCRC \\
\hline U of Tennessee, Knoxville & CoDirector IUCRC \\
\hline U of Washington & Director IUCRC \\
\hline UC Berkeley & Assoc. Prof/Evaluator \\
\hline UC Davis & Director IUCRC \\
\hline Univ of Georgia & Evaluator IUCRC \\
\hline University of Florida & Professor/Evaluator \\
\hline University of Tennessee & Evaluator IUCRC \\
\hline University of Washington & Professor/Evaluator \\
\hline Virginia Tech & Director IUCRC \\
\hline Virginia Tech & Director IUCRC \\
\hline & \\
\hline
\end{tabular}


Appendix B-3: Expert Panels 1 and 2 configuration (Phase 1)

\begin{tabular}{|c|c|c|c|c|}
\hline Panel 1 & Panel 2 & Affiliation & Title & Background \\
\hline $\mathrm{X}$ & & NSF Program & NSF Program Manager & NSF \\
\hline $\mathrm{X}$ & & North Carolina State U & Professor/Director & $\mathrm{C}$ \\
\hline & $\mathrm{X}$ & Ohio State U & Professor/Center Director & $\mathrm{R}$ \\
\hline & $\mathrm{X}$ & $\mathrm{NSF}$ IUCRC & NSF Project Manager & $\mathrm{R}$ \\
\hline & $\mathrm{X}$ & NSF Consultant & Evaluator IUCRC & $\mathrm{R}$ \\
\hline & $\mathrm{X}$ & lowa State & Assoc. Prof/NSF Evaluator & $\mathrm{NSF}$ \\
\hline & $\mathrm{X}$ & University of Washington & Professor/NSF Evaluator & $\mathrm{R}$ \\
\hline & $\mathrm{X}$ & $\mathrm{X}$ & Assoc. Prof/NSF Evaluator & NSF \\
\hline & $\mathrm{X}$ & Un California, Berkeley & Professor/Director IUCRC & $\mathrm{C}$ \\
\hline & $\mathrm{X}$ & Grand Valley state U & Ev /NSF Evaluator & $\mathrm{NSF}$ \\
\hline
\end{tabular}

Background Key: R = Leading Researcher, C = IUCRC Center Director

Appendix C: Validation Data

Appendix C-1: Validation Data for Objectives

\begin{tabular}{|r|r|r|c|}
\hline \multicolumn{4}{|c|}{ Validation of Objectives } \\
\hline ID & Obj 1 & Obj 2 & Obj 3 \\
\hline E1 & 1 & 1 & 1 \\
\hline E2 & 1 & 1 & 1 \\
\hline
\end{tabular}

$\begin{array}{llll}\text { Agreement } & 100 \% & 100 \% & 100 \%\end{array}$




\section{Appendix C-2: Validation Data for Goals}

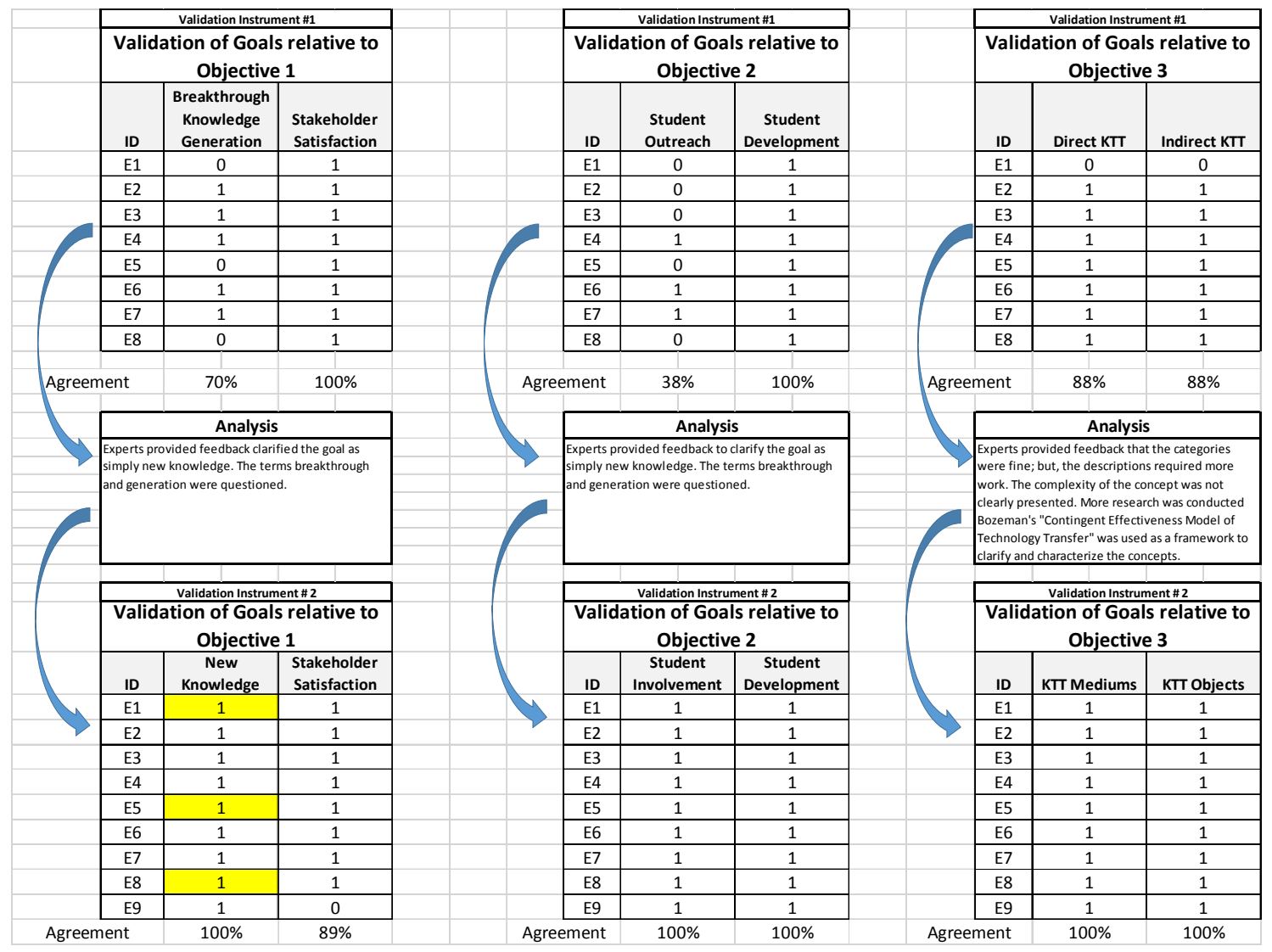




\section{Appendix C-3: Validation Data for Outputs}

\begin{tabular}{|c|c|c|c|c|c|c|}
\hline $\begin{array}{c}\text { Relative } \\
\text { Goal }\end{array}$ & $\begin{array}{l}\text { Validation } \\
\text { Round } 1\end{array}$ & $\%$ Accept & Analysis and Results & Validation Round 2 & \# Experts & \% Accept \\
\hline \multirow{3}{*}{$\begin{array}{l}0 \\
0 \\
0 \\
\frac{0}{3} \\
0 \\
0 \\
\frac{1}{2} \\
3 \\
0 \\
z\end{array}$} & Papers & $100 \%$ & Only count collaborative. & Collaborative Papers & 8 & $100 \%$ \\
\hline & Projects & $100 \%$ & Only count collaborative. & $\begin{array}{l}\text { Collaborative } \\
\text { Projects }\end{array}$ & 8 & $100 \%$ \\
\hline & Patents & $33 \%$ & Removed & & & \\
\hline \multirow{3}{*}{ 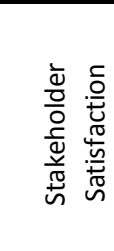 } & $\begin{array}{l}\text { IAB Member } \\
\text { Satisfaction }\end{array}$ & $100 \%$ & Accepted & & 8 & $100 \%$ \\
\hline & $\begin{array}{l}\text { Leveraged } \\
\text { Funding }\end{array}$ & $87 \%$ & Accepted & & 8 & $87 \%$ \\
\hline & $\begin{array}{l}\text { Researcher } \\
\text { Satisfaction }\end{array}$ & $100 \%$ & Accepted & & 8 & $100 \%$ \\
\hline \multirow{3}{*}{ 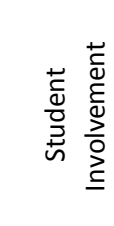 } & Funding & $50 \%$ & Removed & & & \\
\hline & Dissertation & $100 \%$ & $\begin{array}{l}\text { Add theses and count } \\
\text { only topic focused }\end{array}$ & $\begin{array}{l}\text { Topic related thesis } \\
\text { or dissertation }\end{array}$ & 15 & $100 \%$ \\
\hline & \begin{tabular}{|l} 
Meeting \\
Participaton
\end{tabular} & $70 \%$ & $\begin{array}{l}\text { Change to off-site } \\
\text { student participation }\end{array}$ & $\begin{array}{l}\text { Off-site student } \\
\text { meeting attendance }\end{array}$ & 15 & $100 \%$ \\
\hline \multirow{4}{*}{ 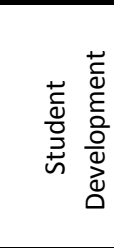 } & Mentorships & $100 \%$ & $\begin{array}{l}\text { Data is not available. } \\
\text { Removed. }\end{array}$ & & & \\
\hline & Projects & $100 \%$ & Revised & \# Students on & 15 & $100 \%$ \\
\hline & Presentations & $100 \%$ & Change from \# to \% & $\begin{array}{l}\text { \% Student } \\
\text { presentations }\end{array}$ & 15 & $100 \%$ \\
\hline & Degrees & $33 \%$ & Removed & & & \\
\hline \multirow{7}{*}{ 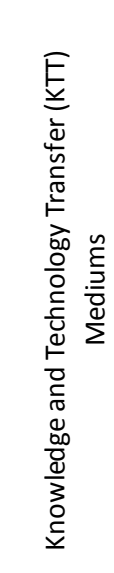 } & Student Jobs & $100 \%$ & Accepted & & 9 & $100 \%$ \\
\hline & Websites & $20 \%$ & $\begin{array}{l}\text { This is required. No } \\
\text { differentiation. }\end{array}$ & & & \\
\hline & Consulting & $100 \%$ & Accepted & & 9 & $100 \%$ \\
\hline & Papers & $100 \%$ & Accepted & & 9 & $100 \%$ \\
\hline & $\begin{array}{l}\text { Professional org } \\
\text { officers or } \\
\text { editorships }\end{array}$ & $50 \%$ & Removed & & & \\
\hline & $\begin{array}{l}\text { Training and } \\
\text { workshops }\end{array}$ & $89 \%$ & Accepted & & 9 & $89 \%$ \\
\hline & $\begin{array}{l}\text { Shared } \\
\text { resources }\end{array}$ & $89 \%$ & Accepted & & 9 & $89 \%$ \\
\hline \multirow{4}{*}{ 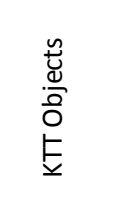 } & New Products & $100 \%$ & Accepted & New Products & 9 & $100 \%$ \\
\hline & New Methods & $100 \%$ & \multirow{2}{*}{$\begin{array}{l}\text { Combined per expert } \\
\text { comments }\end{array}$} & \multirow{2}{*}{$\begin{array}{l}\text { New Methods or } \\
\text { Processes }\end{array}$} & \multirow[b]{2}{*}{9} & \multirow[b]{2}{*}{$100 \%$} \\
\hline & New Processes & $50 \%$ & & & & \\
\hline & Licenses & $100 \%$ & Accepted & Licenses & 9 & $100 \%$ \\
\hline
\end{tabular}


Appendix D: Quantification Data

Appendix D-1: Quantification of Goals

\begin{tabular}{|l|l|l|l|l|l|l|l|}
\hline \multicolumn{7}{|c|}{ Quantification of Goals } \\
\hline Expert & NK & SS & SI & SD & KTT M & KTT O \\
\hline E1 & 40 & 60 & 60 & 40 & 50 & 50 \\
\hline E2 & 60 & 40 & 50 & 50 & 75 & 25 \\
\hline E3 & 50 & 50 & 74 & 26 & 66 & 34 \\
\hline E4 & 90 & 10 & 60 & 40 & 70 & 30 \\
\hline E5 & 60 & 40 & 50 & 50 & 45 & 55 \\
\hline E6 & 10 & 90 & 80 & 20 & 50 & 50 \\
\hline E7 & 80 & 20 & 30 & 70 & 90 & 10 \\
\hline E8 & 60 & 40 & 70 & 30 & 50 & 50 \\
\hline
\end{tabular}


Appendix D-2: Quantification of Outputs

D2-1: New knowledge and stakeholder satisfaction

\begin{tabular}{|l|l|l|c|r|}
\hline & NK & \multicolumn{3}{|c|}{ Stakeholder Sat } \\
\hline Expert & Proj:Pap & IAB:L & R:L & IAB:R \\
\hline E1 & $70: 30$ & $60: 40$ & $50: 50$ & $60: 40$ \\
\hline E2 & $60: 40$ & $50: 50$ & $40: 60$ & $70: 30$ \\
\hline E3 & $85: 15$ & $20: 80$ & $10: 90$ & $52: 48$ \\
\hline E4 & $70: 30$ & $70: 30$ & $63: 37$ & $80: 20$ \\
\hline E5 & $60: 40$ & $50: 50$ & $10: 90$ & $80: 20$ \\
\hline E6 & $50: 50$ & $70: 30$ & $50: 50$ & $60: 40$ \\
\hline E7 & $80: 20$ & $80: 20$ & $25: 75$ & $50: 50$ \\
\hline E8 & $40: 60$ & $30: 70$ & $60: 40$ & $40: 60$ \\
\hline E9 & $70: 30$ & $60: 40$ & $25: 75$ & $70: 30$ \\
\hline E10 & $90: 10$ & $50: 50$ & $50: 50$ & $50: 50$ \\
\hline E11 & $25: 75$ & $25: 75$ & $50: 50$ & $25: 75$ \\
\hline E12 & $70: 30$ & $20: 80$ & $10: 90$ & $20: 80$ \\
\hline E13 & $35: 65$ & $66: 34$ & $40: 60$ & $75: 25$ \\
\hline E14 & $65: 25$ & $70: 30$ & $30: 70$ & $65: 35$ \\
\hline
\end{tabular}


D2-2: Student involvement and student development

\begin{tabular}{|c|c|c|}
\hline & SI & SD \\
\hline Expert & Mtg:Topic & Proj:Pres \\
\hline E1 & $50: 50$ & $50: 50$ \\
\hline E2 & $74: 26$ & $75: 25$ \\
\hline E3 & $21: 79$ & $65: 35$ \\
\hline E4 & $60: 40$ & $20: 80$ \\
\hline E5 & $50: 50$ & $80: 20$ \\
\hline E6 & $20: 80$ & $50: 50$ \\
\hline E8 & $50: 50$ & $70: 30$ \\
\hline E9 & $10: 90$ & $65: 35$ \\
\hline E10 & $25: 75$ & $75: 25$ \\
\hline E11 & $20: 26$ & $75: 25$ \\
\hline E12 & $50: 50$ & $50: 50$ \\
\hline E13 & $20: 80$ & $35: 65$ \\
\hline
\end{tabular}


D2-3: KTT medium

\begin{tabular}{|l|l|l|l|l|l|l|l|l|l|l|l|l|}
\hline & \multicolumn{10}{|c|}{ KTT Media } \\
\hline $\begin{array}{l}\text { Expert } \\
\text { E1 }\end{array}$ & SH:Cons & Cons:Pa & Pap:Tr & Tr:SR & SR: SH & SH:Pap & Pap:SR & SR:Cons & Cons:Tr & Tr:SH \\
\hline E2 & $75: 25$ & $90: 10$ & $10: 90$ & $50: 50$ & $50: 50$ & $80: 20$ & $10: 90$ & $50: 50$ & $60: 40$ & $30: 70$ \\
E3 & & & & & & & & & & \\
\hline E4 & $65: 35$ & $15: 85$ & $50: 50$ & $20: 80$ & $80: 20$ & $45: 55$ & $20: 80$ & $75: 25$ & $10: 90$ & $70: 30$ \\
\hline E5 & $80: 20$ & $50: 50$ & $60: 40$ & $50: 50$ & $30: 70$ & $79: 21$ & $50: 50$ & $50: 50$ & $30: 70$ & $45: 55$ \\
\hline E6 & $80: 20$ & $40: 60$ & $40: 60$ & $65: 35$ & $50: 50$ & $70: 30$ & $55: 45$ & $55: 45$ & $30: 70$ & $50: 50$ \\
\hline E7 & & & & & & & & & & \\
\hline E8 & $90: 10$ & $80: 20$ & $50: 50$ & $50: 50$ & $10: 90$ & $90: 10$ & $20: 80$ & $50: 50$ & $50: 50$ & $20: 80$ \\
\hline E9 & $70: 30$ & $60: 40$ & $60: 40$ & $60: 40$ & $30: 70$ & $50: 50$ & $60: 40$ & $n / r$ & $60: 40$ & $15: 85$ \\
\hline E10 & $75: 25$ & $50: 50$ & $45: 55$ & $35: 65$ & $45: 55$ & $80: 20$ & $35: 65$ & $70: 30$ & $35: 65$ & $30: 70$ \\
\hline E11 & & & & & & & & & & \\
\hline E12 & $50: 50$ & $50: 50$ & $50: 50$ & $75: 25$ & $25: 75$ & $75: 25$ & $75: 25$ & $25: 75$ & $75: 25$ & $50: 50$ \\
\hline E13 & $20: 80$ & $10: 90$ & $40: 60$ & $99: 1$ & $99: 1$ & $1: 99$ & $99: 1$ & $1: 99$ & $10: 90$ & $90: 10$ \\
\hline E14 & $80: 20$ & $20: 80$ & $50: 50$ & $60: 40$ & $40: 60$ & $65: 35$ & $50: 50$ & $70: 30$ & $30: 70$ & $40: 60$ \\
\hline E15 & $65: 35$ & $70: 30$ & $35: 65$ & $50: 50$ & $35: 65$ & $80: 20$ & $65: 35$ & $45: 55$ & $60: 40$ & $40: 60$ \\
\hline E16 & $80: 20$ & $10: 90$ & $90: 10$ & $60: 40$ & $10: 90$ & $60: 40$ & $95: 5$ & $10: 90$ & $10: 90$ & $10: 90$ \\
\hline
\end{tabular}


D2-4: KTT objects

\begin{tabular}{|l|l|l|l|}
\hline & \multicolumn{3}{|c|}{ KTT Objects } \\
\hline Expert & NM:NP & NP:LI & LI:NM \\
\hline E1 & $70: 30$ & $30: 70$ & $20: 80$ \\
\hline E2 & $75: 25$ & $40: 60$ & $25: 75$ \\
\hline E4 & $70: 30$ & $30: 70$ & $20: 80$ \\
\hline E5 & $75: 25$ & $72: 25$ & $10: 90$ \\
\hline E6 & $60: 40$ & $50: 50$ & $40: 60$ \\
\hline E7 & $70: 25$ & $60: 40$ & $30: 70$ \\
\hline E8 & $50: 50$ & $75: 25$ & $20: 80$ \\
\hline E9 & $70: 30$ & $75: 25$ & $25: 75$ \\
\hline E10 & $40: 60$ & $50: 50$ & $30: 70$ \\
\hline E11 & $50: 50$ & $40: 60$ & $80: 20$ \\
\hline E12 & $80: 20$ & $25: 75$ & $25: 75$ \\
\hline E13 & $99: 1$ & $80: 20$ & $20: 80$ \\
\hline E14 & $80: 20$ & $50: 50$ & $1: 99$ \\
\hline E15 & $80: 20$ & $50: 50$ & $20: 80$ \\
\hline & & $35: 65$ & $20: 80$ \\
\hline
\end{tabular}


Appendix D-3: Quantification Data Entry and Analysis Tool

The HDM 2.0 (c) software was used to quantify the expert data. This figure illustrates how expert judgment data was entered for quantification of outputs relative towards characterization of their parent goal, KTT medium.

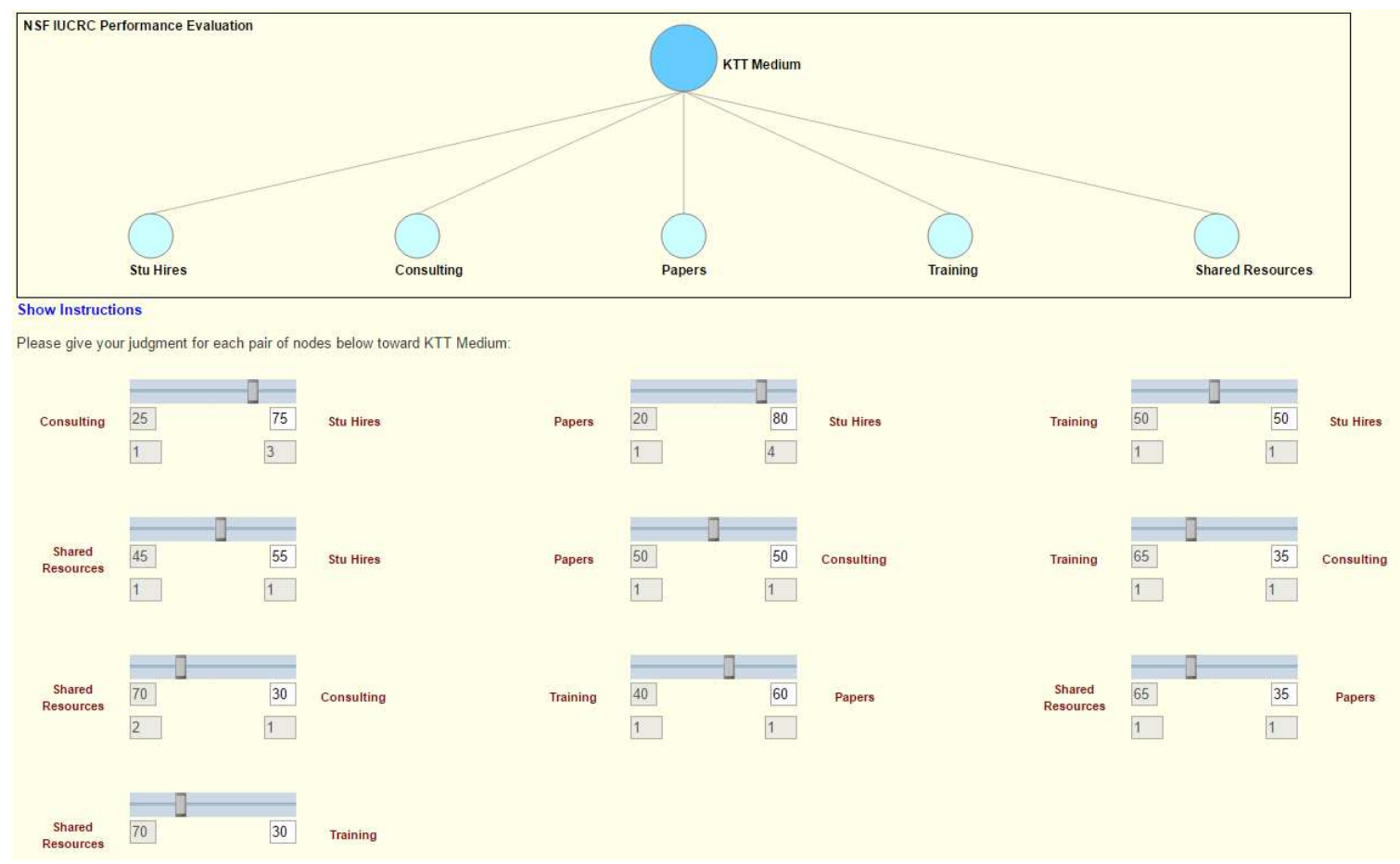


Appendix E: Desirability Curves

Appendix E-1: Desirability Curve illustration

\section{Development of Desirability Curves:}

A desirability curve (utility function) represents how desirable a metric is for the decision maker. The "goodness" or "usefulness" of the value must be determined by experts as it is not a simple linear value.

Illustration:

The metric that represents the "goodness" of collaborative research projects could have a non-linear curve. For example, if an expert says that a case where $80 \%$ of the research projects in an IUCRC is "excellent" or ideal the most desirable value would then be $80 \%$.

Table E-1: Desirability value data example

\begin{tabular}{|l|l|l|}
\hline $\begin{array}{l}\text { Percentage of } \\
\text { collaborative } \\
\text { research projects }\end{array}$ & Notes & $\begin{array}{l}\text { Desirability } \\
\text { Value } \\
\text { Example only }\end{array}$ \\
\hline $100 \%$ & Not realistic; but, great if it happened & $(100 \%)$ \\
\hline $80 \%$ & Ideal & $(100 \%)$ \\
\hline $60 \%$ & Also very good & $(80 \%)$ \\
\hline $40 \%$ & Not bad & $50 \%$ \\
\hline $20 \%$ & Some can't do better in reality & $20 \%$ \\
\hline $0 \%$ & $\begin{array}{l}\text { Does not meet the purpose of the } \\
\text { program }\end{array}$ & 0 \\
\hline
\end{tabular}

The associated function could fit a curve similar to the one shown in figure E-1.

Figure E-1: Desirability curves for collaborative research projects and papers

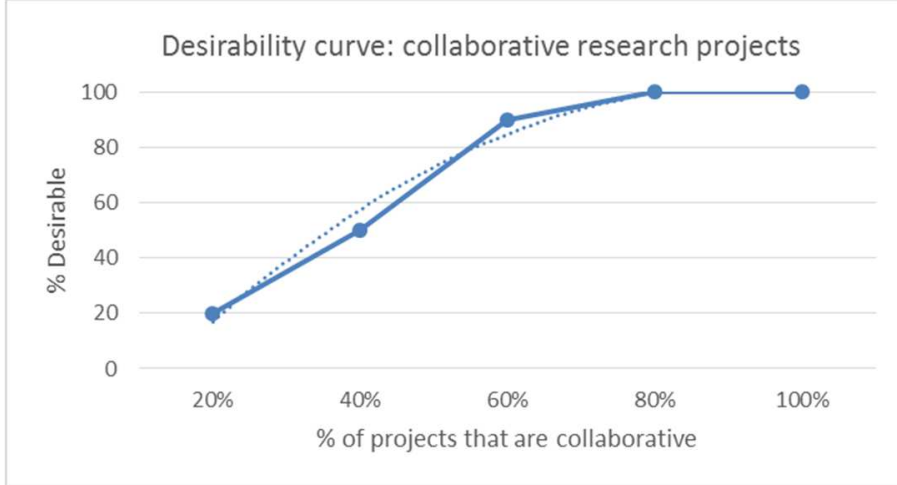


Appendix E-2: Desirability Curve Data

Table E-2-1: Data for collaborative projects

Desirability Curve "\% Collaborative projects/3 years"

\begin{tabular}{|c|c|c|c|c|c|}
\hline Research & \multicolumn{5}{|c|}{ \% Collaborative projects/3 years } \\
\hline Expert & $20 \%$ & $40 \%$ & $60 \%$ & $80 \%$ & $100 \%$ \\
\hline E1 & 20 & 50 & 90 & 100 & 100 \\
\hline E2 & 10 & 20 & 40 & 80 & 14 \\
\hline E3 & 5 & 10 & & 50 & 100 \\
\hline Mean & 12 & 27 & 48 & 77 & 71 \\
\hline
\end{tabular}

Table E-2-2: Data for collaborative papers

Desirability Curve "Number of collaborative papers"

\begin{tabular}{|c|c|c|c|c|c|}
\hline Research & \multicolumn{5}{|c|}{ \% of publications with Industrial co-authorship } \\
\hline Expert & $\mathbf{2 0 \%}$ & $\mathbf{4 0 \%}$ & $\mathbf{6 0 \%}$ & $\mathbf{8 0 \%}$ & $\mathbf{1 0 0 \%}$ \\
\hline E1 & 25 & $\mathbf{2 5}$ & 50 & 100 & 100 \\
\hline E2 & 10 & 30 & 80 & 100 & 100 \\
\hline E3 & 25 & 50 & 80 & 100 & 100 \\
\hline Mean & 20 & 35 & 70 & 100 & 100 \\
\hline Normalized & 20 & 35 & 70 & 100 & 100 \\
\hline
\end{tabular}


Table E-2-3: Data for IAB member satisfaction

Desirability Curve "\% Membership renewal"

Membership renewal

\begin{tabular}{|c|c|c|c|c|c|}
\hline Expert & $\mathbf{n}<\mathbf{4 0} \%$ & $\mathbf{5 5 \%}$ & $\mathbf{7 0 \%}$ & $\mathbf{8 5 \%}$ & $\mathbf{1 0 0 \%}$ \\
\hline E1 & 0 & 20 & 90 & 100 & 100 \\
\hline E2 & 50 & 50 & 90 & 100 & 100 \\
\hline E3 & 25 & 50 & 75 & 100 & 75 \\
\hline Mean & 25 & 40 & 85 & 100 & 91.7 \\
\hline Normalized & 0 & 40 & 85 & 100 & 92 \\
\hline
\end{tabular}

Table E-2-4: Data for leveraged funding

Desirability Curve "Leveraged Funding"

Leveraged funding (\$Total:\$NSF)

\begin{tabular}{|c|r|r|r|r|r|}
\hline Expert & \multicolumn{1}{|c|}{$\mathbf{n}<\mathbf{2}$} & \multicolumn{1}{c|}{$\mathbf{2 < = \mathrm { n } < \mathbf { 3 }}$} & \multicolumn{1}{|c|}{$\mathbf{3 < = \mathrm { n } < \mathbf { 5 }}$} & $\mathbf{5}<=\mathbf{n}<\mathbf{1 0}$ & $\mathbf{n}>\mathbf{= 1 0}$ \\
\hline E1 & 20 & 20 & 80 & 100 & 100 \\
\hline E2 & 50 & 50 & 80 & 90 & 100 \\
\hline E3 & 25 & 25 & 50 & 100 & 100 \\
\hline Mean & 32 & 32 & 70 & 97 & 100 \\
\hline Normalized & 0 & 32 & 70 & 97 & 100 \\
\hline
\end{tabular}

Table E-2-5: Data for researcher satisfaction

Desirability Curve "Researcher Satisfaction"

Average Researcher stability/3 years

\begin{tabular}{|c|c|c|c|c|c|}
\hline Expert & $\mathbf{n}<\mathbf{5 0 \%}$ & $\mathbf{8 0 \%}$ & $\mathbf{1 0 0 \%}$ & $\mathbf{1 2 0 \%}$ & $\mathbf{n}>\mathbf{1 5 0 \%}$ \\
\hline E1 & 25 & 80 & 100 & 100 & 80 \\
\hline E2 & 50 & 100 & 100 & 100 & 100 \\
\hline E3 & 75 & 90 & 100 & 100 & 100 \\
\hline Mean & 50 & 90 & 100 & 100 & 93 \\
\hline Normalized & 50 & 90 & 100 & 100 & 93 \\
\hline
\end{tabular}


Table E-2-6: Data for non-site student attendance

Desirability Curve "Student Attendance"

\% Non-site students in attendance at IAB meeting

\begin{tabular}{|c|c|c|c|c|c|c|}
\hline Expert & $0 \%$ & $20 \%$ & $40 \%$ & $60 \%$ & $80 \%$ & $100 \%$ \\
\hline E1 & 0 & 50 & 100 & 100 & 100 & 100 \\
\hline E2 & 0 & 10 & 25 & 50 & 75 & 100 \\
\hline E3 & 0 & 10 & 50 & 100 & 100 & 100 \\
\hline Mean & 0 & 23 & 58 & 83 & 92 & 100 \\
\hline Normalized & 0 & 23 & 58 & 83 & 92 & 100 \\
\hline
\end{tabular}

Table E-2-7: Data for student dissertation/thesis topics

Desirability Curve "Research Topics"

\# Student Dissertation/Thesis Topics

\begin{tabular}{|c|c|c|c|c|c|c|}
\hline Expert & 0 & 1 or 2 & 3 or 4 & 5 or 6 & 7 or 8 & $9+$ \\
\hline E1 & 0 & 25 & 50 & 100 & 100 & 100 \\
\hline E2 & 10 & 50 & 100 & 100 & 100 & 100 \\
\hline E3 & 0 & 50 & 50 & 75 & 80 & 100 \\
\hline Mean & 3 & 42 & 67 & 92 & 93 & 100 \\
\hline Normalized & 3 & 42 & 67 & 92 & 93 & 100 \\
\hline
\end{tabular}

Table E-2-8: Data for student project supervision ratio

Desirability Curve "Projects"

Number of students/\# scientific faculty

\begin{tabular}{|c|c|c|c|c|c|c|}
\hline Expert & $\mathrm{n}<1$ & $1<=\mathrm{n}<2$ & $2<=\mathrm{n}<3$ & $3<=\mathrm{n}<4$ & $4<=\mathrm{n}<5$ & $5+$ \\
\hline E1 & 50 & 100 & 100 & 75 & 50 & 50 \\
\hline E2 & 50 & 50 & 75 & 100 & 100 & 100 \\
\hline E3 & 50 & 75 & 100 & 100 & 100 & 100 \\
\hline Mean & 50 & 75 & 92 & 92 & 83 & 83 \\
\hline Normalized & 0 & 75 & 92 & 92 & 83 & 83 \\
\hline
\end{tabular}


Table E-2-9: Data for student presentations

Desirability Curve "Presentations"

\% Student Presentations

\begin{tabular}{|c|r|r|r|r|r|}
\hline Expert & \multicolumn{1}{|c|}{$\mathbf{2 0} \%$} & \multicolumn{1}{|c|}{$\mathbf{4 0 \%}$} & \multicolumn{1}{|c|}{$\mathbf{6 0} \%$} & $\mathbf{8 0} \%$ & \multicolumn{1}{c|}{$\mathbf{1 0 0 \%}$} \\
\hline E1 & 5 & 5 & 5 & 50 & 100 \\
\hline E2 & 50 & 50 & 50 & 75 & 100 \\
\hline E3 & 50 & 50 & 50 & 50 & 100 \\
\hline Mean & 35 & 35 & 35 & 58 & 100 \\
\hline
\end{tabular}

Table E-2-10: Data for student hires

Desirability Curve "\# grads hired by industry"

\begin{tabular}{|c|r|r|r|r|r|}
\multicolumn{7}{|c|}{ \# Students Hired by Industry } \\
\hline Expert & \multicolumn{1}{|c|}{$\mathbf{0}$} & \multicolumn{1}{|c|}{$\mathbf{1}$} & \multicolumn{1}{|c|}{$\mathbf{2}$} & \multicolumn{1}{|c|}{ 3 } & \multicolumn{1}{|c|}{ 4+ } \\
\hline E1 & 50 & 100 & 100 & 100 & 100 \\
\hline E2 & 25 & 50 & 100 & 100 & 100 \\
\hline E3 & 50 & 100 & 100 & 100 & 100 \\
\hline Mean & 42 & 83 & 100 & 100 & 100 \\
\hline
\end{tabular}

Table E-2-11: Data for consulting contracts

Desirability Curve "\% Consulting contracts"

$\%$ Researchers under consulting contract

\begin{tabular}{|c|r|r|r|r|r|}
\hline Expert & 0 & $25 \%$ & $50 \%$ & $75 \%$ & $100 \%$ \\
\hline E1 & 0 & 100 & 50 & 25 & 0 \\
\hline E2 & 25 & 50 & 100 & 100 & 100 \\
\hline E3 & 25 & 50 & 100 & 50 & 25 \\
\hline Mean & 17 & 67 & 83 & 58 & 42 \\
\hline Normalized & 20 & 80 & 83 & 70 & 50 \\
\hline
\end{tabular}


Table E-2-13: Data for shared resources

Desirability Curve "Number of shared resources"

Shared resources

\begin{tabular}{|c|r|r|r|r|}
\hline Expert & None & Lab & Equipment & $\begin{array}{c}\text { Both lab } \\
\text { and equip }\end{array}$ \\
\hline E1 & 50 & 50 & 90 & 100 \\
\hline E2 & 0 & 50 & 50 & 100 \\
\hline E3 & 50 & 75 & 75 & 100 \\
\hline Mean & 33 & 58 & 72 & 100 \\
\hline Normalized & 33 & 58 & 72 & 100 \\
\hline
\end{tabular}

Appendix F: Inconsistency

Appendix F-1: Expert 9 Constant sum matrices

Priority Weighting by Pairwise Comparisons

Expert 9 KTT Medium quantification data

Level 4 KTT Medium: 5 nodes

\# of comparisons $\left.=\left[n^{*}(n-1)\right] / 2\right]=5(5-1) / 2=10$ pairwise comparisons

\# of pertubations $=5 !=5 * 4 * 3 * 2 * 1=120$

KTT Media A Training and Workshops

B Papers

C Consulting

D Student Hires

E Shared Resources

Constant Sum Matrices

$\begin{array}{llllll} & \text { A } & \text { B } & \text { C } & \text { D } & \text { E } \\ \text { A } & \text { X } & 40 & 10 & 10 & 1 \\ \text { B } & 60 & \text { X } & 10 & 1 & 1 \\ \text { C } & 90 & 90 & X & 20 & 1 \\ \text { D } & 90 & 99 & 80 & \text { X } & 99 \\ \text { E } & 99 & 99 & 99 & 1 & \text { X }\end{array}$




\begin{tabular}{|c|c|c|c|c|c|c|c|c|c|}
\hline \multicolumn{10}{|c|}{ Ratios for pwc } \\
\hline \multirow[t]{2}{*}{ Matrix A } & & & & & & Matrix B & & & \multirow[b]{2}{*}{$D / E$} \\
\hline & A & B & C & D & $\mathbf{E}$ & A/B & $\mathrm{B} / \mathrm{C}$ & $C / D$ & \\
\hline A & 1.00 & 0.67 & 0.11 & 0.11 & 0.01 & 1.50 & 6.00 & 1.00 & 11.00 \\
\hline B & 1.50 & 1.00 & 0.11 & 0.01 & 0.01 & 1.50 & 9.00 & 11.00 & 1.00 \\
\hline C & 9.00 & 9.00 & 1.00 & 0.25 & 0.01 & 1.00 & 9.00 & 4.00 & 24.75 \\
\hline D & 9.00 & 99.00 & 4.00 & 1.00 & 99.00 & 0.09 & 24.75 & 4.00 & 0.01 \\
\hline \multirow[t]{2}{*}{ E } & 99.00 & 99.00 & 99.00 & 0.01 & 1.00 & 1.00 & 1.00 & 0.01 & 0.01 \\
\hline & & & & & & 1.02 & 9.95 & 4.00 & 7.35 \\
\hline
\end{tabular}

Appendix F-2: Example Orientations

\begin{tabular}{|r|l|l|l|l|r|r|r|r|r|r|}
\hline$\# \quad$ & & & & & MEAN & MEAN & MEAN & MEAN & SET \\
\hline 1 A & B & C & D & E & $>$ & 1.02 & 9.95 & 4.00 & 7.35 & 1 \\
\hline 2 A & C & D & B & E & $>$ & 6.95 & 4.00 & 0.04 & 231.20 & 1 \\
\hline 3 A & D & B & C & E & $>$ & 2000.70 & 0.04 & 9.95 & 44.01 & 1 \\
\hline
\end{tabular}

Appendix F-3: Example Standardized values orientations

\begin{tabular}{|c|c|c|c|c|c|c|c|c|c|c|c|c|c|c|c|}
\hline & & & & & & & & & & Normalize & & & & & \\
\hline & & & & A & B & C & D & $\mathrm{E}$ & Sum & A & B & C & D & $\mathrm{E}$ & Sum \\
\hline $1 \mathrm{~A}$ & $B C$ & C D & $E$ & 298.16 & 292.84 & 29.43 & 7.35 & 1.00 & 628.79 & 0.00 & 0.47 & 0.05 & 0.01 & 0.00 & 1.00 \\
\hline $2 \mathrm{~A}$ & $C D$ & D B & $3 \mathrm{E}$ & 276.19 & 231.20 & 39.74 & 9.93 & 1.00 & 558.06 & 0.49 & 0.41 & 0.07 & 0.02 & 0.00 & 1.00 \\
\hline $3 \mathrm{~A}$ & D B & B C & $E$ & 37626.83 & 437.88 & 44.04 & 18.81 & 1.00 & 38128.56 & 0.99 & 0.01 & 0.00 & 0.00 & 0.00 & 1.00 \\
\hline
\end{tabular}

$\begin{array}{lrrrrrr} & \text { A } & \text { B } & \text { C } & \text { D } & \text { E } & \text { Sum } \\ \text { MEAN } & 0.38 & 0.37 & 0.15 & 0.05 & 0.06 & 1.00 \\ \text { Std Dev } & 0.34 & 0.34 & 0.24 & 0.15 & 0.13 & \\ (\text { Std Dev })^{2} & 0.11 & 0.13 & 0.05 & 0.02 & 0.04 & \\ \text { Variance } & 0.12 & 0.12 & 0.06 & 0.02 & 0.02 & 0.34\end{array}$


Appendix G: Disagreement Analysis using R

\title{
NSF IUCRC performance evaluation \\ PhD Dissertation data analysis using Hierarchical Clustering Analysis (HAC)
}

\section{Elizabeth Gibson, PhD Candidate}

Date of Analysis: April, 2016

\section{Description:}

\begin{abstract}
The hclust function in the R Stats package was used to conduct hierarchical cluster analysis (HAC) on sets of panel data with disagreement values $>0.10$. HAC analyzes the dissimilarities in groups of data and creates a dengrogram as a visual analysis tool.

Usage is included from the $R$ documentation as a reference.(Murtagh)

hclust $(\mathrm{d}$, method $=$ "complete , members $=\mathrm{NULL})$

plot $\left(x\right.$, labels $=$ NULL, hang $=0.1$, axes $=$ TRUE, frame plot $=$ FALSE, ann $=$ TRUE, main $={ }^{*}$ Cluster Dendrogram", sub $=$ NULL, xlab $=$ NULL, ylab $={ }^{\text {"Height" }}, \ldots$ )
\end{abstract}

\section{Analysis using $\mathbf{R}$}

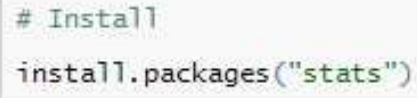


Table G-1-1: New knowledge vs stakeholder satisfaction

\begin{tabular}{|l|c|c|c|}
\hline \multicolumn{1}{|c|}{ Research } & Knowledge & Stakeholder & Inconsistency \\
\hline E1 & 0.8 & 0.2 & 0 \\
\hline E2 & 0.1 & 0.9 & 0 \\
\hline E3 & 0.6 & 0.4 & 0 \\
\hline E4 & 0.6 & 0.4 & 0 \\
\hline E5 & 0.9 & 0.1 & 0 \\
\hline E6 & 0.4 & 0.6 & 0 \\
\hline E7 & 0.5 & 0.5 & 0 \\
\hline E8 & 0.6 & 0.4 & 0 \\
\hline Mean & $\mathbf{0 . 5 6}$ & $\mathbf{0 . 4 4}$ & \\
\hline Minimum & $\mathbf{0 . 1}$ & $\mathbf{0 . 1}$ & \\
\hline Maximum & $\mathbf{0 . 9}$ & $\mathbf{0 . 9}$ & \\
\hline Std. Deviation & $\mathbf{0 . 2 3}$ & $\mathbf{0 . 2 3}$ & \\
\hline Disagreement & & & $\mathbf{0 . 1 7 2}$ \\
\hline
\end{tabular}

\begin{tabular}{|c|c|c|c|c|c|c|c|}
\hline \multicolumn{4}{|l|}{ Cluster A } & \multirow{2}{*}{\begin{tabular}{|l|} 
Research \\
R1 Obj1 \\
\end{tabular}} & \multicolumn{3}{|c|}{ Knowledge Stakeholder Inconsistency } \\
\hline Research & Knowledge & Stakeholder & Inconsistency & & 0.6 & 0.4 & 0 \\
\hline R1 Obj1 & 0.8 & 0.2 & 0 & R2 Obj1 & 0.6 & 0.4 & 0 \\
\hline R5 Obj1 & 0.9 & 0.1 & 0 & R3 Obj1 & 0.6 & 0.4 & 0 \\
\hline Mean & 0.85 & 0.15 & & R4 Obj1 & 0.4 & 0.6 & 0 \\
\hline Minimum & 0.8 & 0.1 & & R5 Obj1 & 0.5 & 0.5 & 0 \\
\hline Maximum & 0.9 & 0.2 & & Mean & 0.54 & 0.46 & \\
\hline Std. Deviation & 0.05 & 0.05 & & Minimum & 0.4 & 0.4 & \\
\hline Disagreement & & & 0.05 & Maximum & 0.6 & 0.6 & \\
\hline & & & & Std. Deviation & 0.08 & 0.08 & \\
\hline & & & & Disagreement & & & 0.072 \\
\hline
\end{tabular}




\section{Appendix G-2: Student Involvement vs. Student Development}

\#This expert data quantifiess goals relative to objective 2 obj2 <- read.csv ("C:/Users/Owner/Desktop/Dendrographs/obj2.csv") $(\mathrm{obj} 2)$

$\begin{array}{lllll}\# \# & & S I & S D \\ \# \# & 1 & 30 & 70 \\ \# \# & 2 & 80 & 20 \\ \# \# & 3 & 50 & 50 \\ \# \# & 4 & 70 & 30 \\ \# \# & 5 & 60 & 40 \\ \# \# & 6 & 60 & 40 \\ \# \# & 7 & 74 & 26 \\ \# \# & 8 & 50 & 50\end{array}$

\#Clustering of goals related to obj2

$s=\operatorname{dist}($ obj 2$)$

s.hclust $=$ hclust (s)

plot(s.hclust, main = "Cluster Dendrogram: student involvement vs development", xlab =

"Clusters of Panel 2 experts")

groups1 <- cutree(s.hclust, $k=2$ ) \# cut tree into 2 clusters

\# draw dendogram with red borders around the 3 clusters

rect.hclust (s.hclust, $k=2$, border="red")

Cluster Dendrogram: student involvement vs development

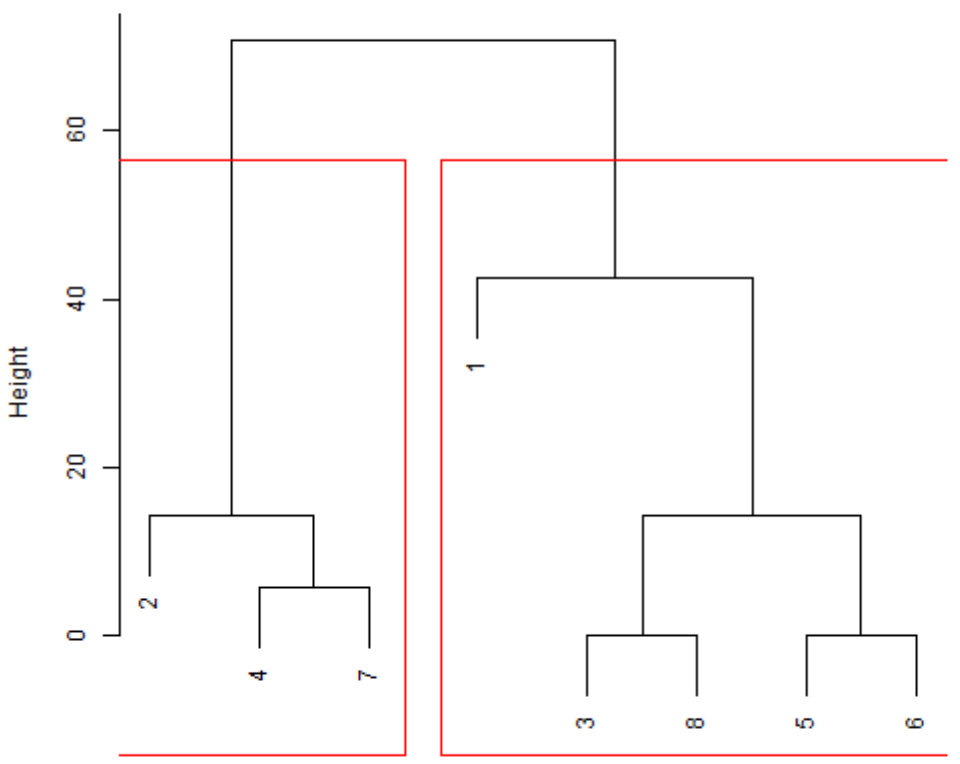

Clusters of Panel 2 experts hclust ( ${ }^{*}$, "complete") 


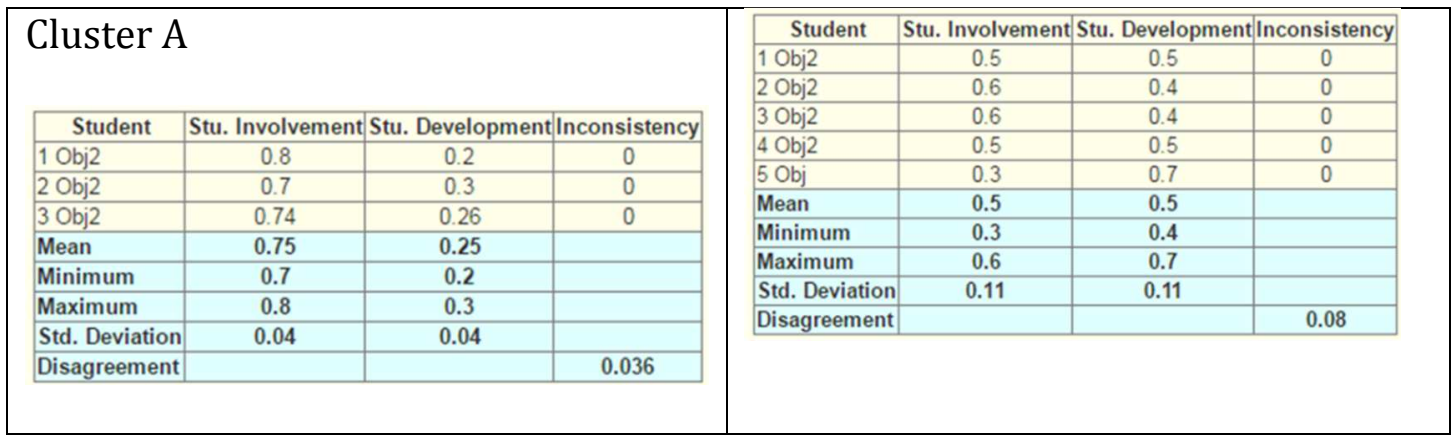

\section{Appendix G-3: KTT Medium vs. KTT Object}

\#This data quantifies goals relative to objective 3

obj3 <- read.csv ("C:/Users/Owner/Desktop/Dendrographs/obj3.csv") (obj3)

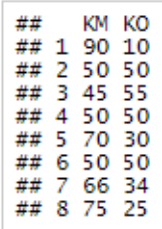


\#Clustering of goals related to objective 3

$\mathrm{t}=\operatorname{dist}(\mathrm{obj} 3)$

t.hclust $=$ hclust $(t)$

plot (t.hclust, main = "Cluster Dendrogram: KTT mediums vs objects", $x 1$ ab = "Clusters of Panel 2 experts")

Cluster Dendrogram: KTT mediums vs objects

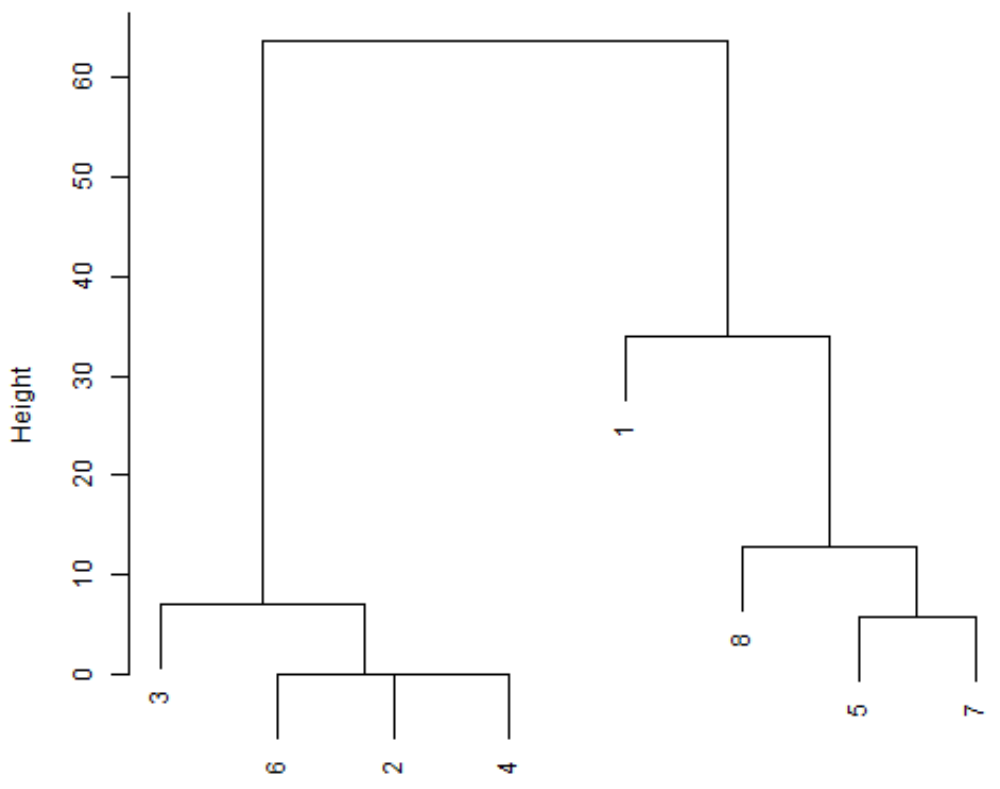

Clusters of Panel 2 experts

hclust (*, "complete")

\begin{tabular}{|l|c|c|c|}
\hline \multicolumn{1}{|c|}{ KTT } & KTT Medium & KTT Object & Inconsistency \\
\hline 1 Obj3 & 0.45 & 0.55 & 0 \\
\hline 2 Obj3 & 0.5 & 0.5 & 0 \\
\hline 3 Obj3 & 0.5 & 0.5 & 0 \\
\hline 4 Obj3 & 0.5 & 0.5 & 0 \\
\hline Mean & 0.49 & 0.51 & \\
\hline Minimum & 0.45 & 0.5 & \\
\hline Maximum & 0.5 & 0.55 & \\
\hline Std. Deviation & 0.02 & 0.02 & \\
\hline Disagreement & & & 0.019 \\
\hline
\end{tabular}

\begin{tabular}{|l|c|c|c|}
\hline \multicolumn{1}{|c|}{ KTT } & KTT Medium & KTT Object & Inconsistency \\
\hline 1 Obj3 & 0.7 & 0.3 & 0 \\
\hline 2 Obj3 & 0.66 & 0.34 & 0 \\
\hline $3 \mathrm{Obj} 3$ & 0.75 & 0.25 & 0 \\
\hline $4 \mathrm{Obj} 3$ & 0.9 & 0.1 & 0 \\
\hline Mean & 0.75 & 0.25 & \\
\hline Minimum & 0.66 & 0.1 & \\
\hline Maximum & 0.9 & 0.34 & \\
\hline Std. Deviation & 0.09 & 0.09 & \\
\hline Disagreement & & & 0.074 \\
\hline
\end{tabular}




\section{Appendix G-4: New knowledge outputs}

\#This data quantifies outputs relative to knowledge

\#These data sets are for outputs $\underset{(N K)}{\text { NK }}<-$ read.table("C:/Users/Owner/Desktop/Dendrographs/NK.csv", header=T, quote=" "'")

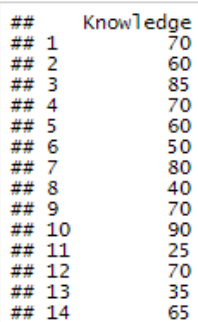

groups $1<-$ cutree $(r . h c l u s t, k=3)$ \# cut tree into 3 clusters

\# draw dendogram with red borders around the 3 clusters

\#rect. hclust ( $r$. hclust, $k=2$, border="red")

\#Clustering of knowledge outputs

Kfit $=\operatorname{dist}(\mathrm{NK})$

Kfit.hclust $=$ hclust (Kfit)

plot(Kfit.hclust, main = "Cluster Dendrogram: knowledge outputs", xlab = "Clusters of Panel 3 experts

groups1 <- cutree(Kfit.hclust, $k=3$ ) \# cut tree into 3 clusters

\# draw dendogram with red borders around the 3 clusters

rect.hclust (Kfit.hclust, $k=3$, border="red")

Cluster Dendrogram: knowledge outputs

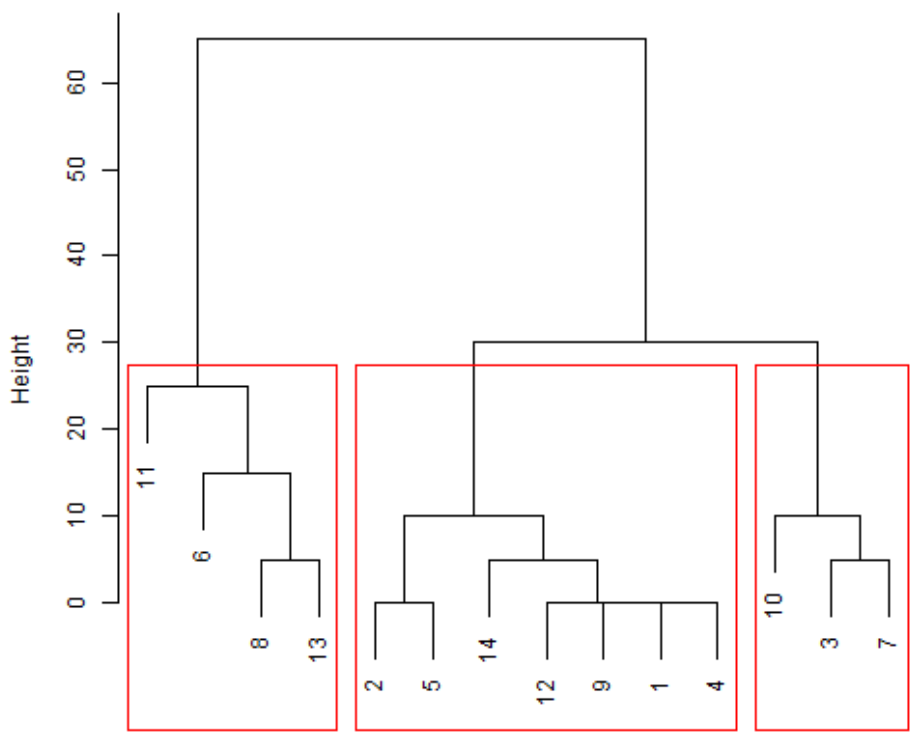

Clusters of Panel 3 experts hclust ( ${ }^{*}$, "complete") 


\begin{tabular}{|l|c|c|c|}
\hline \multicolumn{1}{|c|}{ Knowledge } & Coll Project & Coll Paper & Inconsistency \\
\hline E1 & 0.25 & 0.75 & 0 \\
\hline E2 & 0.5 & 0.5 & 0 \\
\hline E3 & 0.4 & 0.6 & 0 \\
\hline E4 & 0.35 & 0.65 & 0 \\
\hline Mean & $\mathbf{0 . 3 8}$ & $\mathbf{0 . 6 3}$ & \\
\hline Minimum & $\mathbf{0 . 2 5}$ & $\mathbf{0 . 5}$ & \\
\hline Maximum & $\mathbf{0 . 5}$ & $\mathbf{0 . 7 5}$ & \\
\hline Std. Deviation & $\mathbf{0 . 0 9}$ & $\mathbf{0 . 0 9}$ & \\
\hline Disagreement & & & $\mathbf{0 . 0 7 5}$ \\
\hline
\end{tabular}

Cluster A

\begin{tabular}{|l|c|c|c|}
\hline \multicolumn{1}{|c|}{ Knowledge } & Coll Project & Coll Paper & Inconsistency \\
\hline E1 & 0.7 & 0.3 & 0 \\
\hline E2 & 0.65 & 0.35 & 0 \\
\hline E3 & 0.7 & 0.3 & 0 \\
\hline E4 & 0.6 & 0.4 & 0 \\
\hline E5 & 0.7 & 0.3 & 0 \\
\hline E6 & 0.6 & 0.4 & 0 \\
\hline E7 & 0.7 & 0.3 & 0 \\
\hline Mean & $\mathbf{0 . 6 6}$ & $\mathbf{0 . 3 4}$ & \\
\hline Minimum & $\mathbf{0 . 6}$ & $\mathbf{0 . 3}$ & \\
\hline Maximum & $\mathbf{0 . 7}$ & $\mathbf{0 . 4}$ & \\
\hline Std. Deviation & $\mathbf{0 . 0 4}$ & $\mathbf{0 . 0 4}$ & \\
\hline Disagreement & & & $\mathbf{0 . 0 4 1}$ \\
\hline
\end{tabular}

Cluster B above and Cluster C below

\begin{tabular}{|l|c|c|c|}
\hline \multicolumn{1}{|c|}{ Knowledge } & Coll Project & Coll Paper & Inconsistency \\
\hline E1 & 0.9 & 0.1 & 0 \\
\hline E2 & 0.85 & 0.15 & 0 \\
\hline E3 & 0.8 & 0.2 & 0 \\
\hline Mean & $\mathbf{0 . 8 5}$ & $\mathbf{0 . 1 5}$ & \\
\hline Minimum & $\mathbf{0 . 8}$ & $\mathbf{0 . 1}$ & \\
\hline Maximum & $\mathbf{0 . 9}$ & $\mathbf{0 . 2}$ & \\
\hline Std. Deviation & $\mathbf{0 . 0 4}$ & $\mathbf{0 . 0 4}$ & \\
\hline Disagreement & & & $\mathbf{0 . 0 3 3}$ \\
\hline
\end{tabular}




\section{Appendix G-5: Stakeholder satisfaction outputs}

\section{5 <- read.csv("C:/Users/Owner/Desktop/Dendrographs/55. csv")}

(55)

$\begin{array}{lrrrr}\# \# & & \text { IAB_L } & \text { R_L } & \text { IAB_R } \\ \# \# & 1 & 60 & 50 & 60 \\ \# \# & 2 & 50 & 40 & 70 \\ \# \# & 3 & 20 & 10 & 52 \\ \# \# & 4 & 70 & 63 & 80 \\ \# \# & 5 & 50 & 10 & 80 \\ \# \# & 6 & 70 & 50 & 60 \\ \# \# & 7 & 50 & 25 & 75 \\ \# \# & 8 & 30 & 60 & 40 \\ \# \# & 9 & 60 & 25 & 70 \\ \# \# 10 & 50 & 50 & 50 \\ \# \# 11 & 25 & 50 & 25 \\ \# \# 12 & 20 & 10 & 20 \\ \# \# & 13 & 66 & 40 & 75 \\ \# \# & 14 & 70 & 30 & 65\end{array}$

\#Clustering of stakeholder satisfaction outputs

ssfit $=\operatorname{dist}($ SS $)$

ssfit.hclust $=$ hclust (ssfit)

plot(SSfit.hclust, main = "Cluster Dendrogram: stakeholder satisfaction outputs", x1ab

= "Clusters of Panel 3 experts")

groups1 <- cutree(SSfit.hclust, k=4) \# cut tree into 4 clusters

\# draw dendogram with red borders around the 3 clusters

rect.hclust (Ssfit.hclust, $k=4$, border="red")

Cluster Dendrogram: stakeholder satisfaction outputs

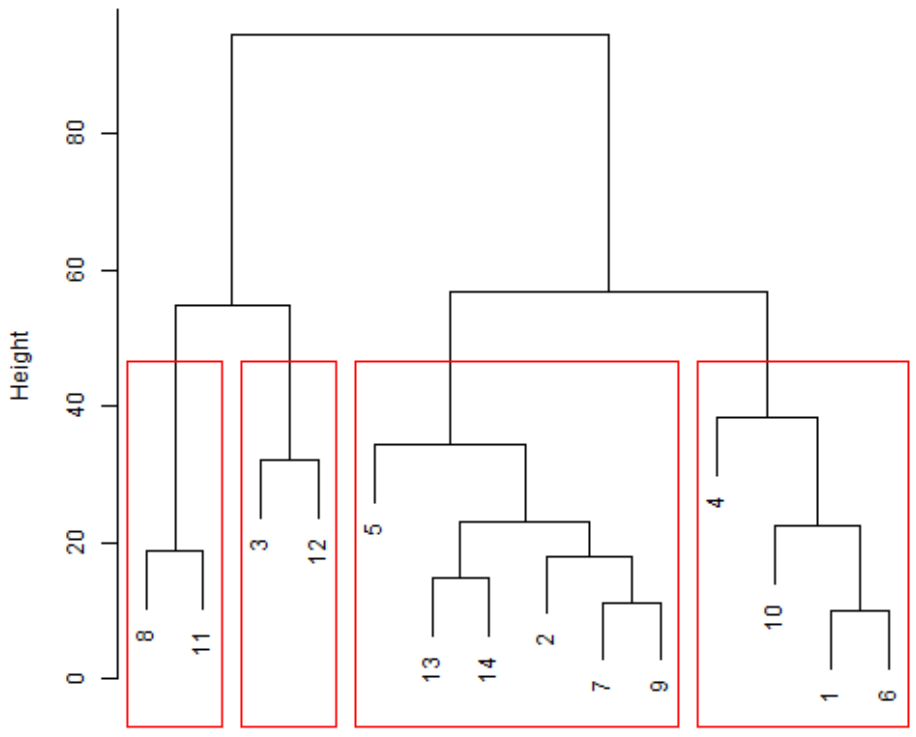

Clusters of Panel 3 experts hclust ( ${ }^{*}$, "complete") 


\begin{tabular}{|c|c|c|c|c|c|}
\hline Stakeholder & $\begin{array}{l}\text { IAB } \\
\text { Sat }\end{array}$ & $\begin{array}{l}\text { Lev. } \\
\text { Funding }\end{array}$ & $\begin{array}{l}\text { Research } \\
\text { Sat }\end{array}$ & & \multirow[t]{8}{*}{ Cluster A } \\
\hline E1 & 0.21 & 0.37 & 0.42 & & \\
\hline E2 & 0.14 & 0.43 & 0.43 & & \\
\hline Mean & 0.18 & 0.4 & 0.43 & & \\
\hline Minimum & 0.14 & 0.37 & 0.42 & & \\
\hline Maximum & 0.21 & 0.43 & 0.43 & & \\
\hline Std. Deviation & 0.04 & 0.03 & 0 & & \\
\hline Disagreement & & & & 0.027 & \\
\hline Stakeholder & $\begin{array}{l}\text { IAB } \\
\text { Sat } \\
\end{array}$ & $\begin{array}{l}\text { Lev. } \\
\text { Funding }\end{array}$ & $\begin{array}{l}\text { Research } \\
\text { Sat }\end{array}$ & & \multirow[t]{8}{*}{ Cluster B } \\
\hline E1 & 0.14 & 0.75 & 0.11 & & \\
\hline E2 & 0.1 & 0.71 & 0.19 & & \\
\hline Mean & 0.12 & 0.73 & 0.15 & & \\
\hline Minimum & 0.1 & 0.71 & 0.11 & & \\
\hline Maximum & 0.14 & 0.75 & 0.19 & & \\
\hline $\begin{array}{l}\text { Std. } \\
\text { Deviation }\end{array}$ & 0.02 & 0.02 & 0.04 & & \\
\hline $\begin{array}{l}\text { Disagreemen } \\
t\end{array}$ & & & & 0.028 & \\
\hline Stakeholder & $\begin{array}{l}\text { IAB } \\
\text { Sat } \\
\end{array}$ & $\begin{array}{l}\text { Lev. } \\
\text { Funding }\end{array}$ & $\begin{array}{c}\text { Research } \\
\text { Sat }\end{array}$ & & \multirow[t]{11}{*}{ Cluster C } \\
\hline $\mathrm{E} 1$ & 0.42 & 0.37 & 0.21 & & \\
\hline E2 & 0.4 & 0.52 & 0.08 & & \\
\hline E3 & 0.43 & 0.43 & 0.14 & & \\
\hline E4 & 0.46 & 0.38 & 0.16 & & \\
\hline $\begin{array}{l}\text { E5 } \\
\text { E6 }\end{array}$ & $\begin{array}{c}0.54 \\
0.5\end{array}$ & $\begin{array}{ll}0.28 \\
0.31\end{array}$ & 0.18 & & \\
\hline Mean & 0.46 & 0.38 & 0.16 & & \\
\hline Minimum & 0.4 & 0.28 & 0.08 & & \\
\hline Maximum & 0.54 & 0.52 & 0.21 & & \\
\hline Std. Deviation & 0.05 & 0.08 & 0.04 & & \\
\hline Disagreement & & & & 0.05 & \\
\hline Stakeholder & $\begin{array}{l}\text { IAB } \\
\text { Sat } \\
\end{array}$ & $\begin{array}{l}\text { Lev. } \\
\text { Funding }\end{array}$ & $\begin{array}{l}\text { Research } \\
\text { Sat }\end{array}$ & & \multirow[t]{10}{*}{ Cluster D } \\
\hline E1 & 0.43 & 0.29 & 0.29 & & \\
\hline E2 & 0.6 & 0.18 & 0.22 & & \\
\hline E3 & 0.48 & 0.24 & 0.28 & & \\
\hline E4 & 0.33 & 0.33 & 0.33 & & \\
\hline Mean & 0.46 & 0.26 & 0.28 & & \\
\hline Minimum & 0.33 & 0.18 & 0.22 & & \\
\hline Maximum & 0.6 & 0.33 & 0.33 & & \\
\hline Std. Deviation & 0.1 & 0.06 & 0.04 & & \\
\hline Disagreement & & & & 0.058 & \\
\hline
\end{tabular}


Appendix G-6: Student involvement outputs

SI <- read.table("C:/Users/Owner/Desktop/Dendrographs/si.csv", header=T, quote=" $\backslash "$ ") (SI)

$\begin{array}{lrr}\# \# & \text { Mtg_Top } \\ \# \# & 1 & 50 \\ \# \# & 2 & 74 \\ \# \# & 3 & 21 \\ \# \# & 4 & 60 \\ \# \# & 5 & 50 \\ \# \# & 6 & 20 \\ \# \# & 7 & 50 \\ \# \# & 8 & 10 \\ \# \# & 9 & 25 \\ \# \# & 10 & 40 \\ \# \# & 11 & 20 \\ \# \# & 12 & 50 \\ \# \# & 13 & 20\end{array}$

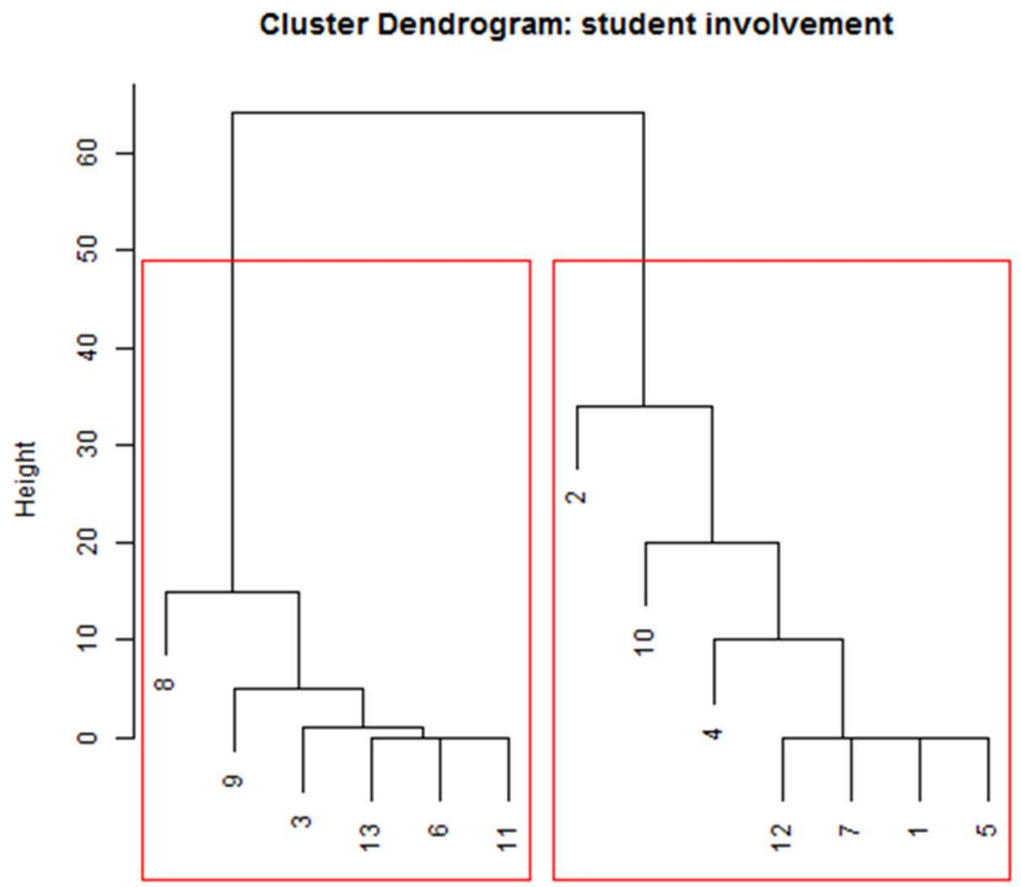

Clusters of Panel 4 experts 


\section{Appendix G-7: Student development outputs}

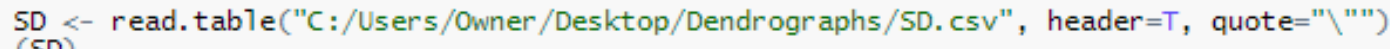

$\begin{array}{llr}\# \# & \text { Proj_Pres } \\ \# \# & 1 & 50 \\ \# \# & 2 & 75 \\ \# \# & 3 & 65 \\ \# \# & 4 & 20 \\ \# \# & 5 & 80 \\ \# \# & 6 & 50 \\ \# \# & 7 & 70 \\ \# \# & 8 & 65 \\ \# \# & 9 & 75 \\ \# \# & 10 & 75 \\ \# \# & 11 & 50 \\ \# \# & 12 & 35 \\ \# \# 13 & 60\end{array}$

\#Clustering of student development outputs

SDfit $=\operatorname{dist}(\mathrm{SD})$

sDfit.hclust $=$ hclust (SDfit)

plot(SDfit.hclust, main = "Cluster Dendrogram: student development", xlab = "Clusters of Panel 4 experts")

groups1 <- cutree(SDfit.hclust, k=3) \# cut tree into 3 clusters

\# draw dendogram with red borders around the 3 clusters

rect.hclust (SDfit.hclust, $k=3$, border="red")

Cluster Dendrogram: student development

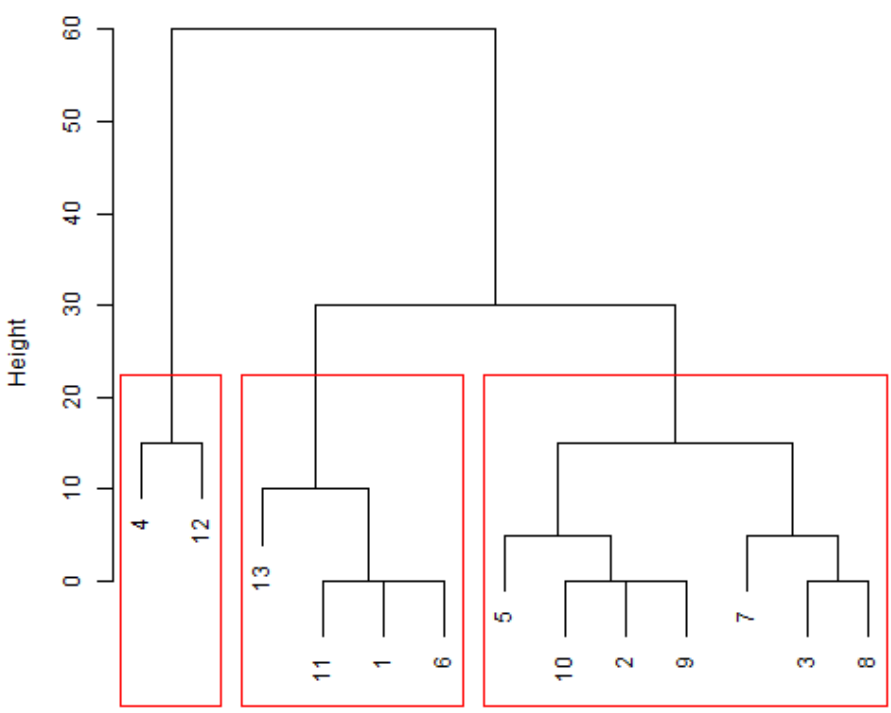


Appendix H: Case Study Data

Appendix H-1: IUCRC selection

IUCRC selection criteria was based upon those centers submitting proposals for the program in 2010 that were funded for 2011. Re-invented centers were removed from the list. Then, records were examined to determine which centers had reported a full set of data for the full 3 years under investigation. Six(6) centers were selected for the study.

\begin{tabular}{|c|l|c|c|}
\hline Funded & Center & $\begin{array}{c}\text { Continuous } \\
\text { Program }\end{array}$ & $\begin{array}{c}\text { Full Data } \\
\text { Report }\end{array}$ \\
\hline 2011 & Advanced Processing & No & \\
\hline 2011 & $\begin{array}{l}\text { Ceramics Composites and Optical Materials } \\
\text { Center }\end{array}$ & No & \\
\hline 2011 & Design of Analog/Digital & No & \\
\hline 2011 & Electric Vehicles & Yes & Yes \\
\hline 2011 & Energy Harvesting Materials and Systems & Yes & No \\
\hline 2011 & Integrative Joining of Materials for Energy & Yes & Yes \\
\hline 2011 & Membrane Science & No & \\
\hline 2011 & Nondestructive Eval & No & Yes \\
\hline 2011 & Pharmaceutical Development & Yes & No \\
\hline 2011 & Power Systems & Yes & No \\
\hline 2011 & Resource Recovery & Yes & Yes \\
\hline 2011 & Security, Software and Engineering & Yes & Yes \\
\hline 2011 & Surveillance Research & Yes & Yes \\
\hline 2011 & Water Equipment and Policy & Yes & Yes \\
\hline 2011 & Wood-Based Composites & Yes & \\
\hline
\end{tabular}


Appendix H-2: Center resource data 2016 from partner websites

\begin{tabular}{|c|c|c|c|}
\hline Faculty & Members & Directors/Staff & Students \\
\hline \multicolumn{4}{|c|}{ Manufacturing and Materials Joining innovcation center (Ma2JIC) } \\
\hline $\begin{array}{l}\text { S Babu (UTK) } \\
\text { A Benatar (OSU) } \\
\text { J Lippold (OSU) } \\
\text { M Mills (OSU) } \\
\text { Z YU (Mines) } \\
\text { W Zhang (OSU) } \\
\text { B Alexandrov (OSU) } \\
\text { A Londono (OSU) } \\
\text { J DuPont (Lehigh) } \\
\text { C Rawn (UTK) } \\
\text { L Stephen (Mines) }\end{array}$ & $\begin{array}{l}\text { Air Force, Acute Tech Services, Alstom } \\
\text { Power, Arcelor Mittal, AZZ, } \\
\text { Babcock\&Wilcox, Cameron, Computhem } \\
\text { LLC, Edison Welding Inst., Electric Power, } \\
\text { ESI NA, Exxon Mobil, FMC Tech, GE Energy } \\
\text { Infra., Hobart (ITW), Honda, Los Alamos } \\
\text { Nat Lab, NASA, NIST, Oak Ridge Nat Lab, } \\
\text { OneSubsea, Petrobras, Rolls-Royce, Shell, } \\
\text { Special Metals, Stress Engineering, Lincoln } \\
\text { Electric, Thermo-Calc Soft., Vallourec }\end{array}$ & $\begin{array}{l}\text { A Londono (OSU) } \\
\text { J DuPont (Lehigh) } \\
\text { C Rawn (UTK) } \\
\text { L Stephen (Mines) }\end{array}$ & $\begin{array}{l}\text { OSU:24 } \\
\text { Mines:2 } \\
\text { Lehigh:2 } \\
\text { UKT:2 }\end{array}$ \\
\hline \multicolumn{4}{|c|}{ Center for Pharmaceutical Development (CPD) } \\
\hline $\begin{array}{l}\text { S Behrens (G) } \\
\text { P Bummer (UK) } \\
\text { B Anderson (UK) } \\
\text { T Dziubla (UK) } \\
\text { A F Miller (UK) } \\
\text { S Lutz (Emory) } \\
\text { D Pack (UK) }\end{array}$ & $\begin{array}{l}\text { Allergan } \\
\text { AbbVie } \\
\text { Genetech } \\
\text { Alkermes } \\
\text { DSM Innovative Synthesis }\end{array}$ & $\begin{array}{l}\text { A Bommarius (G) } \\
\text { E Munson (UK) } \\
\text { Evaluator: } \\
\text { C Scott }\end{array}$ & $\begin{array}{l}\text { Not listed } \\
\text { on website } \\
\text { http://cpd. } \\
\text { gatech.edu }\end{array}$ \\
\hline \multicolumn{4}{|c|}{ Security and Software Engineering research Center (S2ERC) } \\
\hline 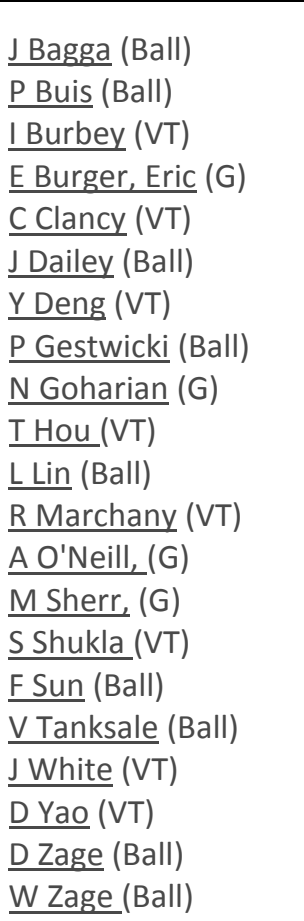 & $\begin{array}{l}\text { Airbus, AT\&T, Beulah Works LLC, Boeing } \\
\text { Research and Technology, CACl, } \\
\text { Comcast,iconectiv, Internet Identity, John } \\
\text { Deere, L-3 Stratis, LGS } \\
\text { Innovations, National Aeronautics and } \\
\text { Space Administration, Naval Surface } \\
\text { Warfare Center, Northrop Grumman } \\
\text { Aerospace Systems, Northrop Grumman } \\
\text { Electronic Systems, Northrop Grumman } \\
\text { Information Systems,Office of the Secretary } \\
\text { of Defense, Ontario Systems, Pacific } \\
\text { Northwest National Laboratory, } \\
\text { Raytheon, Rockwell } \\
\text { Collins, SAIC, Symantec, U.S. Air Force } \\
\text { Research Laboratory, U.S. Department of } \\
\text { Homeland Security, VeriSign Labs, verizon, } \\
\text { Workiva }\end{array}$ & $\begin{array}{l}\text { W Zage (BSU) } \\
\text { E Burger (G) } \\
\text { C Clancy (VT) }\end{array}$ & $\begin{array}{l}\text { Not listed } \\
\text { on website } \\
\text { http://serc. } \\
\text { net }\end{array}$ \\
\hline
\end{tabular}




\begin{tabular}{|c|c|c|c|}
\hline \multicolumn{4}{|c|}{ Center for Surveillance Research (CSR) } \\
\hline $\begin{array}{l}\text { AT WSU: } \\
\text { J Ash, E Brown, } \\
\text { M Fendley, D Petke, } \\
\text { B Rigling, M Saville, } \\
\text { A Shaw, J Skipper } \\
\text { AT OSU: } \\
\text { Y Chi, J Davi,U, } \\
\text { E Ertin,R Moses, } \\
\text { L Potter, P Schniter } \\
\text { D Woods, A Yilmaz }\end{array}$ & $\begin{array}{l}\text { Air Force Research Lab, Army Research Lab, } \\
\text { Boeing, Brilligent Solutions Inc., Etegent } \\
\text { Technologies, Leidos, Raytheon }\end{array}$ & $\begin{array}{l}\text { E Zelnio (AF) } \\
\text { B Myers (Wright) } \\
\text { B Rigling (Wright) } \\
\text { L Potter (OSU) } \\
\text { Evaluator: } \\
\text { T Hill }\end{array}$ & $\begin{array}{l}\text { Not listed } \\
\text { on website } \\
\text { http:// } \\
\text { csr.osu.edu }\end{array}$ \\
\hline \multicolumn{4}{|c|}{ Water Equipment Policy (WEP) } \\
\hline $\begin{array}{l}\text { N Zahara UWM } \\
\text { F Bender MU } \\
\text { H Bootsma UWM } \\
\text { H BravoUWM } \\
\text { J Chen UWM } \\
\text { T Grundl UWM } \\
\text { J Hossenlopp MU } \\
\text { Z He UWM } \\
\text { F Josse MU } \\
\text { CH Lee MU } \\
\text { J Li UWM } \\
\text { Y Li UWM } \\
\text { M Nosonovsky } \\
\text { UWM } \\
\text { P Rohatgi UWM } \\
\text { J Schaefer MU } \\
\text { MSwitzenbaum MU } \\
\text { C Tran MU } \\
\text { S White UW-M } \\
\text { D Zitomer MU }\end{array}$ & $\begin{array}{l}\text { AO Smith, Badger Meter, Inc., Baker } \\
\text { Manufacturing, City of Fond du Lac, Mango } \\
\text { Materials, Marmon Water, MMSD, } \\
\text { Metropolitan Water Reclamation District of } \\
\text { Greater Chicago, New Water, Sloan, } \\
\text { Pentair, Veolia Water, Rexnord, Wisconsin } \\
\text { Dept of Natural Resources, US } \\
\text { Environmental Protection Agency, Veolia } \\
\text { Water, Wisconsin Department of Natural } \\
\text { Resources }\end{array}$ & $\begin{array}{l}\text { J Chen (UWM) } \\
\text { D Zitomer (M) } \\
\text { Evaluator: } \\
\text { D Rivers }\end{array}$ & $\begin{array}{l}\text { Not listed } \\
\text { on website } \\
\text { http:// } \\
\text { www4.uw } \\
\text { m.edu }\end{array}$ \\
\hline \multicolumn{4}{|c|}{ Wood-Based Composites Center (WBC) } \\
\hline $\begin{array}{l}\text { C Frazier VT } \\
\text { F Kamke OSU } \\
\text { A Li OSU } \\
\text { L Muszynski OSU } \\
\text { J Nairn OSU } \\
\text { L Schimleck OSU } \\
\text { J Simonsen OSU } \\
\text { A Sinha OSU } \\
\text { R Smith VT } \\
\text { A Zink-Sharp VT }\end{array}$ & $\begin{array}{l}\text { Arauco North America, Arclin } \\
\text { Ashland, Boise Cascade, Columbia Forest } \\
\text { Products, } \\
\text { Fraunhofer, WKI Institute for Wood } \\
\text { Research, Georgia-Pacific Chemicals, } \\
\text { Henkel Corporation, Hexion } \\
\text { LP Building Products, Oxiquim } \\
\text { Queensland (Australia) Government, } \\
\text { Solenis, States Industries, Willamette Valley } \\
\text { Company }\end{array}$ & $\begin{array}{l}\text { C Frazier (VT) } \\
\text { L Caudill (VT) } \\
\text { F Kamke (OSU) } \\
\text { Evaluator: } \\
\text { E Sundstrom }\end{array}$ & $\begin{array}{l}\text { OSU: } 6 \\
\text { VT: } 6 \\
\text { NCSU: } 2 \\
\text { UoBC: } 1 \\
\text { wbc.vt.edu }\end{array}$ \\
\hline
\end{tabular}


Appendix H-3: Secondary Data Sources

\begin{tabular}{|c|c|c|c|}
\hline Output & Metric & Data & Data Source \\
\hline \multirow[t]{2}{*}{ Collaborative Projects } & \multirow[t]{2}{*}{ \% Collaboration } & \# Collaborative projects & Web Site \\
\hline & & \# Total projects & $\mathrm{SI}$ \\
\hline Collaborative Papers & \# Papers & \# Collaborative papers & $\mathrm{SI}$ \\
\hline \multirow{2}{*}{$\begin{array}{l}\text { IAB Member } \\
\text { Satisfaction }\end{array}$} & \multirow[t]{2}{*}{ \% Renewal } & \# Members Left & $\mathrm{SI}$ \\
\hline & & \# Starting IAB members & $\mathrm{SI}$ \\
\hline \multirow[t]{2}{*}{ Leveraged Funding } & \multirow[t]{2}{*}{ Leverage ratio } & \$Total & $\mathrm{SI}$ \\
\hline & & \$NSF & $\mathrm{SI}$ \\
\hline \multirow{2}{*}{$\begin{array}{l}\text { Researcher } \\
\text { Satisfaction }\end{array}$} & \multirow[t]{2}{*}{$\%$ Change } & \# Faculty Scientists this year & $\mathrm{SI}$ \\
\hline & & \# Faculty Scientists last year & $\mathrm{SI}$ \\
\hline \multirow{2}{*}{$\begin{array}{l}\text { Student mtg } \\
\text { attendance }\end{array}$} & \multirow[t]{2}{*}{$\%$ attendance } & \# Non-site student attendance & Minutes \\
\hline & & \# Non-site students & Minutes \\
\hline \multirow[t]{2}{*}{ Student Topic } & \multirow[t]{2}{*}{$\%$ topics } & \# Research topics & Thesis DB \\
\hline & & \# Total students & $\mathrm{SI}$ \\
\hline \multirow{2}{*}{$\begin{array}{l}\text { Student Research } \\
\text { Projects }\end{array}$} & \multirow{2}{*}{$\begin{array}{l}\text { Student } \\
\text { Supervision ratio }\end{array}$} & \# Total Students & $\mathrm{SI}$ \\
\hline & & \# Faculty Scientists & $\mathrm{SI}$ \\
\hline \multirow[t]{2}{*}{ Student Presentations } & \multirow[t]{2}{*}{ \%Presented } & \# Presentations & $\mathrm{SI}$ \\
\hline & & \# Student Presenters & Minutes \\
\hline Student Hires & \# Student Hires & \# Hires & $\mathrm{SI}$ \\
\hline \multirow[t]{2}{*}{ Consulting } & \multirow{2}{*}{$\begin{array}{l}\% \text { Researchers } \\
\text { contracts }\end{array}$} & \# Contracts & SI \\
\hline & & \# Faculty Scientists & $\mathrm{SI}$ \\
\hline \multirow[t]{2}{*}{ Papers Published } & \multirow{2}{*}{$\begin{array}{l}\text { Ratio } \\
\text { papers:researcher }\end{array}$} & \# Published & $\mathrm{SI}$ \\
\hline & & \# Total Researchers & Calculated \\
\hline \multirow[t]{2}{*}{$\begin{array}{l}\text { Training and } \\
\text { Workshops }\end{array}$} & \multirow[t]{2}{*}{$\%$ Attendance } & \# Researcher attendance & Minutes \\
\hline & & \# Faculty Scientists & SI \\
\hline \multirow[t]{2}{*}{ Shared Resources } & \multirow[t]{2}{*}{ Available } & Shared facilities & $\mathrm{SI}$ \\
\hline & & Shared equipment & $\mathrm{SI}$ \\
\hline $\begin{array}{l}\text { New Methods or } \\
\text { Procesess }\end{array}$ & \# New methods & \# Reported in Compendium & Compendium \\
\hline New Products & \# New products & \# Reported on Website & Compendium \\
\hline Licenses & \# New licenses & \# Granted by IUCRC & NSF (DG) \\
\hline
\end{tabular}


Appendix H-4: Example project scoring sheet (WBC 2014)

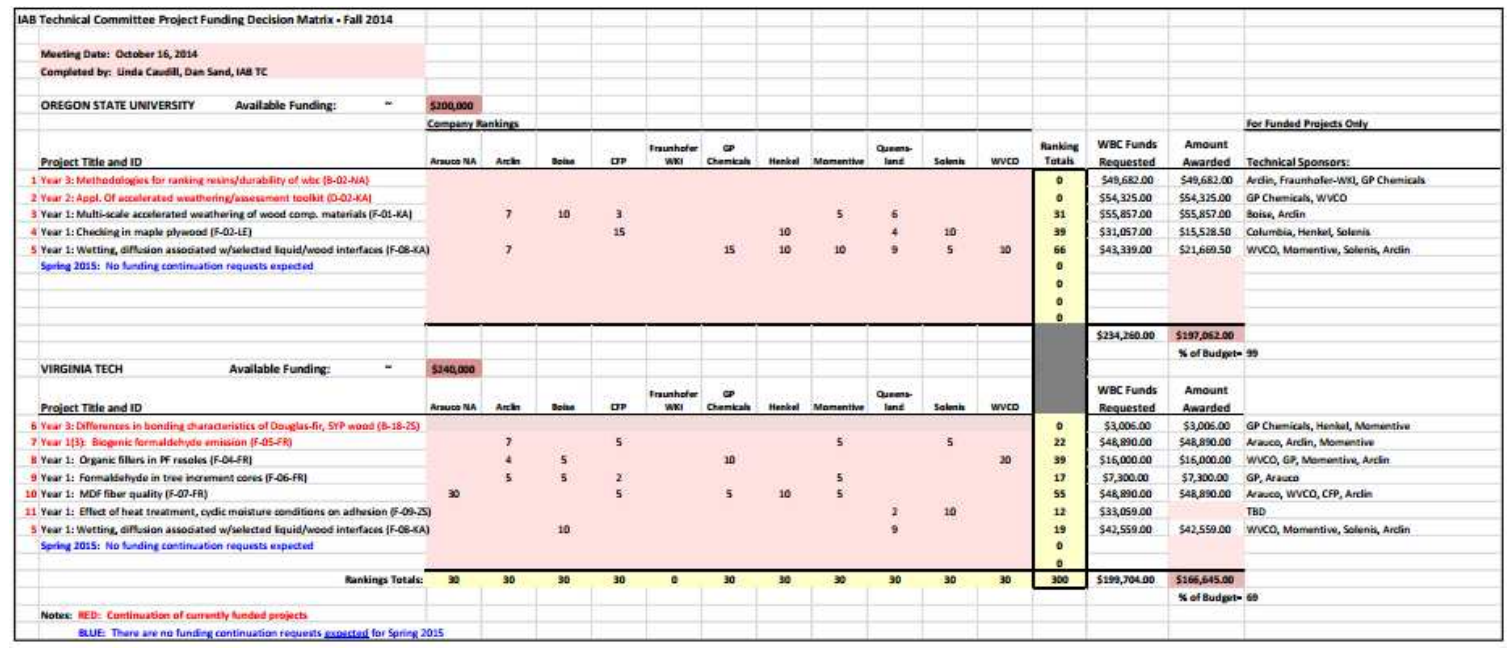

Left Side 


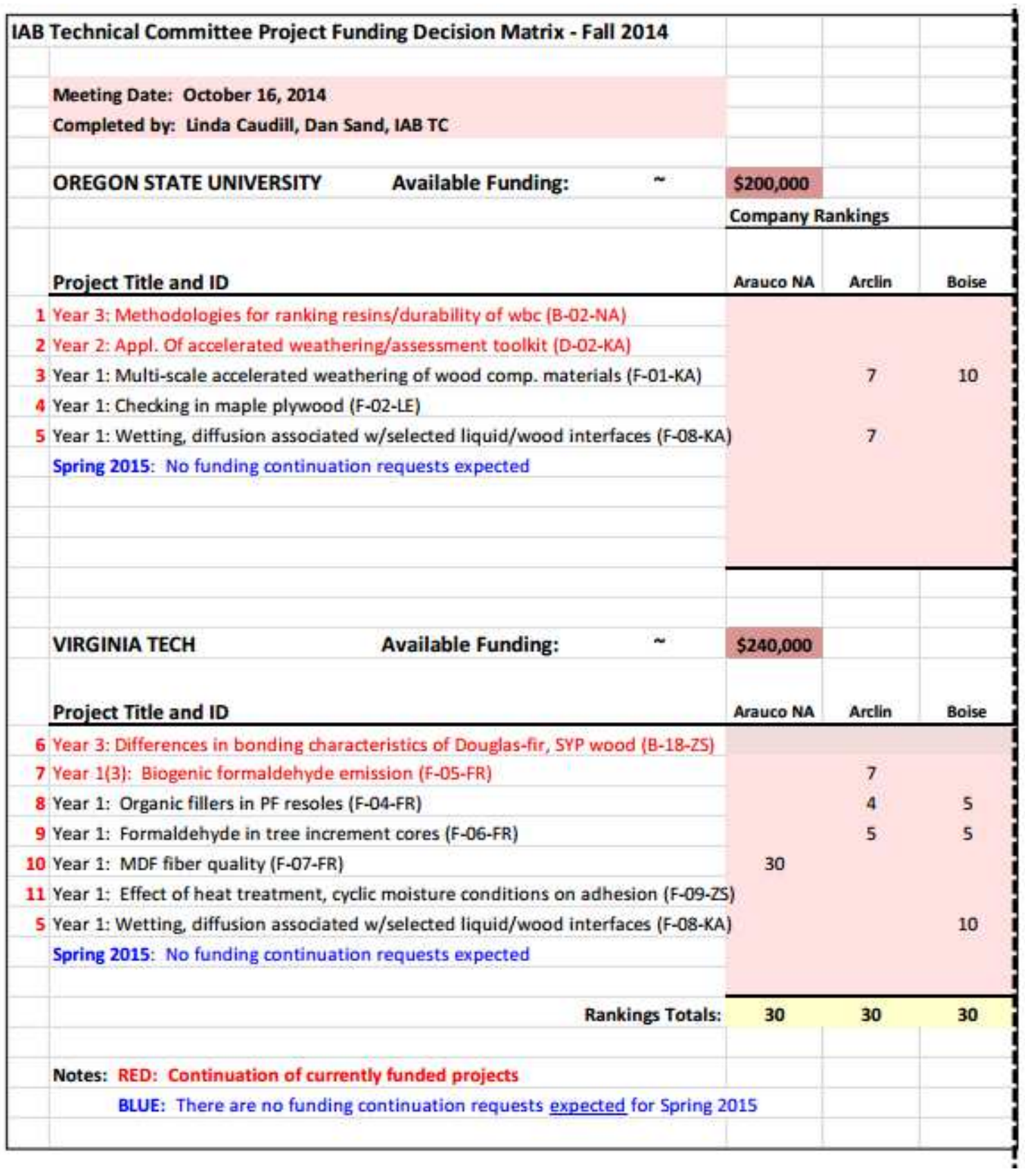

\section{Right Side}




\begin{tabular}{|c|c|c|c|c|c|}
\hline & & & & & \\
\hline & & & & & \\
\hline & & & & & \\
\hline & & & & & \\
\hline & & & & & \\
\hline & & & & & \\
\hline & & & & & For Funded Projects Only \\
\hline Solenis & wvco & $\begin{array}{c}\text { Ranking } \\
\text { Totals }\end{array}$ & $\begin{array}{l}\text { WBC Funds } \\
\text { Requested }\end{array}$ & $\begin{array}{c}\text { Amount } \\
\text { Awarded } \\
\end{array}$ & Technical Sponsors: \\
\hline \multirow{9}{*}{$\begin{array}{c}10 \\
5\end{array}$} & \multirow{9}{*}{10} & 0 & $\$ 49,682.00$ & $\$ 49,682.00$ & Arclin, Fraunhofer-WKI, GP Chemicals \\
\hline & & 0 & $\$ 54,325.00$ & $\$ 54,325.00$ & GP Chemicals, WVCO \\
\hline & & 31 & $\$ 55,857.00$ & $\$ 55,857.00$ & Boise, Arclin \\
\hline & & 39 & $\$ 31,057.00$ & $\$ 15,528.50$ & Columbia, Henkel, Solenis \\
\hline & & 66 & $\$ 43,339.00$ & $\$ 21,669.50$ & WvCO, Momentive, Solenis, Arclin \\
\hline & & 0 & & & \\
\hline & & 0 & & & \\
\hline & & 0 & & & \\
\hline & & 0 & & & \\
\hline \multirow[b]{3}{*}{ Solenis } & \multirow[b]{3}{*}{ wvco } & & $\$ 234,260.00$ & $\$ 197,062.00$ & \\
\hline & & & & $\%$ of Budget = & 99 \\
\hline & & & $\begin{array}{l}\text { WBC Funds } \\
\text { Requested }\end{array}$ & $\begin{array}{l}\text { Amount } \\
\text { Awarded } \\
\end{array}$ & \\
\hline \multirow{3}{*}{5} & & 0 & $\$ 3,006.00$ & $\$ 3,006.00$ & GP Chemicals, Henkel, Momentive \\
\hline & & 22 & $\$ 48,890.00$ & $\$ 48,890.00$ & Arauco, Arclin, Momentive \\
\hline & 20 & 39 & $\$ 16,000.00$ & $\$ 16,000.00$ & WVCO, GP, Momentive, Arclin \\
\hline \multirow{6}{*}{10} & & 17 & $\$ 7,300.00$ & $\$ 7,300.00$ & GP, Arauco \\
\hline & & 55 & $\$ 48,890.00$ & $\$ 48,890.00$ & Arauco, WVCO, CFP, Arclin \\
\hline & & 12 & $\$ 33,059.00$ & & TBD \\
\hline & & 19 & $\$ 42,559.00$ & $\$ 42,559.00$ & WVCO, Momentive, Solenis, Arclin \\
\hline & & 0 & & & \\
\hline & & 0 & & & \\
\hline \multirow[t]{2}{*}{30} & 30 & 300 & $\$ 199,704.00$ & $\$ 166,645.00$ & \\
\hline & & & & \multicolumn{2}{|c|}{$\%$ of Budget $=69$} \\
\hline
\end{tabular}


SUMMARY (FY2015)

Oregon State:

Current requests: $\$ 104,007$ (continuations) $+\$ 130,253$ (new) $=\$ 234,260$

Expected FY2015 continuation requests: Spring 2015 = \$0

Virginia Tech:

Current requests: $\$ 51,896$ (continuations) $+\$ 185,698$ (new) $=\$ 237,594$

Expected FY2015 continuation requests: Spring 2015 $=\$ 0$

\section{CURRENT WBC-FUNDED RESEARCH}

Oregon State University

B-02-NA: Methodologies for ranking resins by their effects on durability of wood composites

\begin{tabular}{|l|l|l|c|c|c|}
\hline Faculty & Technical Sponsors & Award Date & Start Date & End Date & Funding \\
\hline $\begin{array}{l}\text { Oregon State: } \\
\text { J. Nairn }\end{array}$ & Arclin & & & Year $1: \$ 43,498$ \\
A. Sinha & Fraunhofer-WKI & $10 / 18 / 12$ & $1 / 1 / 13$ & & $\begin{array}{c}\text { Year } 2: \$ 43,373 \\
\text { Year } 3: \$ 49,682 \\
\text { GP Chemicals }\end{array}$ \\
$\begin{array}{l}\text { (B. Mirzaei, with } \\
\text { undergraduates } \\
\text { J. Adam, D. Terry) }\end{array}$ & & & & & $\begin{array}{c}\text { Total-date: } \\
\$ 136,553\end{array}$ \\
& & & & & $\begin{array}{c}\text { Expected future } \\
\text { request: } \\
\$ 0\end{array}$ \\
\hline
\end{tabular}

\section{Virginia Tech}

F-04-FR: Organic fillers used in PF resoles

\begin{tabular}{|l|l|l|c|c|c|}
\hline Faculty & Technical Sponsors & Award Date & Start Date & End Date & Funding \\
\hline Virginia Tech: & & & & Year 1: \$16,000 \\
C. Frazier & $\begin{array}{l}\text { Arclin } \\
\text { GP Chemicals } \\
\text { Momentive }\end{array}$ & $10 / 16 / 14$ & $10 / 30 / 14$ & & $\begin{array}{c}\text { Total-to-date: } \\
\$ 0\end{array}$ \\
(X. (Chuck) Wang) & & & & $\begin{array}{c}\text { Expected Year 2 } \\
\text { Request: } \\
\end{array}$ \\
& & & & & $\$ 47,446$ \\
& & & & (Fall 2015) \\
\hline
\end{tabular}




\section{Appendix H-5: WBC Research Project Data}

\section{Current Research Projects (2016)}

\begin{tabular}{|c|c|c|}
\hline Research Project & Config. & Coll \\
\hline $\begin{array}{l}\text { Improving blending efficiency and resin distribution of the rotary drum blending } \\
\text { process using discreet element modeling (G. Smith, Y.-L.(Ingrid) Tsai) }\end{array}$ & UBC & $\mathrm{Y}$ \\
\hline $\begin{array}{l}\text { Multi-scale investigation of adhesive bond durability (P. McKinley, J. Paris, F. } \\
\text { Kamke, A. Sinha) }\end{array}$ & OSU & $\mathrm{N}$ \\
\hline $\begin{array}{l}\text { Multi-scale accelerated weathering of wood composite materials (D. Way, F. } \\
\text { Kamke and A. Sinha) }\end{array}$ & OSU & $\mathrm{N}$ \\
\hline Checking in maple plywood (E. Wilson, S. Leavengood and L. Muszynski) & OSU & $\mathrm{N}$ \\
\hline $\begin{array}{l}\text { Wetting and diffusion associated with selected liquid/wood interfaces (E. Mills, K. } \\
\text { Stables, B. Bakar, F. Kamke and C. Frazier) }\end{array}$ & OSU/VT & Y \\
\hline Organic fillers used in PF resoles (X.C. Wang, C. Frazier) & VT & $\mathrm{N}$ \\
\hline Biogenic formaldehyde emission (G. Wan, C. Frazier) & VT & $\mathrm{N}$ \\
\hline MDF fiber quality (M. Tasooji, C. Frazier) & VT & $\mathrm{N}$ \\
\hline $\begin{array}{l}\text { Numerical simulation of adhesive penetration into realistic wood structures (C. } \\
\text { Hammerquist and J. Nairn) }\end{array}$ & OSU & $\mathrm{N}$ \\
\hline Bio-based polyamide with oligomeric lignin backbone (J. Staudhammer and G. Li) & OSU & $\mathrm{N}$ \\
\hline $\begin{array}{l}\text { Use of acoustic emission to classify wood chips/particles (L. Campbell, R. Lemaster } \\
\text { and G. Velarde) }\end{array}$ & NCSU & Y \\
\hline $\begin{array}{l}\text { Determination of tool life during CNC machining operations for four panel } \\
\text { products (C. Michael, G. Velarde and R. Lemaster) }\end{array}$ & NCSU & Y \\
\hline Comparison of accelerated weathering test protocols (F. Kamke) & OSU & $\mathrm{N}$ \\
\hline Analysis of vertical density profile during hot pressing (F.Kamke) & OSU & $\mathrm{N}$ \\
\hline Comparative analysis of different lignins as phenol substitutes (M.Nejad) & $\mathrm{N} / \mathrm{A}$ & - \\
\hline
\end{tabular}

\section{Past Research Projects (2010-2015)}

- Methodologies for ranking resins by their effects on durability of wood composites (B. Mirzaei, J Nairn and A. Sinha)

- Understanding the differences in bonding characteristics of Douglas-fir and southern yellow pine wood (K. Mirabile, A. Zink-Sharp and S. Renneckar)

- $\quad$ Adhesion fundamentals in spotted gum (Corymbia sp.) (C. Burch and C. Frazier)

- Application of accelerated weathering for the development of an NDT product durability assessment toolkit (P.F. Laleicke and F. Kamke)

- $\quad$ Formaldehyde in tree increment cores (H. Wise and C. Frazier)

- Fundamentals of formaldehyde detection and emission determination (A. Hellenbrand, B. Cole, D. Gardner, R. Fort, C. Frazier, S. Knowles)

- Mechanisms of wood-generated formaldehyde emission (G. Wan and C. Frazier)

- Influence of filler particle size on adhesive penetration and performance (X. Yang and C. Frazier)

- $\quad$ Formaldehyde determination through liquid extraction (M. Tasooji and C. Frazier)

- $\quad$ Resin efficiency for non-structural panels (J. Dettmer, N. Lampert, G. Smith and L. Muszynski) 
- Microscale wood adhesive interaction (J. Paris, M. Schwarzkopf, F. Kamke, J. Nairn and L. Muszynski)

- $\quad$ Developing a reference material for formaldehyde emissions testing (X. Zhao, J. Little, S. Cox and C. Frazier)

- $\quad$ Preliminary investigation of adhesive bonds using IR microscopy (P.Boehm, S. Freitas and F. Kamke)

- $\quad$ Impact of short length veneer on bending properties of LVL (S. Mlasko, M. Belda, R. Gupta, F. Kamke)

- Advancing characterization techniques for structure-property determination of in-situ lignocelluloses (S. Chowhury, C. Frazier)

- The effect of elevated temperature on mechanical behavior of structural wood and wood-based composites (A. Sinha, R. Gupta and J. Nairn)

- Examining the lignin glass transition as a method to screen the effectiveness of wood adhesion coupling agents (J. Hosen and C. Frazier)

- $\quad$ Carboxymethylcellulose acetate butyrate water-dispersions as renewable wood adhesives (J. Paris and C. Frazier)

- $\quad$ Preparation of labeled isocyanates for wood adhesion research (D. Ren and C. Frazier)

- $\quad$ Characterization of mixed-mode fracture testing of adhesively bonded wood specimens (E. Nicoli and D. Dillard)

- $\quad$ New bio-based polymer nanocomposites reinforced with TEMPO-oxidized nanocelluloses (R. Johnson and A. Zink-Sharp)

- $\quad$ Strand dynamics during the oriented strand composites formation process (S. Perry and S. Shaler)

- Effect of cellulose nanocrystals on the rheology, curing behavior and fracture performance of phenol-formaldehyde resol resin (J.K. Hong and M. Roman)

- $\quad$ Photostabilisation of Thermosetting Adhesives (M. Meisner and P. Evans)

- Characterization of Wood Resin-Adhesive Spray (X. Zhang and D. Gardner)

- $\quad$ Simulation modeling for manufacture of wood fiber thermoplastic composites (J.N. Lee and D. Hindman)

- Mechanical analysis of a moisture-cure polyurethane adhesive: dynamic bending versus oscillatory torsion (C. Heinemann)

- Effects of fungal attack on properties of connections between composite sheathing and studs in wood shear walls (N. Melencion and J. Morrell)

- $\quad$ Nanoscale Surface Modification of Wood Veneers for Adhesion (Z. Yu and S. Renneckar)

- $\quad$ DMA Analysis of Solvent Swollen Balsa Wood (J. Hosen and S. Renneckar)

- Non-destructive evaluation of veneer for use in laminated veneer lumber (LVL) using machine vision and ultrasonic stress wave analysis systems (D. DeVallance and J. Funck)

- Multi-scale characterization of wood-thermoplastic composite materials (Y. Wang and L. Muszynski)

- Effect of adhesive on bond durability and associated smoke toxicity for EWP under high temperatures (S. Shi)

- Defining moisture and temperature limits for decay in wood-based composites for use in developing service-life model (S. Shi)

- Applying micro-nano scratch/indentation method to characterize the interfacial bonding shear strength (IBSS) for wood composites and wood-polymer composites (M. Barnes and S. Shi)

- Cellulose fibrils reinforced polymer composites (W. Tze)

- Parallel-plate rheology of polyurethane adhesives in contact with wood (C. Heinemann)

- Polyelectrolytes as adhesives (S. Renneckar)

- Wood/adhesive interactions in a PVAc Latex System (C. Frazier and F.Lopez-Suevos)

- Analysis of structural composite lumber loaded by dowels in perpendicular to grain orientation at yield and capacity (D. Finkenbinder and D. Hindman)

- Coupling model analysis of stress relaxation behavior in Yellow-poplar/HMR system. (N. Sun) 
- Hybrid thermosetting wood adhesives: optimized performance through tailored emulsions. (D. Riedlinger)

- Investigation of Tg as a measure of cure in wood/pMDI systems. (N. Sun)

- Characterization of PF resol/isocyanate hybrid adhesives (D. Riedlinger)

- Using fire-killed trees for wood-based composites (L. Moya and S. Ramaswamy)

- $\quad$ Comparison of Shear Modulus Test Methods (S.K. Harrison and D. Hindman)

- The Influence of Phenolic Additives of PVAc Latex Adhesive Performance (F. Lopez Suevos)

- Improved Interfacial Adhesion in Wood-Plastice Composites: Developments of New Compatibilizers (C. Zhang and K. Li)

- A Preliminary Investigation Of The Properties of Engineered Wood Composite Panels Treated With Copper Naphthenate (J. Kirkpatrick \& M. Barnes)

- Dynamic Mechanical Analysis of the Interphase Morphology of Wood-polymeric Isocyanate Bondlines (S. Das)

- $\quad$ WBC Sim (hot pressing model) (J. Lee,J. Shu and L. Watson)

- Natural Fiber Reinforced Thermoplastic Composites from the Wetlay Process (R. Johnson)

- Effect of Grain Direction on the Dynamic Mechanical Analysis of Wood (S. Das)

- $\quad$ Cure Characterization of a Phenol-formaldehyde Adhesive (B. Scott)

- Dielectric Characterization of Phenol-formaldehyde Cure (B. Scott)

- Hydro-thermal Stabilization of Wood-based Materials (M. Reynolds)

- $\quad$ Effects of Moisture Cycling on the Shear Strength Properties of OSB (N. Deringer)

- $\quad$ Changes in OSB Mat Permeability During Hot-pressing (J. Hood)

- Modification of Wood Fiber with Thermoplastics by Raxtive Steam-Explosion Processing (S. Renneckar)

- An Investigation of Nail Connection Performance in a Cyclic-humidity Conditioned Environment (J. Smith)

- Incentives/Barriers to the Increased Utilization of Wood-Based Structural Panels in Industrial Markets (D. Gilbert, D. Bailey, P. Duvall)

- Infrared Microscopy and Confocal Laser Scanning Microscopy Analysis of Polyolefin Modified Wood Fibers (S. Renneckar)

- Investigating the Surface Energy and Bond Performance of Compression Densified Wood (J. Jennings)

- $\quad$ Self-assembly of Pullulan Abietate (S. Gradwell)

- $\quad$ Studies of PF Resole / Isocyanate Hybrid Adhesives (J. Zheng)

- Molecular Aspects of Performance in Crosslinking PVA Latex Adhesives (N. Brown)

- $\quad$ Rheology of Powdered Phenol Formaldehyde Adhesives (D. Riedlinger)

- $\quad$ Developing the Basis for Capacity Design of Connections (J. Smart)

- Investigation of the Wood / Phenol-Formaldehyde Adhesive Interphase Morphology (M. Laborie)

- Wood Magic in a Distance Education Format (C. Pugh)

- $\quad$ Comparative Analysis of Inactivated Wood Surfaces (M. Sernek)

- $\quad$ Characterizing the Durability of PF and pMDI Adhesives Through Fracture Testing (C. Scoville)

- Mechanism of Flake Drying and Its Correlation to Quality (E. Deomano)

- Improvements in the Fracture Cleavage Testing of Adhesively-Bonded Wood (J. Gagliano)

- $\quad$ Modeling the Transient Effects during the Hot-Pressing of Wood-Based Composites (B. Zombori)

- $\quad$ Feasibility of Implementing a Resin Distribution Measurement System for MDF Fiber (K. Scott)

- $\quad$ Public Perceptions of the U.S. Forest Products Industry (P. Uhrig)

- Wood Material Behavior in Severe Environments (C. Lenth)

- Analysis of Calcutta Bamboo for Structural Composite Materials (M. Ahmad)

- Analysis and Testing of a Ready-to-Assemble Wood Framing System (V. Kochkin)

- $\quad$ The Wood Species Dependence of pMDI Adhesive Performance (M. Malmberg) 
Appendix H-6: WBC Student topics

The data was mined using the "ProQuest Dissertations \& Theses Global" database.

\begin{tabular}{|l|l|l|l|}
\hline Advisor & Type & Year & Topic \\
\hline Frazier & D & 2005 & Wood/polymeric isocyanate resin interactions \\
\hline Smith & D & 2008 & \\
\hline Zink & D & 2010 & TEMPO-oxidized nanocelluloses: \\
\hline Kamke & D & 2009 & Computed tomography analysis of wood-adhesive bonds \\
\hline Lemaster & D** & 2015 & Improvement of Wood-Based Machining Operations... \\
\hline Nairn & D & 2010 & Numerical modeling and experiments on wood-strand... \\
\hline Nairn & D*** & 2010 & The effect of elevated temperature in mechanical behavior... \\
\hline Simonsen & D & 2011 & Transient Electric Birefringence for the Characterization... \\
\hline
\end{tabular}

*Kamke previous advisor at Virginia Tech. Data not recorded (pre-IUCRC) ** Within year of IUCRC *** Sinha, Arijit, 2010

\begin{tabular}{|l|l|l|l|}
\hline Year & D/T Topic & Acknowledged & Project \\
\hline 2015 & $\begin{array}{l}\text { Gisip - Improvement of Wood-Based Machining } \\
\text { Operations on a CNC Router through Extending Tool } \\
\text { Life }\end{array}$ & $\begin{array}{l}\text { No NSF } \\
\text { Yes: US Dept } \\
\text { of Ag Wood }\end{array}$ & No \\
\hline 2011 & $\begin{array}{l}\text { Taylor - Transient Electric Birefringence for the } \\
\text { Characterization of Cellulose Nanocrystals and } \\
\text { Tobacco Mosaic Virus }\end{array}$ & No & No \\
\hline
\end{tabular}

Appendix H-7: WBC IAB attendance data

IAB meetings were held at different sites on the following dates:

\begin{tabular}{|l|l|l|l|l|}
\hline Date & Place & \# Students & \# Non site & Scientists \\
\hline Oct 2017 & Atlanta GA & & & \\
\hline May 2017 & Virginia Tech & & & \\
\hline Oct 2016 & Oregon State & & & \\
\hline May 2016 & Atlanta GA & 15 & 15 & \\
\hline Oct 2015 & Oregon State & 15 & 9 & \\
\hline May 2015 & Virginia Tech & 16 & 9 & \\
\hline *Oct 2014 & Oregon State & 14 & $4 / 8$ & $10 / 13$ \\
\hline$* *$ April 2014 & Atlanta Ga & 14 & $8 / 14$ & $8 / 13$ \\
\hline
\end{tabular}


**Atlanta (site of member organization Georgia Pacific Chemicals)

Non-Site attending students: 4 graduate students from VT, 2 from OSU and 1 each from affiliated (but not NSF-funded) university sites U. of Maine and U. of British Columbia. Scientist count: 3 from VT, 3 from OSU, and 1 each from Maine and BC, all PIs and/or co-investigators for center-funded projects. Not attending: 1 scientist from OSU, a coPI. Also not attending: 2 scientists identified as centeraffiliated from VT and 2 from OSU, all of whom were coPls of projects proposed but not funded by the center.

Proxy measure used for student attendance for calendar year 2014.

$\%$ of non-site student attendance $=[(4 / 8+8 / 14) / 2]=0.57$

$\%$ presenting $=[(10 / 14+8 / 14) / 2]=0.64$

Research scientists $=[(10 / 13+8 / 13) / 2]=0.69$

Appendix H-8: WBC performance evaluation score

\begin{tabular}{|c|c|c|c|}
\hline Output Contribution & Weights & WBC & Score \\
\hline C. Research Projects & 0.14 & 0.35 & 0.05 \\
\hline C. Research Papers & 0.08 & 0.20 & 0.02 \\
\hline IAB Member Sat & 0.06 & 1.00 & 0.06 \\
\hline Leveraged Funding & 0.07 & 0.70 & 0.05 \\
\hline Researcher Sat. & 0.04 & 1.00 & 0.04 \\
\hline Visiting Students & 0.07 & 0.83 & 0.06 \\
\hline Student Topics & 0.12 & 0.03 & 0.00 \\
\hline Student Projects & 0.08 & 0.75 & 0.06 \\
\hline Student Presentations & 0.05 & 0.35 & 0.02 \\
\hline Student Hires & 0.06 & 1.00 & 0.06 \\
\hline Consulting & 0.03 & 0.50 & 0.02 \\
\hline Papers & 0.02 & 0.80 & 0.02 \\
\hline $\begin{array}{l}\text { Training and } \\
\text { Workshops }\end{array}$ & 0.04 & 0.75 & 0.03 \\
\hline Shared Resources & 0.03 & 1.00 & 0.03 \\
\hline New Methods/Proc. & 0.07 & 1.00 & 0.07 \\
\hline New Products & 0.02 & 0.50 & 0.01 \\
\hline \multirow[t]{2}{*}{ Licenses } & 0.02 & \multirow[t]{2}{*}{0.50} & 0.01 \\
\hline & 1.00 & & 0.59 \\
\hline
\end{tabular}


Appendix H-9: Research projects

Appendix H-9-1: CPD 2016 Research projects

Transamination and Reductive Amination Bommarius AS, Au SK Molecular Dynamics Simulation of Amorphous Indomethacin-Poly (Vinylpyrrolidone) Glasses: Solubility and Hydrogen Bonding Interactions Xiang TX, Anderson BD Biphasic Reaction System Allows for Conversion of Hydrophobic Substrates by Amine Dehydrogenases Au SK, Bommarius BR, Bommarius AS A Novel Chimeric Amine Dehydrogenase Shows Altered Substrate Specificity Compared to its Parent Enzymes Bommarius BR, Schurmann M, Bommarius AS Gauging Colloidal and Thermal Stability in Human IgG1-Sugar Solutions through Diffusivity Measurements Rubin J, Sharma A, Linden L, Bommarius AS, Behrens SH.

Appendix H-9-2-2: S2ERC 2016 Research projects

Cybersecurity Education Game. Paul Gestwicki; Ball State.

Assured Asserted Identity in the Next Generation Network. Eric Burger; Georgetown.

Cloud-based Screening of Massive Data for Security Leaks in Enterprise Environments. Daphne Yao, Fang Liu; Virginia Tech.

Components of a Modern Quality Approach to Software Development. Dolores Zage, Wayne Zage; Ball State

Cost Effective GNU Radio Direction Finding. Joseph Ernst; Virginia Tech.

Cyber Threat Intelligence Sharing Ecosystem (CyberISE). Eric Burger; Georgetown.

Evaluating CoNNeCTions. Dolores Zage, Wayne Zage; Ball State.

Honeymail. Micah Sherr, Eric Burger; Georgetown.

Lateral Malware Propagation. Joseph Ernst, Avik Sengupta; Virginia Tech.

MIDAS - Metrics IDentification of Attack Surfaces. Dolores Zage, Wayne Zage; Ball State. Next Generation Telecom Routing. Eric Burger; Georgetown.

Protecting Consumer Information in Smart Grids using Homomorphic Encryption. Ahmed Abdelhadi; Virginia Tech.

PSTN Transition Study. Eric Burger; Georgetown.

Resilient Host-based Intusion Detection for Cloud Containers. Michael Fowler, Amr Abed;

Virginia Tech.

Rural Call Completion. Eric Burger; Georgetown

Software Analytics. Dolores Zage, Wayne Zage; Ball State. National Science Foundation.

Towards Scalable Modeling for Rigorous Software Specification and Testing. Lan Lin; Ball State. 
Manufacturing in America: Understanding the New York Nano-cluster. Charles Wessner;

Georgetown

Unmanned System Cyber Security Evaluation in a C4ISR Architecture. Jonathan Black; Virginia Tech

Vendor Truth Serum. Eric Burger, James Hill; Georgetown and IUPUI.

Zero-Knowledge Cloud Sharing. Inja Youn; Georgetown.

\section{Appendix H-9-3: S2ERC 2016 Research projects}

Coupled titanium dioxide photocatalysis and filtration for simultaneous reduction of organic matter, viruses, and estrogenic compounds Brooke Mayer - Marquette University Micro thermal devices for flow, pressure, and temperature measurements Chung Hoon Lee Marquette University Advanced High-Rate Wet-Weather Treatment Process - Phase 2 D Zitomer Marquette University System for Biomethane Production from Bioplastics II D Zitomer - Marquette University Reducing chloride discharges to area waterways; a menu of options for policymakers $D$ Strifling Marquette University Modeling the transport and fate of Phosphorus from a point source in a Lake Michigan nearshore zone H Bravo, UW-Milwaukee Self-Cleaning Coating By Creating A Novel 3D Nano-Structured 'Lotus Leaf' J Niu - UWMilwaukee

A Comprehensive, Quantitative Decision-Making Tool for Evaluating and Improving the Reliability, Cybersecurity, and Resiliency of Water and Wastewater Infrastructures L Wang - UWMilwaukee Engineered Macroporous Material for the Removal of Emerging Persistent Organic Pollutants (POPs) from Water M Silva - UW-Milwaukee

Surface texturing, alloying and compositing during manufacturing of components for improving the corrosion resistance of water industry components P Rohatgi - UW-Milwaukee Study to Reduce Cavitation Damage in Hydro-Turbines Ryo Samuel Amano - UW-Milwaukee Low-cost electrochemical phosphate sensor Woo Jin Chang UW-Milwaukee Improved Design of Silica-Based Adsorbents for Water Purification Application Yin Wang UWMilwaukee Phosphate-Free Inorganic Inhibitors for Water Supplies to Mitigate Lead Release and Corrosion Yin Wang - UW-Milwaukee 
Appendix H-10: New processes and methods data

\begin{tabular}{|l|l|}
\hline Center & Technology \\
\hline CIMJSEA & Very High Power Ultrasonic Additive Manufacturing for Energy Applications \\
\hline S$^{2}$ ERC & Design Metrics Technology \\
\hline S$^{2} E R C$ & Visual Intrusion Detection System (VIDS) Tool \\
\hline WBC & Extending Timber Resources Through Advanced Composite Science \\
\hline CPD & Improving Tablets Manufacturing \\
\hline CPD & New routes to Active Pharmaceutical Ingredients \\
\hline
\end{tabular}

Appendix I: Sensitivity Analysis

\section{Appendix I-1: OAT Substitution Data}

\begin{tabular}{|c|c|c|c|c|c|c|c|c|c|c|}
\hline & & Scenario B & Scenario C & Scenario D & Scenario E & Scenario $\mathrm{F}$ & Scenario & Scenario $\mathrm{H}$ & Scenario I & Scenario J \\
\hline Criteria & Original Data & Research 2A & Research 2C & Student A & Student B & KTT B & NK: Group A & SS: A & SS: B & SS: C \\
\hline Objective 1 & 0.39 & 0.39 & 0.39 & 0.39 & 0.39 & 0.39 & 0.39 & 0.39 & 0.39 & 0.39 \\
\hline Objective 2 & 0.33 & 0.33 & 0.33 & 0.33 & 0.33 & 0.33 & 0.33 & 0.33 & 0.33 & 0.33 \\
\hline Objective 3 & 0.28 & 0.28 & 0.28 & 0.28 & 0.28 & 0.28 & 0.28 & 0.28 & 0.28 & 0.28 \\
\hline New Knowledge & 0.56 & 0.77 & 0.53 & 0.56 & 0.56 & 0.56 & 0.56 & 0.56 & 0.56 & 0.56 \\
\hline Stakeholder & 0.44 & 0.23 & 0.47 & 0.44 & 0.44 & 0.44 & 0.44 & 0.44 & 0.44 & 0.44 \\
\hline S. Involvement & 0.59 & 0.59 & 0.59 & 0.75 & 0.5 & 0.59 & 0.59 & 0.59 & 0.59 & 0.59 \\
\hline S. Development & 0.41 & 0.41 & 0.41 & 0.25 & 0.5 & 0.41 & 0.41 & 0.41 & 0.41 & 0.41 \\
\hline KTT Mediums & 0.62 & 0.62 & 0.62 & 0.62 & 0.62 & 0.75 & 0.62 & 0.62 & 0.62 & 0.62 \\
\hline KTT Objects & 0.38 & 0.38 & 0.38 & 0.38 & 0.38 & 0.25 & 0.38 & 0.38 & 0.38 & 0.38 \\
\hline C. Research Projects & 0.59 & 0.59 & 0.59 & 0.59 & 0.59 & 0.59 & 0.38 & 0.59 & 0.59 & 0.59 \\
\hline C. Research Papers & 0.41 & 0.41 & 0.41 & 0.41 & 0.41 & 0.41 & 0.63 & 0.41 & 0.41 & 0.41 \\
\hline IAB Member Sat & 0.37 & 0.37 & 0.37 & 0.37 & 0.37 & 0.37 & 0.37 & 0.18 & 0.12 & 0.46 \\
\hline Leveraged Funding & 0.39 & 0.39 & 0.39 & 0.39 & 0.39 & 0.39 & 0.39 & 0.4 & 0.73 & 0.38 \\
\hline Researcher Sat. & 0.24 & 0.24 & 0.24 & 0.24 & 0.24 & 0.24 & 0.24 & 0.43 & 0.15 & 0.16 \\
\hline Visiting Students & 0.38 & 0.38 & 0.38 & 0.38 & 0.38 & 0.38 & 0.38 & 0.38 & 0.38 & 0.38 \\
\hline Student Topics & 0.62 & 0.62 & 0.62 & 0.62 & 0.62 & 0.62 & 0.62 & 0.62 & 0.62 & 0.62 \\
\hline Student Projects & 0.59 & 0.59 & 0.59 & 0.59 & 0.59 & 0.59 & 0.59 & 0.59 & 0.59 & 0.59 \\
\hline Student Presentations & 0.41 & 0.41 & 0.41 & 0.41 & 0.41 & 0.41 & 0.41 & 0.41 & 0.41 & 0.41 \\
\hline Student Hires & 0.33 & 0.33 & 0.33 & 0.33 & 0.33 & 0.33 & 0.33 & 0.33 & 0.33 & 0.33 \\
\hline Consulting & 0.15 & 0.15 & 0.15 & 0.15 & 0.15 & 0.15 & 0.15 & 0.15 & 0.15 & 0.15 \\
\hline Papers & 0.14 & 0.14 & 0.14 & 0.14 & 0.14 & 0.14 & 0.14 & 0.14 & 0.14 & 0.14 \\
\hline Training and Workshops & 0.21 & 0.21 & 0.21 & 0.21 & 0.21 & 0.21 & 0.21 & 0.21 & 0.21 & 0.21 \\
\hline Shared Resources & 0.17 & 0.17 & 0.17 & 0.17 & 0.17 & 0.17 & 0.17 & 0.17 & 0.17 & 0.17 \\
\hline New Methods/Proc. & 0.62 & 0.62 & 0.62 & 0.62 & 0.62 & 0.62 & 0.62 & 0.62 & 0.62 & 0.62 \\
\hline New Products & 0.22 & 0.22 & 0.22 & 0.22 & 0.22 & 0.22 & 0.22 & 0.22 & 0.22 & 0.22 \\
\hline Licenses & 0.17 & 0.17 & 0.17 & 0.17 & 0.17 & 0.17 & 0.17 & 0.17 & 0.17 & 0.17 \\
\hline
\end{tabular}


Appendix I-2: Scenario related weights

\begin{tabular}{|c|c|c|c|c|c|c|c|c|c|c|}
\hline Output Contribution & Data & Scenario B & Scenario C & Scenario D & Scenario $\mathrm{E}$ & Scenario F & Scenario G & Scenario $\mathrm{H}$ & Scenario I & Scenario J \\
\hline C. Research Projects & 0.14 & 0.18 & 0.12 & 0.13 & 0.13 & 0.13 & 0.08 & 0.13 & 0.13 & 0.13 \\
\hline C. Research Papers & 0.08 & 0.12 & 0.08 & 0.09 & 0.09 & 0.09 & 0.14 & 0.09 & 0.09 & 0.09 \\
\hline IAB Member Sat & 0.06 & 0.03 & 0.07 & 0.06 & 0.06 & 0.06 & 0.06 & 0.03 & 0.02 & 0.08 \\
\hline Leveraged Funding & 0.07 & 0.03 & 0.07 & 0.07 & 0.07 & 0.07 & 0.07 & 0.07 & 0.13 & 0.07 \\
\hline Researcher Sat. & 0.04 & 0.02 & 0.04 & 0.04 & 0.04 & 0.04 & 0.04 & 0.07 & 0.03 & 0.03 \\
\hline Visiting Students & 0.07 & 0.07 & 0.07 & 0.09 & 0.06 & 0.07 & 0.07 & 0.07 & 0.07 & 0.07 \\
\hline Student Topics & 0.12 & 0.12 & 0.12 & 0.15 & 0.10 & 0.12 & 0.12 & 0.12 & 0.12 & 0.12 \\
\hline Student Projects & 0.08 & 0.08 & 0.08 & 0.05 & 0.10 & 0.08 & 0.08 & 0.08 & 0.08 & 0.08 \\
\hline Student Presentations & 0.05 & 0.06 & 0.06 & 0.03 & 0.07 & 0.06 & 0.06 & 0.06 & 0.06 & 0.06 \\
\hline Student Hires & 0.06 & 0.06 & 0.06 & 0.06 & 0.06 & 0.07 & 0.06 & 0.06 & 0.06 & 0.06 \\
\hline Consulting & 0.03 & 0.03 & 0.03 & 0.03 & 0.03 & 0.03 & 0.03 & 0.03 & 0.03 & 0.03 \\
\hline Papers & 0.02 & 0.02 & 0.02 & 0.02 & 0.02 & 0.03 & 0.02 & 0.02 & 0.02 & 0.02 \\
\hline Training and Workshops & 0.04 & 0.04 & 0.04 & 0.04 & 0.04 & 0.04 & 0.04 & 0.04 & 0.04 & 0.04 \\
\hline Shared Resources & 0.03 & 0.03 & 0.03 & 0.03 & 0.03 & 0.04 & 0.03 & 0.03 & 0.03 & 0.03 \\
\hline New Methods/Proc. & 0.07 & 0.07 & 0.07 & 0.07 & 0.07 & 0.04 & 0.07 & 0.07 & 0.07 & 0.07 \\
\hline New Products & 0.02 & 0.02 & 0.02 & 0.02 & 0.02 & 0.02 & 0.02 & 0.02 & 0.02 & 0.02 \\
\hline Licenses & 0.02 & 0.02 & 0.02 & 0.02 & 0.02 & 0.01 & 0.02 & 0.02 & 0.02 & 0.02 \\
\hline Key & 1st & 2nd & $3 \mathrm{rd}$ & 4 th & 5 th & & & & & \\
\hline
\end{tabular}


Appendix I-3: IUCRC scores for scenarios D, G, and J

\begin{tabular}{|c|c|c|c|c|c|c|c|}
\hline Output Contribution & $D$ & Ma2JIC & CPD & $S^{2} E R C$ & CSR & WEP & WBC \\
\hline C. Research Projects & 0.13 & 0.05 & 0.02 & 0.02 & 0.02 & 0.02 & 0.05 \\
\hline C. Research Papers & 0.09 & 0.02 & 0.02 & 0.06 & 0.03 & 0.08 & 0.02 \\
\hline IAB Member Sat & 0.06 & 0.06 & 0.06 & 0.05 & 0.06 & 0.06 & 0.06 \\
\hline Leveraged Funding & 0.07 & 0.02 & 0.07 & 0.05 & 0.05 & 0.06 & 0.05 \\
\hline Researcher Sat. & 0.04 & 0.04 & 0.04 & 0.04 & 0.04 & 0.04 & 0.04 \\
\hline Student Topics & 0.12 & 0.12 & 0.06 & 0.12 & 0.00 & 0.00 & 0.00 \\
\hline Student Projects & 0.08 & 0.06 & 0.07 & 0.06 & 0.06 & 0.06 & 0.06 \\
\hline Student Hires & 0.06 & 0.03 & 0.06 & 0.06 & 0.03 & 0.03 & 0.06 \\
\hline Consulting & 0.03 & 0.03 & 0.03 & 0.01 & 0.01 & 0.01 & 0.01 \\
\hline Papers & 0.02 & 0.01 & 0.01 & 0.01 & 0.01 & 0.00 & 0.02 \\
\hline Shared Resources & 0.03 & 0.03 & 0.01 & 0.01 & 0.01 & 0.01 & 0.03 \\
\hline New Methods/Proc. & 0.07 & 0.03 & 0.07 & 0.07 & 0.07 & 0.03 & 0.07 \\
\hline \multirow[t]{2}{*}{ New Products } & 0.02 & 0.01 & 0.01 & 0.01 & 0.01 & 0.01 & 0.01 \\
\hline & & 0.63 & 0.64 & 0.71 & 0.48 & 0.53 & 0.58 \\
\hline Output Contribution & Scenario d & Ma2JIC & CPD & $S^{2}$ ERC & CSR & WEP & WBC \\
\hline C. Research Projects & 0.08 & 0.03 & 0.01 & 0.01 & 0.01 & 0.01 & 0.03 \\
\hline C. Research Papers & 0.14 & 0.04 & 0.03 & 0.10 & 0.04 & 0.12 & 0.03 \\
\hline IAB Member Sat & 0.06 & 0.06 & 0.06 & 0.05 & 0.06 & 0.06 & 0.06 \\
\hline Leveraged Funding & 0.07 & 0.02 & 0.07 & 0.05 & 0.05 & 0.06 & 0.05 \\
\hline Researcher Sat. & 0.04 & 0.04 & 0.04 & 0.04 & 0.04 & 0.04 & 0.04 \\
\hline Student Topics & 0.12 & 0.12 & 0.06 & 0.12 & 0.00 & 0.00 & 0.00 \\
\hline Student Projects & 0.08 & 0.06 & 0.07 & 0.06 & 0.06 & 0.06 & 0.06 \\
\hline Student Hires & 0.06 & 0.03 & 0.06 & 0.06 & 0.03 & 0.03 & 0.06 \\
\hline Consulting & 0.03 & 0.03 & 0.03 & 0.01 & 0.01 & 0.01 & 0.01 \\
\hline Papers & 0.02 & 0.01 & 0.01 & 0.01 & 0.01 & 0.00 & 0.02 \\
\hline Shared Resources & 0.03 & 0.03 & 0.01 & 0.01 & 0.01 & 0.01 & 0.03 \\
\hline New Methods/Proc. & 0.07 & 0.03 & 0.07 & 0.07 & 0.07 & 0.03 & 0.07 \\
\hline \multirow[t]{2}{*}{ New Products } & 0.02 & 0.01 & 0.01 & 0.01 & 0.01 & 0.01 & 0.01 \\
\hline & & 0.62 & 0.64 & 0.74 & 0.49 & 0.57 & 0.57 \\
\hline Output Contribution & Scenario J & Ma2JIC & CPD & $S^{2}$ ERC & CSR & WEP & WBC \\
\hline C. Research Projects & 0.13 & 0.05 & 0.02 & 0.02 & 0.02 & 0.02 & 0.05 \\
\hline C. Research Papers & 0.09 & 0.02 & 0.02 & 0.06 & 0.03 & 0.08 & 0.02 \\
\hline IAB Member Sat & 0.08 & 0.08 & 0.08 & 0.07 & 0.07 & 0.08 & 0.08 \\
\hline Leveraged Funding & 0.07 & 0.02 & 0.07 & 0.05 & 0.05 & 0.06 & 0.05 \\
\hline Researcher Sat. & 0.03 & 0.02 & 0.03 & 0.03 & 0.03 & 0.03 & 0.03 \\
\hline Student Topics & 0.12 & 0.12 & 0.06 & 0.12 & 0.00 & 0.00 & 0.00 \\
\hline Student Projects & 0.08 & 0.06 & 0.07 & 0.06 & 0.06 & 0.06 & 0.06 \\
\hline Student Hires & 0.06 & 0.03 & 0.06 & 0.06 & 0.03 & 0.03 & 0.06 \\
\hline Consulting & 0.03 & 0.03 & 0.03 & 0.01 & 0.01 & 0.01 & 0.01 \\
\hline Papers & 0.02 & 0.01 & 0.01 & 0.01 & 0.01 & 0.00 & 0.02 \\
\hline Shared Resources & 0.03 & 0.03 & 0.01 & 0.01 & 0.01 & 0.01 & 0.03 \\
\hline New Methods/Proc. & 0.07 & 0.03 & 0.07 & 0.07 & 0.07 & 0.03 & 0.07 \\
\hline \multirow[t]{2}{*}{ New Products } & 0.02 & 0.01 & 0.01 & 0.01 & 0.01 & 0.01 & 0.01 \\
\hline & & 0.63 & 0.64 & 0.71 & 0.48 & 0.53 & 0.58 \\
\hline
\end{tabular}




\section{Appendix J: Acronyms}

\begin{tabular}{|c|c|}
\hline Acronymn & Description \\
\hline AHP & Analytic hierarchy process \\
\hline AIR & Small business assistance program \\
\hline ANP & Analytic network process \\
\hline AUTM & Association of university technology transfer managers \\
\hline CPD & Center for Pharmaceutical Development \\
\hline CPRS & Composite performance rating system \\
\hline CRC & Cooperative (Collaborative) Research Center \\
\hline CSR & Center for Surveillance Research \\
\hline ERC & Engineering research center \\
\hline GPRA & Government performance and results act of 1993 \\
\hline HAC & Hierarchical agglomerative clustering \\
\hline HDM & Hierarchical Decision Model \\
\hline $\mathrm{IAB}$ & Industrial advisory board \\
\hline ICC & Intraclass correlation coefficient \\
\hline IU & Industry/University \\
\hline IUCRC & Industry/University Cooperative Research Center \\
\hline KPMI & Knowledge management performance index \\
\hline KTT & Knowledge and technology transfer \\
\hline LIFE & Level of interest and feedback evaluation form \\
\hline Ma2JIC & Integrative Joining of Materials for Energy Applications Center \\
\hline MAUT & Multi-attribute utility theory \\
\hline MCDA & Multi-criteria deciaion analysis \\
\hline MCDM & Multi-criteria decision making \\
\hline MLDM & Multi-level decision model \\
\hline MOGSA & Mission-objectives-goals-strategies-activities \\
\hline MRSEC & Materials research science and engineering center \\
\hline NBER & National Bureau of Economic Research (US) \\
\hline NISTEP & National Institute of Science and Technology Policy (Japan) \\
\hline NSF & National Science Foundation \\
\hline OAT & One at a time \\
\hline OECD & Organization for Economic and Co-operation and Development \\
\hline RSV & Root sum variance \\
\hline S2ERC & Security and Software Engineering Research Center \\
\hline SBIR & Small business innovation research \\
\hline SciSIP & Science of Science and Innovation Policy \\
\hline SI & Science indicators \\
\hline SNA & Social network analysis \\
\hline STI & Science and technology indicators \\
\hline TTO & Technology transfer office \\
\hline WBC & Wood-Based Composites Center \\
\hline WEP & Water Equipment Policy \\
\hline
\end{tabular}

